Celane Néry de Oliveira Batista

\title{
Contribuição à análise da capacidade de processamento de trens cargueiros em linhas ferroviárias singelas no Brasil
}

Dissertação apresentada à Escola de Engenharia de São Carlos da Universidade de São Paulo, como parte dos requisitos para obtenção do título de Mestre em Engenharia Civil: Planejamento e Operação de Sistemas de Transportes.

ORIENTADOR: Prof. Dr. João Alexandre Widmer

São Carlos 


\section{FOLHA DE JULGAMENTO}

\section{Candidata: Engenheira CELANE NÉRY DE OLIVEIRA BATISTA}

Dissertação defendida e julgada em 26-06-2006 perante a Comissão Julgadora:



Prof. Titular JOÃo ALEXANDRE WIDMER (Orientador)



(Escola de Engenharia de São Carlos/USP)

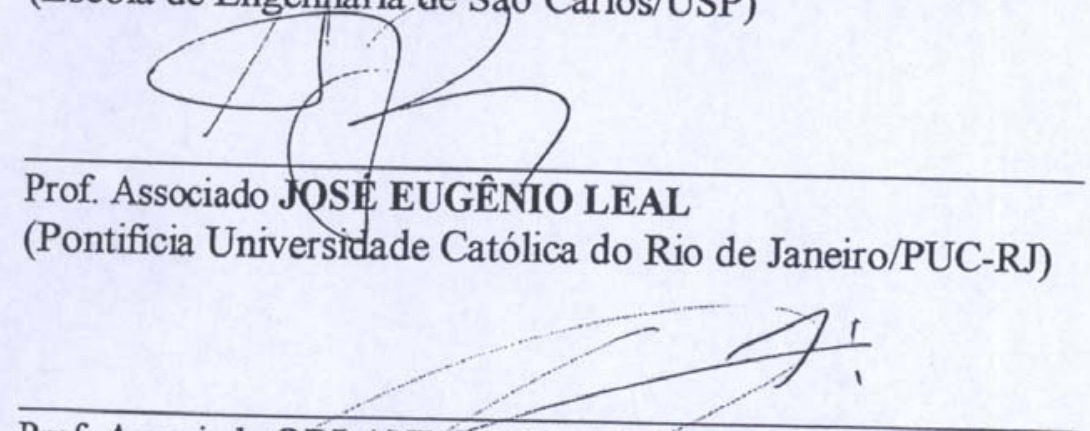

Prof. Associado ORLANDO FONTES LIMA JUNIOR

(Universidade Estadual de Campinas/UNICAMP)
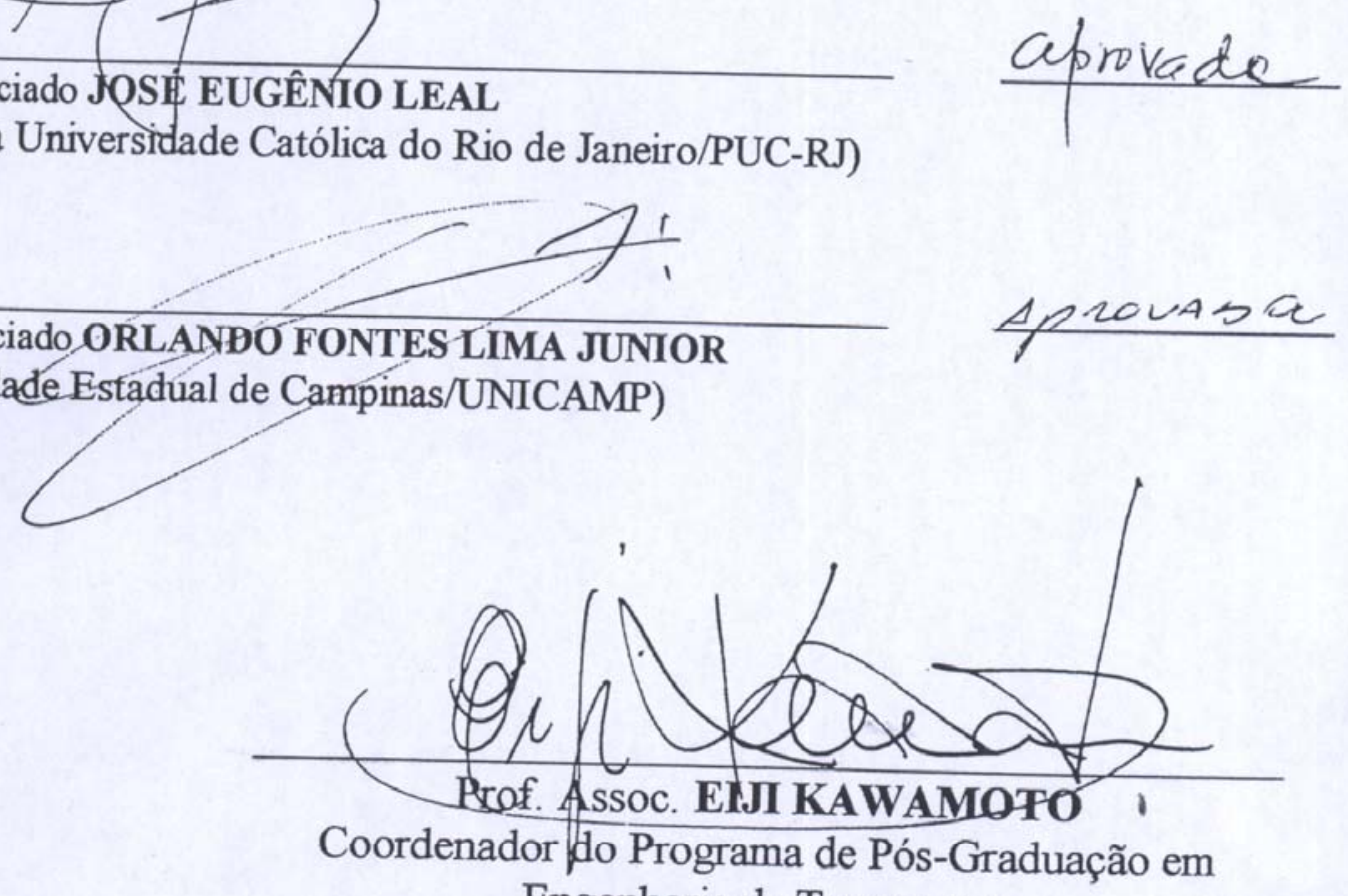

Engenharia de Transportes




DEDICATÓRIA

Dedico este trabalho a minha mãe, Cleonice, exemplo de força e dedicação. 


\section{AGRADECIMENTOS}

Ao Prof. João Alexandre Widmer pela confiança depositada, orientação, amizade, conselhos de vida e ser principal incentivador no desenvolvimento do trabalho.

Aos meus pais, minhas irmãs, Ceane, Cibele, Cíntia e meu sobrinho Marcos Henrique por apoiarem minhas decisões e serem o principal estímulo em tudo que faço.

Ao CNPq pela concessão da bolsa de estudo.

Ao engenheiro João Artur de Melo Ferraz da Brasil Ferrovias pelo suporte na obtenção de dados e explicações sobre a operação ferroviária.

A todos os professores e funcionários do Departamento de Transportes pelo auxílio oferecido durante este tempo.

Aos “irmãos" Karênina, Leandro, Ricardo (Xaxá), Serginho, Vitor e Waldemiro pela convivência e por tentar tranqüilizar-me nos momentos difíceis. Ao Cassiano Isler e Isabel Brufau pela contribuição direta no trabalho.

Ao "quarteto fantástico" André, Andréa Julia, Camilla e Vivianne, pelo companheirismo e amizade. Aos novos amigos, Elaine, Henrique (Carneiro) e Idalíria.

À Jeanette e Cacá por me acolherem em São Carlos, incentivo e momentos de descontração.

Às Conventinas por serem sempre presentes em minha vida e toda força que me passam.

A todos os colegas do departamento de Transportes e amigos. Não caberiam aqui os nomes dos que de alguma forma me ajudaram.

E a Deus, por tudo! 
"As dificuldades fizeram-se para serem vencidas" Irineu Evangelista de Sousa - Barão de Mauá 
Batista, C. N. O (2006). Contribuição à Análise da Capacidade de Processamento de Trens Cargueiros em Linhas Ferroviárias Singelas no Brasil. São Carlos, 2006. 157p. Dissertação (Mestrado) - Escola de Engenharia de São Carlos, Universidade de São Paulo.

O expressivo crescimento do setor ferroviário com o processo de privatizações das operações a partir de 1996, fez com que a modalidade aumentasse sua participação na matriz de transportes brasileira. Porém, essa expansão, obtida essencialmente com a substituição e aumento de locomotivas e vagões, juntamente com a modernização do sistema de controle de tráfego, deverá em breve encontrar limites impostos pela geometria e superestrutura da malha ferroviária. O objetivo da dissertação é analisar como esses fatores afetam a capacidade de processamento de trens através de uma linha ferroviária singela. Para alcançar este objetivo desenvolveu-se um modelo capaz de identificar as características da via que restringem as velocidades e o headway das composições ferroviárias. O modelo proposto permite, através da análise de desempenho em cada um dos arcos de um trecho de linha ferroviária, obter uma medida de desempenho global no trecho e identificar os gargalos. O método adotado para determinar a capacidade do trecho para cenários operacionais alternativos é o da utilização de diagramas espaço-tempo. Os diagramas espaço-tempo são elaborados através de um algoritmo em MatLab que soluciona os conflitos nos cruzamentos para um determinado tempo de cruzamento nas estações e efetua a contagem de pares de trens. O desempenho dos trens em cada um dos arcos, dado de entrada do algoritmo, é adquirido através de um modelo de simulação de desempenho de trens elaborado pela Association of Amerian Railroads (AAR). Como aplicação prática apresenta-se uma análise de capacidade para um dos principais corredores de exportação, um trecho da Brasil Ferrovias S.A. entre as cidades de Santa Fé do Sul e Araraquara no Estado de São Paulo. A análise dos resultados mostra que o principal fator limitante da velocidade média no espaço dos trens é a atual condição da superestrutura ferroviária e que, uma vez eliminada esta restrição, a supressão de passagens de nível e a relocação de estações de cruzamento, produzem ganhos expressivos.

Palavras-chave: transporte ferroviário, capacidade de tráfego, ferrovia singela, desempenho do trem, simulação 


\begin{abstract}
Batista, C. N. O (2006). Contribution to analysis of process capacity of cargo trains on single track railroad line in Bražil. São Carlos, 2006. 157p. Dissertação (Mestrado) - Escola de Engenharia de São Carlos, Universidade de São Paulo.
\end{abstract}

The expessive growth of the railway sector due to the privatization of the operations since 1996, is increasing the participation of this mode in the brazilian transport matrix. However, this growth is obtained mainly from the replacement and increase of the rolling stock and the modernization of the traffic control system, and will soon reach some important limits imposed by the railway geometry and superstructure. The thesis objective is to analyze how these factors affect the capacity to process trains through a single track railroad line. To reach this objective, a model that identifies the restrictions that impose limits to the speed and headways of the trains was developed. Through the performance analysis on each arc of a railway segment, the model obtains a global performance measure for the whole segment and identifies the bottlenecks. Time-space graphs are developed to determine the capacity of the segment for different operating scenarios. To build the space-time graphs, solve the conflicts at the crossings for a given time to cross and count the trains per day, an algorithm using the MathLab software was developed. The train performance on each arc is obtained through a simulation model developed by the Association of American Railroads (AAR). As a practical application, a capacity analysis of one of the most important export corridors is presented, a segment of the Brasil Ferrovias S.A. network between the cities of Santa Fé do Sul and Araraquara in the state of São Paulo. The analysis of the results shows that the present railway superstructure condition is the main train average space speed limiting factor and, once this restriction is eliminated, the supression of at grade crossings and the relocation of the crossing stations produce expressive gains.

Key words: rail transport, traffic capacity, single track railway, train performance, simulation. 


\section{LISTA DE FIGURAS}

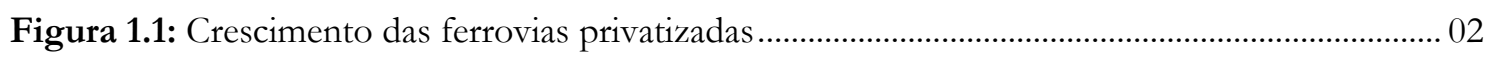

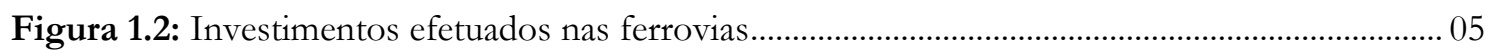

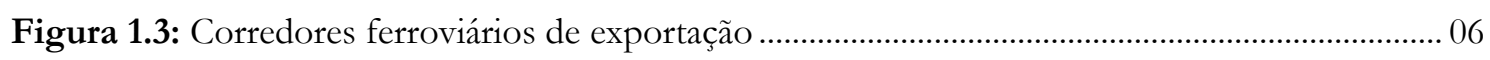

Figura 3.1: Etapas do modelo de capacidade..........................................................................................15

Figura 3.2: Estrutura de um processo produtivo...................................................................................... 16

Figura 3.3: Representação dos componentes de um sub-trecho ferroviário......................................... 17

Figura 3.4: Diagrama espaço-tempo entre dois nós.............................................................................. 21

Figura 3.5: Diagrama espaço-tempo de um sub-trecho ...................................................................... 23

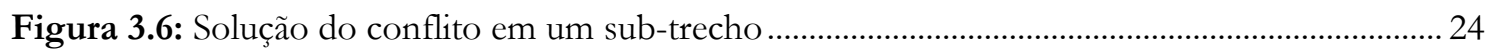

Figura 3.7: Análise da capacidade no diagrama espaço-tempo.............................................................. 26

Figura 4.1: Trecho ferroviário de aplicação do modelo ........................................................................ 30

Figura 4.2: Projeção do transporte ferroviário - bitola larga ................................................................... 31

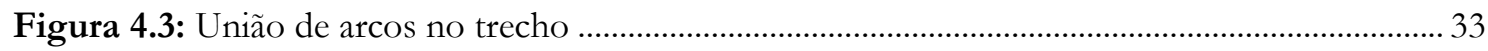

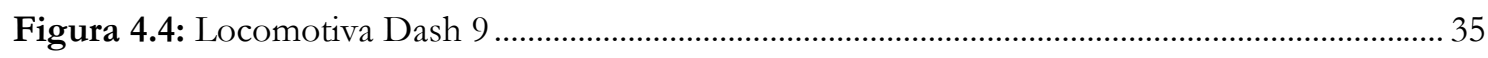

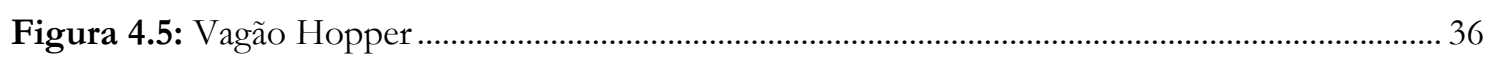

Figura 4.6: Diagrama espaço-tempo para o sub-trecho ZRU-ZUC ....................................................... 49

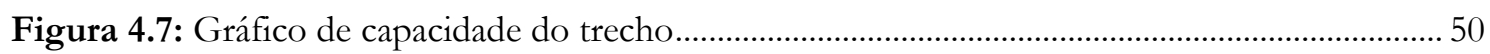

Figura 5.1: Comparação entre os Cenários 1.1 e 1.2 …………………………………………….... 52

Figura 5.2: Aumento da capacidade com a retirada dos limites de velocidade .................................. 53

Figura 5.3: Variação da capacidade em função dos tempos mínimos de parada (10 a 20 minutos)..54

Figura 5.4:Variação da capacidade em função dos tempos mínimos de parada (15 a 30 minutos)..55

Figura 5.5: Variação da capacidade em função das estações utilizadas .................................................. 56 


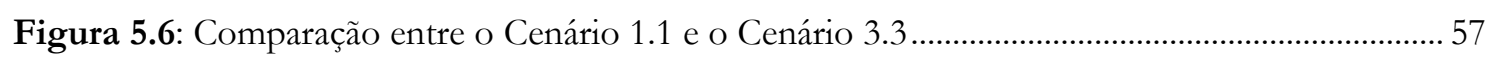

Figura 5.7: Comparação entre o Cenário 1.1, 3.3 e o Cenário 3.4 …………………………………......57

Figura 5.8: Aumento da capacidade com a retirada das PN ............................................................. 58

Figura 5.9: Comparação entre os resultados dos Cenários 1.2, 4.2 e 4.3 ……………......................... 59

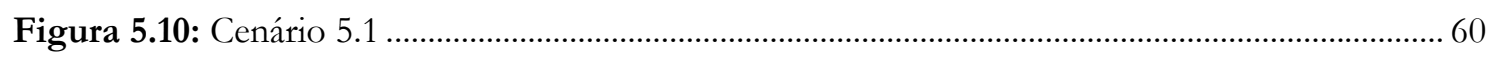

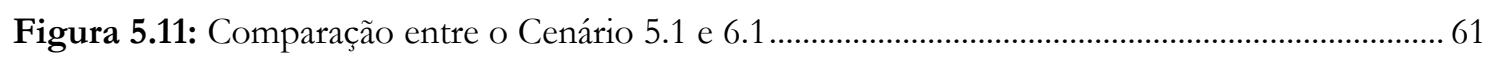

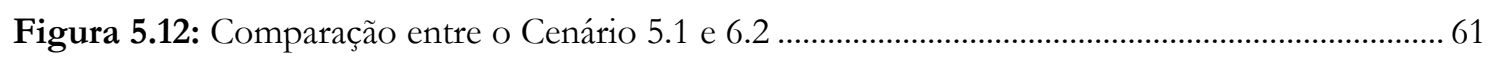

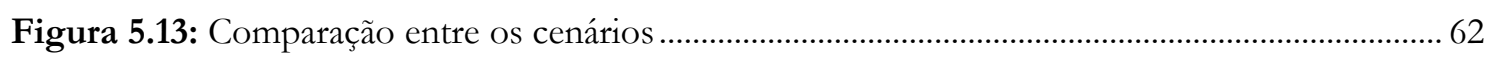

Figura 5.14: Desempenho do trem de Santa Fé do Sul a Araraquara - Cenário real........................... 63

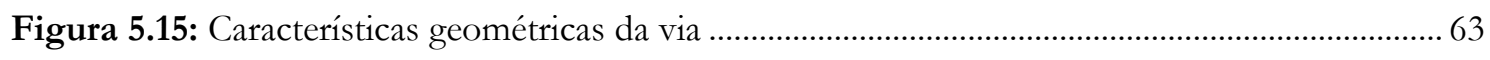

Figura 5.16: Desempenho do trem de Santa fé do Sul a Araraquara - VMA 70 km/h .................... 65 


\section{LISTA DE TABELAS}

Tabela 4.1: Comprimento dos arcos do trecho da Brasil Ferrovias........................................................ 32



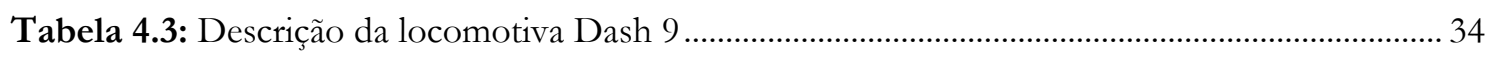

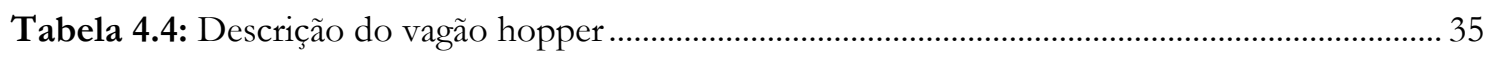

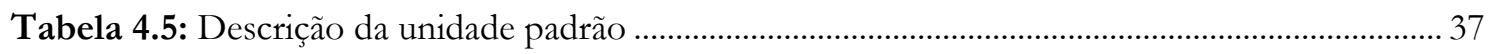

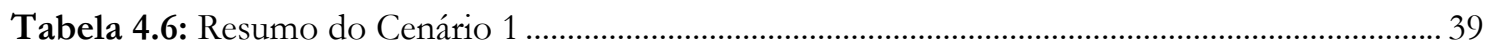

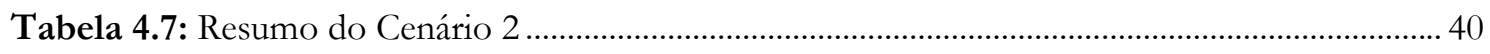

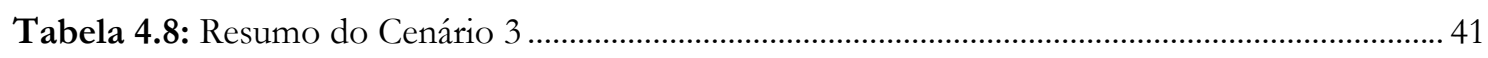

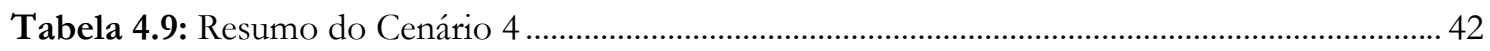

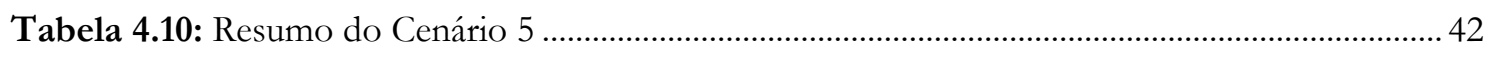

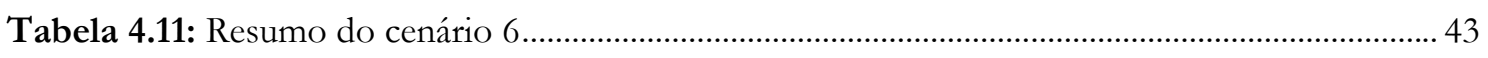

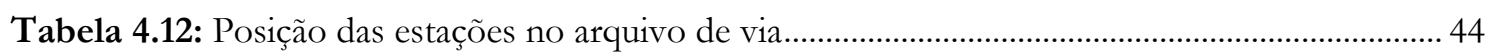

Tabela 4.13: Resultados da simulação do arco ZRU-ZSP ..................................................................... 47 


\section{LISTA DE ABREVIATURAS E SIGLAS}

AAR - Association of American Railroads.

ALL - América Latina Logística.

AMV - Aparelho de mudança de via.

ANTF - Associação Nacional do Transporte Ferroviário.

ANTT - Agência Nacional de Transportes Terrestres.

Brasil Ferrovias -Holding resultante de uma joint venture entre Ferronorte, Ferroban, Novoeste e Portofer.

CAGR - Compount Annual Grouth Rate.

CEL - Centro de estudos em Logística.

Coppead - Centro de Ensino e estudos em avançados em Gerência de Negócios da Universidade federal do Rio de Janeiro (UFRJ).

CVRD - Companhia Vale do Rio Doce.

E. U. A. - Estados Unidos da América.

EESC - Escola de Engenharia de São Carlos.

EFC - Estrada de Ferro Carajás.

FCA - Ferrovia Centro-Atlântica.

FEPASA - Ferrovia Paulista S. A.

FERROBAN - Ferrovia Bandeirantes S. A.

Ferronorte - Ferrovias Norte Brasil. 
GE - General Electric.

MatLab - Linguagem de Programação.

MRS - MRS Logística S.A.

OUT-Arquivo de saída do TEM 2.5.

Novoeste - Ferrovia Novoeste S. A.

NTC - Associação Nacional do Transporte de Carga e Logística.

PBT - Peso Bruto Total.

PBTC - Peso Bruto Total Combinado.

RFFSA - Rede Ferroviária Federal S. A.

RPT-Relatório de Simulação.

SDT-Simulador de Desempenho do Trem.

TEM 2.5 - Train Energy Model version 2.5.

TPC - Train Performance Calculator.

TU - Tonelada Útil.

USP - Universidade de São Paulo.

VMA - Velocidade máxima autorizada.

ZEB - Estação Engenheiro Balduíno.

ZED - Estação Estrela Dóeste.

ZFN - Estação Fernandópolis.

ZFS - Estação Santa Fé do Sul.

ZJA - Estação Jales.

ZKY - Estação Comosrama.

ZRU - Estação Rio Preto Paulista.

ZSP - Estação São José do Rio Preto.

ZTF - Estação Três Fronteiras.

ZUC - Estação Uchoa.

ZUR - Estação Urânia. 
RESUMO

iv

ABSTRACT

LISTA DE FIGURAS ……………………………………………………………………... vi

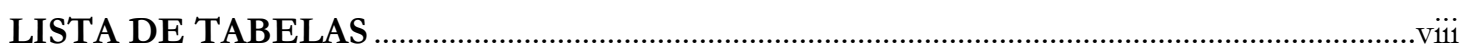

LISTA DE ABREVIATURAS E SIGLAS ……………................................................... ix





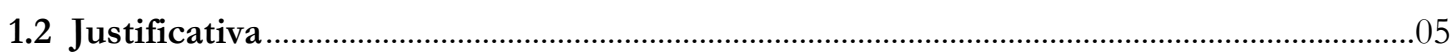

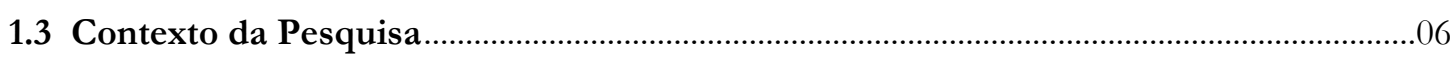

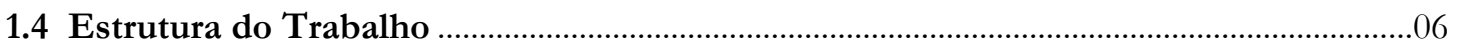

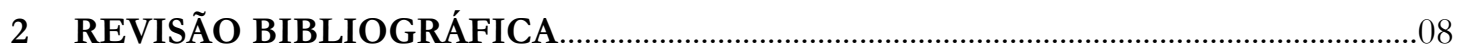

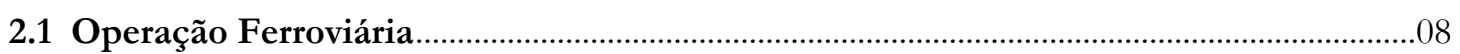

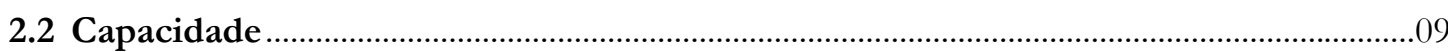

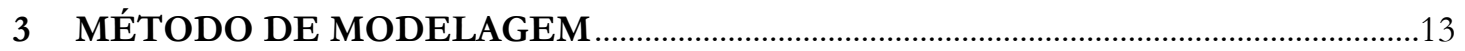

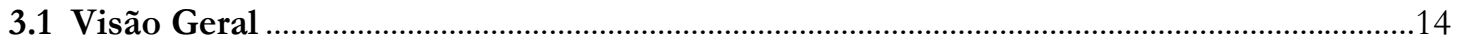

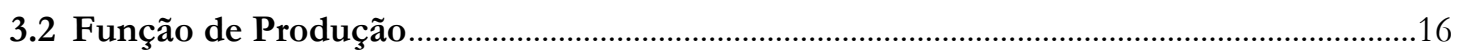

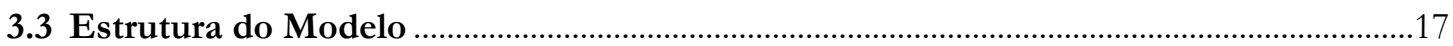



3.4.1 Variáveis relativas aos arcos ............................................................................................



3.4.3 Variáveis relativas às unidades ..........................................................................................19

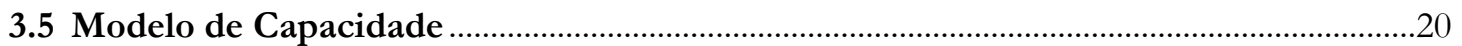

3.5.1 Diagrama espaço-tempo .................................................................................................2

3.5.1.1 Solução do conflito...........................................................................................22

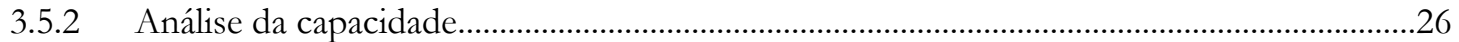

3.5.3 Análise do desempenho dos trens em um trecho .................................................................27

3.5.3.1 O Simulador de Desempenho do Trem ……………………………………........28 


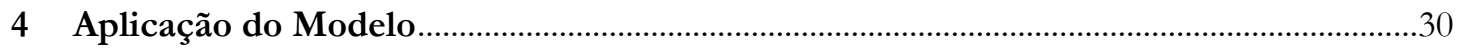

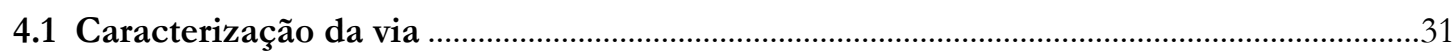

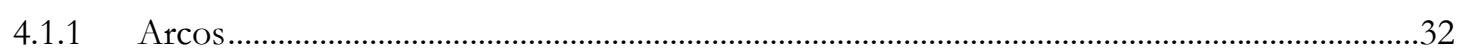

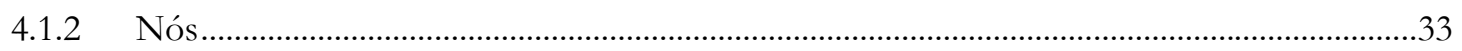

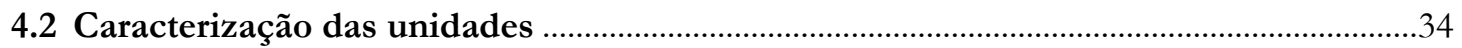



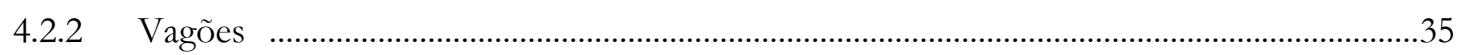

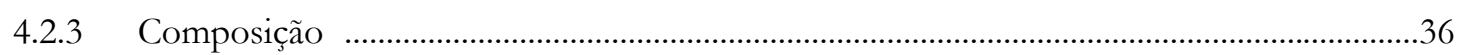



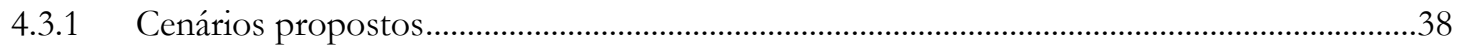

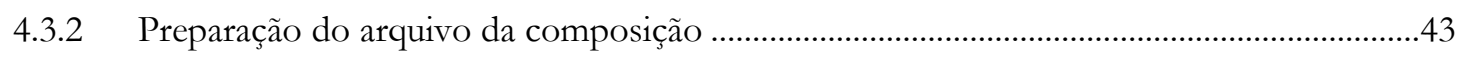

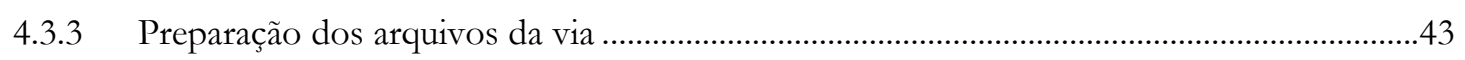

4.3.4 Preparação dos arquivos dos sub-trechos..............................................................................4

4.3.5 Geração de velocidade no simulador de desempenho do trem ..........................................45

4.3.6 Geração do diagrama espaço-tempo ..................................................................................46

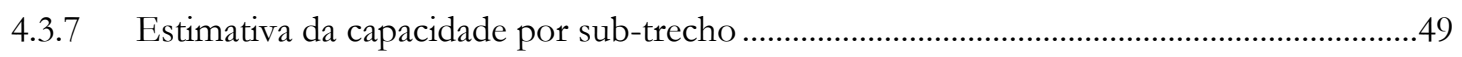

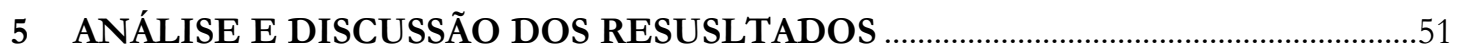

5.1 Análise da influência dos limites de velocidade operacionais .........................................51

5.2 Análise da influência dos tempos mínimos de parada .....................................................53

5.3 Análise da influência das estações utilizadas ....................................................................55

5.4 Análise da influência da existência de passagem de nível ....................................................58

5.5 Análise da influência da otimização dos fatores de produção ...........................................59

5.6 Análise da influência da distância entre as estações .........................................................60





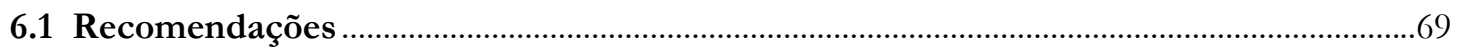

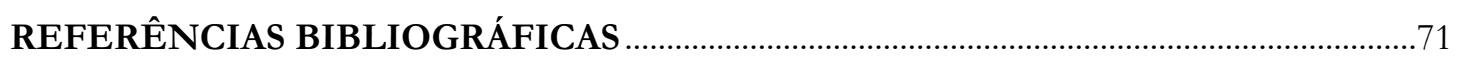

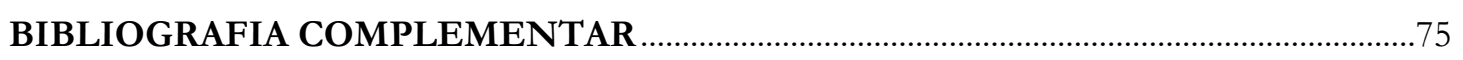

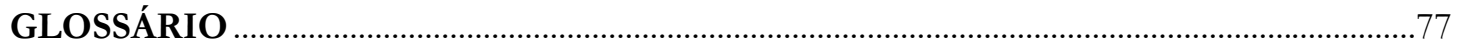

APÊNDICE A: MODELO DE SIMULAÇÃO DE MARCHA.................................................80

APÊNDICE B: MODELO DE LOCOMOÇÃO .......................................................................93 
APÊNDICE C: RESULTADO DOS CENÁRIOS …………….................................................108





APÊNDICE F: ARQUIVO DE PARADA..........................................................................128

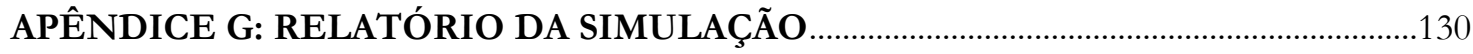

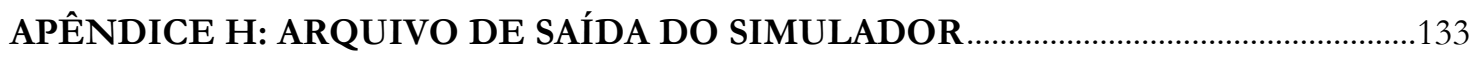

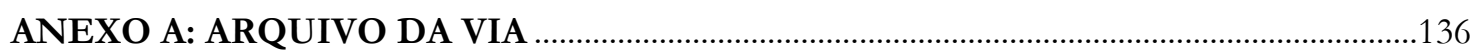




\section{INTRODUÇÃO}

O desenvolvimento ferroviário brasileiro sempre esteve ligado às políticas de governo, as quais sofreram mudanças ao longo da história. A primeira ferrovia do Brasil data de 1852, construída pelo Barão de Mauá, permitiu a integração das modalidades de transporte aquaviário e ferroviário, ou seja, a primeira operação intermodal do Brasil. As ferrovias do estado de São Paulo também foram construídas a partir da segunda metade do século XIX, formando uma rede de escoamento do café em direção ao Porto de Santos.

Segundo a Associação Nacional dos Transportadores Ferroviários (ANTF), a Rede Ferroviária Federal S.A. - RFFSA - foi criada em 1957, resultado da aglutinação de quase duas dezenas de ferrovias controladas pelo governo federal. No início da década de 70, com o objetivo de integrar as ferrovias estaduais, até então operando de forma isolada, o governo de São Paulo criou a FEPASA - Ferrovia Paulista S. A. - a qual incorporou a Companhia Paulista de Estradas de Ferro, a Estrada de Ferro Sorocabana, a Companhia Mogiana de Estradas de Ferro, a Estrada de Ferro São Paulo \& Minas e a Estrada de Ferro Araraquarense.

A crescente escassez de investimentos por parte do poder público levou a FEPASA a uma redução cada vez maior de sua participação no transporte de cargas e passageiros e, em 1998, como parte da renegociação de dívidas entre o governo federal e o estado de São Paulo, foi acertada sua transferência para o controle da Rede Ferroviária Federal S.A., sendo denominada "malha paulista". Tal malha foi a leilão em 10 de novembro de 1998, sendo adquirida pela FERROBAN que assumiu o controle em $1^{\circ}$ de janeiro de 1999 [ANTF, 2005].

Entre as décadas de 80 e 90, o sistema ferroviário brasileiro foi afetado drasticamente. Tanto as ferrovias pertencentes à RFFSA como à FEPASA passaram por um processo de acelerada deterioração em função da escassez de recursos tanto para 
operação quanto para manutenção, o que ocasionou expressiva perda de mercado para o modal rodoviário. A privatização, através da concessão da operação a partir de 1996, foi a forma usada para reverter tal processo e modernizar as principais ferrovias brasileiras. Dentre as empresas concessionárias, estão presentes no estado de São Paulo a MRS Logística S. A., a América Latina Logística (ALL), a Ferrovia Centro-Atlântica (FCA) e a Brasil Ferrovias S. A., cuja capacidade de processamento de carga será investigada neste trabalho.

Entre 1959 e 2001, a produção das ferrovias brasileiras cresceu 6,5\% ao ano, apresentando evolução negativa em apenas sete dos 43 anos - 1981-83, 1990, 1992, 1996 e 1999 [LACERDA, 2002]. Percebe-se, contudo, que, após as concessões, o sistema ferroviário brasileiro passou por diversas mudanças. A Figura 1.1 mostra a produção ferroviária e o CAGR (Compount Annual Grouth Rate) antes e depois do processo de privatização.

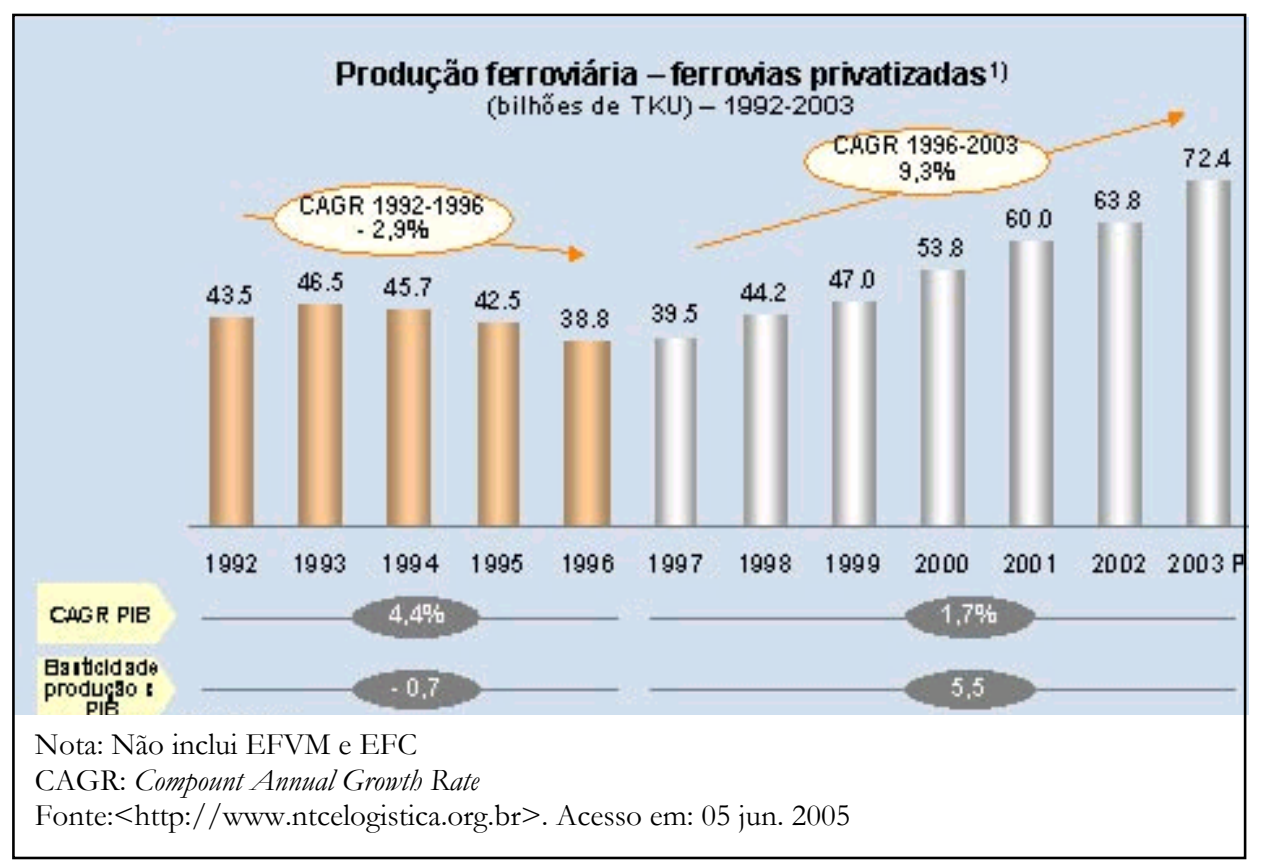

Figura 1.1 - Crescimento das ferrovias privatizadas

De acordo com os dados da Agência Nacional de Transportes Terrestres (ANTT) e o Ministério dos Transportes, de 1997 até 2004, o volume de carga transportada pela ferrovia cresceu 48,7\%, saltando de 138 para 206 bilhões de toneladas quilômetro útil (TKU). Mesmo com o baixo custo do transporte rodoviário de cargas no Brasil, a modalidade ferroviária aumentou a participação na matriz de transporte brasileira de 20,7\% 
para 23,8 \% entre 2001 e 2004, período no qual cresceu de 305 milhões para 378 milhões de cargas transportadas (TU).

Segundo o levantamento dos indicadores do transporte ferroviário do Centro de Estudos em Logística do COPPEAD [CEL/COPPEAD - 10/01/2006], houve um crescimento no total de cargas transportadas de 9,1\% TU (tonelada útil tracionada), comparando-se o ano de 2004 com o de 2003, sendo o minério de ferro, soja, produtos da indústria siderúrgica, carvão e coque assim como a produção agrícola os principais produtos que puxaram o índice para esse patamar positivo. Em 2005, o setor ferroviário apresentou um crescimento bastante robusto e, para 2006, a expectativa do volume transportado para a modalidade permanece favorável.

A ANTF construiu dois cenários para 2008 com base nos estudos da consultoria A.T. Kearney [NTC Notícias - 22/02/2005]. No primeiro deles, as ferrovias chegariam a 28\% de participação (ou 269,4 bilhões de TKU). Nesse caso, cresceriam 27\% (sobre a produção que tiveram em 2004). No segundo, o modo ferroviário passaria a deter $30 \%$ (291,1 bilhões de TKU, 37,4\% acima da produção do ano passado). Para alcançar o primeiro cenário bastaria que as concessionárias mantivessem o mesmo nível de investimentos. Para alcançar o segundo cenário, é necessário investimentos de cerca de R\$ 4,3 bilhões da união entre os anos de 2004 a 2008. Nessa projeção, até o ano de 2008, haveria um expressivo crescimento no transporte de cargas gerais no estado de São Paulo.

Essa previsão de substancial aumento de transporte de carga pela ferrovia traz à tona uma questão: a capacidade de absorção de tráfego dessa modalidade de transporte. Segundo a revista Agro Exame, no 17, de setembro de 2004, os gargalos representam uma ameaça séria ao desenvolvimento das exportações brasileiras. O agronegócio brasileiro possui a terceira maior taxa anual de crescimento $(6 \%)$ do comércio exterior de produtos agrícolas, analisando-se os dados de 1990 a 2003. O atual ministro da agricultura, Roberto Rodrigues, diz que há o risco do crescimento da produção se voltar contra o produtor, que acaba preso em uma crise de abundância sem escoamento; tal fato que está sendo chamado de "apagão logístico".

De acordo com os dados levantados pelo CEL-COPPEAD para o ano de 2004, a produção do transporte de carga pela ferrovia (em bilhões de TKU) nos Estados Unidos foi 13 vezes maior que a produção brasileira, a densidade média de tráfego (1000 TKU $/ \mathrm{km}$ ) é 2,4 vezes superior. Além disto, os investimentos por extensão da malha em 
2003 foram 3 vezes maiores do que aqueles feitos em nosso país. Confrontando-se esses dados, percebe-se que, apesar da perspectiva de crescimento do setor ferrovário, ainda há uma defasagem muito grande em comparação ao cenário mundial.

Segundo estatísticas da ANT'T, os maiores investimentos efetuados pelas concessionárias ferroviárias são em material rodante, superestrutura e infra-estrutura da via, sendo que os dois primeiros representam, respectivamente, $50,48 \%$ e $23,42 \%$ do total de investimentos feitos de 1997 a 2004. Na Figura 1.2, pode-se observar a evolução do investimento nas principais áreas de aplicação.

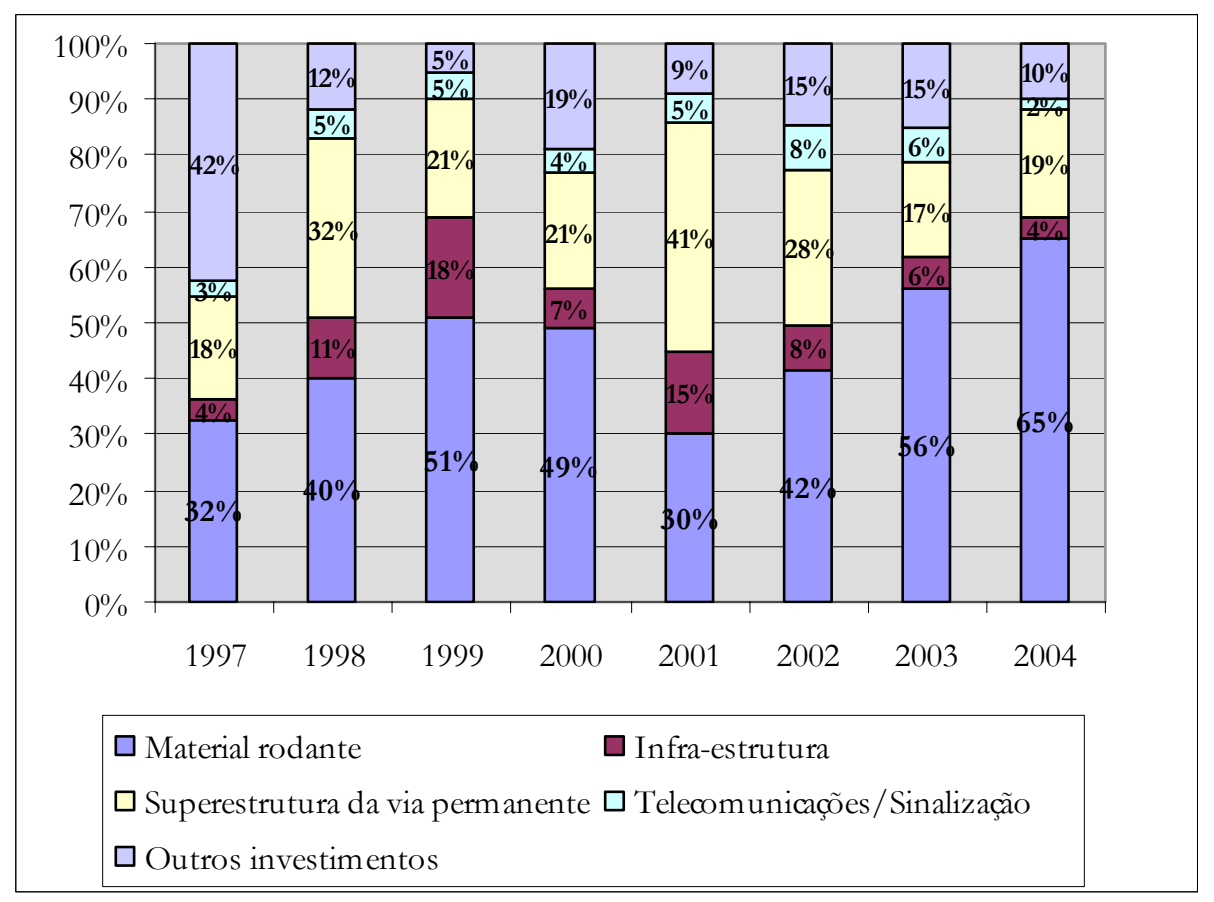

Figura 1.2 - Investimentos efetuados nas ferrovias

Com este trabalho e sua análise, propõe-se identificar os fatores que estão restringindo a capacidade ferroviária e desenvolver uma ferramenta para hierarquizar a alocação de recursos.

Pretende-se caracterizar de forma específica um trecho da malha ferroviária que atravessa o Estado de São Paulo, principal corredor de exportação do Brasil e responsável por grande volume de produtos movimentados em direção ao porto. Na Figura 1.3 é possível observar os principais canais de escoamento da produção pelo Estado. 


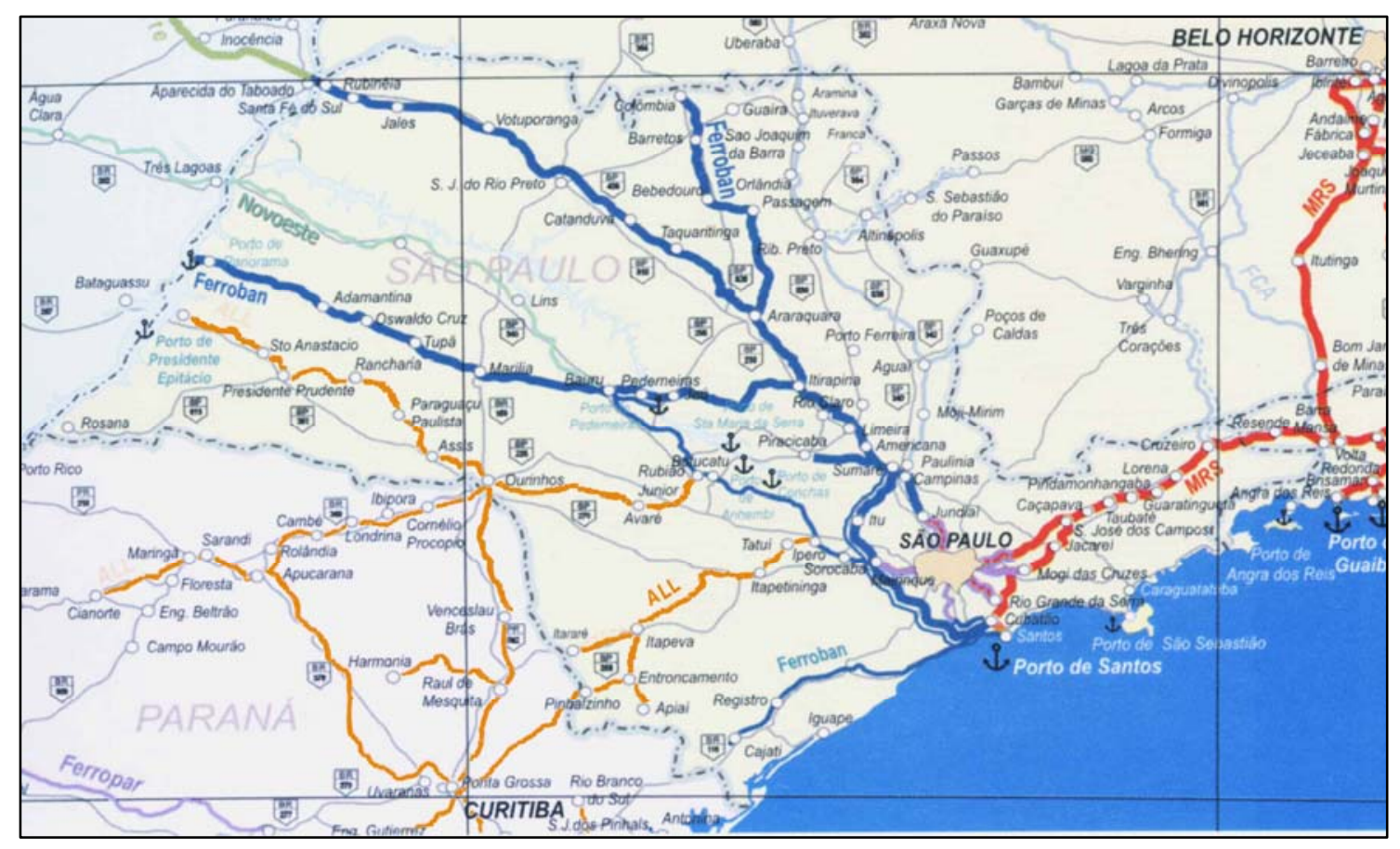

Figura 1.3 - Corredores ferroviários de exportação

\subsection{Objetivos}

O objetivo principal desta pesquisa é propor um método para analisar a capacidade de processamento de trens unidade em uma linha ferroviária singela, sujeita às restrições físicas e operacionais da via permanente.

O objetivo subjacente do trabalho é aplicar o método a um corredor de transporte ferroviário de elevado volume de tráfego. A partir dos resultados numéricos dessa aplicação avaliar-se-á o impacto relativo dos parâmetros da via que afetam sua capacidade.

\subsection{Justificativa}

A partir do panorama exposto anteriormente acerca da situação atual do transporte ferroviário no Brasil e as perspectivas de aumento na demanda, surgiu a motivação de se estudar a operação ferroviária com o propósito de investigar a capacidade de processamento da carga dessa modalidade. O conhecimento da capacidade do sistema ferroviário é um instrumento fundamental, tanto no gerenciamento operacional quanto no apoio a decisões sobre investimentos a serem efetivados nas ferrovias. 
A pesquisa em questão se destaca por abordar um problema estratégico crítico de um dos mais importantes setores de serviço do país. Em relação à participação do transporte ferroviário na matriz brasileira de transporte, percebe-se que, mesmo com o aumento da participação modal de TKU de $19 \%$ para $24 \%$ após as concessões, esse valor está bem abaixo da participação de outros países de grandes extensões continentais, como é o caso da Russia, Índia e EUA com 81\%, 50\% e 43\%, respectivamente.

O trabalho justifica-se pela carência de estudos sobre o transporte ferroviário de carga no Brasil e pela necessidade de avançar-se com pesquisas que investiguem sua real capacidade de processamento. No Brasil, cerca de $96 \%$ da malha ferroviária é linha singela. A perspectiva crescente de demanda motiva estudar as folgas do sistema e os gargalos existentes.

\subsection{Contexto da Pesquisa}

Este trabalho pertence a uma linha de pesquisa mais ampla, desenvolvida pelo Prof. João Alexandre Widmer no Departamento de Transportes da Escola de Engenahria de São Carlos, que tem como objetivo investigar estratégias de investimento para o desenvolvimento do transporte de cargas no país. Dentro dessa temática, pesquisas analisaram o processamento de cargas nas regiões portuárias e as possíveis vantagens econômicas em se utilizar a intermodalidade.

Nessa linha, foram localizados os pontos mais promissores para a instalação de futuros terminais intermodais de carga rodo-ferroviários [Tiago, 2002]; investigada a integração modal rodo-hidroviária no transporte de cargas frigoríficas [Rorato, 2003]; analisada a utilização do modal rodo-ferroviário no transporte de açúcar para o porto de Santos [Silva, 2005] e uma análise prospectiva da capacidade de processamento de vagões no Porto de Santos [Ramos, 2003]. Dando continuidade a esses estudos, o trabalho aqui apresentado pretende analisar a capacidade de processamento de carga em uma linha ferroviária singela.

\subsection{Estrutura do Trabalho}

Este trabalho está organizado em seis partes distintas. O capítulo 1 contém a introdução, na qual é apresentado um breve panorama sobre o aumento da participação da 
modalidade ferroviária no transporte de carga do Brasil, assim como o objetivo já apresentado, a contextualização da pesquisa e sua justificativa.

O Capítulo 2 traz uma revisão da bibliografia sobre os princípios básicos da operação ferroviária, descrição de modelos do sistema ferroviário e abordagens sobre a capacidade ferroviária.

No Capítulo 3 é apresentado o método de modelagem utilizado nesta dissertação para determinar-se a capacidade ferroviária.

Com o modelo aplicado, foram gerados cenários alternativos que são discutidos no Capítulo 4. Por meio desses cenários, foi investigada a influência de alguns fatores de produção na capacidade geral do sistema.

Os resultados do trabalho são apresentados no Capítulo 5, seguidos de sua análise e discussão. No Capítulo 6 são expostas as conclusões encontradas com o desenvolvimento da pesquisa e as recomendações para pesquisas futuras.

No final do trabalho é apresentado os Apêndices e o Anexo. O Apêndice A contém uma descrição do modelo de simulação utilizado, o Apêndice B detalha o modelo de locomoção ferroviária utilizado no simulador de marcha da AAR, o Apêndice C contém os resultados dos cenários elaborados. Os outros Apêndices descrevem os arquivos do simulador de desempenho do trem e o Anexo A descreve o arquivo da via. 


\section{REVISÃO BIBLIOGRÁFICA}

Foram encontrados trabalhos que tratam especificamente da operação ferroviária, de classificação nos pátios e dos problemas de despacho ou circulação de trens. Esta revisão enfoca as operações ferroviárias e a capacidade ferroviária, apresentando conceitos e modelos relacionados com os problemas de movimentação dos trens.

A revisão bibliográfica realizada permitiu constatar a existência de diversos estudos relacionados ao transporte ferroviário de carga no Brasil e no exterior. No entanto, após investigação, percebeu-se que os modelos levantados não são adequados para alcançar-se os objetivos propostos.

\subsection{Operação Ferroviária}

O sistema de transporte ferroviário é composto de instalações físicas como pátios de formação de trens, terminais e estações, linhas primárias e secundárias e pontos de junção. Esse conjunto configura uma rede na qual os vagões se movem em grupos denominados blocos. Um ou mais blocos adicionados a uma locomotiva formam um trem, que transporta passageiros ou carga. Trens viajam através de rotas pré-definidas com freqüências e programação específica.

Segundo Petersen \& Taylor [1982], os modelos de linha férrea podem ser classificados em três categorias: analíticos, de simulação e de otimização, embora os modelos de otimização possam ser considerados um subconjunto dos modelos analíticos. Os autores propuseram um modelo de simulação baseado em uma estrutura lógica que descreve o movimento dos trens sobre a linha, podendo ser aplicado em linha singela ou múltipla. O trabalho fornece uma estrutura geral do modelo, para uso na simulação da operação ferroviária. 
Há vários modelos de planejamento da operação ferroviária na literatura, entre eles Petersen [1977a, b], Turnquist \& Daskin [1982], Goh \& Mees [1991], Kraay et al. [1991], com o objetivo de programar a movimentação dos trens e solucionar os possíveis conflitos em uma linha, além de otimizar a utilização dos componentes do sistema ferroviário.

Em relação à programação da atividade ferroviária, Higgins et al. [1995] aponta a confiabilidade de toda a programação como medida do provável desempenho em termos da aderência à programação, sendo tal conceito importante tanto para o serviço ferroviário de passageiros urbanos e não urbanos, quanto para o transporte ferroviário de cargas, uma vez que essa é uma medida de desempenho crítica para todo o mercado ferroviário.

De acordo com Carey \& Lockwood [1995], o despacho de trens refere-se ao problema de alocar trens para linhas disponíveis em uma rede ferroviária (linhas, plataformas, etc.) de modo a minimizar o seu atraso e custos decorrentes, satisfazer a demanda e garantir que todos os trens nas linhas e nas estações satisfaçam às condições de espaçamento (headway) necessárias.

Em uma linha singela, o controle do tráfego exige maior cautela devido à possibilidade de choque entre os trens. Um dos trens deve aguardar em uma linha secundária (desvio), enquanto o outro efetua a passagem em sentido contrário. Leal et al. [2004] apresentam um procedimento heurístico para a resolução do problema de programação de trens em vias singelas. O modelo proposto por ele é uma ferramenta de auxílio na resolução dos conflitos entre trens, incorporando técnicas de Branch and Bound sugeridas por Higgins [1996] e técnicas de descida de vários níveis na árvore binária de solução.

Fernández et al. [2004] formularam e analisaram um modelo estratégico para o sistema ferroviário de transporte de carga para uma determinada região. O modelo equilibra o fluxo e o nível de serviço de acordo com a demanda de transporte para um conjunto de diferentes produtos, levando-se em consideração a capacidade do sistema e seus componentes e características operacionais.

\subsection{Capacidade}

Devido à complexidade do sistema ferroviário, muitas definições de capacidade foram utilizadas sob diferentes aspectos, assim como os modelos já formulados relacionam 
parâmetros diversificados. Nesse item, serão expostos alguns conceitos específicos de capacidade assim como alguns modelos encontrados na literatura.

\section{Capacidade de circulação de uma linha}

É o número máximo de trens que pode trafegar durante um determinado intervalo de tempo, em ambos os sentidos sob determinadas condições de serviço. Esse conceito é também conhecido como vazão de uma linha.

\section{Capacidade de transporte de uma linha}

É a tonelagem máxima de carga que pode ser transportada durante um determinado intervalo de tempo, em ambos os sentidos, sob determinadas condições de serviço.

\section{Capacidade teórica máxima}

É o número máximo de trens que pode circular durante um determinado intervalo de tempo, em ambos os sentidos de uma linha, sob condições ideais.

\section{Capacidade prática}

Idêntica à definição da capacidade teórica máxima, menos as condições ideais, ou seja, são consideradas as possibilidades e limitações impostas pelos meios e procedimentos empregados são considerados.

\section{Capacidade utilizada}

Corresponde ao volume de tráfego atual que está operando no território. A capacidade utilizada reflete as variações de tráfego e operações que acontecem de fato na ferrovia.

\section{Capacidade disponível}

Define-se como a diferença entre a capacidade utilizada e a capacidade prática, correspondendo ao possível aumento do fluxo de tráfego dentro das condições de desempenho determinadas. 


\section{Capacidade econômica}

É a capacidade que corresponde a melhor opção econômica para a empresa. A capacidade econômica de um segmento de linha pode ser definida como o número de trens por dia, com determinado nível de congestionamento do tráfego para o qual o custo unitário de transporte é mínimo.

O movimento dos trens na linha férrea é uma atividade básica que ocorre dentro do sistema de transporte ferroviário. Nos modelos, seja de capacidade ou operação ferroviária, a velocidade dos trens constitui, além de um dado de entrada, um elemento fundamental que exerce influência considerável sobre os resultados.

Vários modelos são descritos na literatura com foco na determinação das capacidades máximas e práticas de uma linha. Entre eles Rallis [1977] apud Janic, Assad [1980], Janic [1984, 1988] e Kraft [1983].

Janic [1984] desenvolveu um modelo analítico probabilístico para determinar a capacidade máxima de uma linha singela. No modelo, são utilizados diversos parâmetros como dados de entrada, entre eles, a velocidade dos trens. Cada trecho da linha representa um servidor a ser ocupado por um trem, sendo o tempo de processamento função do comprimento e da velocidade média do trem no trecho.

Nos modelos analíticos de capacidade, a velocidade dos trens é um parâmetro que se integra diretamente nas equações e fórmulas de cálculo.

Para efeito prático, os modelos analíticos são integrados em programas de simulação, que permitam tratar uma maior quantidade de dados, além de admitir o estudo dos comportamentos transitórios, [Petersen \& Taylor, 1982]. Nos simuladores específicos de capacidade, os valores de velocidade incorporados são geralmente calculados por meio de um simulador de desempenho do trem, conhecido como Train Performance Calculator (TPC). É o caso do modelo computacional de análise de capacidade de Ramsey et al. [1986] e do modelo de avaliação de desempenho ferroviário de Smith et al. [1997], entre outros. O TPC exibe a trajetória do trem no espaço e no tempo, permitindo o uso de paradas na simulação e calculando diretamente, a partir das características do trem e da geometria da via, o tempo mínimo de percurso e o consumo de combustível de um trem tipo circulando pela linha. 
Leilich [1998] investigou os diferentes modelos de simulação ferroviária e os parâmetros que afetam a capacidade. Segundo ele a velocidade média desenvolvida no percurso é, possivelmente, o fator mais importante na determinação da capacidade, tanto em linha singela quanto dupla.

$\mathrm{O}$ autor adverte que muitos modelos de simulação utilizam tempos de percurso calculados por um TPC externo, considerando os trechos da linha sem restrições. Depois, os modelos realizam ajustes nesses valores de tempos de percurso baseando-se na ocorrência de atrasos observados nos trens. Portanto, é essencial que o TPC usado reproduza o desempenho dos trens atuais. Para isso, é necessário compreender o modelo utilizado pelo TPC e, caso tenha que adaptar os dados obtidos pelo TPC, é necessário fazer um ajuste adequado que garanta que os dados "modificados" sejam representativos.

Krueger [1998] elaborou um modelo paramétrico de capacidade, cuja capacidade é definida como o maior volume de trens por dia que podem ser movidos em trecho dentro de um cronograma específico e plano de operação, sem exceder um limite específico. Os parâmetros por ele utilizados são subdivididos em parâmetros de geometria, tráfego e de operação. 


\section{MÉTODO DE MODELAGEM}

O conceito de capacidade está associado à possibilidade de se transportar determinada quantidade de carga em um intervalo de tempo especifico. Essa quantidade depende da infra-estrutura da via, das instalações fixas (pátios e terminais), do material rodante disponível e do sistema operacional empregado.

A capacidade, no contexto desta pesquisa, refere-se ao número de trens de carga com características uniformes de PBTC (peso bruto total combinado) e tração que possam circular pelo trecho em determinado intervalo de tempo. No presente trabalho, a capacidade será determinada em pares de trens processados por dia, pois à medida que os trens carregados são encaminhados em direção aos portos, outros voltam na direção contrária, por hipótese, com carga de retorno, assim, sua lotação é ocupada tanto na ida quando na volta. Para a análise proposta, será necessário, antes de tudo, ter uma visão geral do sistema e verificar as variáveis que influenciam sua capacidade.

Com o objetivo de determinar a capacidade em um trecho de linha singela, um modelo que represente de forma adequada a realidade do sistema ferroviário foi elaborado. Segundo Law \& Kelton [1991], um modelo é a representação matemática ou lógica de um sistema real, que é um conjunto de partes interrelacionadas e interdependentes que realizam atividades coordenadas, visando atingir uma meta comum. Esse modelo tem normalmente a forma de um conjunto de suposições relativas à operação e ao funcionamento do sistema real. O modelo é também uma simplificação do sistema real, devendo ser suficientemente detalhado para que as conclusões obtidas sejam representativas da realidade.

\subsection{Visão Geral}

O modelo proposto permite através das aplicações microscópicas na linha ferroviária ter uma visão geral do trecho analisado e, por meio de hipóteses adotadas e simplificações, 
gerar uma solução robusta para o problema analisado. A capacidade do sistema é determinada através de diagramas espaço-tempo. Neste estudo, o diagrama espaço-tempo é elaborado a partir da simulação das velocidades dos trens em cada subtrecho, utilizando-se um simulador de desempenho do trem, o SDT Train Energy Model [AAR, 1993].

O diagrama espaço-tempo é a base para o planejamento ferroviário, além de ser também um documento essencial para o controle da operação. Segundo Brina [1983] através do gráfico, analisando-se o percurso do trem (atrasos, cruzamentos), medidas para melhoria da circulação poderão ser tomadas. Verifica-se, também, se os cruzamentos se darão nos pontos programados, e a estação que será mais conveniente para que ocorra tais cruzamentos, no caso de atrasos dos trens em circulação.

Brina [1983] afirma que o diagrama espaço-tempo é útil não só para o controle da circulação e programação dos trens como também é possível verificar o número de trens que poderão circular em determinado trecho em função de diversas circunstâncias (prioridade dos trens, velocidade, cruzamentos, etc.).

Hay [1982] apresenta o diagrama espaço-tempo como ferramenta de análise do efeito da redução de curvas e rampas na velocidade e, também, para um aperfeiçoamento da programação atual dos trens variando as taxas de tonelagem, ou a determinação da capacidade com o uso de um novo tipo de tração.

A Figura 3.1 ilustra de forma simplificada as etapas do modelo de capacidade que serão detalhadas a seguir.

Inicialmente, para uma melhor compreensão do modelo elaborado, é preciso definir alguns termos fundamentais para o transporte ferroviário. Uma linha ferroviária singela é uma linha única que permita a movimentação dos trens nos dois sentidos devido à presença de dois pátios adjacentes. Esses pátios são formados por pelo menos uma linha adicional ao lado da principal e são utilizados para a circulação, formação, manobras e estacionamento de trens e vagões e, também, para o cruzamento e ultrapassagens. 
Dados de Entrada

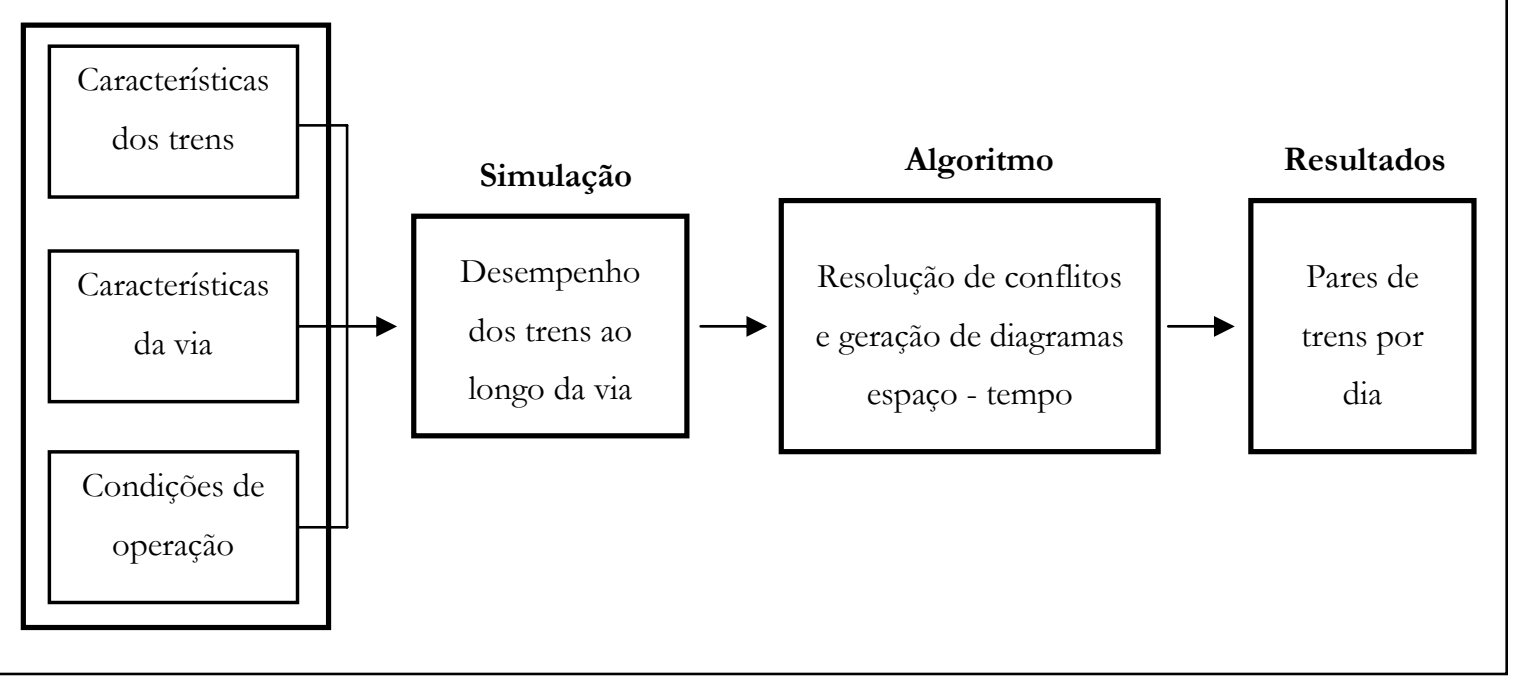

Figura 3.1: Etapas do modelo de capacidade

A ultrapassagem ocorre, essencialmente, quando um trem é seguido por outra composição de velocidade superior, é o caso, por exemplo, do trem de carga e do trem de passageiros trafegando na mesma linha, no qual o trem de passageiros é geralmente mais rápido. Nesse caso, o trem menos veloz ocupa uma das linhas do pátio e aguarda a ultrapassagem do trem mais veloz. A linha ocupada é conectada à linha principal por AMVs (aparelhos de mudanças de via ) e é conhecida também como desvio. No caso de cruzamento entre trens, fato essencial que ocorre para permitir o transporte nos dois sentidos da linha, um dos trens aguarda em um desvio enquanto o outro passa em direção contrária.

Tanto a ultrapassagem quanto o cruzamento ocorrem para evitar conflitos. Esses conflitos podem ser considerados como o fenômeno que ocorre quando dois ou mais trens estão prestes a ocupar o mesmo espaço da linha ao mesmo tempo.

Portanto, como premissas básicas deste trabalho, será admitido que apenas um trem ocupe uma mesma linha em determinado período de tempo, somente uma unidade pode ocupar um desvio de cada vez, os locais dos desvios são fixos e possuem comprimento suficiente para alocar o trem, visto que o objetivo do trabalho não é avaliar projetos e, sim, verificar o que pode ser feito para aumentar a capacidade de uma linha utilizando-se a infraestrutura existente. Também será admitido que os pátios existentes são capazes de processar a quantidade de trens encontrada. 


\subsection{Função de Produção}

Em operações ferroviárias os trens são sincronizados de forma a se encontrarem nos pátios, com itinerários que permitam uma melhor produção. O desempenho de um trem na linha férrea se dá em função de vários fatores como as estações utilizadas, o tempo de espera, a força tratora utilizada, as condições da via, entre outros. No decorrer deste trabalho será verificado, por meio dos cenários criados, como alguns fatores afetam a capacidade total do sistema.

O sistema de transporte é um sistema produtivo, e os fatores anteriormente citados podem ser entendidos como insumos. Através da utilização desses insumos será gerado um determinado número de trens por dia, ou seja, será gerada uma determinada produção. Pretende-se, portanto, investigar a função de produção do sistema ferroviário.

Os insumos físicos, em diferentes quantidades e tipos, entram no processo produtivo, com determinados esquemas operacionais, e geram produtos e serviços [Novaes, 1986]. A combinação desses insumos para obter um maior nível de produção é conhecida como função de produção, representada na Figura 3.2.

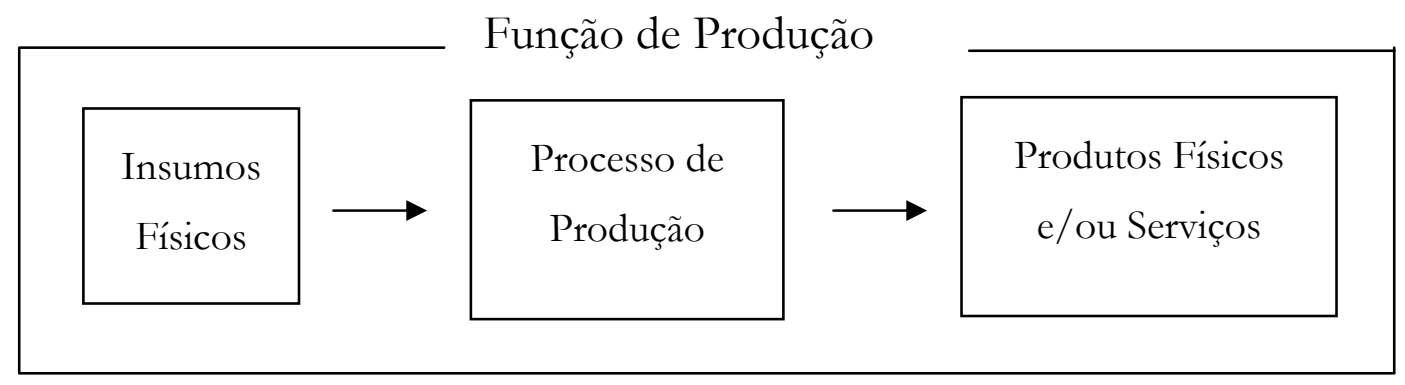

Adaptado de Novaes, 1986

Figura 3.2: Estrutura de um processo produtivo

A aplicação do modelo permite localizar os pontos de gargalos da via, ou seja, os locais restritivos ao processamento de trens por dia, bem como determinar os próximos gargalos que surgirão caso os primeiros tenham sido resolvidos. Dessa forma, permite, também, priorizar os investimentos através da investigação da função de produção. A hipótese subjacente ao método é que o modelo, através de cenários operacionais 
alternativos, permite avaliar os fatores e suas combinações que maximizem a produção da ferrovia em função das restrições da via.

\subsection{Estrutura do modelo}

No modelo, a rede ferroviária será constituída por um conjunto de pontos (pátios), denominados nós e linhas férreas que permitam a ligação entre estes nós, denominados arcos. Sobre esses nós e arcos, os trens, denominados unidades, circulam em ambos os sentidos no transporte das cargas. A representação da rede elaborada apresentada a seguir, permite a análise macroscópica da linha sem a utilização de complexos modelos de programação de trens.

A linha ferroviária é formada por um conjunto de subtrechos, as quais por sua vez são compostos por três arcos, o $\operatorname{arco}_{j-1}$, o $\operatorname{arco}_{j}$ e o $\operatorname{arco}_{j+1}$. Cada $\operatorname{arco}_{j}$ une dois pátios de cruzamento adjacentes, chamados de nó e nó $_{i+1}$. Estes nós são compostos pelo menos por duas linhas férreas: a linha principal, que é uma continuação da linha entre os nós, e a linha

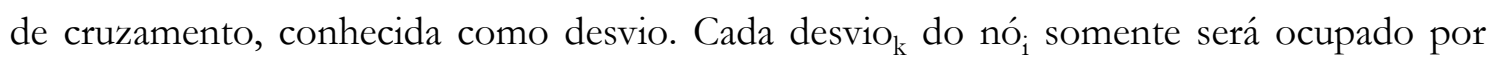
uma unidade por vez. Os arcos são divididos em segmentos $s_{n}$, permitindo o tráfego nos dois sentidos. Cada segmento $s_{n}$ possui características físicas e condições específicas que impõem limites à velocidade desenvolvida pela unidade. Na Figura 3.3 tem-se a representação simbólica dos componentes físicos de um subtrecho ferroviário.

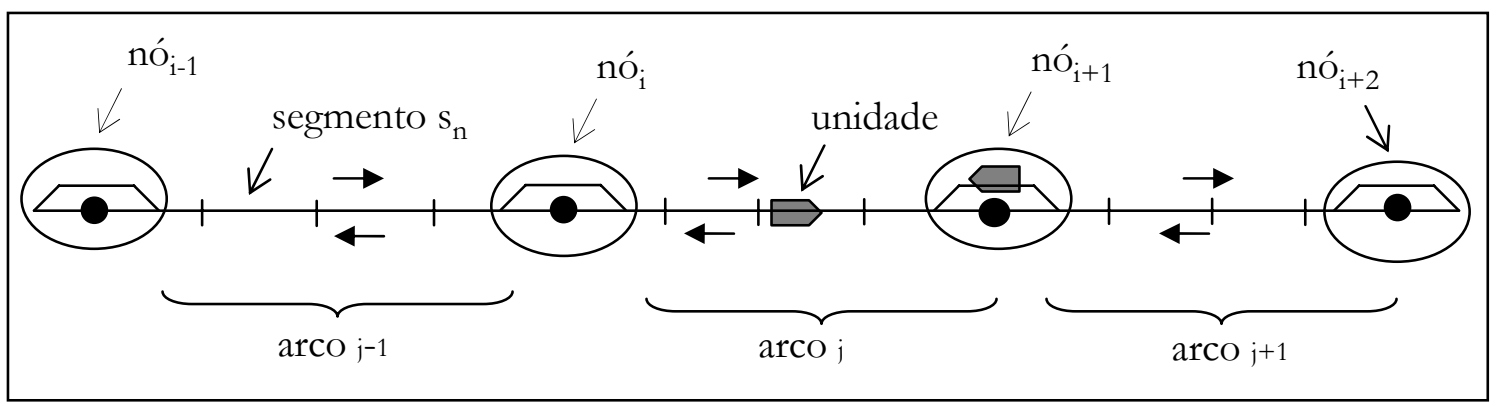

Figura 3.3 - Representação dos componentes de um subtrecho ferroviário

\subsection{Variáveis envolvidas}

Nessa etapa serão caracterizados os atributos da via e dos veículos, que servirão como dados de entrada na elaboração do modelo. 


\subsubsection{Variáveis relativas aos arcos:}

- Velocidade operacional permitida pela configuração do arco: A limitação da capacidade da linha está condicionada a dois parâmetros geométricos: raio mínimo das curvas e aclive máximo; e um parâmetro estrutural: condição da superestrutura.

- Velocidade máxima autorizada (VMA): Velocidade máxima estabelecida, atendendo-se às condições da via permanente, sua conservação, estado das obras de arte, etc. [Brina, 1983].

- Tempo de percurso entre as estações (nós): O tempo de percurso entre as estações depende do greide da linha (topografia do trecho), distância entre estações (localização), velocidade permitida, condições climáticas, condução do maquinista, etc.

- Espaçamento entre as estações (nós): A distância entre as estações exerce influência no tempo de percurso dos trens: quanto maior a distância maior o tempo para percorrê-la. Segundo Brina [1983], as estações devem estar localizadas, idealmente, de tal forma que os tempos de percurso entre as estações sejam, aproximadamente, iguais.

- Números de vias: A malha ferroviária é formada por trechos de linha singela, dupla ou tripla. Essa variável indica a quantidade de trens que podem ocupar cada arco, por vez.

\subsubsection{Variáveis relativas aos nós}

- Tipos de nós: Existem quatro tipos principais de nós em uma malha ferroviária: pátios, terminais, desvios e pontos de junção. Pátio é o conjunto de vias preparado para formação de trens, manobras e estacionamento de veículos ferroviários e outros fins; terminal é um conjunto de equipamentos e instalações situados no extremo dos arcos ou, mesmo, em pontos intermediários, ocupados para o reagrupamento de cargas e, também, a formação e despacho de trens; desvio é uma linha adjacente à linha principal ou a outro desvio, destinada aos cruzamentos, passagens e formação de trens; e os pontos de junção se referem à interseção de uma via férrea com outra. $O$ 
número e a freqüência desses elementos na linha fazem parte do conjunto de fatores que afetam a capacidade da ferrovia [ANTF, 2005].

- Número de nós: O número de estações onde os trens possam encontrar outras composições. Esse número tem influência direta no tempo total de percurso e no número total de trens que possam está no trecho em um dado instante para que não ocorram congestionamento e bloqueio da linha.

- Comprimento das estações: As estações permitem a movimentação dos trens através da rede. Seu comprimento restringe os comboios de trens sucessivos num mesmo sentido.

- Utilização dos terminais: A capacidade de transporte de um corredor ferroviário é função direta da capacidade de carga e descarga dos terminais que operam nos extremos e ao longo do corredor. Os terminais devem estar preparados, conseqüentemente, para operar de tal forma que não comprometam a capacidade de transporte da linha.

\subsubsection{Variáveis relativas às unidades}

- Potência das locomotivas: Uma parcela significativa da potência do motor da locomotiva é transformada em força motriz, responsável pela locomoção da composição.

- Comprimento do trem: O comprimento total do trem é o somatório do comprimento dos vagões e das locomotivas. Esse valor é limitado pelo comprimento dos desvios, a tração exercida pelas locomotivas e a capacidade de carga dos engates.

- Sentido de circulação: O greide da linha (topografia) atua de maneira diferenciada para cada sentido de circulação dos trens, influenciando no tempo de percurso e na capacidade de tração das locomotivas.

- Headways: O número de trens na linha em um dado instante depende da separação temporal entre os mesmos (headway), influenciando no número de conflitos de trens, no tempo total de percurso e, assim, na capacidade do trecho. 
- Carga transportada por vagão: a carga transportada por vagão depende da limitação por peso ou volume dos vagões utilizados. Esse parâmetro está, diretamente relacionado com a potência das locomotivas empregadas, às condições da via e os custos de manutenção da linha devido às solicitações dinâmicas exercidas.

- Carga por eixo: É a solicitação exercida em cada eixo devido ao peso da carga e do vagão (PBT).

- Carga transportada por trem: Esse índice é dado a partir do comprimento dos trens e a carga transportada (peso útil) de cada vagão.

\subsection{Modelo de Capacidade}

\subsubsection{Diagrama espaço-tempo}

A representação gráfica das operações dos trens, usando-se diagramas espaço-tempo tem sido utilizada para a análise da movimentação das composições ferroviárias e determinação da capacidade do trecho [Hay, 1982]. O espaço é representado no eixo vertical, nele estão contidos os desvios, estações e pátios de manobra. O tempo é representado no eixo horizontal e o intervalo utilizado depende da capacidade que se quer avaliar.

Apesar do seu comprimento, os veículos ferroviários são visualizados nos diagramas espaço-tempo como partículas que descrevem o movimento, variando sua velocidade ao longo do tempo. Quando um trem inicia o movimento ele, passa por um processo de aceleração; quando realiza uma parada, ele passa por um processo de desaceleração, sendo que, devido às características de cada segmento do arco e condições operacionais impostas, o veículo sofre alterações em sua velocidade ao longo do percurso.

No modelo de determinação da capacidade, entretanto, a distribuição da velocidade nos arcos será descrita pela velocidade média no espaço, encontrada através do registro do desempenho do trem ao longo da via. Com dois pontos extremos definidos, via de regra, nas estações de cruzamento, é encontrada a declividade do segmento de reta $\mathrm{AB}$, conforme, a Figura 3.4 ilustra. 




Figura 3.4 - Diagrama espaço-tempo entre dois nós

Matematicamente, a velocidade média no espaço pode ser determinada pela equação 3.1:

$$
\bar{u}_{s}=\frac{n \cdot s}{\sum_{i=1}^{n} t_{i}}
$$

na qual:

$\bar{u}_{s}=$ velocidade média no espaço, em $\mathrm{km} / \mathrm{h}$

$\mathrm{S}=$ espaçamento do segmento, em $\mathrm{km}$

$\mathrm{t}_{\mathrm{i}}=$ tempo gasto pelo i-ésimo trem para percorrer o segmento s, em $\mathrm{h}$.

A mesma aplicação é feita para os trens que se movimentam na direção oposta, do nó ${ }_{i+1}$ para o nó . A nomenclatura adotada para essas direções foi sentido exportação (em direção ao porto) e importação (em direção ao interior do país). Obtida a velocidade média dos trens nos dois sentidos, é necessário que eles se encontrem nos pontos fixos da linha que permitam esse cruzamento, sem que haja conflito. Para Hay [1982], o primeiro fator do controle operacional é prevenir colisões entre veículos.

\subsubsection{Solução do conflito}

A movimentação dos trens em uma linha singela só é possível se houver uma sincronia entre os trens de forma que se encontrem apenas nas estações que possuam trechos de linha dupla, evitando-se, assim os conflitos. Para a elaboração do diagrama 
espaço-tempo, a resolução do conflito foi feita através de um algoritmo formulado em MatLab.

O algoritmo é baseado em uma heurística que busca a otimização da solução fazendo uma varredura no espaço. Parte-se, inicialmente de um conjunto de dados que contenham o desempenho do trem ao longo de uma linha, na qual consta posição, tempo e velocidade instantânea do trem em cada subtrecho.

Como mostrado anteriormente cada subtrecho é composto por três arcos, o $\operatorname{arco}_{j-1}, \mathrm{o}$ $\operatorname{arco}_{j}$ e o $\operatorname{arco}_{j+1}$ e quatro pátios de cruzamento adjacentes, nó ${ }_{i-1}$, nó ${ }_{i}$, nó $_{i+1}$, e nó ${ }_{i+2}$. Sendo o nó $_{i-1}$ a estação inicial e nó ${ }_{i+2}$ a estação final do subtrecho.

As unidades efetuam os cruzamentos nos nós demandando um determinado tempo de espera. Para os tempos de cruzamento, utilizou-se a premissa que trens, nos dois sentidos, permanecem, pelo menos, o tempo mínimo de espera. Dessa forma, em cada nó, o trem chega em um determinado instante de tempo e sai em outro, que serão expressos pelas varáveis ini e fim respectivamente.

A programação possui vários trens na linha. Assim, durante o procedimento, esses trens poderão adotar os dois sentidos, exportação ou importação. Para representá-los, cada unidade i possuirá uma variável (E) ou (I) de acordo com o sentido do percurso. A variável E representa o sentido exportação, com quilometragem crescente, e a variável I representa o sentido contrário, com quilometragem decrescente.

A programação inicial é originada de duas matrizes independentes que contenham o tempo, posição e velocidade para o sentido exportação e, a outra, para o sentido importação obtidos através do SDT. Os nós são identificados a partir do valor numérico velocidade; quando esta é nula, os valores do espaço e tempo correspondentes a um nó são gravados. Uma vez determinados os nós calcula-se a velocidade média no espaço entre nós sucessivos. Dessa forma são criadas novas matrizes com apenas os pontos de entrada e saída do trem em cada nó. Na Figura 3.5 esses pontos são representados. 




Figura 3.5 - Diagrama espaço-tempo de um subtrecho

Cada unidade i desenvolverá o movimento ao longo dos pontos j. Os tempos serão descritos como $\left(t_{i, j}\right)$, o mesmo ocorre com o espaço, descrito como $\left(\mathrm{s}_{\mathrm{i}, \mathrm{j}}\right)$. A representação, em forma de matriz do tempo e espaço, para o exemplo geral da Figura 3.5, tem o seguinte formato:

Matriz Tempo:

\begin{tabular}{c|cc|cc|c} 
nó $_{i-1}$ & \multicolumn{2}{|c|}{ nó $_{\mathrm{i}}$} & \multicolumn{2}{|c|}{ nó $_{\mathrm{i}+1}$} & nó $_{\mathrm{i}+2}$ \\
\hline (fim) & (ini) & (fim) & (ini) & (fim) & (ini)
\end{tabular}

unidade $_{1}(\mathrm{E})\left[\begin{array}{llllll}\mathrm{t}_{1,1} & \mathrm{t}_{1,2} & \mathrm{t}_{1,3} & \mathrm{t}_{1,4} & \mathrm{t}_{1,5} & \mathrm{t}_{1,6}\end{array}\right]$

Matriz Espaço:

\begin{tabular}{c|cc|cc|c} 
nó $_{\text {i-1 }}$ & \multicolumn{2}{|c|}{ nó $_{\mathrm{i}}$} & \multicolumn{2}{|c|}{ nó $_{\mathrm{i}+1}$} & nó $_{\mathrm{i}+2}$ \\
\hline (fim) & (ini) & (fim) & (ini) & (fim) & (ini)
\end{tabular}

unidade $_{1}(\mathrm{E})\left[\begin{array}{llllll}\mathrm{s}_{1,1} & \mathrm{~s}_{1,2} & \mathrm{~s}_{1,3} & \mathrm{~s}_{1,4} & \mathrm{~s}_{1,5} & \mathrm{~s}_{1,6}\end{array}\right]$

No caso de uma unidade em sentido contrário, a representação em forma de matriz será análoga, porém os espaços serão invertidos. $\mathrm{O} \mathrm{s}_{1,1}(\mathrm{I})$ será igual ao $\mathrm{s}_{1,6}(\mathrm{E})$, o s $\mathrm{s}_{1,2}(\mathrm{I})$ será igual ao $\mathrm{s}_{1,4}(\mathrm{E})$, e assim sucessivamente. 
Para a programação dos trens, adotou-se que a unidade $(\mathrm{E})$ inicia o movimento no par ordenado $\left(t_{1,1}, s_{1,1}\right)$ igual a $(0,0)$. O mesmo não ocorre com a unidade $1(\mathrm{I})$, o início de seu movimento está condicionado ao tempo de viagem até o $\mathrm{s}_{1,2}(\mathrm{I})$. A partir das primeiras unidades, (E) e (I), encontra-se o headway (h), como pode ser observado na Figura 3.6.

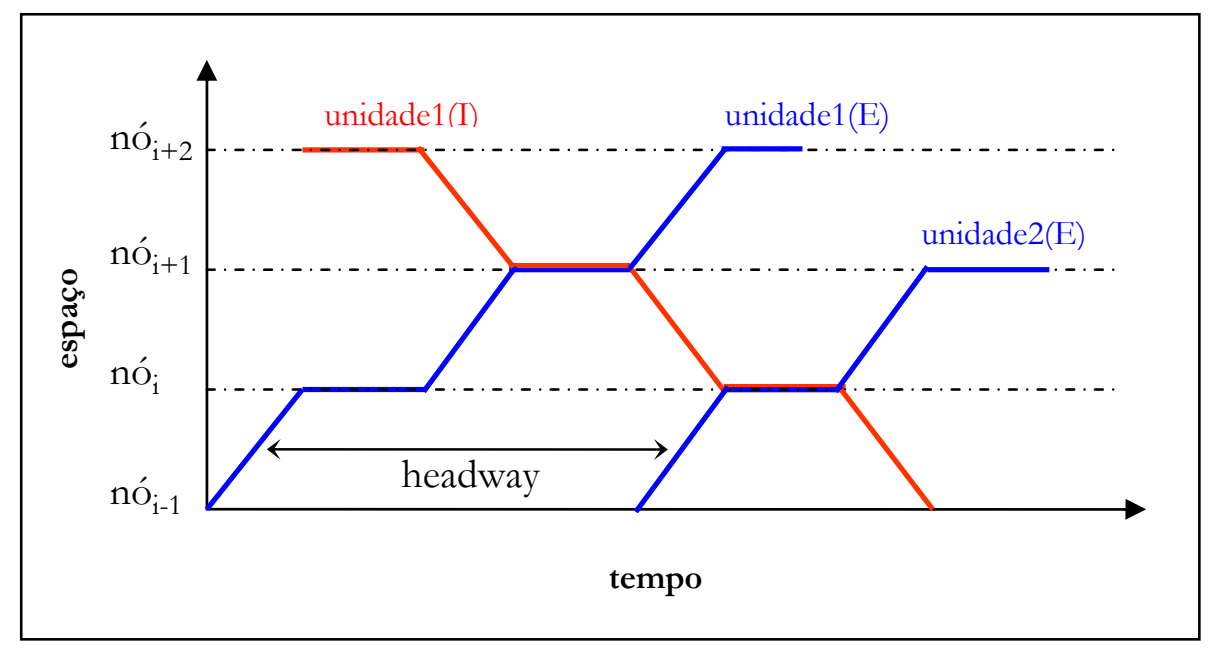

Figura 3.6 - Solução do conflito em um subtrecho

O headway (h) é o intervalo temporal entre os trens, deve possuir valor suficiente para prevenir o choque entre os veículos. Como o objetivo do algoritmo é solucionar os conflitos, mais duas unidades em cada sentido são acrescentadas nas matrizes iniciais de tempo. Os novos valores são encontrados da seguinte forma:

a) sentido exportação:

$$
\begin{gathered}
t_{2, j}(E)=t_{1, j}(E)+h \\
t_{3, j}(E)=t_{2, j}(E)+\text { h ou t }_{3, j}(E)=t_{1, j}(E)+2 h
\end{gathered}
$$

a) sentido importação:

$$
\begin{gathered}
t_{2, j}(I)=t_{1, j}(I)+h \\
t_{3, j}(I)=t_{2, j}(I)+\text { h ou }_{3, j}(I)=t_{1, j}(I)+2 h
\end{gathered}
$$

Como estão sendo analisados três arcos, o conflito ocorre no primeiro e/ou último arco. As condições para que exista o conflito nas unidades em direções opostas são, respectivamente: 


$$
\begin{aligned}
& \text { Se } t_{1,6}(E)-t_{2,1}(I)>0 \\
& \mathrm{E} \mathrm{t}_{1,6}(\mathrm{I})-\mathrm{t}_{3,1}(\mathrm{E})>0
\end{aligned}
$$

Durante o procedimento, os conflitos são resolvidos ocasionando atrasos da unidade i nos nós intermediários, nó ${ }_{i}$ e nó ${ }_{i+1}$. Como os conflitos podem ocorrer nos $\operatorname{arco}_{j-1}$ e/ou $\operatorname{arco}_{j+1}$ os atrasos são identificados pela variável $i n f$, caso ocorra no $\operatorname{arco}_{j-1}$; e pela variável sup, caso ocorra no $\operatorname{arco}_{\mathrm{j}+1}$. Os atrasos podem ser encontrados da seguinte forma:

$$
\begin{aligned}
& \operatorname{atraso}_{\text {sup }}=\mathrm{t}_{1,6}(\mathrm{E})-\mathrm{t}_{2,1}(\mathrm{I}) \\
& \text { atraso }_{\text {inf }}=\mathrm{t}_{1,6}(\mathrm{I})-\mathrm{t}_{3,1}(\mathrm{E})
\end{aligned}
$$

Como os conflitos podem ocorrer nos dois arcos, é necessário verificar qual dos dois provoca um atraso maior nas unidades. Após esta etapa, são refeitos os horários do trem adicionando um tempo de espera ou atraso. Assim:

a) $\mathrm{Se}_{\text {atraso }}$ sup $>$ atraso $_{\text {inf }}$, fazer:

$$
\begin{aligned}
& \mathrm{t}_{\mathrm{i}, 3}(\text { atrasado })=\mathrm{t}_{\mathrm{i}, 3}+\left(\text { atraso }_{\text {sup }} / 2\right) \\
& \mathrm{t}_{\mathrm{i}, 4}\left(\text { atrasado }=\mathrm{t}_{\mathrm{i}, 4}+\left(\text { atraso }_{\text {sup }} / 2\right)\right. \\
& \mathrm{t}_{\mathrm{i}, 5}(\text { atrasado })=\mathrm{t}_{\mathrm{i}, 5}+\left(\text { atraso }_{\text {sup }}\right) \\
& \mathrm{t}_{\mathrm{i}, 6}(\text { atrasado })=\mathrm{t}_{\mathrm{i}, 6}+\left(\text { atraso }_{\text {sup }}\right)
\end{aligned}
$$

b) Se por outro lado atraso $\mathrm{inf}_{\text {inf }}>$ atraso $_{\text {sup }}$ fazer:

$$
\begin{aligned}
& \mathrm{t}_{\mathrm{i}, 3}\left(\operatorname{atrasado}=\mathrm{t}_{\mathrm{i}, 3}+\left(\text { atraso }_{\text {inf }} / 2\right)\right. \\
& \mathrm{t}_{\mathrm{i}, 4}\left(\text { atrasado }=\mathrm{t}_{\mathrm{i}, 4}+\left(\text { atraso }_{\text {inf }} / 2\right)\right. \\
& \mathrm{t}_{\mathrm{i}, 5}\left(\text { atrasado }=\mathrm{t}_{\mathrm{i}, 5}+\left(\text { atraso }_{\text {inf }}\right)\right. \\
& \mathrm{t}_{\mathrm{i}, 6}\left(\text { atrasado }=\mathrm{t}_{\mathrm{i}, 6}+\left(\text { atraso }_{\text {inf }}\right)\right.
\end{aligned}
$$




\subsubsection{Análise da capacidade}

Os diagramas são elaborados para cada subtrecho de forma consecutiva. Assim, o $\operatorname{arco}_{j-1}$ é abandonado enquanto o $\operatorname{arco}_{j}$ e o $\operatorname{arco}_{j+1}$ tornam-se consecutivamente os $\operatorname{arco}_{j-1}$ e o $\operatorname{arco}_{j}$ do próximo subtrecho. Desta forma, é possível a investigação de todo o trecho, independente do número de estações (nós) existentes, identificando os estrangulamentos da capacidade na linha.

Cada subtrecho possui instalações fixas (desvios, estações e pátios de manobra) determinadas, o que promove espaçamentos e headways específicos. A redução da velocidade em um desses arcos faz com que os trens apresentem headways maiores, provocando uma diminuição na capacidade do sistema. Observando-se a Figura 3.5, percebe-se pelo primeiro diagrama que é possível processar 3 pares de trens por período de tempo; já no segundo, apenas 2 pares de trens são processados para o mesmo intervalo de tempo, devido à redução da velocidade do $\operatorname{arco}_{j}$.

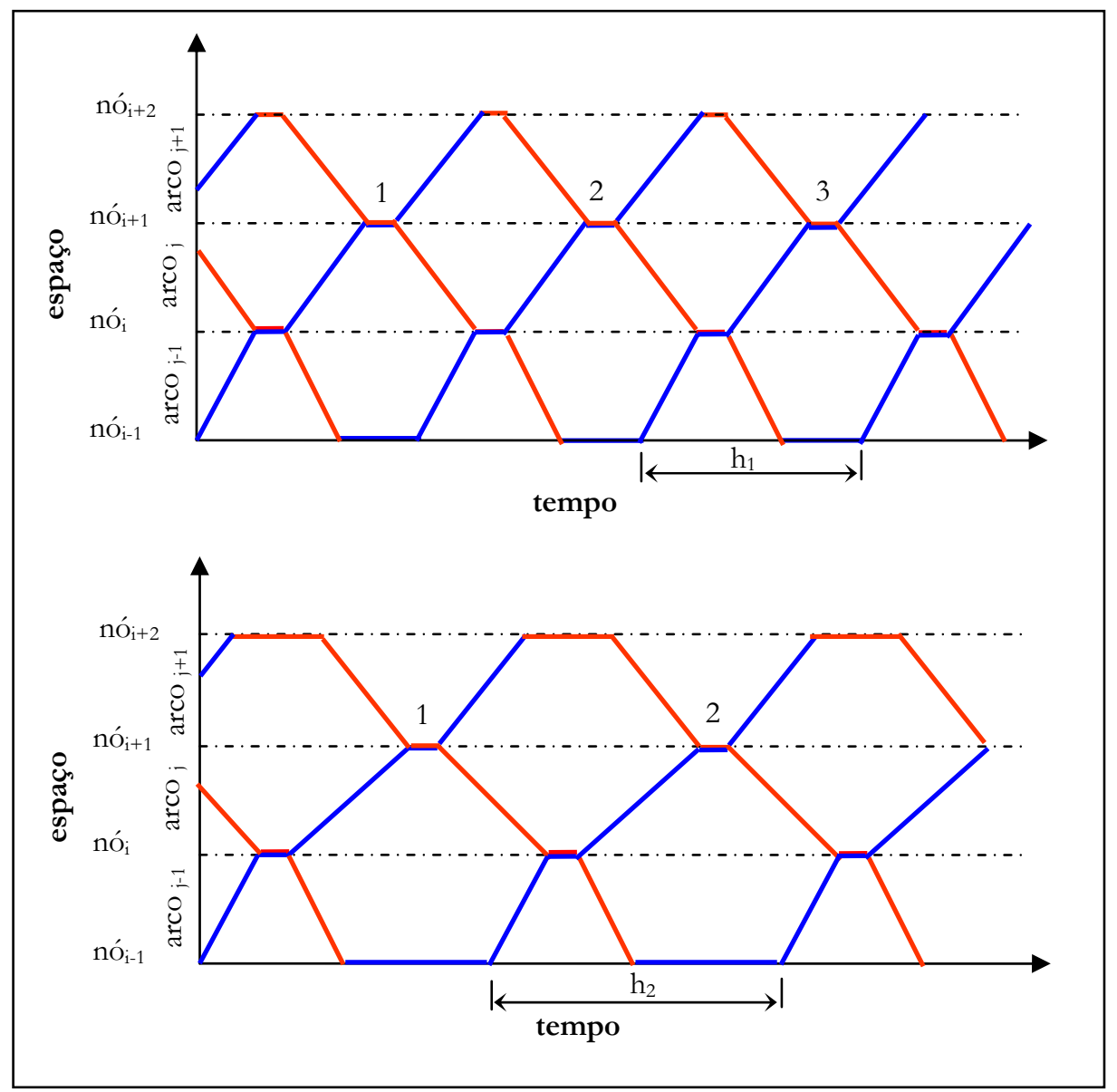

Figura 3.7: Análise da capacidade no diagrama espaço-tempo 
A velocidade exerce interferência direta sobre a capacidade. Quanto mais lento se movimentar uma unidade mais tempo irá gastar para percorrer um determinado arco, além disto, afetará os horários de partida nos outros arcos devido ao controle dos cruzamentos nos nós.

\subsubsection{Análise do desempenho dos trens em um trecho}

A velocidade real da unidade nos arcos, necessária para construção do diagrama espaço-tempo foi adquirida através de um simulador de desempenho do trem, desenvolvido pela Association of American Railroads-AAR, o qual permite avaliar o movimento dos trens no decorrer do percurso, a partir de condições determinadas. Esse modelo de simulação foi escolhido para ser utilizado neste trabalho devido à adequação aos objetivos da pesquisa e à facilidade de aquisição.

A simulação é uma técnica que permite representar a operação de um sistema real durante um período de tempo de forma idealizada. Em sistemas mais complexos, os modelos matemáticos e lógicos são integrados a um programa computacional. Com essa técnica é possível avaliar alterações em projetos e operações antes de sua implementação e, também, experimentar novas alternativas de operação e utilização das instalações que possam ser necessárias.

Segundo Law \& Kelton [1991], os modelos de simulações possuem várias vantagens: a simulação permite estimar o desempenho de um sistema existente dentro de um conjunto de condições operacionais; operações alternativas podem ser comparadas através da simulação a fim de se encontrar a melhor solução testada; em uma simulação, é possível manter um melhor controle das condições do experimento a serem testadas; além disso a simulação permite estudar um sistema estruturado em um tempo longo em um curto prazo gerando previsões futuras.

Quando devidamente validado, o simulador permite representar, também, situações as quais dificilmente seriam testadas na prática. No caso de uma ferrovia singela, isso seria mais dramático, devido às dimensões das composições e das paradas no funcionamento regular para a realização de testes. A simulação ainda permite analisar as operações sem intervenções no sistema real; desta forma, é possível simular diversos cenários e analisar o desempenho das composições sob diferentes condições sem maiores dificuldades. 
Os modelos que permitem verificar o desempenho das composições ferroviárias ao decorrer da linha (SDT) permitem experimentar vários tipos de composições, carregamentos, modificações na geometria da via (rampa, curva) e condições operacionais como prioridades e tempo de parada. A maioria dos modelos de desempenho são integrados a programas computacionais entre eles, pode-se mencionar o Railsim (<http://www.railsim.com/TPC.htm>), o $\quad$ TEM (AAR) e $\quad$ o Microrail (http://www.microrail-fr.com/).

\subsubsection{O Simulador de Desempenho do Trem}

O SDT utilizado é o Train Energy Model desenvolvido pela AAR (Association of American Railroads), cujo objetivo inicial fora o de usá-lo em estudos de consumo de combustível, relacionados à resistência e tração dos trens. A primeira versão data de 1986, a partir dela, com inclusões ao modelo, surgiram as versões 1.7, 2.0 e 2.5, sendo esta última utilizada nesta pesquisa [AAR,1993].

O simulador de desempenho do trem utilizado permite que se determine o tempo, a velocidade, a distância e o consumo de combustível de um trem que trafega sobre um determinado perfil da via. O modelo inclui também os efeitos das rampas, curvas, resistências do trem, limites de velocidade, características da propulsão e da frenagem e condições operacionais.

O programa pode ser estruturado em três partes, a saber: dados de entrada, algoritmo interno e dados de saída. Os dados de entrada são as características físicas e mecânicas das composições ferroviárias, as características da via, as condições operacionais e as opções de simulação. O algoritmo é composto por um modelo físico, equações de movimento e métodos numéricos, usados para integrar as equações de movimento no simulador. Os dados de saída podem ser visualizados em forma de gráficos e tabelas, com destaque para: a distância percorrida, a velocidade instantânea e o ponto de aceleração e desaceleração. A estrutura do simulador e como foi utilizado está descrito no Apêndice A.

O algoritmo interno é um modelo matemático baseado nas equações físicas que regem o movimento de uma composição ferroviária e as relações empíricas, já consagradas 
na indústria ferroviária. Essas equações permitem o cálculo do esforço trator, das resistências impostas pelas locomotivas e vagões, do esforço nos engates, da aceleração e frenagem, a distância e o tempo necessários para frear, além de outros fatores relativos ao movimento. A partir dessas equações, o modelo emite o desempenho do trem calculando, para cada instante, as forças que atuam sobre a composição. No Apêndice B são descritos detalhadamente os princípios da locomoção ferroviária usados no simulador. 


\section{APLICAÇÃO DO MODELO}

A aplicação refere-se a um trecho de operação em linha singela da Brasil Ferrovias, que reúne as operações da Ferronorte, Ferroban e a Novoeste. O trecho de estudo, um corredor de exportação de bitola larga, pertence à malha da FERROBAN - Ferrovias Bandeirantes S.A., que interliga a Baixada Santista/Porto de Santos e as cidades de Santa Fé do Sul, Panorama e Colômbia, uma rede de $2.916 \mathrm{~km}$ de comprimento total, que possibilita o escoamento da produção dos estados de Mato Grosso do Sul, Mato Grosso e São Paulo. Sua malha pode ser observada na Figura 4.1, bem como o trecho destacado, no qual serão realizadas simulações.

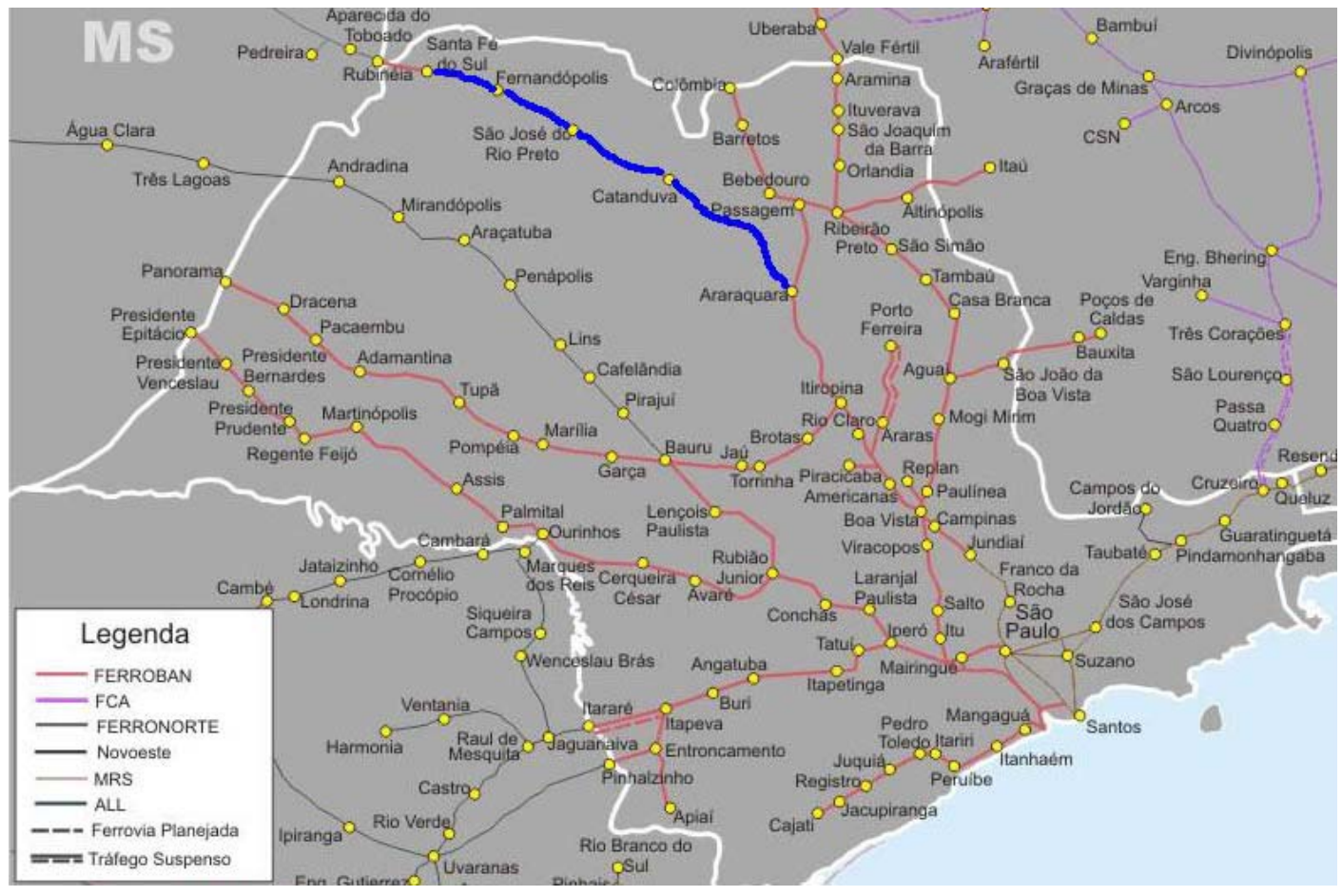

Figura 4.1 - Trecho ferroviário de aplicação do modelo 
Com relação aos portos, a FERROBAN possui interconexões não somente com o Porto de Santos, mas também com os portos fluviais de Pederneiras, Panorama e Presidente Epitácio, e pelo sistema da MRS Logística S.A, com os portos de Sepetiba e Rio de Janeiro.

As principais mercadorias transportadas no trecho em estudo são: produtos agrícolas, soja e farelo de soja, adubos e fertilizantes, carvão e coque, escórias, combustíveis e carga geral. O gráfico da Figura 4.2 mostra a projeção de volume de transporte da Brasil Ferrovias (FERROBAN, FERRONORTE e NOVOESTE) para bitola larga até o ano de 2013. Analisando-os é fácil perceber a expansão esperada da concessionária.

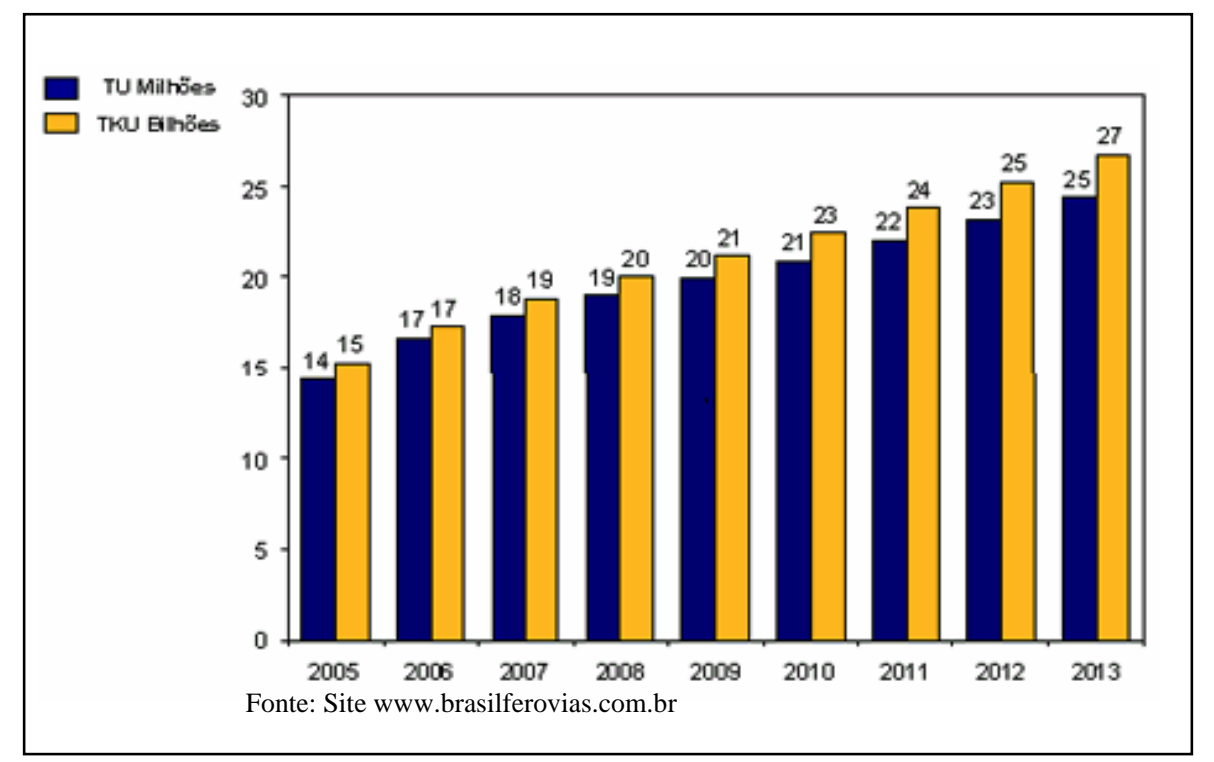

Figura 4.2 - Projeção do transporte ferroviário - bitola larga

Segundo a Brasil Ferrovias, a empresa transportou 8,1 milhões de toneladas úteis (TU) em 2004. O levantamento de 2005 mostrou que foram transportadas $40 \%$ a mais do que o volume transportado em 2004, o que representa cerca de 3\% do total de toneladas transportadas no Brasil e 5,3\%, se excluirmos o fluxo de minério de ferro da Companhia Vale do Rio Doce (CVRD). Tal crescimento ocorreu graças a investimentos efetuados na reestruturação da holding, com previsão de movimento para 2006 de cerca de 20 milhões de toneladas [http://brasilferrovias.com.br].

\subsection{Caracterização da Via}

Como exposto no método desta pesquisa, a rede ferroviária será formada por estações caracterizadas como nós; linhas, que serão os arcos do modelo proposto; e trens, 
indicados como unidades, que circulam pela linha ferroviária. Uma vez descrito o modelo, é necessário conhecer as características de cada um dos recursos que servirão como dados de entrada.

\subsubsection{Arcos}

O modelo será aplicado em um trecho da linha férrea que liga a cidade de Santa Fé do Sul, divisa com o estado do Mato Grosso do Sul, até a cidade de Araraquara, que também interliga uma linha tronco proveniente da cidade de Colômbia, na divisa com Minas Gerais.

Os dados dos arcos como posições, altitude, aclives, declives, grau de curva e velocidade máxima autorizada foram fornecidos pela diretoria da Brasil Ferrovias reproduzidos no Anexo A.

O trecho de estudo, com todas as estações, é composto por 28 arcos no total, com comprimentos apresentados na Tabela 4.1.

Tabela 4.1: Comprimento dos arcos do trecho da Brasil Ferrovias

\begin{tabular}{cccc}
\hline Arco & Comprimento $(\mathbf{k m})$ & Arco & Comprimento $(\mathbf{k m})$ \\
\hline 1 & 7,20 & 15 & 10,53 \\
\hline 2 & 27,86 & 16 & 19,33 \\
\hline 3 & 12,50 & 17 & 17,27 \\
\hline 4 & 16,10 & 18 & 13,48 \\
\hline 5 & 18,01 & 19 & 10,53 \\
\hline 6 & 10,48 & 20 & 12,93 \\
\hline 7 & 13,84 & 21 & 24,19 \\
\hline 8 & 12,42 & 22 & 15,86 \\
\hline 9 & 24,48 & 23 & 15,81 \\
\hline 10 & 14,52 & 24 & 16,27 \\
\hline 11 & 17,73 & 25 & 11,73 \\
\hline 12 & 27,32 & 26 & 6,37 \\
\hline 13 & 14,77 & 27 & 17,71 \\
\hline 14 & 4,46 & 28 & 7,26 \\
\hline
\end{tabular}


Para o modelo de simulação, como mencionado no Capítulo 3, foi realizada uma divisão do trecho da malha ferroviária em subtrechos compostos de três arcos, que serão simulados consecutivamente. Nos cenários nos quais nem todos os nós são utilizados, arcos adjacentes são unidos formando, assim, um novo arco maior que o anterior, como pode ser observado na Figura 4.3.

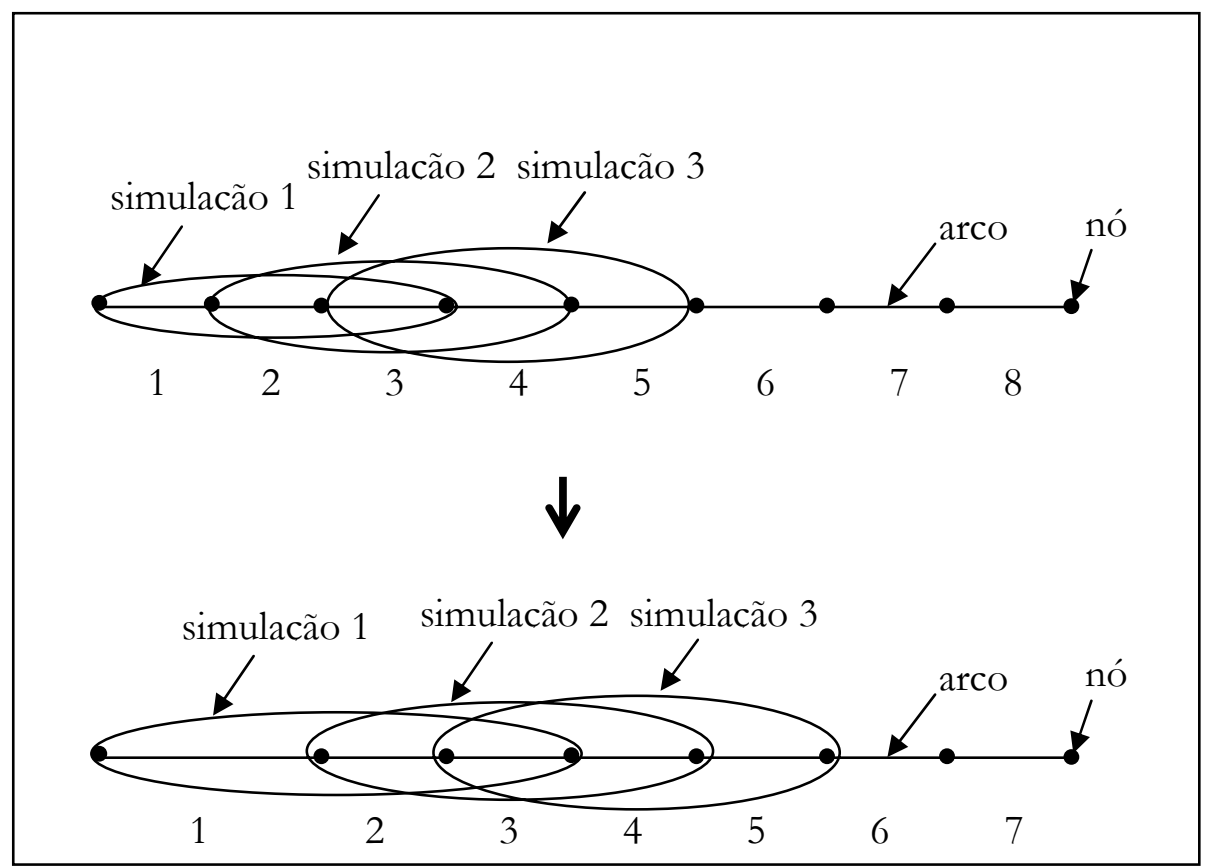

Figura 4.3: União de arcos no trecho

\subsubsection{Nós}

Os dados relacionados às características físicas e localização dos nós foram obtidos do mesmo arquivo que continha os dados dos arcos (ver Anexo A). A Tabela 4.2 apresenta o comprimento das estações que compõem o trecho analisado e, também, a nomenclatura (sigla) utilizada para representá-las. O valor do comprimento das estações é utilizado como restrição na construção dos cenários com menor número de desvios.

Tabela 4.2: Comprimento das estações do trecho.

\begin{tabular}{lllcrlllc}
\hline Nó & Nome da estação & Sigla & $\begin{array}{c}\text { Comprimento } \\
\mathbf{( k m )}\end{array}$ & Nó & Nome da estação Sigla & $\begin{array}{c}\text { Comprimento } \\
\mathbf{( k m})\end{array}$ \\
\hline \hline 1 & Santa Fé do Sul & ZFS & 1,29 & 16 & Eng. Schimitt & ZEH & 0,46 \\
\hline 2 & Três Fronteiras & ZTF & 0,55 & 17 & Uchoa & ZUC & 0,70 \\
\hline 3 & Urânia & ZUR & 0,70 & 18 & Catigua & ZCT & 0,68 \\
\hline
\end{tabular}




\begin{tabular}{|c|c|c|c|c|c|c|c|}
\hline 4 & Jales & ZJA & 0,95 & 19 & Catanduva & $\mathrm{ZCV}$ & 0,97 \\
\hline 5 & Estrela D'Oeste & ZED & 0,73 & 20 & Pindorama & $\mathrm{ZPN}$ & 0,98 \\
\hline 6 & Fernandópolis & $\mathrm{ZFN}$ & 0,81 & 21 & Santa Adelia & ZSD & 1,05 \\
\hline 7 & Meridiano & ZMR & 0,70 & 22 & Candido Rodrigue & $\mathrm{ZCZ}$ & 0,93 \\
\hline 8 & Valentim Gentil & ZVG & 0,73 & 23 & Taquaritinga & ZTQ & 0,69 \\
\hline 9 & Votuporanga & ZVP & 0,91 & 24 & Santa Ernestina & $\mathrm{ZSH}$ & 0,47 \\
\hline 10 & Cosmorama & ZKY & 0,68 & 25 & Matao & ZMA & 1,75 \\
\hline 11 & Ecatu & ZEC & 0,64 & 26 & Silvania & ZZL & 0,75 \\
\hline 12 & Eng. Balduino & ZEB & 0,69 & 27 & Bueno de Andrade & ZDZ & 1,77 \\
\hline 13 & Mirassol & $\mathrm{ZMO}$ & 0,67 & 28 & Tutoia & ZTO & 1,76 \\
\hline 14 & Rio Preto Paulista & ZRU & 1,40 & 29 & Araraquara & ZAR & 0.64 \\
\hline 15 & S. Jose do Rio Preto & ZSP & 0,43 & & & & \\
\hline
\end{tabular}

\subsection{Caracterização das unidades}

As unidades são formadas por unidades tratoras, as locomotivas, e unidades rebocáveis, os vagões. A seguir será caracterizado o material rodante selecionado para formar o trem padrão utilizado no modelo.

\subsubsection{Locomotivas}

No experimento, foram utilizadas locomotivas modelo Dash 9 (Figura 4.4), máquinas ferroviárias fabricadas pela GE com potência máxima de tração de cerca de $4.400 \mathrm{hp}$. Na tabela 4.3 são apresentadas as características dessa locomotiva relevantes para o estudo.

Tabela 4.3: Descrição da Locomotiva Dash 9

\begin{tabular}{|l|l|}
\hline \multicolumn{2}{|c|}{ Principais características } \\
\hline \hline Número de eixos & 6 \\
\hline Potência para tração & $3930 \mathrm{hp}$ \\
\hline Tara & $180 \mathrm{t}$ \\
\hline $\begin{array}{l}\text { Peso máximo do } \\
\text { combustível }\end{array}$ & $29 \mathrm{t}$ \\
\hline Comprimento & $21,5 \mathrm{~m}$ \\
\hline Área & $14 \mathrm{~m}^{2}$ \\
\hline $\begin{array}{l}\text { Máximo coeficiente de } \\
\text { aderência }\end{array}$ & 0,28 \\
\hline
\end{tabular}


Para a simulação, as características da locomotiva são divididas em três arquivos, um contendo o número de eixos, peso bruto, tara, comprimento e área frontal do veículo; e os outros dois contendo o esforço trator e a frenagem.

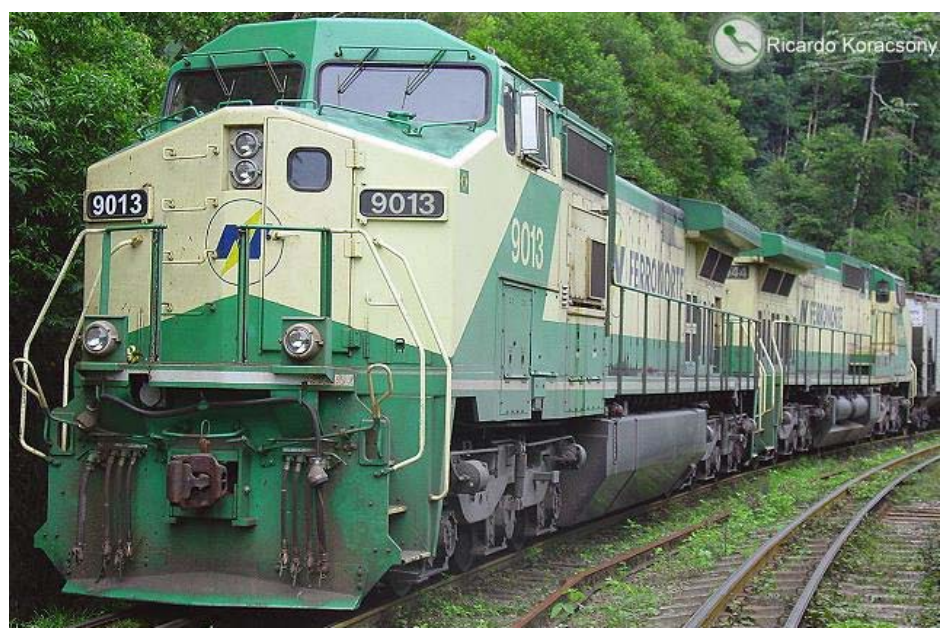

Figura 4.4: Locomotiva Dash 9

\subsubsection{Vagões}

A unidade rebocável selecionada foi o vagão Hopper. Esses vagões são projetados para um peso bruto máximo de 120t. Na tabela 4.4 são descritas as características relevantes do vagão Hopper utilizado pela Ferroban.

Tabela 4.4: Descrição do vagão Hopper

\begin{tabular}{|l|l|}
\hline \multicolumn{2}{|c|}{ Principais características } \\
\hline \hline Número de eixos & 4 \\
\hline Bitola & $1,60 \mathrm{~m}$ \\
\hline Altura & $3,90 \mathrm{~m}$ \\
\hline Comprimento & $16,2 \mathrm{~m}$ \\
\hline Tara & $32,5 \mathrm{t}$ \\
\hline Lotação & $106 \mathrm{t}$ \\
\hline
\end{tabular}

Na Figura 4.5 temos um exemplo de um vagão Hopper fechado, de classificação HFT, provido de paredes retas, com três compartimentos independentes de carga e três bocas de descarga do tipo gaveta deslizante. 




Figura 4.5: Vagão Hopper

\subsubsection{Composição}

O transporte por estrada de ferro incorpora um número relativamente amplo de variáveis que interferem em sua capacidade. Em primeira instância, para se aumentar a quantidade de carga processada em uma linha ferroviária, pode-se variar o número de vagões na composição e/ou aumentar a quantidade de carga em cada vagão. No primeiro caso, quanto maior o número de vagões maior o comprimento do trem, o qual por sua vez, está restrito ao comprimento disponível das estações. No segundo caso, a quantidade de carga transportada é restrita à lotação máxima de cada vagão, seja esta limitada pela capacidade volumétrica, pelo peso útil máximo estrutural do vagão ou pelo limite de suporte de carga/eixo da via.

O aumento de cargas na composição a serem rebocadas gera a redução da velocidade desenvolvida pelo trem no arco que pode ser solucionada pela adição de tração. A tração pode ser simples, dupla ou tripla, porém a velocidade do trem também é restrita às características geométricas e conservação da via permanente.

$\mathrm{Na}$ operação ferroviária em uma linha singela há dois aspectos conflitantes. Por um lado, ao se formar composições de baixa tonelagem, a velocidade média aumenta, o trem desocupa o arco em menor tempo, além de não haver grandes problemas com o comprimento das estações. Por outro lado, aumentando-se o peso rebocado da composição, transporta-se maior quantidade de carga, porém se faz necessário o uso de mais tração e estações de maior comprimento. A maximização da tração e a maximização da produção foram modeladas por Novaes [1978] e Novaes [1986] respectivamente. 
Com base na diversidade de composições que possam ser formadas, a aplicação do modelo de capacidade parte da premissa da utilização de uma unidade ou composição ferroviária que represente um trem típico a circular na linha férrea descrita. A partir deles são geradas alternativas operacionais, testadas em forma de cenários.

A unidade padrão empregada é formada de 2 locomotivas Dash 9 e 41 vagões Hopper, totalizando um trem de 5.000 toneladas. A Tabela 4.5 resume suas características.

Tabela 4.5: Descrição da unidade padrão

\begin{tabular}{|l|l|}
\hline \multicolumn{2}{|c|}{ Principais características } \\
\hline \hline Número de blocos de veículos & 3 \\
\hline Número de locomotivas & 2 \\
\hline Número de locomotivas líderes & 2 \\
\hline Número de vagões & 41 \\
\hline Comprimento total do trem & $707 \mathrm{~m}$ \\
\hline Potência total do trem & $7860 \mathrm{hp}$ \\
\hline Peso total do trem & $5000 \mathrm{t}$ \\
\hline Peso da carga & $3300 \mathrm{t}$ \\
\hline Peso do trem vazio & $1700 \mathrm{t}$ \\
\hline Relação Potência/Peso & $1.56 \mathrm{hp} / \mathrm{t}$ \\
\hline
\end{tabular}

\subsection{Geração de resultados}

O procedimento empregado para a aplicação do modelo mostrado no Capítulo 3 seguiu as seguintes etapas:

- Definição dos cenários;

- Preparação do arquivo contendo as características da composição (unidade) utilizada para o simulador (TEM 2.5);

- Preparação dos arquivos contendo as características de cada subtrecho para o simulador (TEM 2.5);

- Preparação dos arquivos de via a serem utilizados pelo simulador (TEM 2.5);

- Execução da simulação nos dois sentidos, exportação e importação, utilizando os arquivos elaborados; 
- Cálculo da velocidade média no espaço em cada arco, a partir dos valores das velocidades instantâneas.

- Introdução no algoritmo elaborado para resolução de conflitos e construção do diagrama espaço-tempo;

- Estimativa da capacidade do trecho para cada cenário.

\subsubsection{Cenários propostos}

O objetivo da divisão em cenários visa verificar a influência dos fatores de produção no trecho em análise, comparando-se a capacidade de processamento de trens por dia. Entre esses fatores, investigar-se-á a influência da velocidade dos trens, o tempo de parada dos trens nos desvios, o número de estações utilizadas, a existência de passagens de nível na via e a combinação destes fatores de forma otimizada.

$\mathrm{Na}$ escolha desses fatores levou-se em consideração suposições de modelos já existentes e resultados preliminares das simulações. Parte-se do conceito de trens unidade de comprimento fixo. Os cenários escolhidos para a aplicação do modelo são descritos a seguir:

\section{Cenário 1: Influência dos limites de velocidade operacionais}

Pretende-se com esse cenário verificar a influência na capacidade dos limites de velocidade impostos ao longo da via. A Tabela 4.6 resume o cenário.

- Cenário 1.1: A partir da unidade padrão verifica-se o desempenho do trem utilizando-se todas as estações, tendo inicio em Santa Fé do Sul (ZFS) e chegada em Araraquara (ZAR). Todos os subtrechos serão simulados, consecutivamente, e com tempo de parada mínimo de 15 minutos. O trecho possui limites operacionais de velocidade ao longo da via variando de $14.5 \mathrm{~km} / \mathrm{h}$ a $70 \mathrm{~km} / \mathrm{h}$, essa configuração é chamada de real devido os limites serem atualmente utilizados na Ferroban. São consideradas todas as passagens de nível que, consequentemente, impõem reduções adicionais na velocidade. Devido a esse cenário ser o mais próximo da realidade, será usado como padrão para a comparação entre os resultados dos outros cenários.

- Cenário 1.2: Esse é similar ao Cenário 1.1, exceto que os limites operacionais de velocidade são uniformes para todo o trecho, com o valor de $70 \mathrm{~km} / \mathrm{h}$. 
Tabela 4.6: Resumo do Cenário 1

\begin{tabular}{|l|l|l|}
\hline \multicolumn{1}{|c|}{ Variáveis } & \multicolumn{1}{|c|}{ Cenário 1.1 } & \multicolumn{1}{c|}{ Cenário 1.2 } \\
\hline Estações utilizadas & todas & todas \\
\hline Tempo de parada & 15 minutos & 15 minutos \\
\hline Limites de velocidade & real & $70 \mathrm{~km} / \mathrm{h}$ \\
\hline $\begin{array}{l}\text { Passagem de nível } \\
\text { existente }\end{array}$ & todas & todas \\
\hline
\end{tabular}

\section{Cenário 2: Influência dos tempos mínimos de parada}

O objetivo desse cenário é verificar a influência do tempo mínimo de parada nas estações. Estes tempos de espera foram estipulados a partir do conhecimento do tempo médio real que ocorre nos cruzamentos na linha férrea. A Tabela 4.7 resume-o.

- Cenário 2.1: Esse cenário é similar ao Cenário 1.1, exceto que o tempo de parada mínimo nos desvios são de 10 minutos.

- Cenário 2.2: Esse também é similar ao Cenário 1.1, exceto que o tempo de parada mínimo nos desvios são de 20 minutos.

- Cenário 2.3: Esse de igual maneira é similar ao Cenário 1.1, exceto que o tempo de parada mínimo nos desvios são de 30 minutos.

Tabela 4.7: Resumo do Cenário 2

\begin{tabular}{|l|l|l|l|}
\hline \multicolumn{1}{|c|}{ Variáveis } & \multicolumn{1}{|c|}{ Cenário 2.1 } & \multicolumn{1}{|c|}{ Cenário 2.2 } & \multicolumn{1}{|c|}{ Cenário 2.3 } \\
\hline \hline Estações utilizadas & todas & todas & todas \\
\hline Tempo de parada & 10 minutos & 20 minutos & 30 minutos \\
\hline Limites de velocidade & real & real & real \\
\hline $\begin{array}{l}\text { Passagem de nível } \\
\text { existente }\end{array}$ & todas & todas & todas \\
\hline
\end{tabular}




\section{Cenário 3: Influência das estações utilizadas}

Pretende-se com esse cenário verificar a influência da utilização das estações de cruzamento dos trens em função de seu limite de comprimento, das velocidades entre os arcos e de sua localização ao longo do trecho. A localização de cada estação ao longo da via pode ser observada no Anexo 1 e o resumo do cenário é exposto na Tabela 4.8.

- Cenário 3.1: Esse cenário é similar ao Cenário 1.1, exceto pelo número de estações utilizadas. Nesse cenário o critério usado é o comprimento das estações. São eliminadas as estações com comprimento inferior a $0,70 \mathrm{~km}$. O critério foi adotado com o objetivo de excluir as estações que não possuam comprimento do desvio suficiente para alocar a composição.

- Cenário 3.2: Esse é similar ao Cenário 1.1, exceto pelo número de estações utilizadas. Nesse cenário, o critério usado é a velocidade entre os arcos. São eliminadas as estações existentes entre um arco cuja velocidade desenvolvida seja baixa e outro em que a velocidade seja alta. Esse critério foi adotado com o objetivo de equilibrar as velocidades nos arcos.

- Cenário 3.3: Esse também é similar ao Cenário 1.1, exceto o número de estações utilizadas. Neste cenário o critério usado é a distância entre as estações. São eliminadas as estações existentes entre arcos adjacentes com comprimento inferior a $25 \mathrm{~km}$. Esse critério foi adotado com o objetivo de equilibrar os tamanhos dos arcos.

- Cenário 3.4: Esse de igual maneira é similar ao Cenário 3.3, exceto que os limites operacionais de velocidade são uniformes para todo o trecho, com o valor de $70 \mathrm{~km} / \mathrm{h}$, e as passagens de nível foram eliminadas. 
Tabela 4.8: Resumo do Cenário 3

\begin{tabular}{|c|c|c|c|c|}
\hline Variáveis & Cenário 3.1 & Cenário 3.2 & Cenário 3.3 & Cenário 3.4 \\
\hline $\begin{array}{l}\text { Estações } \\
\text { utilizadas }\end{array}$ & $\begin{array}{l}\text { ZFS, ZJA, ZED, } \\
\text { ZFN, ZMR, ZVG, } \\
\text { ZVP, ZRU, ZCV, } \\
\text { ZPN, ZSD, ZCZ, } \\
\text { ZMA, ZZL, ZDZ, } \\
\text { ZTO. }\end{array}$ & $\begin{array}{lll}\text { ZFS, } & \text { ZUR, } & \text { ZJA, } \\
\text { ZED, } & \text { ZFN, } & \text { ZMR, } \\
\text { ZVP, } & \text { ZEC, } & \text { ZMO, } \\
\text { ZSP, } & \text { ZUC, } & \text { ZCV, } \\
\text { ZSD, } & \text { ZSH, } & \text { ZZL, } \\
\text { ZDZ, } & \text { ZTO. }\end{array}$ & $\begin{array}{l}\text { ZFS, ZUR, ZED, } \\
\text { ZMR, ZVP, ZKY, } \\
\text { ZEB, ZMO, ZEH, } \\
\text { ZCT, ZPN, ZCZ, } \\
\text { ZSH, ZZL, ZTO. }\end{array}$ & $\begin{array}{l}\text { ZFS, ZUR, ZED, } \\
\text { ZMR, ZVP, ZKY, } \\
\text { ZEB, ZMO, ZEH, } \\
\text { ZCT, ZPN, ZCZ, } \\
\text { ZSH, ZZL, ZTO. }\end{array}$ \\
\hline $\begin{array}{l}\text { Tempo de } \\
\text { parada }\end{array}$ & 15 minutos & 15 minutos & 15 minutos & 15 minutos \\
\hline $\begin{array}{l}\text { Limites de } \\
\text { velocidade }\end{array}$ & real & real & real & $70 \mathrm{~km} / \mathrm{h}$ \\
\hline $\begin{array}{l}\text { Passagem } \\
\text { de nível } \\
\text { existente }\end{array}$ & todas & todas & todas & nenhuma \\
\hline
\end{tabular}

\section{Cenário 4: Influência da existência de passagem em nível}

As passagens em nível impõem uma redução na velocidade dos trens. O objetivo deste cenário é verificar o impacto da retirada desse dispositivo. A Tabela 4.9 resume o cenário.

- Cenário 4.1: Esse cenário é similar ao Cenário 1.1, exceto pela ausência de passagens de nível.

- Cenário 4.2: Esse é similar ao Cenário 1.2, exceto pelas passagens de nível que são eliminadas nas proximidades das cidades com população de até cerca de 11.000 habitantes.

- Cenário 4.3: Esse é também é similar ao Cenário 1.2, exceto pelas passagens de nível que foram todas eliminadas. 
Tabela 4.9: Resumo do Cenário 4

\begin{tabular}{|l|l|l|l|}
\hline \multicolumn{1}{|c|}{ Variáveis } & \multicolumn{1}{|c|}{ Cenário 4.1 } & \multicolumn{1}{|c|}{ Cenário 4.2 } & Cenário 4.3 \\
\hline \hline Estações utilizadas & todas & todas & todas \\
\hline Tempo de parada & 15 minutos & 15 minutos & 15 minutos \\
\hline Limites de velocidade & real & $70 \mathrm{~km} / \mathrm{h}$ & $70 \mathrm{~km} / \mathrm{h}$ \\
\hline $\begin{array}{l}\text { Passagem de nível } \\
\text { existente }\end{array}$ & nenhuma & $\begin{array}{l}\text { Em cidades com } \\
\text { população superior } \\
\text { a } 11.000 \text { hab. }\end{array}$ & nenhuma \\
\hline
\end{tabular}

\section{Cenário 5: Influência da otimização dos fatores de produção analisados}

Esse cenário corresponde a uma condição máxima teórica dada geometria da via e localização das estações no trecho investigado e ausência de locomotiva de auxílio. Nesse caso são utilizados os fatores de produção investigados de forma otimizada empregando-se os melhores resultados obtidos nos cenários anteriores. A Tabela 4.10 resume o cenário.

- Cenário 5.1: Esse cenário utiliza todas as estações, com o tempo de parada mínimo igual a 10 minutos e nenhuma passagem de nível.

Tabela 4.10: Resumo do Cenário 5

\begin{tabular}{|l|l|}
\hline \multicolumn{1}{|c|}{ Variáveis } & \multicolumn{1}{c|}{ Cenário 5.1 } \\
\hline \hline Estações utilizadas & todas \\
\hline Tempo de parada & 10 minutos \\
\hline Limites de velocidade & $70 \mathrm{~km} / \mathrm{h}$ \\
\hline $\begin{array}{l}\text { Passagem de nível } \\
\text { existente }\end{array}$ & nenhuma \\
\hline
\end{tabular}




\section{Cenário 6: Influência do espaçamento entre as estações}

Esse cenário foi criado a posteriore a partir da análise do cenário 5.1. Seu objetivo é apresentar uma melhor solução para o gargalo existente. Nesse caso não houve eliminação de estações, mas, sim, uma recolocação à distâncias que implique igual tempo de percurso entre as estações. A Tabela 4.11 resume o cenário.

- Cenário 6.1: Esse cenário utiliza todas as estações, sendo 7 das 29 estações reposicionadas, o tempo de parada mínimo igual a 10 minutos e não há nenhuma passagem de nível.

- Cenário 6.2: Esse é similar ao Cenário 6.1, exceto pelo número de estações reposicionadas, sendo 9 das 29 estações.

Tabela 4.11: Resumo do Cenário 6

\begin{tabular}{|l|l|l|}
\hline \multicolumn{1}{|c|}{ Variáveis } & \multicolumn{1}{|c|}{ Cenário 6.1 } & \multicolumn{1}{c|}{ Cenário 6.2 } \\
\hline Estações utilizadas & Todas (7 reposicionadas) & Todas (9 reposicionadas) \\
\hline Tempo de parada & 10 minutos & 10 minutos \\
\hline Limites de velocidade & $70 \mathrm{~km} / \mathrm{h}$ & $70 \mathrm{~km} / \mathrm{h}$ \\
\hline $\begin{array}{l}\text { Passagem de nível } \\
\text { existente }\end{array}$ & nenhuma & nenhuma \\
\hline
\end{tabular}

\subsubsection{Preparação do arquivo da composição}

Para que o software Train Energy Model, o TEM 2.5, realize corretamente as simulações é necessário que os dados sejam formatados num padrão reconhecido por ele. Para isso o simulador possui uma interface de entrada de dados, que é descrita no Apêndice A.

O arquivo da composição utilizado pelo simulador de desempenho do trem encontra-se detalhado no Apêndice D.

\subsubsection{Preparação dos arquivos da via}


O SDT verifica o desempenho da composição em uma determinada linha férrea. As características da linha estão contidas no arquivo de via (Anexo A) estruturado em colunas, com cada ponto da linha possuindo uma posição, elevação, rampa, curva e limite de velocidade correspondente.

Esse arquivo permite obter a localização das estações, que é necessária para a formação dos arquivos do subtrecho (item 4.3.4).

Como observado, o limite operacional da velocidade é imposto através deste arquivo (arquivo da via). Para adequar a velocidade às condições de alguns cenários esses valores foram modificados através de planilha eletrônica.

\subsubsection{Preparação dos arquivos dos subtrechos}

No modelo foram construídos os arquivos que delimitam cada subtrecho para cada cenário formulado. Esses subtrechos são nomeados por suas estações, assim, o subtrecho que vai de Santa Fé do Sul até Jales (Tabela 4.2), contendo os arcos 1, 2 e 3 (Tabela 4.1) é denominado ZFS-ZJA.

Para rodar o simulador de marcha (TEM 2.5) corretamente, os arquivos com a posição inicial de partida (Apêndice E) e os arquivos de parada com a posição e tempo que os trens devem permanecer nas estações (Apêndice F) são construídos separadamente.

A Tabela 4.12 mostra a posição das estações baseada no arquivo de via, através dela são localizados os pontos de partida e de parada de cada subtrecho. Devido ao sistema inglês de unidades, adotado no SDT utilizado, essas posições são dadas em milhas (mi) e pés (ft), as quais foram convertidos para $\mathrm{km}$ via planilha.

Tabela 4.12: Posição das estações no arquivo de via

\begin{tabular}{|c|c|ccc|ccc|}
\hline \multirow{2}{*}{ Nó } & \multirow{2}{*}{ Sigla } & \multicolumn{3}{|c|}{ Sentido Exportação } & \multicolumn{3}{c|}{ Sentido Importação } \\
& & $\mathbf{( m i )}$ & $\mathbf{( f t )}$ & $\mathbf{( K m})$ & $\mathbf{( m i )}$ & $\mathbf{( f t )}$ & $\mathbf{( K m )}$ \\
\hline \hline 1 & ZFS & 204 & 2059.2 & 328.93 & 536 & 1372.80 & 863.03 \\
\hline 2 & ZTF & 208 & 4540.8 & 336.13 & 531 & 4118.40 & 855.82 \\
\hline 3 & ZUR & 226 & 897.6 & 363.99 & 514 & 2481.60 & 827.96 \\
\hline 4 & ZJA & 233 & 4963.2 & 376.49 & 506 & 3748.80 & 815.47 \\
\hline 5 & ZED & 243 & 4963.2 & 392.59 & 496 & 3696.00 & 799.37 \\
\hline
\end{tabular}




\begin{tabular}{|c|c|ccc|ccc|}
6 & ZFN & 255 & 739.2 & 410.61 & 485 & 2692.80 & 781.35 \\
\hline 7 & ZMR & 261 & 3432.0 & 421.08 & 478 & 5260.99 & 770.87 \\
\hline 8 & ZVG & 270 & 1320.0 & 434.93 & 470 & 2059.20 & 757.03 \\
\hline 9 & ZVP & 277 & 5121.6 & 447.35 & 462 & 3537.60 & 744.61 \\
\hline 10 & ZKY & 293 & 950.4 & 471.83 & 447 & 2428.80 & 720.13 \\
\hline 11 & ZEC & 302 & 1108.8 & 486.35 & 438 & 2323.20 & 705.60 \\
\hline 12 & ZEB & 313 & 1214.4 & 504.09 & 427 & 2217.60 & 687.87 \\
\hline 13 & ZMO & 330 & 1056.0 & 531.41 & 410 & 2323.20 & 660.54 \\
\hline 14 & ZRU & 339 & 2006.4 & 546.18 & 401 & 1372.80 & 645.77 \\
\hline 15 & ZSP & 342 & 792.0 & 550.64 & 398 & 2640.00 & 641.32 \\
\hline 16 & ZEH & 348 & 3643.2 & 561.17 & 391 & 5016.00 & 630.78 \\
\hline 17 & ZUC & 360 & 3748.8 & 580.50 & 379 & 4963.20 & 611.45 \\
\hline 18 & ZCT & 371 & 2323.2 & 597.77 & 369 & 1108.80 & 594.19 \\
\hline 19 & ZCV & 379 & 4276.8 & 611.25 & 360 & 4382.40 & 580.70 \\
\hline 20 & ZPN & 386 & 1900.8 & 621.78 & 354 & 1531.20 & 570.17 \\
\hline 21 & ZSD & 394 & 2059.2 & 634.71 & 346 & 1372.80 & 557.25 \\
\hline 22 & ZCZ & 409 & 2217.6 & 658.90 & 331 & 1214.40 & 533.06 \\
\hline 23 & ZTQ & 419 & 1478.4 & 674.76 & 321 & 1953.60 & 517.19 \\
\hline 24 & ZSH & 429 & 528.0 & 690.58 & 311 & 2851.20 & 501.38 \\
\hline 25 & ZMA & 439 & 1108.8 & 706.84 & 301 & 2270.40 & 485.11 \\
\hline 26 & ZZL & 446 & 2640.0 & 718.57 & 294 & 792.00 & 473.39 \\
\hline 27 & ZDZ & 450 & 2376.0 & 724.94 & 290 & 1003.20 & 467.02 \\
\hline 28 & ZTO & 461 & 2428.8 & 742.65 & 279 & 1003.20 & 449.31 \\
\hline 29 & ZAR & 465 & 5121.6 & 749.91 & 274 & 3590.40 & 442.05 \\
\hline
\end{tabular}

A diferença dos valores nos sentidos ocorre devido à necessidade de inversão da via, o que provoca modificações na localização das estações.

\subsubsection{Geração de velocidades no simulador de desempenho do trem}

As simulações executadas obedeceram à estrutura descrita no item 4.3. Sendo assim, para cada simulação são necessários o arquivo da via, o arquivo com o ponto de início da simulação e o arquivo com as três paradas (posição e tempo mínimo). Foi construído apenas um arquivo da composição devido à determinação de um trem padrão para a aplicação do modelo.

Com o uso do TEM 2.5, todos os subtrechos foram simulados para cada cenário. Assim, para o Cenário 1.1, em que se utilizaram todas as estações, foram realizadas 26 simulações para o sentido exportação, a primeira de ZFS a ZJA, a segunda de ZTF a ZED, a terceira de ZUR a ZFN e, assim, sucessivamente. 
Para a construção do diagrama espaço-tempo é preciso obter-se o desempenho do trem nos dois sentidos da linha férrea. Assim, utilizou-se uma ferramenta do simulador de desempenho do trem a qual permite reverter a via. Dessa forma, simulou-se novamente os 26 subtrechos, porém em sentido contrário, de ZJA a ZFS, de ZED a ZTF, de ZFN a ZUR e assim por diante.

Como o simulador TEM 2.5 segue o sistema de unidade inglês, os valores inseridos nos arquivos foram adequados a tal padrão, bem como nas análises efetuadas os dados dos arquivos de saída foram convertidos para o sistema internacional de medidas.

\subsubsection{Geração do diagrama espaço-tempo}

Após cada simulação no TEM 2.5, os dados gerados são fornecidos em dois arquivos. Um, apresenta de forma resumida os resultados da simulação e, o outro, contém os resultados detalhados para um determinado intervalo de tempo.

O primeiro arquivo (.RPT) é um relatório compactado da simulação. O arquivo contém dados da composição, tempo e distância total, número de paradas, velocidade média, consumo de combustível e o trabalho resultante das forças que atuam na composição, como pode ser observado no Apêndice G. O segundo arquivo (. OUT) contém informações como tempo, posição, velocidade, aceleração e força de tração corrente para 30 segundos (intervalo de tempo determinado), sua descrição em detalhes pode ser observada no Apêndice H. Os dados de saída contêm informações que podem ser usadas para avaliar vários fatores de desempenho do trem: tempo, velocidade, consumo de combustível, entre outros.

Os resultados do TEM 2.5 de interesse são tempos, posição e velocidade a partir dos quais se calcula a velocidade média no espaço de cada arco; . A guia de ilustração, na Tabela 4.13 são apresentados uma parte dos dados gerados com a simulação. Os resultados são referentes ao arco de ZRU a ZSP, localizados entre os quilômetros 546 a 550. Esse arco foi selecionado por ser o menor arco do trecho, consequentemente, com a menor quantidade de dados a serem expostos.

É válido ressaltar que os valores da Tabela 4.13 são referentes a um arco do subtrecho ZRU a ZUC, portanto, apenas a parte de interesse para o sentido exportação e importação é exposta. A posição de início e parada é relativa à Tabela 4.12, diferenças nos 
valores ocorrem devido ao modelo de locomoção da composição, detalhado no Apêndice B.

Tabela 4.13: Resultados da simulação do arco ZRU-ZSP

\begin{tabular}{|c|c|c|c|c|c|c|c|c|c|c|c|c|c|}
\hline \multicolumn{7}{|c|}{ Sentido Exportação } & \multicolumn{7}{|c|}{ Sentido Importação } \\
\hline \multicolumn{2}{|c|}{$\begin{array}{l}\text { Tempo } \\
\text { (h) (min) }\end{array}$} & (s) & \multicolumn{3}{|c|}{ Posição } & $\begin{array}{c}\text { Velocidade } \\
(\mathrm{mph})\end{array}$ & \multicolumn{2}{|c|}{ Tempo } & (s) & (mi) & \multicolumn{2}{|c|}{ Posição } & $\begin{array}{c}\text { Velocidad } \\
(\mathrm{mph})\end{array}$ \\
\hline$\overline{0}$ & $\overline{0}$ & $\overline{0}$ & 339 & 2006 & 2546,18 & 0,00 & $\overline{11}$ & 32 & 33 & 398 & 2977 & 641,43 & 0,00 \\
\hline 0 & 0 & 30 & 339 & 2031 & 546,19 & 1,13 & 1 & 47 & 36 & 398 & 2977 & 641,43 & 0,00 \\
\hline 0 & 1 & 0 & 339 & 2106 & 546,21 & 2,25 & 1 & 48 & 0 & 398 & 3035 & 641,44 & 4,09 \\
\hline 0 & 1 & 30 & 339 & 2229 & 546,25 & 3,34 & 1 & 48 & 30 & 398 & 3308 & 641,53 & 8,11 \\
\hline 0 & 2 & 0 & 339 & 2395 & 546,30 & 4,13 & 1 & 49 & 0 & 398 & 3735 & 641,66 & 9,93 \\
\hline 0 & 2 & 30 & 339 & 2589 & 546,36 & 4,68 & 1 & 49 & 30 & 398 & 4183 & 641,79 & 10,73 \\
\hline 0 & 3 & 0 & 339 & 2824 & 546,43 & 6,29 & 1 & 50 & 0 & 398 & 4628 & 641,93 & 9,12 \\
\hline 0 & 3 & 30 & 339 & 3135 & 546,52 & 7,78 & 1 & 50 & 30 & 398 & 5049 & 642,06 & 10,00 \\
\hline 0 & 4 & 0 & 339 & 3504 & 546,64 & 8,92 & 1 & 51 & 0 & 399 & 225 & 642,20 & 10,67 \\
\hline 0 & 4 & 30 & 339 & 3918 & 546,76 & 9,72 & 1 & 51 & 30 & 399 & 710 & 642,34 & 11,73 \\
\hline 0 & 5 & 0 & 339 & 4336 & 546,89 & 9,50 & 1 & 52 & 0 & 399 & 1270 & 642,52 & 13,43 \\
\hline 0 & 5 & 30 & 339 & 4775 & 547,02 & 10,36 & 1 & 52 & 30 & 399 & 1873 & 642,70 & 13,75 \\
\hline 0 & 6 & 0 & 340 & 20 & 547,18 & 12,88 & 1 & 53 & 0 & 399 & 2541 & 642,90 & 15,87 \\
\hline 0 & 6 & 30 & 340 & 491 & 547,33 & 8,82 & 1 & 53 & 30 & 399 & 3164 & 643,09 & 12,49 \\
\hline 0 & 7 & 0 & 340 & 867 & 547,44 & 8,71 & 1 & 54 & 0 & 399 & 3619 & 643,23 & 9,04 \\
\hline 0 & 7 & 30 & 340 & 1269 & 547,56 & 9,57 & 1 & 54 & 30 & 399 & 4046 & 643,36 & 10,35 \\
\hline 0 & 8 & 0 & 340 & 1707 & 547,70 & 10,28 & 1 & 55 & 0 & 399 & 4518 & 643,51 & 11,01 \\
\hline 0 & 8 & 30 & 340 & 2178 & 547,84 & 11,45 & 1 & 55 & 30 & 399 & 5000 & 643,65 & 11,00 \\
\hline 0 & 9 & 0 & 340 & 2715 & 548,00 & 12,91 & 1 & 56 & 0 & 400 & 204 & 643,80 & 11,19 \\
\hline 0 & 9 & 30 & 340 & 3314 & 548,19 & 14,94 & 1 & 56 & 30 & 400 & 692 & 643,95 & 11,02 \\
\hline 0 & 10 & 0 & 340 & 3981 & 548,39 & 16,00 & 1 & 57 & 0 & 400 & 1179 & 644,10 & 11,01 \\
\hline 0 & 10 & 30 & 340 & 4687 & 548,61 & 13,25 & 1 & 57 & 30 & 400 & 1665 & 644,25 & 11,08 \\
\hline 0 & 11 & 0 & 340 & 5175 & 548,75 & 11,73 & 1 & 58 & 0 & 400 & 2149 & 644,39 & 10,98 \\
\hline 0 & 11 & 30 & 341 & 422 & 548,91 & 10,68 & 1 & 58 & 30 & 400 & 2632 & 644,54 & 11,04 \\
\hline 0 & 12 & 0 & 341 & 945 & 549,07 & 14,49 & 1 & 59 & 0 & 400 & 3119 & 644,69 & 11,08 \\
\hline 0 & 12 & 30 & 341 & 1640 & 549,29 & 14,78 & 1 & 59 & 30 & 400 & 3602 & 644,84 & 10,97 \\
\hline 0 & 13 & 0 & 341 & 2198 & 549,46 & 10,51 & 2 & 0 & 0 & 400 & 4087 & 644,98 & 11,03 \\
\hline 0 & 13 & 30 & 341 & 2640 & 549,59 & 10,13 & 2 & 0 & 30 & 400 & $\begin{array}{l}4559 \\
\end{array}$ & 645,13 & 10,16 \\
\hline 0 & 14 & 0 & 341 & 3081 & 549,73 & 10,39 & 2 & 1 & 0 & 400 & 5035 & 645,27 & 11,22 \\
\hline 0 & 14 & 30 & 341 & 3517 & 549,86 & 9,58 & 2 & 1 & 30 & 401 & 231 & 645,42 & 10,69 \\
\hline 0 & 15 & 0 & 341 & 3952 & 549,99 & 9,21 & 2 & 2 & 0 & 401 & 675 & 645,55 & 10,32 \\
\hline 0 & 15 & 30 & 341 & 4313 & 550,10 & 7,33 & 2 & 2 & 30 & 401 & 1127 & 645,69 & 10,85 \\
\hline 0 & 16 & 0 & 341 & 4685 & 550,21 & 9,64 & 2 & 2 & 54 & 401 & 1494 & 645,80 & 9,82 \\
\hline 0 & 16 & 30 & 341 & 5169 & 550,36 & 12,08 & 2 & 2 & 57 & 401 & 1536 & 645,82 & 9,59 \\
\hline 0 & 17 & 0 & 342 & 396 & 550,52 & 10,75 & 2 & 3 & 0 & 401 & 1577 & 645,83 & 8,84 \\
\hline 0 & 17 & 30 & 342 & 815 & 550,64 & 8,20 & 2 & 3 & 3 & 401 & 1614 & 645,84 & 8,13 \\
\hline 0 & 17 & 36 & 342 & 885 & 550,67 & 7,56 & 2 & 3 & 6 & 401 & 1649 & 645,85 & 7,42 \\
\hline 0 & 17 & 39 & 342 & 917 & 550,68 & 7,21 & 2 & 3 & 9 & 401 & 1680 & 645,86 & 6,71 \\
\hline 0 & 17 & 42 & 342 & 947 & 550,68 & 6,33 & 2 & 3 & 12 & 401 & 1708 & 645,87 & 6,00 \\
\hline 0 & 17 & 45 & 342 & 974 & 550,69 & 5,64 & 2 & 3 & 15 & 401 & 1733 & 645,88 & 4,25 \\
\hline 0 & 17 & 48 & 342 & 997 & 550,70 & 4,95 & 2 & 3 & 18 & 401 & 1745 & 645,88 & 1,46 \\
\hline 0 & 17 & 51 & 342 & 1017 & 550,71 & 4,26 & 2 & 3 & 21 & 401 & 1745 & 645,88 & 1,46 \\
\hline 0 & 17 & 54 & 342 & 1034 & 550,71 & 3,57 & 2 & 3 & 24 & 401 & 1745 & 645,88 & 0,00 \\
\hline 0 & 17 & 57 & 342 & 1049 & 550,72 & 1,81 & 2 & 3 & 24 & 401 & 1745 & 645,88 & 0,00 \\
\hline 0 & 18 & 0 & 342 & 1050 & 550,72 & 1,79 & & & & & & & \\
\hline 0 & 18 & 3 & 342 & 1050 & 550,72 & 0,00 & & & & & & & \\
\hline 0 & 18 & 6 & 342 & 1050 & 550,72 & 0,00 & & & & & & & \\
\hline 0 & 33 & 9 & 342 & 1050 & 550,72 & 0,00 & & & & & & & \\
\hline
\end{tabular}


Para a elaboração do diagrama espaço-tempo, os dados completos do arquivo .OUT são utilizados como dados de entrada para o algoritmo elaborado em MatLab. No algoritmo, há a conversão de unidades e são efetuadas as rotinas descritas no item 3.5.1.1 para a resolução dos conflitos.

Dessa forma, constroem-se matrizes de tempos (em minutos) e espaços (em quilômetros) para os três arcos. Para o subtrecho ZRU a ZUC, por exemplo, as seguintes matrizes, nos sentidos exportação e importação, são elaboradas:

Matriz Tempo:

\begin{tabular}{c|cc|cc|c} 
nó $_{\text {i-1 }}$ & \multicolumn{2}{|c|}{ nó $_{\mathrm{i}}$} & \multicolumn{2}{|c|}{ nó $_{\mathrm{i}+1}$} & nó $_{\mathrm{i}+2}$ \\
\hline (fim) & (ini) & (fim) & (ini) & (fim) & (ini)
\end{tabular}

unidade ${ }_{1}(\mathrm{E})\left[\begin{array}{llllll}0,0 & 18,1 & 33,2 & 55,1 & 70,1 & 125,8\end{array}\right]$

Matriz Espaço:

\begin{tabular}{l|ll|ll|l} 
nó $_{\text {o-1 }}$ & \multicolumn{2}{|c|}{ nó $_{i}$} & \multicolumn{2}{|c|}{ nó $_{i+1}$} & nó $_{i+2}$ \\
\hline (fim) & (ini) & (fim) & (ini) & (fim) & (ini)
\end{tabular}

unidade $_{1}(\mathrm{E})\left[\begin{array}{llllll}546,2 & 550,7 & 550,7 & 561,4 & 561,4 & 580,6\end{array}\right]$

Matriz Tempo:

\begin{tabular}{c|cc|cc|c} 
nó $_{i-1}$ & \multicolumn{2}{|c|}{ nó $_{\mathrm{i}}$} & \multicolumn{2}{|c|}{ nó $_{\mathrm{i}+1}$} & nó $_{\mathrm{i}+2}$ \\
\hline (fim) & (ini) & (fim) & (ini) & (fim) & (ini)
\end{tabular}

unidade $_{1}(\mathrm{I})\left[\begin{array}{llllll}9,1 & 55,1 & 94,3 & 125,8 & 164,9 & 180,7\end{array}\right]$

Matriz Espaço:

\begin{tabular}{c|cc|cc|c} 
nó $_{\text {i-1 }}$ & \multicolumn{2}{|c|}{ nó $_{i}$} & \multicolumn{2}{|c|}{ nó $_{i+1}$} & nó $_{i+2}$ \\
\hline (fim) & (ini) & (fim) & (ini) & (fim) & (ini)
\end{tabular}

unidade $_{1}(\mathrm{I})\left[\begin{array}{llllll}580,6 & 561,4 & 561,4 & 550,7 & 550,7 & 546,2\end{array}\right]$ 
Observa-se que a composição levou tempos diferentes para percorrer os $4,5 \mathrm{~km}$. No sentido exportação, a composição foram 18,1 minutos, já no sentido importação, 15,8 minutos. Estes pontos são marcados e ligados por segmentos de retas que representa a velocidade do trem.

Através da programação o valor do beadway é encontrado e, a partir dele, as matrizes são multiplicadas e plotadas. Para o exemplo, o valor do beadway é de 131,8 minutos e o diagrama espaço-tempo pode ser visualizado na Figura 4.6. Neste caso a capacidade do subtrecho é de 10 pares de trens por dia.

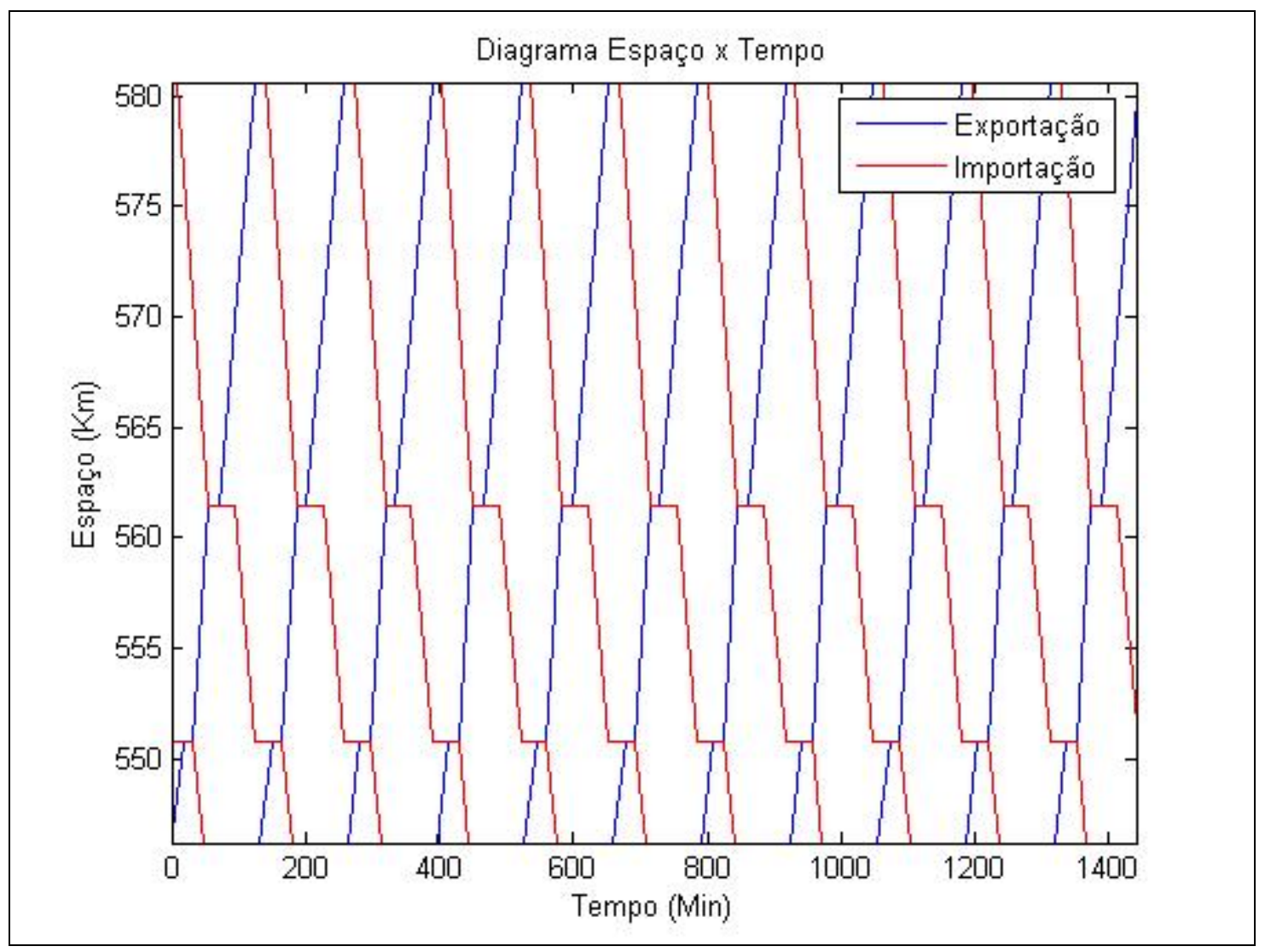

Figura 4.6: Diagrama espaço-tempo para o subtrecho ZRU-ZUC

\subsubsection{Estimativa da capacidade por subtrecho}

Após a execução das etapas para a elaboração dos diagramas espaço-tempo, como comentado até aqui, a capacidade de cada subtrecho é determinada a partir da contagem do 
número de pares que são processados completamente em 1.440 minutos, ou um dia. Esse número é fornecido automaticamente pela programação em MatLab e seus valores são armazenados em planilha eletrônica para cada cenário elaborado.

A partir desses dados, gráficos que permitam a visualização de todo o trecho são construídos. A representação apresentada na Figura 4.7 ilustra o resultado final do modelo para um cenário. Observa-se que o valor da capacidade do subtrecho ZRU a ZUC é indicado no gráfico da Figura 4.7 com o valor correspondente ao resultado do digrama exposto na Figura 4.6, ou seja, 10 pares.

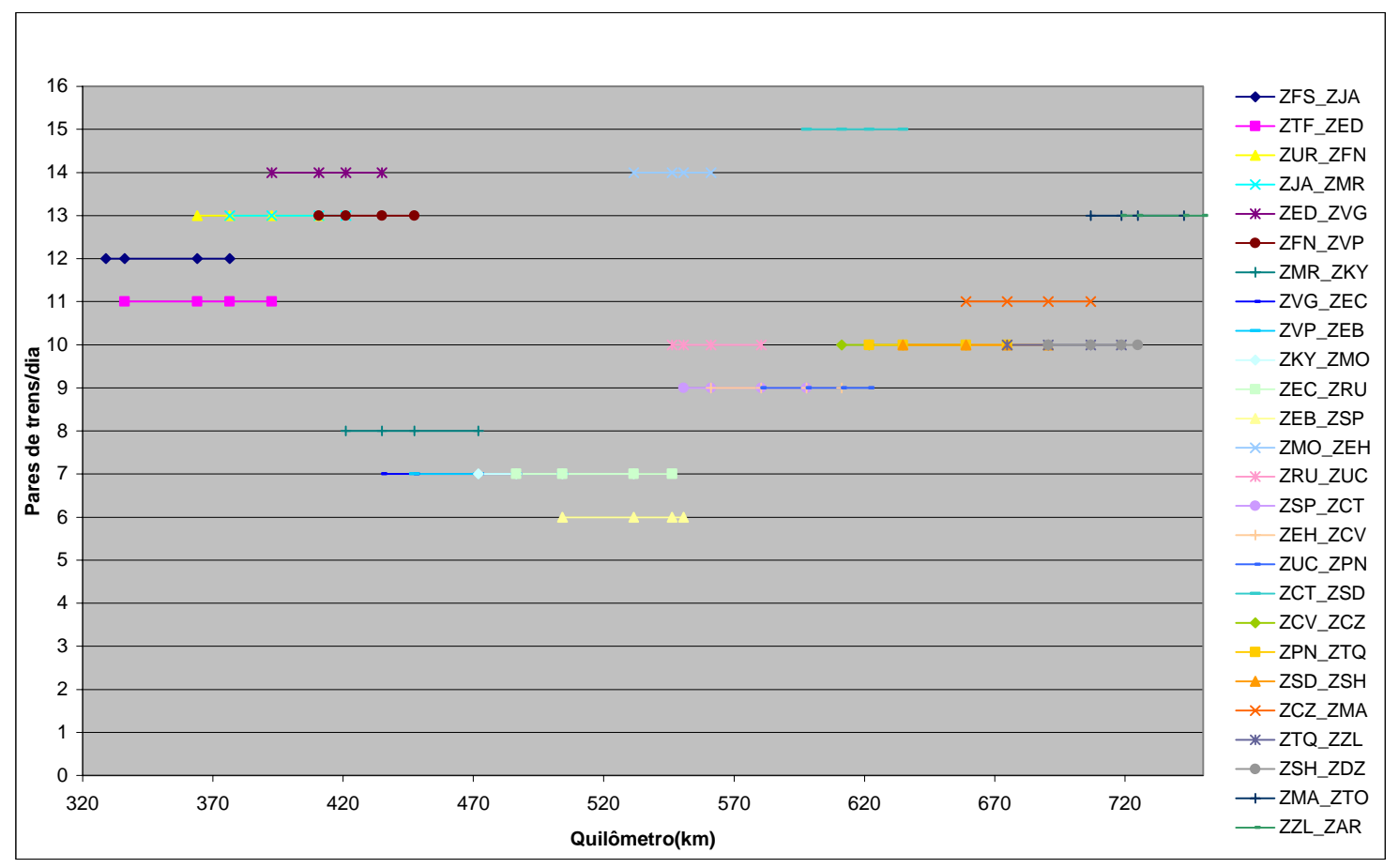

Figura 4.7: Gráfico da capacidade do trecho

O gráfico da Figura 4.7 representa o Cenário 1.1. Percebe-se que o subtrecho localizados entre os quilômetros 480 e 550 é o que restringe a capacidade do sistema. Desta forma, o gráfico elaborado permite a identificação dos gargalos e a comparação dos resultados entre os cenários.

Através da abordagem microscópica do modelo, com os resultados das simulações em vários subtrechos consecutivos da linha, é possível analisar macroscopicamente a linha férrea, indicando sua frequência máxima em pares de trens por dia. 


\section{ANÁLISE E DISCUSSÃO DOS RESULTADOS}

Nesse capítulo serão apresentados e discutidos os resultados gerados pela aplicação do modelo de capacidade para os diversos cenários enunciados no Capítulo 4. Estes cenários serão analisados a partir da definição de grupos de influência, de acordo com alguns fatores de produção como limites de velocidade operacional, tempos mínimos de parada, estações utilizadas, existência de passagem em nível e da otimização dos fatores de produção.

Através dos resultados dos cenários elaborados, investigou-se a influência desses fatores na capacidade do trecho. Assim, foi possível identificar qual fator é determinante na restrição da capacidade. É conveniente explicar que a capacidade será analisada pelo número máximo de pares de trens que possam ser processados por dia no subtrecho crítico que compõe a via férrea.

Por meio desta análise é possível verificar através dos cenários criados, quais fatores de produção maximizam a capacidade do sistema em termos de processamento de pares de trens por dia. Busca-se, então, apresentar a opção mais vantajosa, dentro de cada grupo de análise e no conjunto global dos cenários.

Os gráficos construídos para as análises a seguir são baseados nos resultados de cada cenário, que podem ser visualizados no Apêndice C.

\subsection{Análise da influência dos limites de velocidade operacionais}

Nesse cenário verificou-se como o limite operacional da velocidade interfere na quantidade de trens processados. 
Como observado no Anexo A (arquivo da via), na operação atual, os trens possuem velocidades limites de até $14,5 \mathrm{~km} / \mathrm{h}$, o que reduz bastante o número de trens processados.

A partir dos resultados da aplicação do modelo a Figura 5.1 foi construída, que permite comparar a capacidade resultante, utilizando-se os limites de velocidade reais (Cenário 1.1) e a velocidade limite de $70 \mathrm{~km} / \mathrm{h}$, mantendo-se todas as 23 passagens de nível existentes no trecho de $420 \mathrm{~km}$ e as demais características geométricas da via (Cenário 1.2).

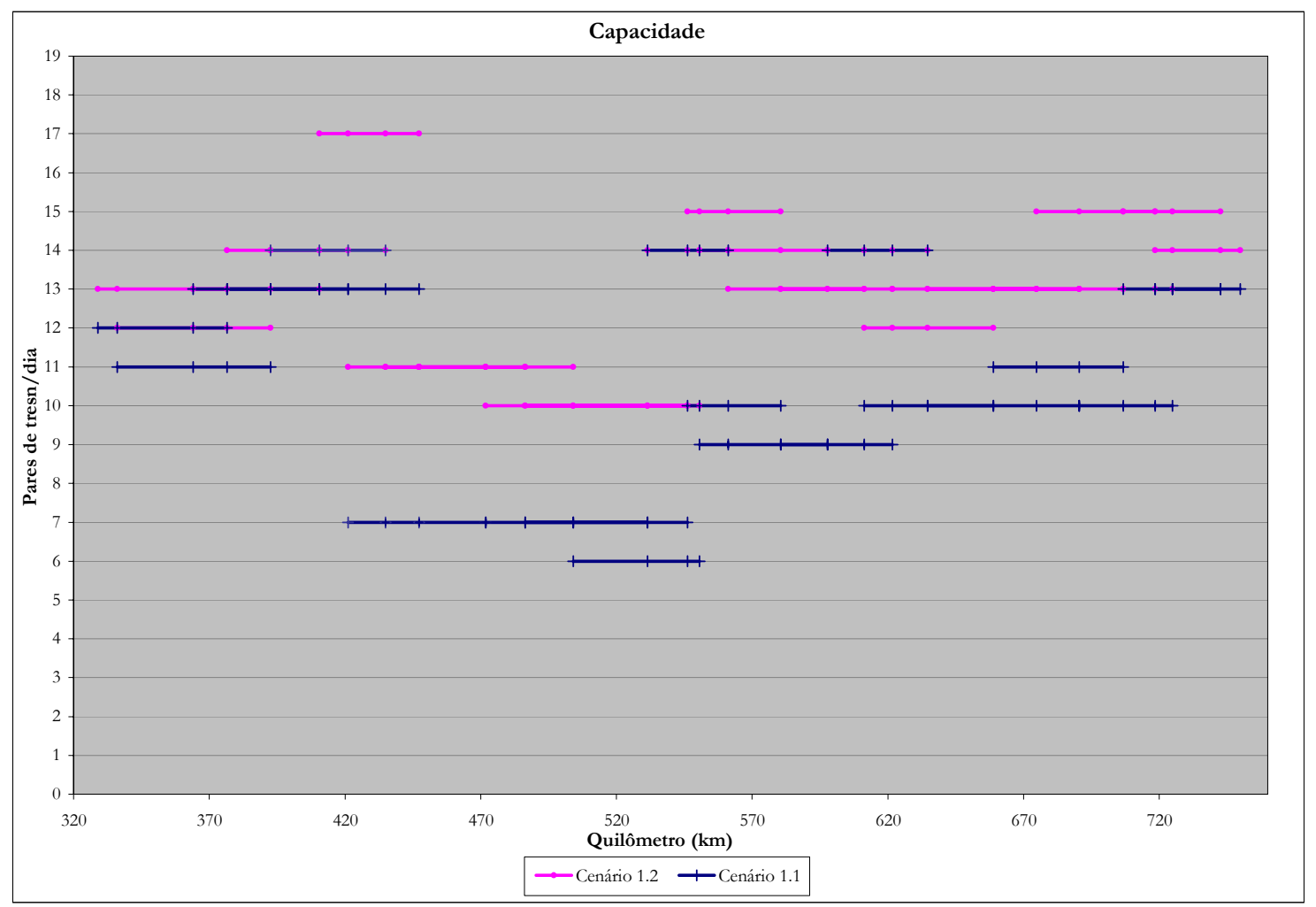

Figura 5.1 - Comparação entre os Cenários 1.1 e 1.2

A Figura 5.1 mostra que, no Cenário 1.1 existe um trecho da via, do quilômetro 500, até o quilômetro $550 \mathrm{com}$ um gargalo, permitindo apenas a passagem de 6 pares de trens por dia no subtrecho crítico. Eliminando-se a restrição da velocidade, verifica-se que a quantidade máxima de trens movimentados passará a ser de 10 pares. Nota-se, portanto, que há outros fatores além da geometria da via e das limitações de velocidade, impostas nos locais da passagem de nível que afetam a capacidade.

A Figura 5.2, representa de forma mais clara os limites de capacidade de cada subtrecho para cada um dos dois cenários para se avaliar esse impacto. Informações, colhidas junto às concessionárias, indicam que as restrições de velocidade máxima nos 
trechos são fortemente dependentes da condição da superestrutura ferroviária (lastro, dormente, trilho, AMV).

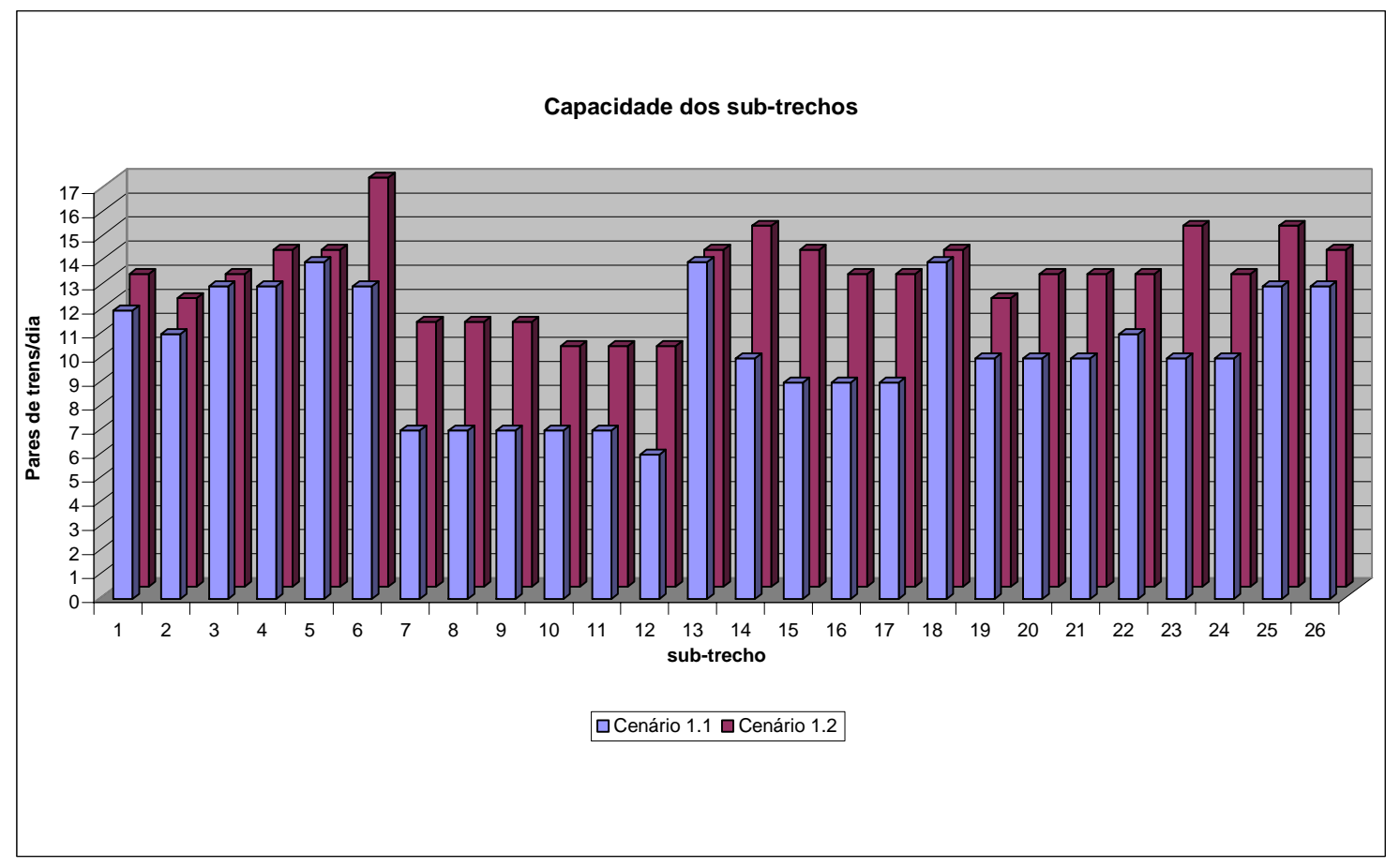

Figura 5.2 - Aumento da capacidade com a retirada dos limites de velocidade

Percebe-se pela Figura 5.2, que se confrontando as duas alternativas, o Cenário 1.2 representa um aumento de mais de $65 \%$ na capacidade, em relação ao Cenário 1.1. Em termos de carga, considerando-se que cada trem típico utilizado transporta, aproximadamente, 3.300t de carga, para os limites de velocidade impostos, seria possível processar apenas 39.600t por dia, enquanto que, com o limite de velocidade único de 70 $\mathrm{km} / \mathrm{h}$, seria possível transportar cerca de 66.000t diárias.

\subsection{Análise da influência dos tempos mínimos de parada}

Como relatado no Capítulo 3, foi considerado, neste modelo, que os trens circulando em direção ao porto (sentido exportação) têm prioridade em relação trens em sentido importação. Independente de tal prioridade, os trens nos dois sentidos, obrigatoriamente despenderão um tempo mínimo de espera nos desvios.

As alternativas consideradas no Cenário 2, têm como objetivo verificar se a variação desse fator é significativa para a capacidade do sistema. O Cenário 1.1 também está incluido nesta avaliação, como referência de tempo de parada mínimo de 15 minutos. 
Os cenários foram divididos em dois gráficos para uma melhor visualização. Os Cenários 2.1 e 2.2 são comparados na Figura 5.3 e os Cenários 1.1 e 2.3. têm seus resultados confrontados na Figura 7.4.

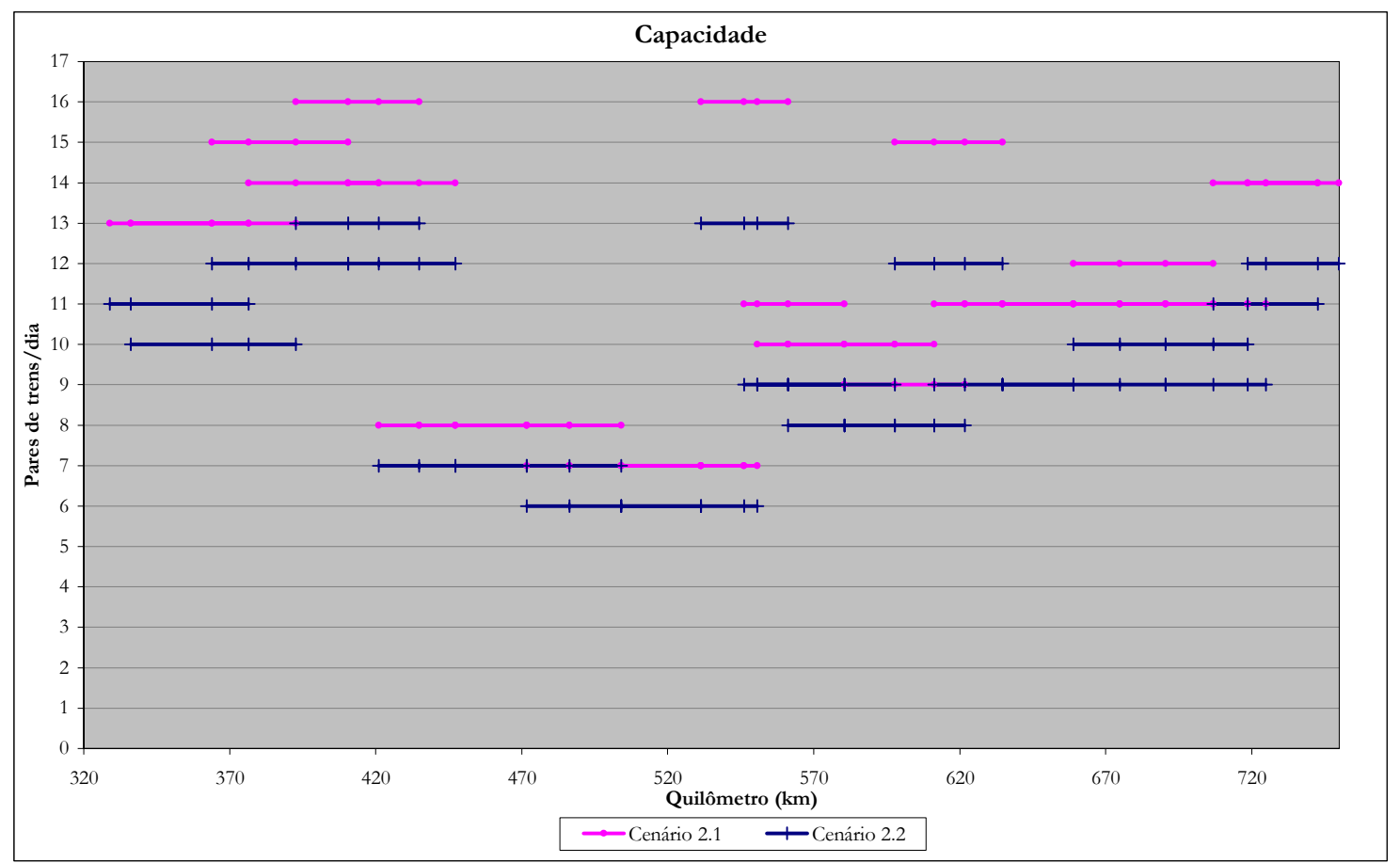

Figura 5.3 - Variação da capacidade em função dos tempos mínimos de parada (10 e 20 minutos)

Observando-se a Figura 5.3, percebe-se que, quando o tempo de permanência mínimo do trens no pátio for reduzido em $50 \%$, de 20 para 10 minutos, a capacidade do sistema no trecho crítico do quilômetro 500 a 550 aumenta de 6 para 7 pares de trens por dia, cerca de $17 \%$. Observando os outros subtrechos, percebe-se que o ganho mínimo com essa modificação nos tempos de parada é em sua maioria 1 par por dia.

Comparando-se os resultados apresentados na Figura $5.3 \mathrm{com}$ os resultados do Cenário 1.1 (Figura 5.1) nota-se que o valor mínimo de espera de 15 minutos leva a um resultado praticamente igual ao de 20 minutos.

$\mathrm{Na}$ Figura 5.4, são apresentados os resultados para o tempo mínimo de espera de 30 minutos (Cenário 2.3) e para 15 minutos (Cenário 1.1). Percebe-se que, nesse caso, a redução de $50 \%$ do tempo desencadeou um aumento na quantidade mínima de trens 
processados, de 5 para 6 pares de trens por dia. Nesse caso, 1 trem por dia por sentido representa um ganho de $20 \%$.

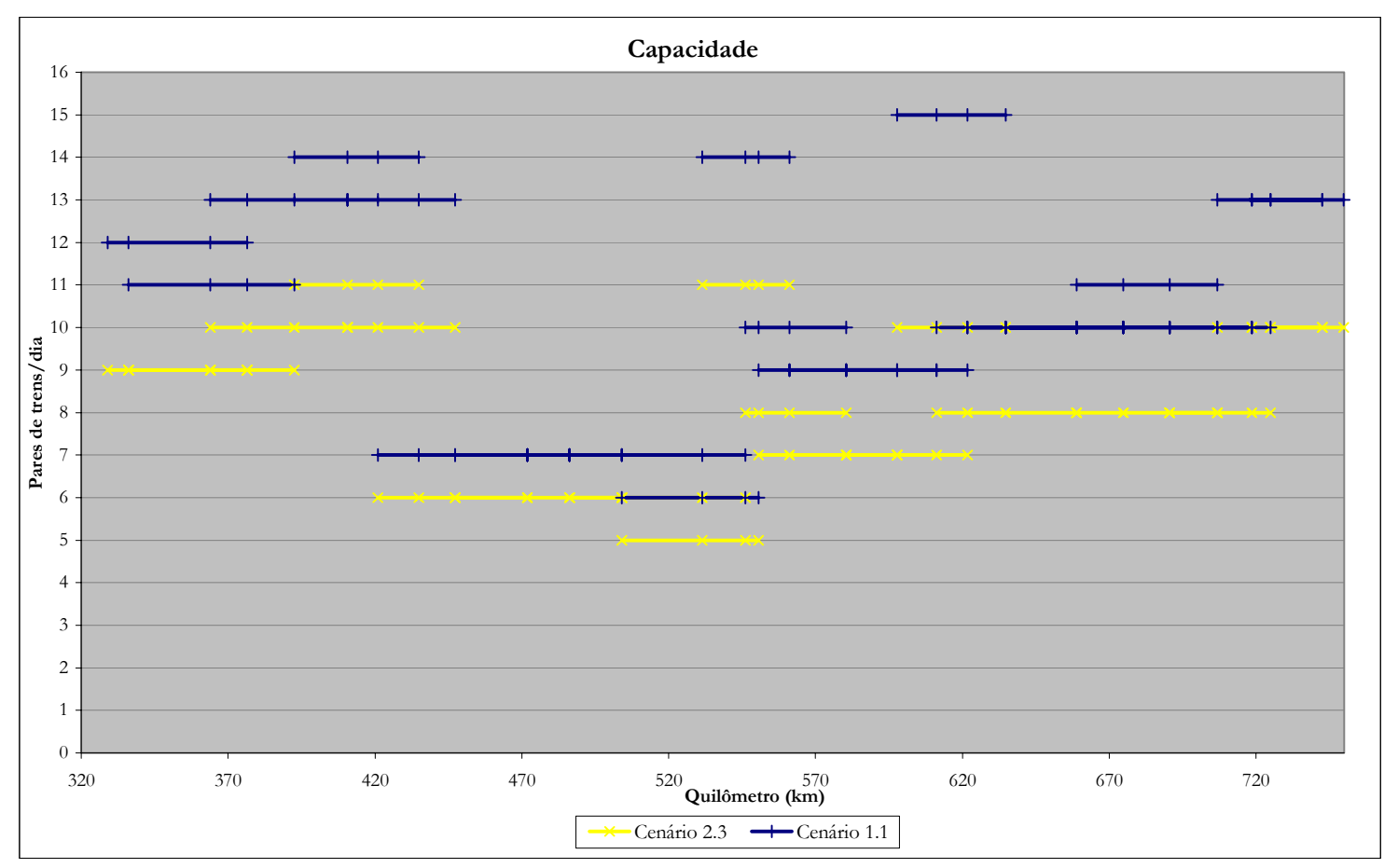

Figura 5.4 - Variação da capacidade em função dos tempos mínimos de parada (15 e 30 minutos)

Em relação à capacidade, a redução de 5 minutos (de 20 para 15) não representou aumento na quantidade de trens processados. Porém, a redução de 15 para 10 minutos aumentou a capacidade em 1 par por dia.

\subsection{Análise da influência das estações utilizadas}

O Cenário 3 foi construído com o propósito de investigar uma melhor forma de utilizar as 29 estações existentes no trecho. A escolha das estações na elaboração dos cenários obedeceram alguns critérios: no Cenário 3.1, foram eliminadas as estações com comprimentos inferiores a 0,70 quilômetros, uma vez que o trem padrão tem 707 metros de comprimento; no Cenário 3.2, a seleção foi baseada na velocidade dos trens nos arcos com o objetivo de equilibrá-la; no Cenário 3.3, utilizou-se como critério a manutenção de distâncias semelhantes entre as estações. 
Confrontando-se os Cenários 3.1, 3.2 e 3.3, descritos na Figura 5.5, percebe-se que o uso das estações do Cenário 3.1 é desvantajoso em termo de capacidade, com apenas 1 par de trens por dia. Como esta opção é desvantajosa, avaliou-se o ganho na capacidade com a redução do comprimento do arco através da inclusão de duas estações no trecho crítico, a estação ZEB e a ZUC. Apesar de dobrar a capacidade do sistema, passando para 2 pares por dia, tal configuração confirma ser desvantajosa e o Cenário 3.2 exprime uma melhora significativa em relação ao cenário 3.1, passando de 1 para 4 pares de trens por dia.

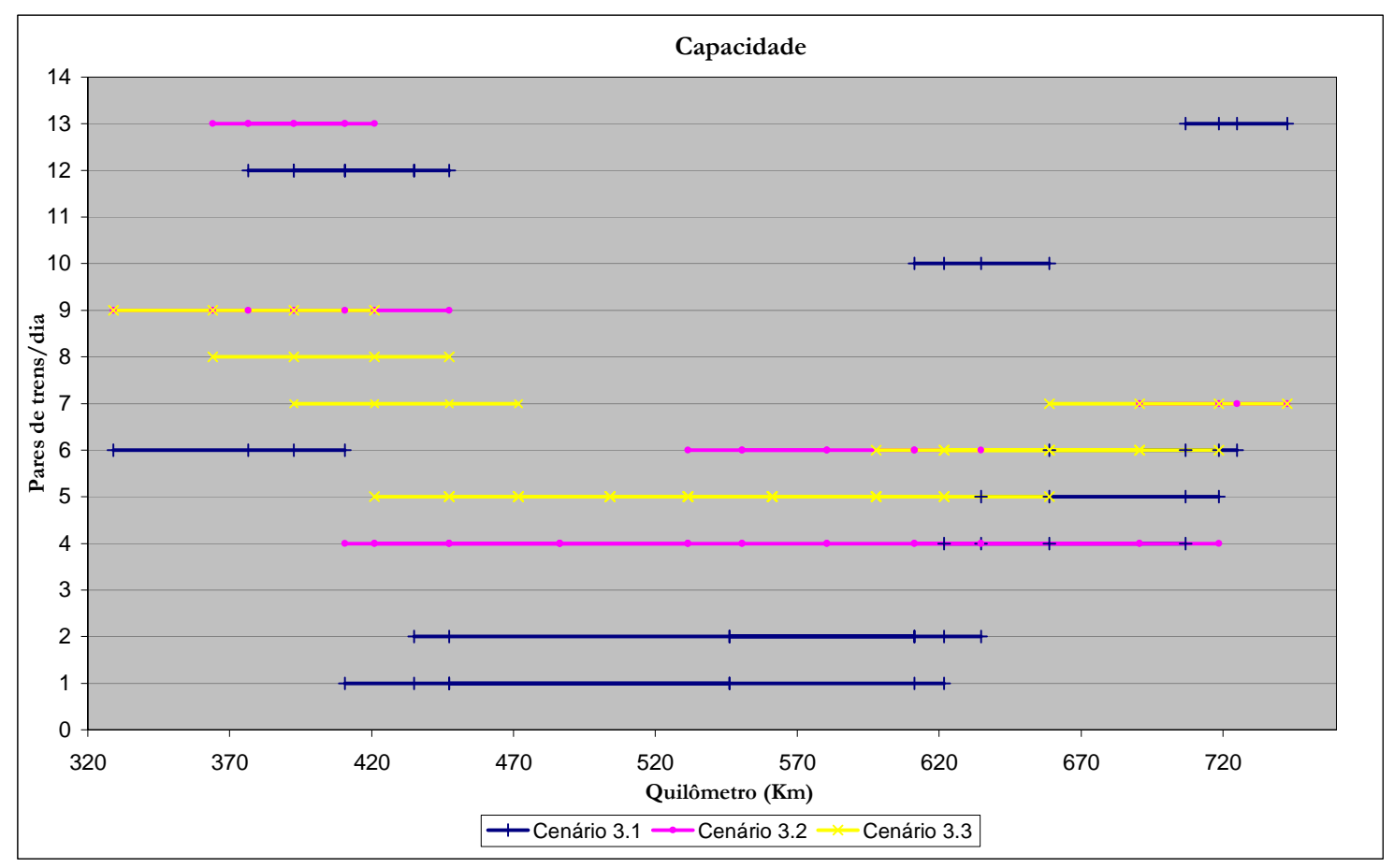

Figura 5.5 - Variação da capacidade em função das estações utilizadas

Apesar do Cenário 3.3 apresentar um aumento de $25 \%$ na capacidade em relação ao Cenário 3.2, ainda assim esse número é inferior ao resultado do Cenário 1.1 como pode ser observado na Figura 5.6.

É evidente que entre os três cenários elaborados com configurações diferentes de estações abertas, o que apresenta maior ganho em termo de capacidade é o Cenário 3.3. Coube, então, uma investigação do ganho que se teria nesse cenário, retirando-se os limites de velocidade impostos na operação. O novo cenário elaborado, o Cenário 3.4, obteve como capacidade mínima de transporte em seu trecho, de 8 pares de trens por dia. 


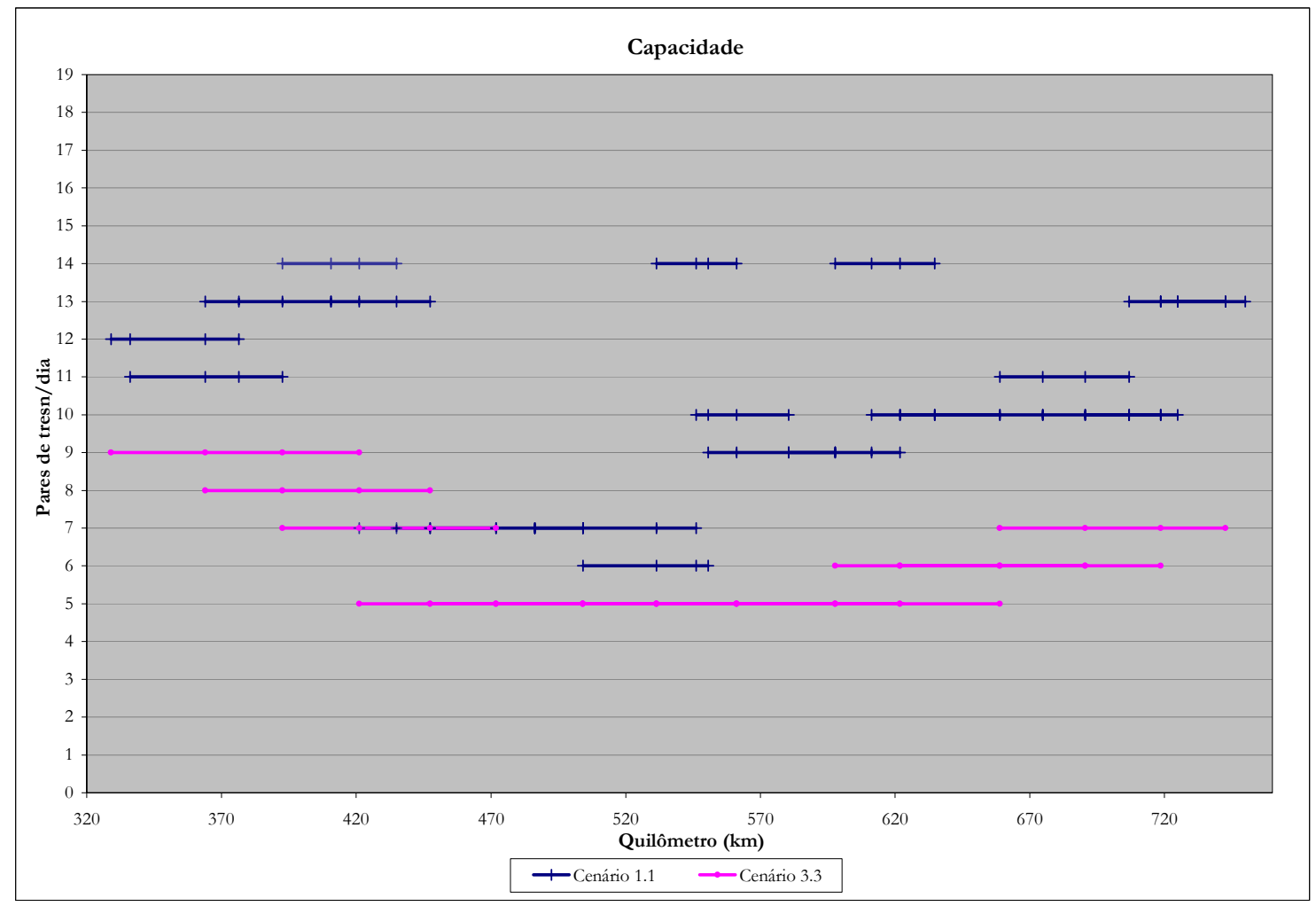

Figura 5. 6 - Comparação entre o Cenário 1.1 e o Cenário 3.3

Essa vantagem, como pode ser observado na Figura 5.7, representa um aumento de $33 \%$ em pares de trens processados, em relação ao cenário padrão (Cenário 1.1) e 60\%, em relação ao Cenário 3.3.

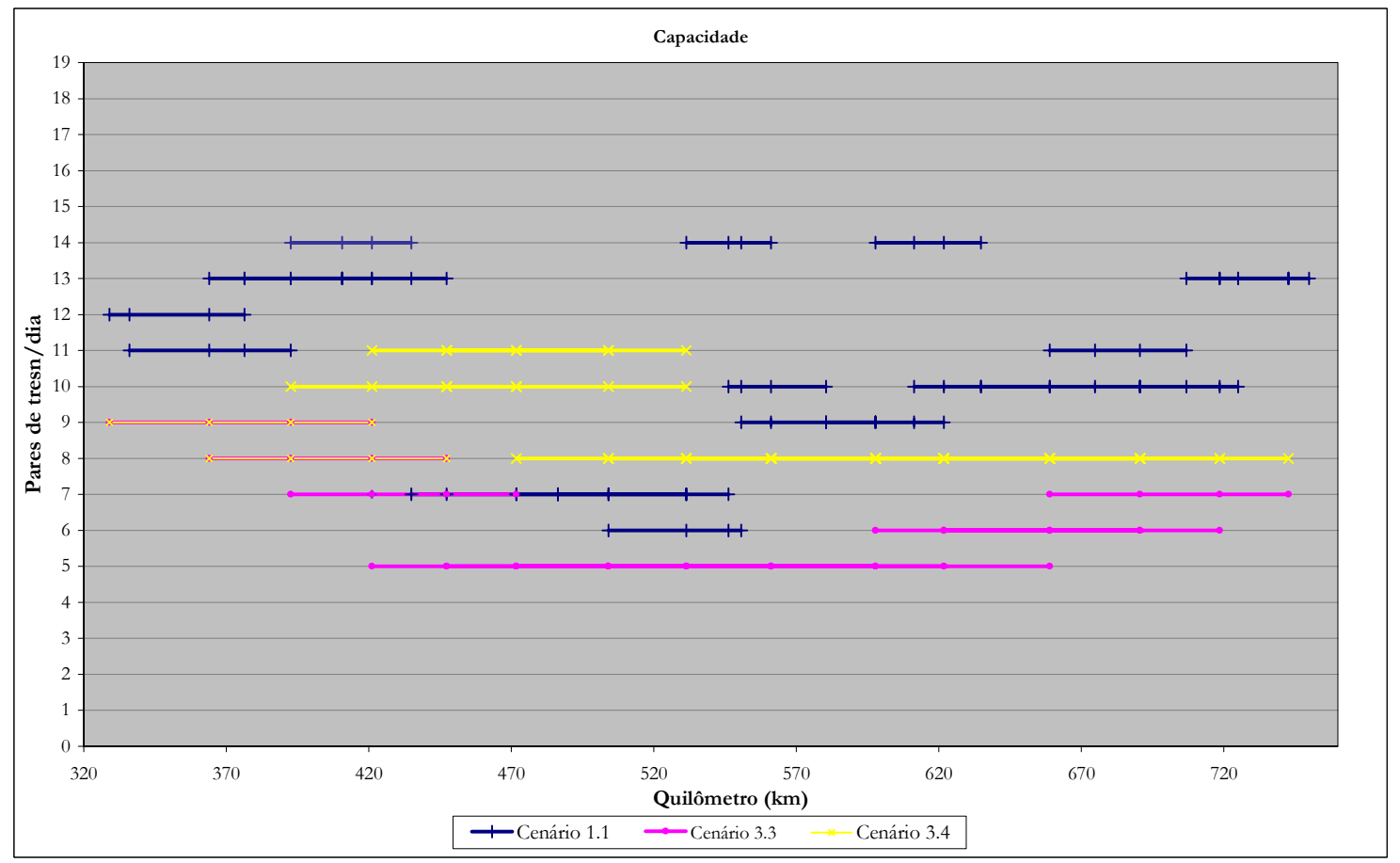

Figura 5. 7 - Comparação entre o Cenário 1.1 , 3.3 e o Cenário 3.4 


\subsection{Análise da influência da existência de passagem em nível}

O objetivo da criação do Cenário 4 foi verificar a influência da existência de passagens de nível na via. As passagens de nível representam pontos nos quais existe cruzamento da via férrea com uma rodovia principal, ou secundária, no mesmo nível. $\mathrm{O}$ trecho analisado possui 23 passagens de nível que impõem limites de $20 \mathrm{Km} / \mathrm{h}$ na velocidade das composições.

No cenário 4.1, mantêm-se os limites operacionais de velocidade e retira-se todas as passagens de nível existentes. Comparando-se esse cenário com o Cenário 1.1, percebe-se que não ocorre um aumento significativo na capacidade do trecho crítico, de 6 pares de trens por dia passaram a ser movimentados 7 pares. A partir deste resultado, pode-se afirmar que a retirada de todas as passagens de nível, mantendo os limites de velocidade atuais, representa um ganho de capacidade de apenas 17\% em relação ao Cenário 1.1, um ganho modesto quando comparado com o fator aumento de velocidade máxima.

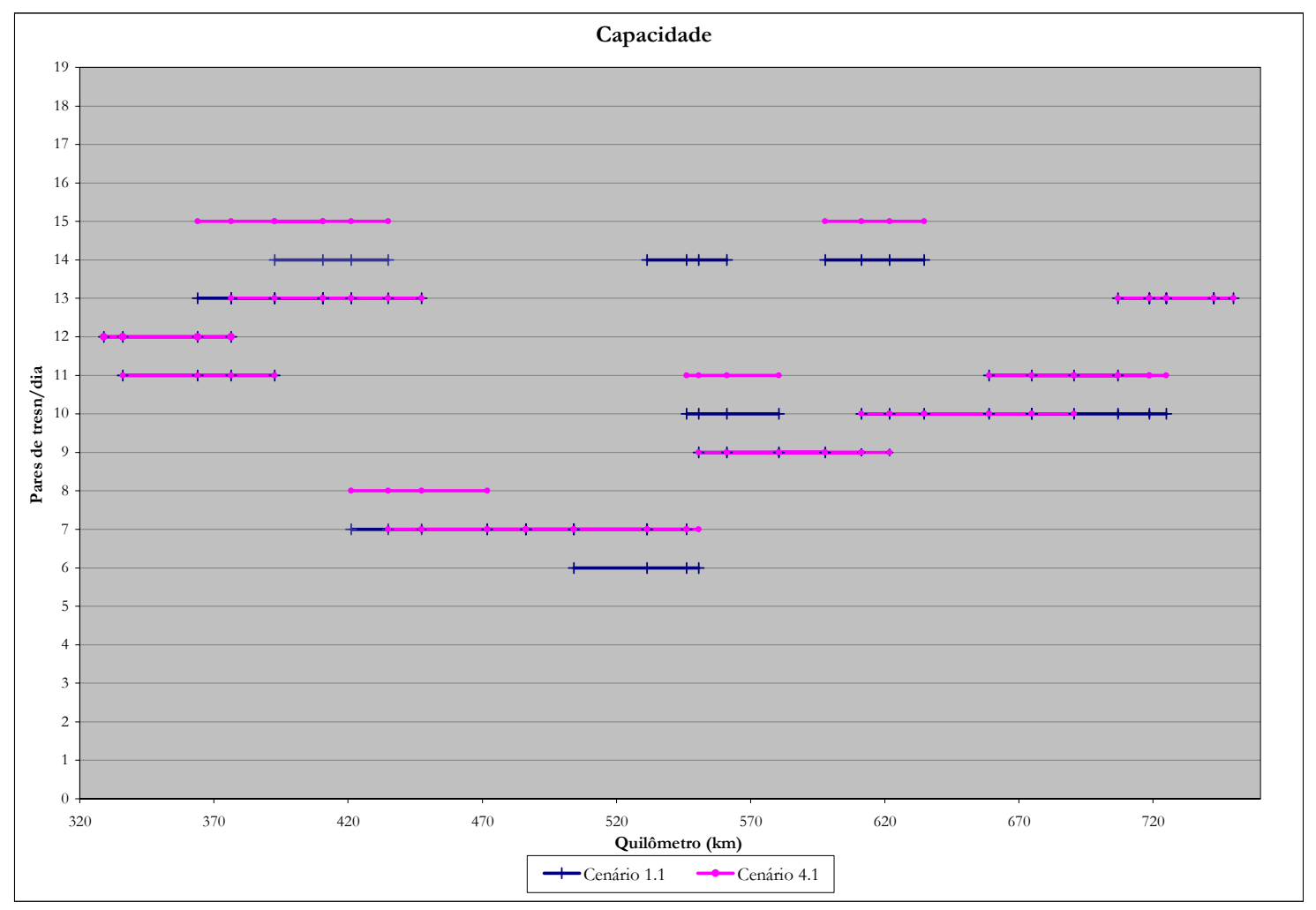

Figura 5.8 - Aumento da capacidade com a retirada das passagens de nível

Esse fato levou a outra análise, considerando-se o limite de velocidade de $70 \mathrm{~km} / \mathrm{h}$. $\mathrm{Na}$ Figura 5.8, tem-se os resultados dos Cenários 1.2, 4.2 e 4.3. A proposta inicial era averiguar se a exclusão das passagens de nível, nos municípios pequenos representava um 
ganho significativo. Analisando-se os resultados do Cenário 1.2 e o do Cenário 4.2, pode-se concluir que a retirada das passagens de nível apenas nas cidades menores (população até cerca de 11 mil habitantes) não altera o número máximo de trens processados por dia, mantendo o valor de 10 pares.

No entanto, a retirada de todas as passagens de nível, posterior a eliminação das restrições da velocidade (Cenário 4.3), permite um aumento de 30\% na capacidade, passando de 10 para 13 pares de trens, um total de 85.800 toneladas diárias.

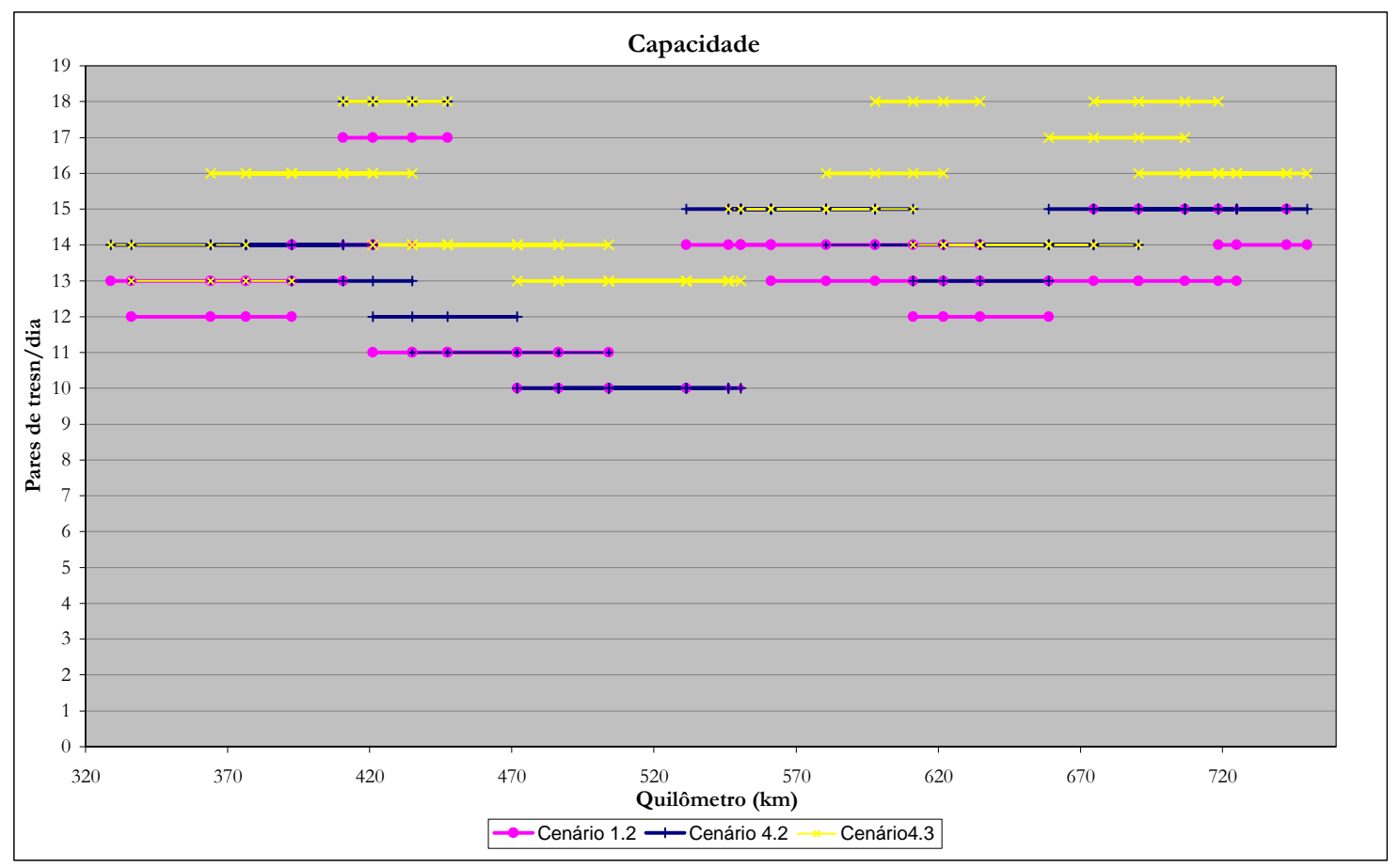

Figura 5.9 - Comparação entre os resultados dos Cenários 1.2, 4.2 e 4.3

\subsection{Análise da influência da otimização dos fatores de produção}

Esse cenário foi elaborado com o intuito de verificar o resultado da combinação dos fatores de produção otimizados, ou seja, o tempo mínimo de espera de 10 minutos, com limite de velocidade de $70 \mathrm{~km} / \mathrm{h}$ e nenhuma passagem de nível. Pela inspeção da Figura 5.10, nota-se que seria possível processar 14 pares de trens por dia, e transportar 62.400 toneladas diárias.

Melhorias adicionais, em relação à capacidade só seriam obtidas com mudanças de traçados e otimização de localização dos desvios. Essa discussão será promovida no próximo item. 
A partir dos resultados dos Cenários 1.1 e do Cenário 5.1, é pertinente fazer o seguinte comentário: o último cenário oferece uma vantagem de 8 pares de trens a mais por dia em relação ao primeiro, um ganho de 133\% em termos de capacidade, ou seja, no Cenário 1.1 apenas 39.600 toneladas diárias são transportadas enquanto que, utilizando-se a configuração do Cenário 5.1, é possível transportar 92.400 toneladas diárias pela ferrovia.



Figura 5.10 - Cenário 5.1

\subsection{Análise da influência da distância entre as estações}

Observando-se os resultados até o Cenário 5.1, identifica-se o gargalo localizado entre as estações de Cosmorama (ZKY) e São José do Rio Preto (ZSP), um trecho com cerca de $80 \mathrm{~km}$.

Os Cenários 6.1 e 6.2 foram criados com o objetivo de investigar o trecho crítico. Percebe-se que a variação da capacidade está entre 14 e 22 pares de trens por dia. O trecho entre os quilômetros 330 a 390 e 445 a 550, representa restrições para o processamento dos trens. A realocação das estações existentes nesses dois trechos em distâncias que permitam tempos de percurso semelhante, proporcionou melhorias na movimentação dos trens, alcançando os resultados observados na Figura 5.11. A capacidade mínima do trecho passa para 16 pares de trens por dia, um acréscimo de quase $15 \%$ em relação ao Cenário 5.1. 




Figura 5.11 - Comparação entre o Cenário 5.1 e 6.1

Para os próximos gargalos, localizados nos quilômetros 420 a 480 e 610 a 690, é aplicado o mesmo critério de localização das estações. Na Figura 5.12, nota-se o aumento de mais de $20 \%$ na capacidade, comparando-se ao Cenário 5.1.

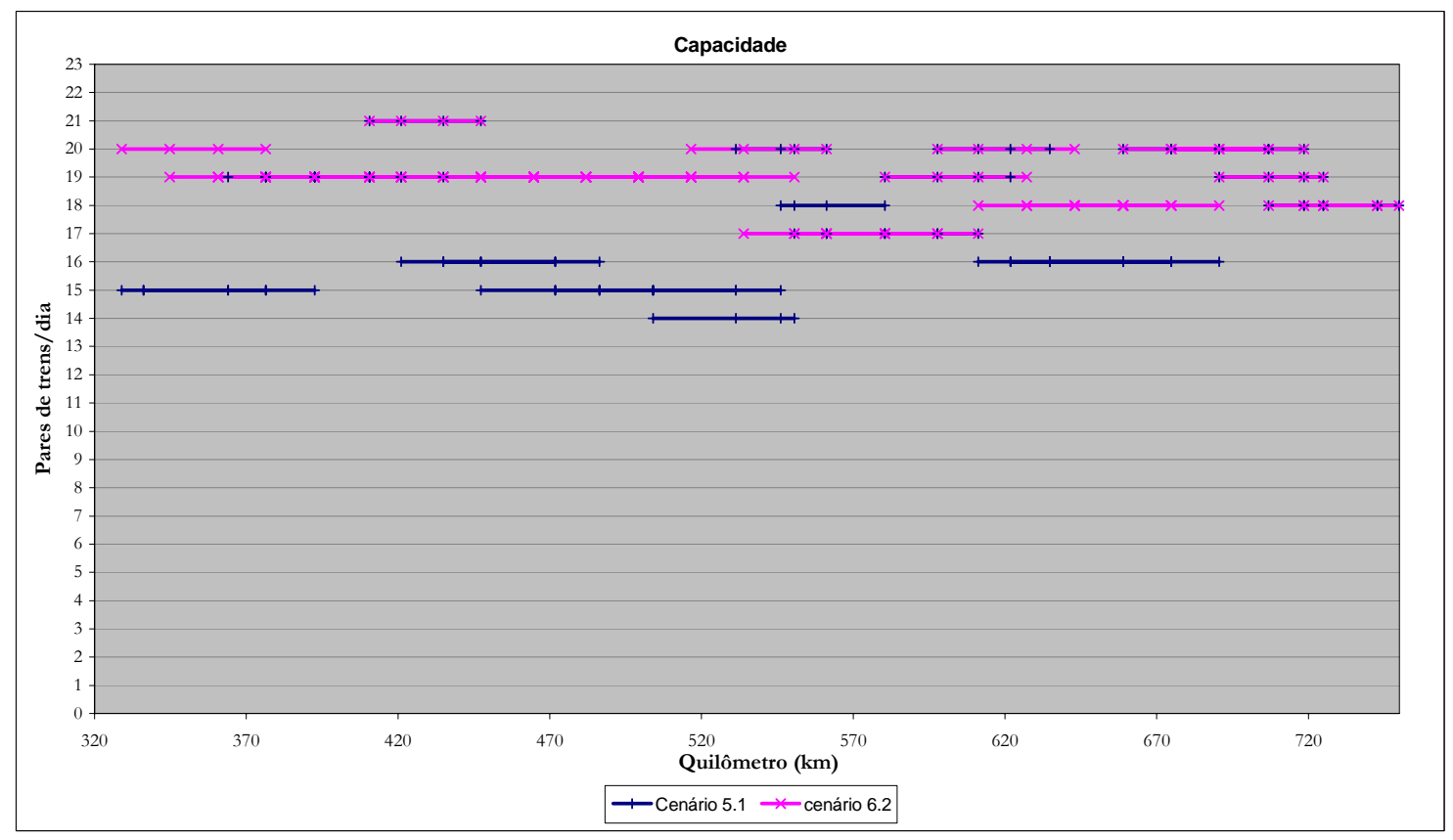

Figura 5. 12 - Comparação entre o Cenário 5.1 e 6.2

Apresenta-se a Figura 5.13 para efeito de comparação entre todos os cenários, cuja capacidade, em toneladas transportada por dia, pode ser visualizada no eixo das ordenadas 
e a quantidade de pares de trens por dia processados, no trecho mais crítico, está descrita no topo de cada barra do gráfico.

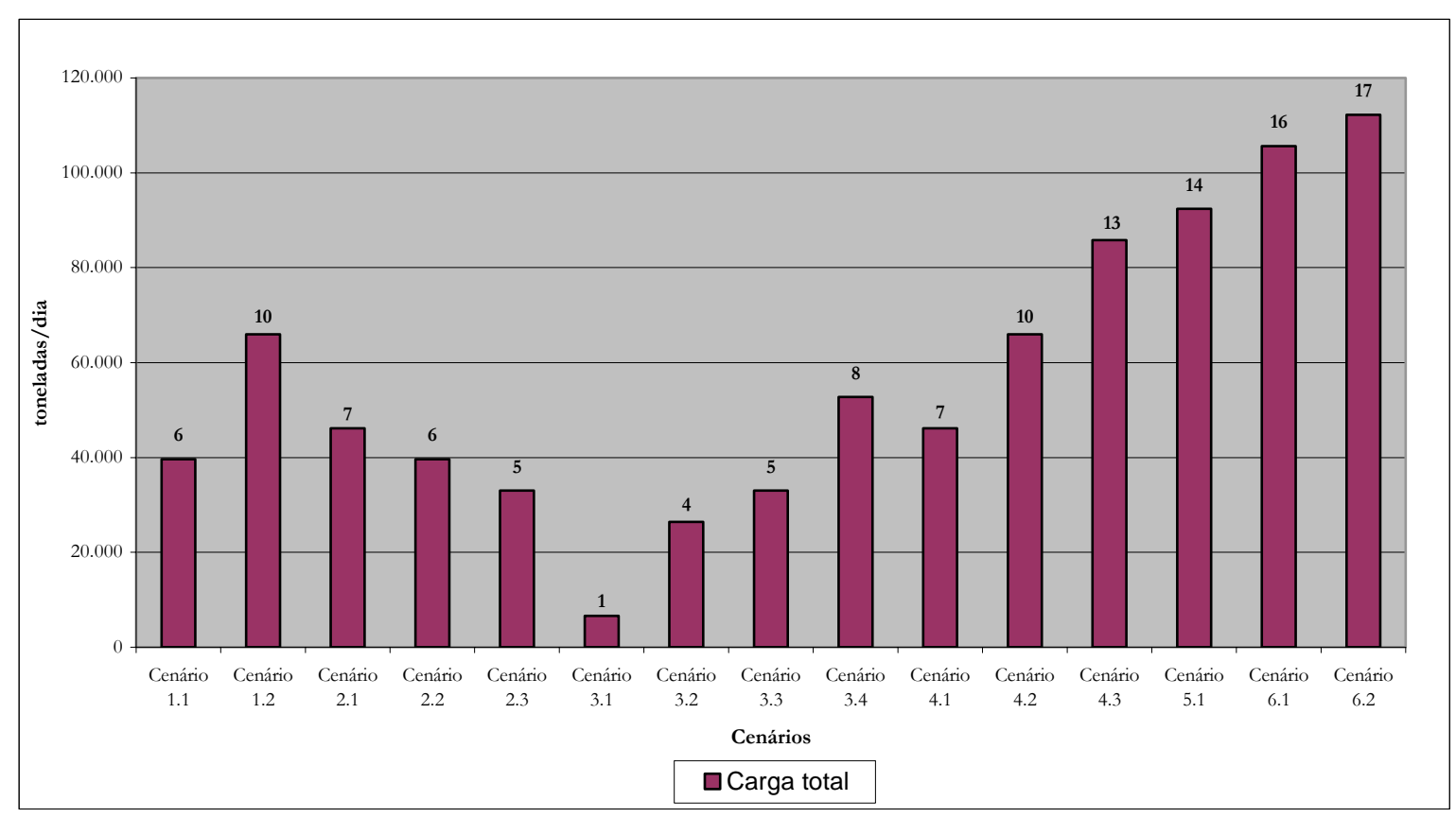

Figura 5. 13 - Comparação entre os cenários

\subsection{Análise geral}

Após a exposição dos resultados dos cenários elaborados, é pertinente uma discussão sobre os parâmetros que estão restringindo a capacidade do trecho.

O Cenário que reflete o cenário real é o Cenário 1.1. Comparando-o com o Cenário 4.3, observa-se que o aumento do limite da VMA para $70 \mathrm{~km} / \mathrm{h}$, incluindo a retirada de PN, provoca um ganho de mais de $65 \%$, em termos de capacidade em pares de trens por dia. Os limites de velocidade impõem, atualmente, valores de até $15 \mathrm{~km} / \mathrm{h}$ em alguns trechos críticos. Na Figura 5.14, observa-se os limites de velocidade impostos às composições e o desempenho da composição no trecho da malha analisado, de Santa Fé do Sul até Araraquara, sem paradas intermediárias. 


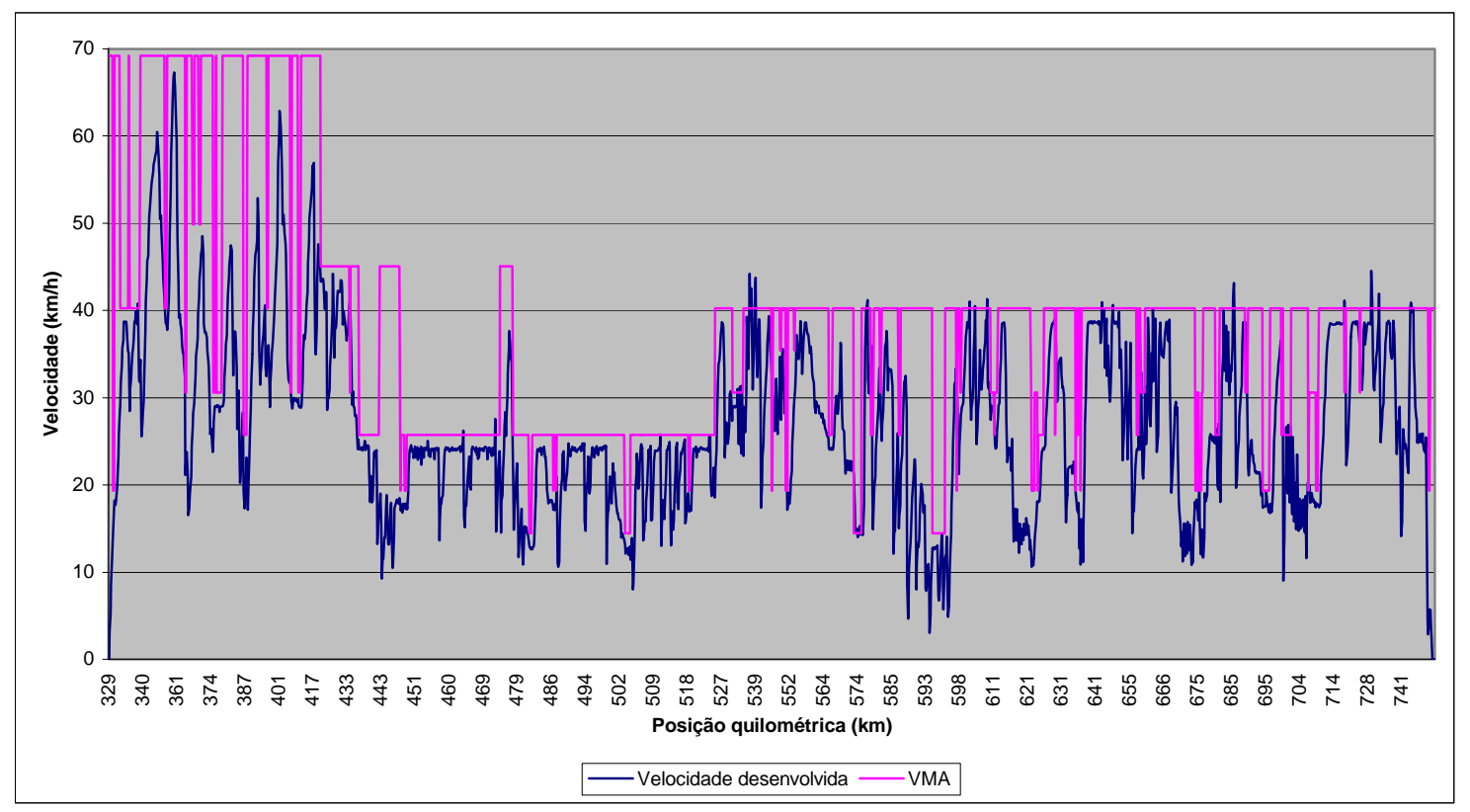

Figura 5.14 - Desempenho do trem de Santa Fé do Sul a Araraquara - Cenário real

$\mathrm{Na}$ busca das relações causais para esse cenário, foi possível identificar algumas características que são apresentadas a seguir.

Observando-se o arquivo de via (Anexo A), cujos aclives e raios de curvas estão esquematizados na Figura 5.15, percebe-se que a rampa máxima no trecho é de 1,4\% e, no gargalo, entre os quilômetros 420 e 550, o valor máximo é de 1\%. Conclui-se, portanto, que os aclives não são o fator limitante, visto que a tração disponível permitiria velocidades mais elevadas.

Porém, observando-se os raios das curvas representadas na Figura 5.15, nota-se que o gargalo está localizado nos subtrechos onde ocorrem os menores raios de curva.

O gargalo atual está localizado nos subtrechos onde a VMA é, em sua maioria, igual a $25 \mathrm{~km} / \mathrm{h}$, entre as estações de Engenheiro Balduíno e São José do Rio Preto.

Levanta-se, portanto, duas hipóteses a serem discutidas: o parâmetro restritivo é a geometria horizontal da via, ou seja, as curvas, nas quais a velocidade está sendo limitada pelo risco de tombamento, ou a restrição é devido à superestrutura, cujo desgaste dos trilhos e o deslocamento dos dormentes provocam a redução da velocidade da composição. 


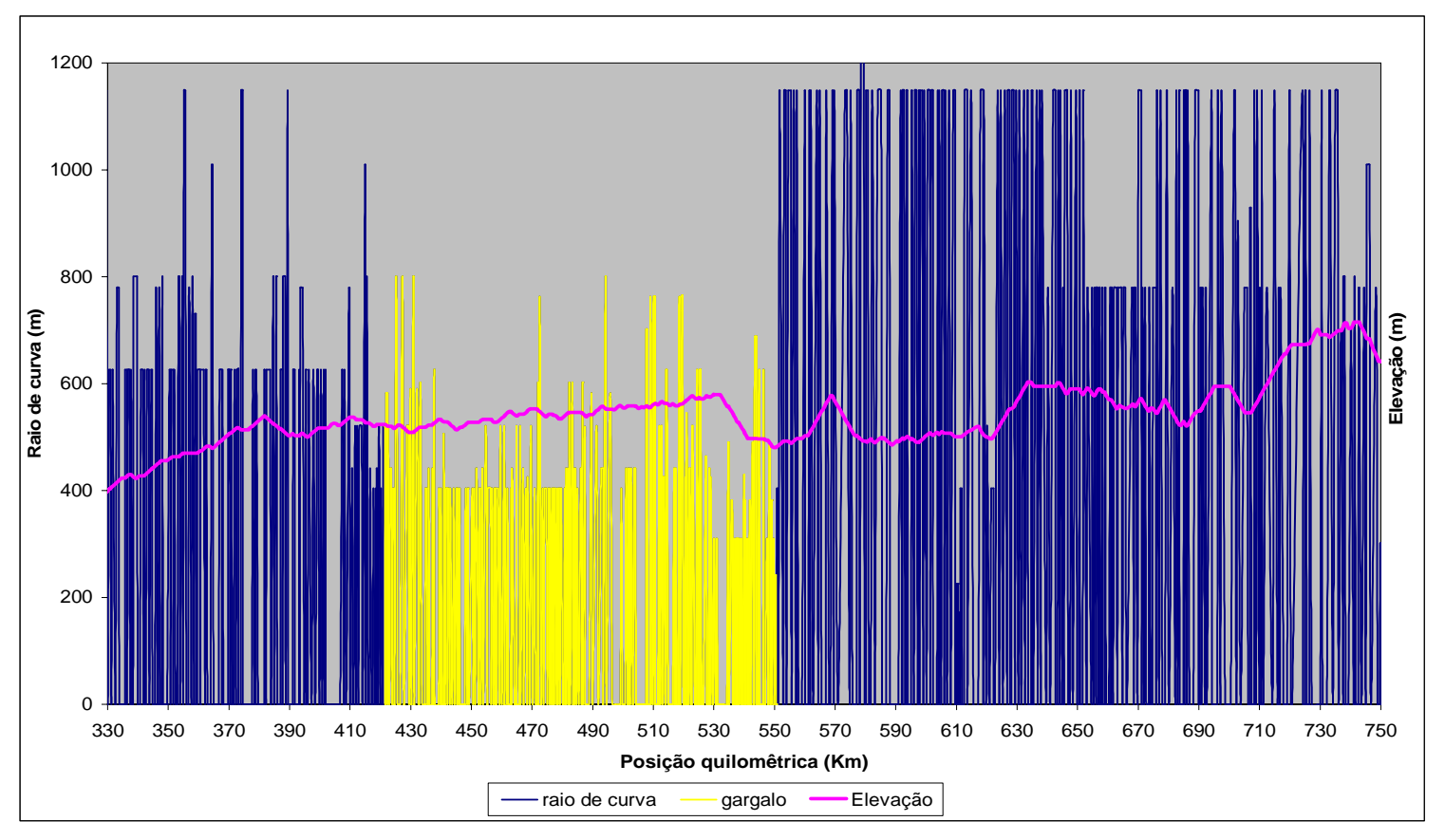

Figura 5.15 - Características geométricas da via

Segundo Hay [1982], a velocidade crítica de tombamento nas curvas pode ser encontrada através da seguinte expressão:

$$
V=\left(\frac{E_{a}+3}{0,0007 \cdot D}\right)^{1 / 2}
$$

no qual:

$\mathrm{V}$ : velocidade permitida com a superelevação $\mathrm{E}_{\mathrm{a}}(\mathrm{mph})$.

$\mathrm{E}_{\mathrm{a}}:$ Superelevação(in)

D: grau de curva.

Adotando-se superelevação zero e utilizando o menor raio de curva da via, 240 metros, a velocidade resultante seria de $40 \mathrm{~km} / \mathrm{h}$.

No entanto, explorando-se os resultados do SDT para a mesma composição, com VMA de $70 \mathrm{~km} / \mathrm{h}$ no trecho de estudo (Figura 5.16), nota-se que a velocidade do trecho crítico, determinada pelo modelo da AAR, oscila entre os valores de 47 e $70 \mathrm{~km} / \mathrm{h}$. Os maiores decréscimos de velocidade e suas maiores oscilações, com valores de até $37 \mathrm{~km} / \mathrm{h}$, ocorrem nos locais de aclives acentuados, locais estes que não configuram um gargalo 
expressivo do trecho estudado e poderiam ter seu efeito minorado com a adição de tração na composição.

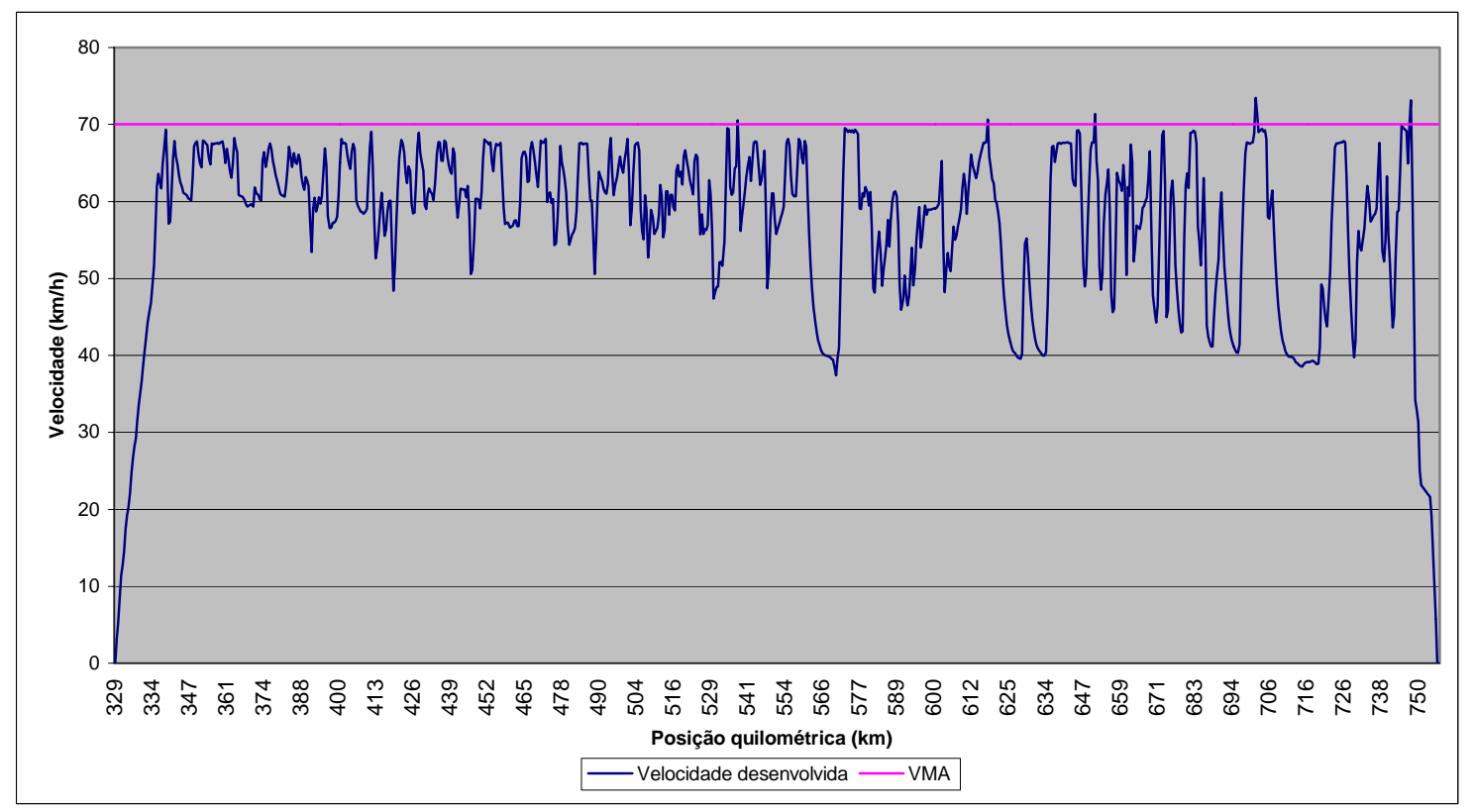

Figura 5.14 - Desempenho do trem de Santa Fé do Sul a Araraquara - VMA 70 km/h

Dessa forma, conclui-se que atualmente, o parâmetro que está restringindo a velocidade é a condição de manutenção da linha. O desgaste da via permanente é decorrente da ação mecânica entre a roda e o trilho e a rapidez com que ocorre é função do raio das curvas e do peso da carga por eixo dos veículos. A correção das deficiências da superestrutura é, portanto, o fator de melhoria prioritária.

Após a retirada dos limites de velocidade, o gargalo continua localizado praticamente no mesmo trecho (Cenário 1.2). Duas hipóteses adicionais sobre os parâmetros que estão afetando a capacidade podem ser levantadas: o número de passagens de nível e a própria geometria da via.

Com relação às passagens de nível, sua retirada total (Cenário 4.3) representou um ganho de 30 \% sobre a capacidade, ou seja, após a correção dos defeitos da superestrutura e o aumento da VMA, a retirada das passagens de nível representa um ganho expressivo. Porém, a retirada das PN de forma isolada, mantendo os limites de velocidades atuais (Cenário 4.1), representa ganhos pouco significativos.

Realizadas as modificações operacionais, eliminadas as interferências na via, de forma a permitir o aumento da VMA para $70 \mathrm{~km} / \mathrm{h}$ e retirando-se as passagens de nível, como 
segundo passo, investigou-se os ganhos decorrentes de alterações nas localizações das estações. A linha ferroviária analisada possui estações localizadas de forma irregular ao longo da via e com dimensões insuficientes para alocar as composições decorrentes da estratégia de projeto e construção da via permanente, iniciada no século XIX. Os Cenários 6.1 e 6.2, representados nas Figuras 5.11 e 5.12, permitiram verificar o ganho proveniente da otimização da localização das estações.

A realocação das estações, executada de forma que os tempos de percurso as entre estações fossem da mesma ordem de grandeza, provocou um aumento adicional de $20 \%$ na capacidade, alcançando 17 pares de trens por dia, contra o valor atual de 6 pares de trens por dia. As estações foram localizadas com espaçamento entre 15 a $17 \mathrm{~km}$, com headways resultantes de aproximadamente 72 minutos.

Um ponto relevante que pode ser observado com a realocação das estações foi a mudança de localização dos gargalos. Essa alternativa provocou também a redução da variabilidade da capacidade emitida pelo modelo (Figura 5.12), alcançando quase três vezes mais a quantidade processada atualmente, valor compatível com a experiência prática da Companhia Vale do Rio Doce, na Estrada de Ferro Carajás. 


\section{CONCLUSÕES E RECOMENDAÇÕES}

Este trabalho teve como objetivo a elaboração de um modelo de capacidade para uma linha ferroviária singela, permitindo identificar os gargalos existentes bem como os parâmetros que restringem a capacidade do sistema. Por meio da elaboração de cenários para um trecho real da Brasil Ferrovias S. A., no Estado de São Paulo, foi possível avaliar alternativas operacionais e investigar alternativas de aumento da capacidade de processamento de trens por dia.

As maiores dificuldades encontradas durante a realização deste trabalho ocorreram na fase de aprendizagem do uso do simulador. O simulador de desempenho do trem da AAR é complexo e possui muitas variáveis, sendo sua interface pouco amigável e a geração dos cenários, um processo trabalhoso.

Os resultados, obtidos com a aplicação do modelo em uma via real para um conjunto de cenários propostos, permitiram mostrar onde está localizado o problema e o porquê dele estar ocorrendo. Dessa forma, o método permite hierarquizar os investimentos a serem efetivados na ferrovia, tornando-se uma ferramenta estratégica útil na análise de tais investimentos.

Atualmente, o trecho de linha singela analisado apresenta uma capacidade máxima igual a seis pares de trens por dia, sendo o gargalo localizado entre as estações de Engenheiro Balduíno e São José do Rio Preto.

Os resultados do modelo mostram que, eliminando-se as restrições impostas pela condição da superestrutura, é possível aumentar a capacidade de seis para dez trens por dia por sentido, ou seja um aumento de $67 \%$.

Se a intervenção for apenas operacional, limitada ao tempo de cruzamento das composições nas estações, nota-se que a redução do tempo de espera apresenta ganhos 
pouco significativos na capacidade, frente à restrição imposta pela condição atual da superestrutura do trecho explorado. Investigou-se a influência do tempo mínimo de espera, com valores de 10,15, 20 e 30 minutos. A redução desses tempos pela metade, de 30 para 15 minutos ou 20 para 10 minutos, representa um ganho de um par de trem por dia.

Da mesma forma, a eliminação de algumas estações intermediárias com o propósito de reduzir-se o número de cruzamentos e, consequentemente, eliminar o tempo perdido na desaceleração, espera e aceleração das composições, sem se intervir na condição da superestrutura, é relativamente ineficiente para aumentar a capacidade de processamento de trens no trecho considerado.

Em relação às passagens de nível, observou-se que sua retirada apenas nas cidades menores (cidades com menos de 11.000 habitantes) também não tem efeito significativo sobre a capacidade, sem a intervenção na condição da superestrutura.

A intervenção na superestrutura ferroviária é, portanto, a condição essencial de melhora nos limites de capacidade de processamento de trens no trecho investigado.

Uma vez sanada a condição da superestrutura ferroviária para permitir uma VMA de $70 \mathrm{~km} / \mathrm{h}$ em todo o trecho, a eliminação das passagens de nível implica em um ganho adicional de 30\% na capacidade de processamento de trens (13 trens por dia, por sentido).

Um terceiro passo, através de medidas operacionais, de se reduzir o tempo de cruzamento nas estações, de 15 para 10 minutos, mantendo a configuração de localização atual das estações, implicou um ganho adicional de mais um par de trens por dia.

A conclusão central do estudo é que a otimização dos fatores de produção analisados na ordem correta, ou seja, correção das deficiências da superestrutura com aumento da VMA para $70 \mathrm{~km} / \mathrm{h}$, a redução dos tempos de espera nas estações para 10 minutos e a retirada das passagens de nível, permitiria um aumento na capacidade da ordem de 133\% em relação ao cenário atual. Pela atuação conjunta dos melhores resultados dos cenários elaborados, a capacidade de processamento passou de seis para quatorze pares de trens por dia, no trecho investigado.

Uma busca para obter-se níveis de capacidade mais elevadas conduziu o estudo de realocação das estações, visto que a investigação da eliminação, pura e simplesmente, de algumas estações intermediárias, antes da eliminação das restrições da superestrutura não 
representa resultados promissores. A nova localização das estações foi feita de forma que o trem mantivesse o mesmo tempo de percurso entre as estações, cerca de 25 minutos, chegando a um aumento adicional de $20 \%$ no número máximo de pares de trens por dia, chegando a 17 pares processados.

Dessa forma, os resultados da técnica de modelagem e avaliação, propostas neste estudo, chegaram a valores praticamente iguais à capacidade prática da ferrovia singela de melhor condição operacional no Brasil, a Estrada de Ferro Carajás (EFC), cuja capacidade atual de processamento é de 16 pares de trens por dia (15 de carga e um de passageiros) [JUNGER, 2005]. Vale a pena ressaltar que esse valor foi encontrado sem interferências significativas na geometria da via férrea, fator este que, talvez, permitisse um ganho adicional.

Considera-se, portanto, que os objetivos do trabalho foram alcançados, uma vez que se conseguiu, com o modelo proposto, não só determinar a capacidade de uma linha ferroviária singela, mas também determinar onde e quais fatores restringem a capacidade de todo o sistema. Os pontos de gargalos foram identificados, bem como os próximos gargalos, que surgiriam quando os primeiros fossem eliminados.

O modelo é generalizável para qualquer trecho de ferrovia e constitui, a nosso ver, uma ferramenta de solução robusta e apropriada para a análise estratégica de restrições de capacidade na malha ferroviária brasileira.

\subsection{Recomendações}

Para trabalhos futuros e complementares a este, recomenda-se que sejam investigados, em maior profundidade, outros fatores de produção do sistema ferroviário. Pode ser avaliada, utilizando-se a modelagem formulada, a influência do comprimento do trem, da carga por eixo e quantidade de tração, entre outros, na capacidade da via. Além disso, pode ser considerada a variação conjunta de fatores de produção no sistema ferroviário.

Também poder-se-ia aumentar a abrangência dessa análise avaliando-se a interferência do comprimento e espaçamento das estações na capacidade ferroviária. Uma das soluções a ser investigada nesse caso, seria a redução dos espaçamentos entre as 
estações e consequente redução dos headway, que, no caso de inserção de um número elevado de desvios, levaria praticamente à condição de duplicação da via.

Outra proposta é aplicar o modelo a uma rede de transporte ferroviário, visto que sua aplicação limitou-se a um trecho de linha singela, sem ramais de alimentação. Esse tipo de aplicação permitirá uma investigação mais ampla dos principais sistemas ferroviários brasileiros de exportação.

Eventualmente, o SDT utilizado para a verificação do desempenho do trem (TEM 2.5) pode ser empregado para a avaliação de outras alternativas operacionais como melhor aproveitamento da força tratora. Os arquivos de saída do simulador permitem verificar o desempenho energético das composições, promovendo uma avaliação de gastos de combustível.

Um outro ponto que poderia ser explorado seria avaliar o impacto de alterações geométricas da via permanente na capacidade de um trecho ferroviário, ou seja, qual o benefício decorrente de uma VMA maior que $70 \mathrm{~km} / \mathrm{h}$, em trens de carga processados.

Recomenda-se também o aperfeiçoamento do algoritmo utilizado para a solução dos conflitos. Pode-se melhorar sua interface, permitindo uma transferência mais eficiente dos dados de saída do simulador, além de promover a solução de conflitos e construção do diagrama para trechos com quaisquer quantidades de arcos, visto que o algoritmo foi usado para um subtrecho composto de três arcos.

Sugere-se a inclusão no modelo da análise da provável variação de demanda em um determinado trecho ou conjunto de trecho de uma rede ferroviária, promovendo, assim, uma perspectiva de tempo de saturação do sistema, com o objetivo de avaliar o potencial de expansão do sistema frente a um aumento gradativo da demanda e a identificação dos gargalos imediatos e futuros do sistema.

Por fim, propõe-se que seja inserido no modelo uma função custo nas alternativas avaliadas para o aumento da capacidade. Os cenários elaborados neste trabalho não levaram em consideração investimentos despendidos para a melhora da superestrutura, para a retirada de passagens de nível, para a redução de tempo de espera e a relocação das estações. 


\section{REFERÊNCIAS BIBLIOGRÁFICAS}

AAR - Association of American Railroads [1993]. AAR Report SD-39 Supp - Train Energy Model version 2.0 user's manual (version 2.5 supplement). AAR Research and Test Department Technical Center. Chicago, Ill., 1993.

ANTF - Associação Nacional de Transporte Ferroviário. Disponível em: $<$ http://www.antf.org.br>. Acesso em: 20 fev. 2005.

ANTT - Agencia Nacional de Transportes Terrestres. Disponível em: <http://www.antt.gov.br>. Acesso em: 28 fev. 2005.

ASSAD, A. A. [1980]. Models for rail transportation. Transportation Research - A, v. 14, p. 205-220.

BRASIL FERROVIAS - Empresa ferroviária Brasil Ferrovias. Disponível em: < http://www.brasilferrovias.com.br/bf/index.html> Acesso em: 10 mar. 2005.

BRINA, H. L. [1983]. Estradas de ferro. Rio de Janeiro: LTC - Livros Técnicos e Científicos Editora S. A.

CAREY, M; LOCKWOOD, D. [1995]. A model, algorithms and strategy for train pathing. Journal of the Operational Research Society, Vol 46, p 988-1005.

CEL - Centro de Estudos em Logística do COPPEAD/UFRJ. Disponível em: < http://www.cel.coppead.ufrj.br> Acesso em: 10 jan. 2006. 
FERNÁNDEZ L, J. E. ; DE CEA CH., J. ; GIESEN E, R. [2004]. A strategic model of freight operations for rail transportation systems. Transportation Planning and Technology. v 27. $n^{\circ}$ 4. P 231-260.

GOH, C. J.; MEES, A. I. [1991]. Optimal control on a graph with application to train scheduling. Mathematical Computer Modelling, v. 15, p. 49-58.

HAY, W. W [1982]. Railroad Engineering. 2. ed. Nova York: John Wiley \& Sons.

HIGGINS, A., KOZAN, E.; FERREIRA, L. [1996]. Optimal scheduling of trains on a single line track. Transportation Research Part B, v. 30B, n. 2, p. 147-161.

HIGGINS, A.; FERREIRA, L; KOZAN, E. [1995]. Modeling delay risks associated with train schedules. Transportation Planning and Technology, v. 19, p. 89-108.

JANIC, M. [1984]. Single track line capacity model. Transportation Planning and Technology, v. 9, p. 135-151.

JANIC, M. [1988]. A practical capacity model of a single track line. Transportation Planning and Technology, v. 12, p. 301-318.

JUNGER, E. C. [2005]. Apresentação Institucional Vale Logística - Companhia Vale do Rio Doce. In: Empregabilidade no setor logístico. Piracicaba: Escola Superior de Agricultura Luiz de Queiroz - USP, 2005.

KRAFT, E. R. [1983]. Jam capacity of single track rail lines. Transportation Research Forum Proceedings, v. 23, p. 461-471.

KRAAY, D.; HARKER, P.; CHEN, B. [1991]. Optimal pacing of trains in freight railroads. Operations Research, v. 39, p. 82-99.

KRUEGER, H. [1999] - Parametric Modeling in Rail Capacity Planning - Proceedings of the 1999 Winter Simulation Conference, 1999. Disponível em:< http://www.informs-cs.org>. Acesso em: 28 fev. 2005. 
LACERDA, S. M. [2002] - O Transporte Ferroviário de Cargas. Disponível em:< http://www.bndes.gov.br/conhecimento/livro_setorial/setorial15.pdf. Acesso em: 10 mar. 2005.

LAW, A. M.; KELTON, W. D. [1991]. Simulation Modeling e Analysis. New York, McGrawHill, Inc.

LEAL, J. E. SOARES, A. C.; NUNES, L. S. N. (2004). Uma abordagem heurística para o problema de programação de trens em linhas singelas. In: XVIII Congresso de Pesquisa e Ensino em Transportes - ANPET, 18, Florianópolis, 2004. Anais, p.945-956.

LEILICH, R. H. [1998]. Application of Simulation Models in Capacity Constrained Rail Corridors - Proceedings of the 1998 Winter Simulation Conference, 1998. Disponível em: $<$ http://www.informs-cs.org >. Acesso em: 26 fev. 2005.

Ministério dos Transportes - Disponível em: <http://www.transportes.gov.br>.

NTC \& Logística - Disponível em: <http://www.ntcelogistica.org.br>. Acesso em: 05 jun. 2005

NOVAES, A.G. [1986]. Sistemas de transportes: análise de oferta, V. 2, Editora Edgard Blücher Ltda, 1986.

NUNES, L. S. N. [2004]. Sistema de apoio à decisão ao centro de controle operacional no gerenciamento do tráfego ferroviário. 123 p. Dissertação (mestrado) - Departamento de Engenharia industrial, Pontifícia Universidade Católica do Rio de Janeiro, Rio de Janeiro, 2004.

PETERSEN, E. R. [1977a]. Railyard modelling: Part 1, prediction of put-through time. Transportation Science. V. 11, p. 37-49.

PETERSEN, E. R. [1977b]. Railyard modelling: Part 2, the effect pf yard facilities on congestion. Transportation Science. V. 11, p. 50-59.

PETERSEN, E. R; TAYLOR, A. J. [1982]. A Structured Model for Rail Line Simulation and Optimization. Transportation Science. V. 16, n. 2, p. 192-206.

PORTO, T. G. [2004]. Apostila do curso de ferrovias. Departamento de Engenharia de Transportes, Escola Politécnica da Universidade de São Paulo, 2004. 
RAMSEY, G. R. S.; HUTCHINSON B.G.; M. ASCE; RILETT, L. R. [1986]. Simplified

Railroad Capacity Analysis Model. Journal of Transportation Engineering. V. 112, n. 4, p. 358368.

RAMOS, G. M.[2003]. Análise prospectiva da capacidade de processamento de cargas pela ferrovia no Porto de Santos. 99 p. Dissertação (mestrado) - Escola de Engenharia de São Carlos, Universidade de São Paulo, São Carlos. 2003.

REVISTA EXAME: Infra-estrutura [2004]. n. 17, ano 38, 825 a edição, setembro 2004.

RORATO, R. J. [2003]. Perspectivas de transporte doméstico de contêineres frigorificos utilizando a integração modal rodo-hidroviária. 213 p. Dissertação (mestrado) - Escola de Engenharia de São Carlos, Universidade de São Paulo. 2003.

SAAD, J. A. C. [1999]. Modelo para análise da operação de trechos ferroviários em linha singela. 115 p. Dissertação (Mestrado) - Escola de Engenharia de São Carlos, Universidade de São Paulo, São Carlos. 1999.

SILVA, V. B. [2005]. Distribuição modal rodo-ferroviária em uma rede de exportação de açúcar a granel para o Porto de Santos..169 p. Dissertação (Mestrado) - Escola de Engenharia de São Carlos, Universidade de São Paulo, São Carlos. 2005.

SMITH, M. E.; RESOR, R. R.; PATEL, P [1997]. Train Dispatching Effectiveness with Respect to Communications-Based Train Control. Quantification of the Relationship. Transportation Research Record. n. 1584. p. 22-30.

TURNQUIST, M. DASKIN, M. [1982]. Queunig models of classification and connection delay ins railyards. Transportation Science. V. 16, p. 207-230. 
CAVALCANTI, A. Q. B.[1981]. Análise de capacidade de um corredor ferroviário em função do comprimento dos desvios de cruqamentos.152 p. Dissertação (Mestrado) - Instituto Militar de Engenharia , 1981.

CORDEAU, J. F.; TOTH, P.; VIGO, D. [1998]. A survey of optimization models for train routing and scheduling. Transportation Science, v. 32, p. 380-404.

COSTA, J. I. A. [1979]. Comparação econômica entre transportes rodoviários e ferroviários - Instituto Militar de Engenharia. 1979.

DAGANZO, C.F. [1987a]. Dynamic blocking for railyards. Part I. Homogeneous traffic. Transportation Research, v. 21B, p. 1-27.

DAGANZO, C.F. [1987b]. Dynamic blocking for railyards. Part II. Heterogeneous traffic. Transportation Research., v.. 21B, p. 29-40.

DAGANZO, C.F.; DOWLING, R. G.; HALL, R. W. [1983]. Railroad classification yard throughput: The case of multistage triangular sorting. Transportation Research, v. 17A, p. 95106.

FERREIRA, L (1997). Planning australian freight rail operations: an overview. Transportation Research-A, v. 31, p. 335-348.

FORBES, M. A.; HOLT, J. N.; WATTS, A. M. [1991].Exact solution of locomotive scheduling problems. Journal of the Operational Research Society, v. 42, p. 825-831.

HAGHANI, A. E. [1989]. Formulation and solution of a combined train routing and makeup, and empty car distribution model. Transportation Science B, v. 23, p. 433-452. 
HE, S.; SONG, R.; CHAUDHRY, S.S. [2000]. Fuzzy dispatching model and genetic algorithms for railyards operations. European Journal of Operational Research, v. 124, p. 307331.

JOVANOVIC, D.; HARKER, P. T. [1991]. Tactical scheduling of rail operations: The SCAN I system. Transportation Science, v. 25, n. 1, p. 46-64.

KOZAN, E. ; BURDETT, R. [2004] - A Railway Capacity Determination Model and Rail Access Charging Methodologies - Transportation Planning and Technology, V28, n. 1, fevereiro de 2005.

FONSECA NETO, R. [1986]. Modelo de planejamento e otimização ferroviária. Instituto Militar de Engenharia, 286 p. Dissertação (Mestrado) - Rio de Janeiro, 1986.

NOVAES, A. G. N. [1975]. Pesquisa operacional e transportes. São Paulo. McGrawHill.(KOLMOGORV)

NOVAES, A. G. N. [1978]. Métodos de Otimização: Aplicação aos Transportes. Ed. Edgard Blücher Ltda., 1ํㅗㄹ Edição, TRANSESP. São Paulo, SP.

SILVA, E. J. M. [1979]. Metodologia para avaliação e aumento da capacidade de um corredor ferroviário. 135 p. Dissertação (Mestrado) - Instituto Militar de Engenharia, Rio de Janeiro.1979

TIAGO, R. P. [2002]. Estudo dos pontos promissores para instalação de terminais intermodais rodoferroviários de contêineres no Estado de São Paulo. 103 p . Dissertação (Mestrado) - Escola de Engenharia de São Carlos, Universidade de São Paulo, São Carlos. 2002.

VIDAL, J. S F [1991] Aumento da capacidade de transporte de uma ferrovia em linha singela - Critério para decisão de investimento: Frota ou instalações fixas. 132 p. Dissertação (Mestrado) Instituto Militar de Engenharia, Rio de Janeiro, 1991. 
Aparelho de mudança de via (AMV) - mecanismo destinado a possibilitar a passagem de veículos ferroviários de uma vi apara a outra.

Circulação dos trens - movimentação do trem entre locais de licenciamento.

Comboios de trens - série de carros e vagões rebocados por locomotiva.

Composição ferroviária - conjunto de carros de um trem, formado segundo critérios de capacidade, tonelagem, tipos de mercadorias, etc.

Cruzamento - interseção de uma via férrea com outra.

Desvio - é a via que está ligada por AMV à via corrida, à via principal, ou a qualquer outra.

Diagrama espaço-tempo - gráfico que permite visualização da movimentação do trem bem como sua programação através do tempo e do espaço.

Dormente - peça de madeira, concreto, concreto protendido ou ferro, onde os trilhos são apoiados e fixados e que transmitem ao lastro parte dos esforços e vibrações produzidos pelos trens.

Estações - local onde os trens podem se cruzar ou ultrapassar e compreende igualmente o edifício ali construído para a realização dos serviços que lhe são próprios e para acomodação dos passageiros e ou cargas.

Gargalo - locais restritivos ao processamento dos trens.

Headways - intervalo temporal mínimo entre os trens para previnir choques.

Lastro - parte da superestrutura ferroviária, que distribui uniformemente na plataforma os esforços da via férrea transmitidos através dos dormentes, impedindo o deslocamento dos mesmos, 
oferecendo suficiente elasticidade à via, reduzindo impactos e garantindo-lhe eficiente drenagem e aeração.

Linha Singela - trecho da via férrea em que a circulação normal dos trens é feita através da mesma via.

Material rodante - compõem-se de material de tração, carros de passageiros, vagões para mercadorias, animais, bagagens, etc.

Passagem de nível - é o cruzamento de uma ou mais linhas com uma rodovia principal ou secundária, no mesmo nível.

Pátios - conjunto de vias preparado par aformação de trens, manobras, estacionamentos e outros fins.

Peso útil máximo - lotação do veículo.

Pontos de junção - conexão de vias férreas.

Superestrutura - parte superior da estrutura da via que suporta diretamente os esforços dos veículos e os transmite à infraestrutura.

Tempo de Percurso - tempo de aceleração mais o tempo na velocidade de cruzeiro mais o tempo de desaceleração.

Terminais - conjunto de equipamentos e edifícios situados nas pontas das linhas de uma estrada de ferro (inicio ou término da linha) ou mesmo em pontos intermediários, ocupados para o trânsito de passageiros, e reagrupamento de cargas e também formação e despacho de trens.

Tração dupla - tração exercida por duas locomotivas.

Tração simples - tração exercida por uma locomotiva.

Tração tripla - tração exercida por três locomotivas.

Trilho - perfilado metálico da seção transversal semelhante ao duplo T, com características de viga, que suporta e guia as rodas do veículo ferroviário e constitue a superfície de rolamento da via.

Unidade rebocável - vagões e outros veículos que não possuem força tratora.

Unidade tratora - locomotivas. 
Velocidade máxima autorizada (VMA) - velocidade máxima permitida, indicada no horário ou nas instruções especiais.

Via dupla - é o trecho da via férrea em que a circulação normal é feita em duas vias com sentido preestabelecido.

Via permanente - abrange toda a instalação física da linha férrea. 


\section{A MODELO DE SIMULAÇÃO DE MARCHA}

Neste apêndice é mostrado os principais elementos do SDT (o Train Energy Model versão 2.5) e sua estrutura a fim de explicar seu funcionamento.

\section{A.1 Train Energy Model}

O Train Energy Model versão 2.5 é um modelo de simulação de linha ferroviária singela desenvolvido pelo Programa de Pesquisas em Energia da Association of American Railroads com o propósito de verificar o consumo de combustível e o desempenho de vários tipos de trens.

O TEM 2.5 é um modelo de simulação microscópico, pois o movimento de cada composição é modelada individualmente. O trem é considerado um bloco simples ou seja, durante um dado intervalo de tempo todo o veículo possui a mesma velocidade e aceleração, o que imprime duas vantagens: a primeira é a simplificação dos cálculos, já que apenas uma equação de movimento é requerida para a obter avelocidade, aceleração e a posição do veiculo e a segunda é que, desde que se conheça a posição de cada veículo as forças podem ser somadas para calcular a força total agindo no trem para cada intervalo de tempo na simulação [AAR, 1993].

\section{A.2 Estrutura Básica}

O TEM é organizado em três níveis de desenvolvimento na seguinte ordem:

1. Modelo Matemático

2. Lógica de controle do trem

3. Algoritmo automático de desempenho do trem

O modelo matemático é a base do simulador e é composto de um modelo físico, equações de movimento, métodos numéricos usados para integrar as equações de movimento, relações empíricas usadas no modelo de resistência do trem, características usadas para o modelo das locomotivas, etc. 
Segundo o TEM User's Manual [AAR, 1993] aplicações em grande escala mostraram que resultados do simulador são realistas, o modelo matemático é adequado para o nível de detalhes incorporados ao TEM. Em simulações de movimentos do TEM, o erro computacional é usualmente menor que 1\% (mesmo para tempos de simulação excedendo 30 horas).

A lógica de controle do trem no SDT utilizado é baseada na estrutura de comandos que são usadas para dirigir a simulação do trem. Experiências mostraram que esta lógica tem a habilidade de controlar todos os tipos de trens em todas as rotas de maneira realística [AAR, 1993].

O algoritmo automático de desempenho do trem no simulador, chamado de ATA (Automatic Train-handling Algorithm), é uma forma de inteligência artificial que busca alcançar o movimento real do trem para uma determinada duração de tempo, funcionando como um controlador universal.

\section{A.3 Descrição do programa}

O Train Energy Model é constituído de quatro programas:

1. O programa editor - EDI

2. O preprocessador aerodinâmico - DRAG

3. O programa preprocessador - PRE

4. O simulador - TEM

5. O programa avaliador - EVA

A relação entre esses programas citados acima pode ser verificada através da Figura A.1.

Nesta versão, TEM 2.5, foram incluidos o programa conversor (FIX), que altera os arquivos da versão 2.0 para que possam ser utilizados na versão 2.5 , e o o arquivo TEM.CRC que contém uma tabela com coeficientes de resistência de curva. 
1.Geração do grupo de arquivos

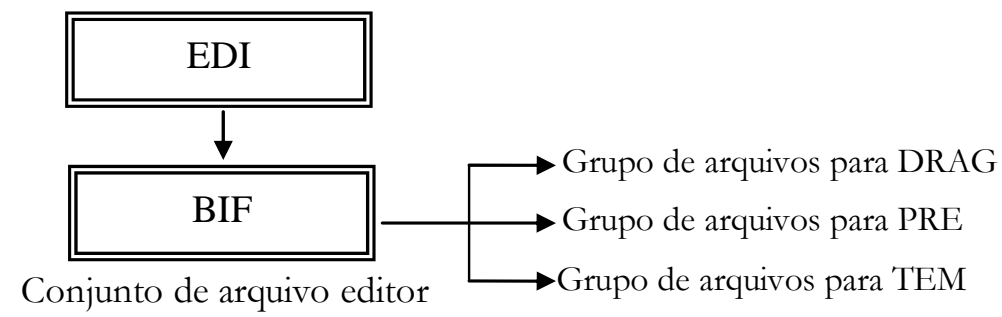

\section{Preprocessamento}

Grupo de arquivos para DRAG

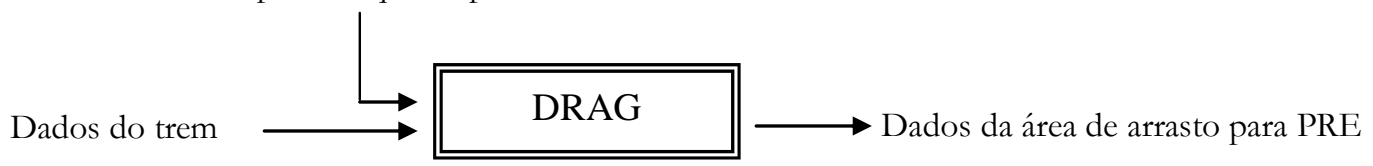

Preprocessador aerodinâmico

Grupo de arquivos para PRE

Dados do trem

e da área de

arrasto

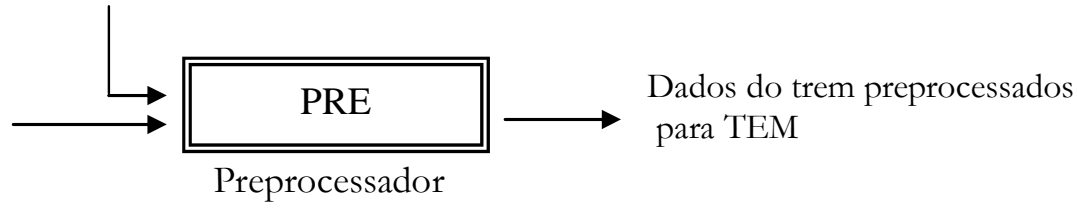

\section{Simulação}

Grupo de arquivos para TEM

Dados do trem

e da via

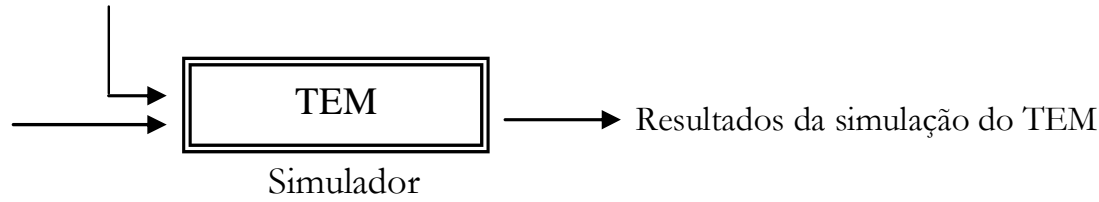

preprocessados

Simulador

\section{Visualização dos resultados}

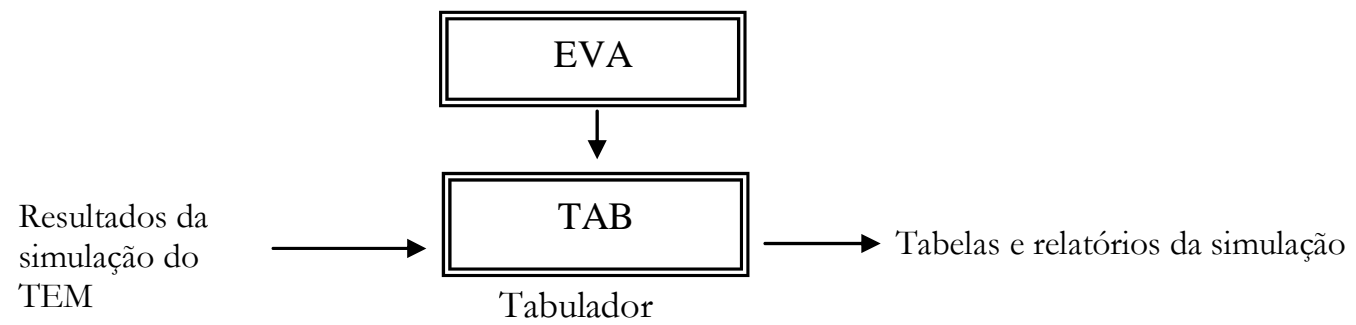

Figura A.1: Relação entre os programas do Train Energy Model 


\section{A.3.1 O programa editor (EDI)}

O programa editor (EDI) inclui três outros arquivos de programas:

1. O conjunto de arquivo editor - BIF

2. O programa construtor - FEB

3. O processador de utilidades para linha/trem - TUP

\section{A.3.1.1 O conjunto de arquivo editor (BIF)}

O conjunto de arquivo editor (BIF) permite ao usuário instalar os arquivos requeridos para rodar o preprocessador aerodinâmico (DRAG), o programa preprocessador (PRE) e o programa simulador (TEM). Para isto utilizam-se as seguintes funções:

Função 1: Editar o grupo de arquivo DRAG;

Função 2: Editar o grupo de arquivo PRE;

Função 3: Editar o grupo de arquivo TEM.

Através da função 1 é gerado o arquivo GOAIR.BAT. Este arquivo contém um sistema de comandos que copiam as informações para o AIR.BIF (arquivo de inicialização do grupo DRAG) e rodam DRAG.

A função 2 possui como arquivo de saída o GOPRE.BAT. O GOPRE.BAT contém um sistema de comandos que copiam as informações para o PRE.BIF (arquivos de inicalização do grupo PRE) e rodam PRE.

O arquivo de saída gerado pela função 3 é o GOTEM.BAT. Este arquivo contém um sistema de comandos que copiam as informações para o TEM.BIF (arquivo de inicialização do grupo TEM) e rodam TEM. 
A.3.1.2 O arquivo editor e programa construtor (FEB)

Os programas DRAG, PRE, e TEM requerem informações de vários arquivos de entrada numa determinada ordem para desenvolver suas tarefas. O propósito do arquivo editor e programa construtor (FEB) é fornecer uma conveniente forma para os usuários construirem estes arquivos de entrada para rodar as simulações.

O FEB possui 9 funções:

Função 1: Construir novo arquivo da composição (.CON);

Função 2 : Construir novo arquivo de paramêtros dos veículos (.PAR);

Função 3: Construir novo arquivo de via (. TRK);

Função 4: Construir um novo arquivo com a configuração aerodinâmica (. WND)

Função 5: Construir um novo arquivo de paradas (.STP);

Função 6: Construir ou editar o arquivo de parâmetro ATA (.ATA);

Função 7: Construir ou editar o arquivo de inicialiazação (.INI);

Função 8: Construir um novo arquivo de comando (.CMD);

Função 9: Construir um novo arquivo de carga intermodal (.CGO).

A.3.1.3 O processador de utilidades para linha/trem (TUP)

O propósito primário do TUP (processador de utilidades para linha/trem) é permitir ao usuário construir o arquivo da via em formato apropriado para o TEM. Além disto possui outras ferramentas elencadas a seguir:

Função 1: Reverte o arquivo de via existente.

Função 2: Calcula a rampa a partir das elevações.

Função 3: Calcula as elevações a partir da rampa. 
Função 4: Adiciona constantes no arquivo de via

Função 5: Gera arquivo da relação do esforço trator e a velocidade

\section{A.3.2 O preprocessador aerodinâmico (DRAG)}

O preprocessador aerodinâmico (DRAG) gera áreas de arrasto (de vento) para cada veículo e armazena os valores no arquivo de dados (.DRG).

Quando o grupo DRAG é rodado, o arquivo. DRG é gerado e usado pelo programa preprocessador PRE para gerar o arquivo de dados do trem (.DAT). O programa DRAG requer informações dos arquivos .CON e .PAR, se houver carregamento intermodal será necessário o arquivo .CGO.

\section{A.3.3 O programa preprocessador (PRE)}

O programa PRE coloca o arquivo descritivo da composição e dados da área de arrasto de forma que possa ser usado diretamente pelo TEM. O objetivo do preprocessador é reduzir o tempo requerido para a simulação, já que todas as informações necessárias para o simulador (TEM) são computadas primeiramente pelo programa PRE.

O programa preprocessador requer sete arquivos de entrada para ser rodado:

.DRG - Este arquivo contém a área de arrasto para cada veículo gerada pelo programa DRAG;

.CON - Este arquivo especifica a composição;

.PAR - Este arquivo especifica os parâmetros dos veículos que são diferentes para cada tipo;

.THL - Este arquivo contém a descrição do esforço trator . São diferentes para cada tipo de locomotiva.

.DYN - Este arquivo contém a descrição do esforço de frenagem dinâmica. São diferentes para cada tipo de locomotiva. 
TEM.AIR - Este arquivo contém os parâmetros para o sistema automático de frenagem aerodinâmica.

PRE.BIF - Este arquivo obtem informações do GOPRE.BAT para cada arquivo .CON a ser processado.

Após ser rodado o programa preprocessador PRE gera alguns arquivos de saída:

.DAT - Este arquivo contém todos os dados do trem preprocessados, incluindo as velocidades de equilíbrio.

.FYI - Este arquivo contém informações sobre trens processados com locomotivas auxiliares (belpers) na operação, caso exista.

.TES - Este arquivo contém uma tabela de velocidade de equilíbrio para o trem com helpers sincronizadas em operação, caso exista.

.DES - Este arquivo contém uma tabela de ajustes dinâmicos requeridos para o trem manter a velocidade de equilíbrio em declive com o uso de belpers sincronizadas em operação, caso exista.

.AER - Este arquivo contém uma tabela de redução da pressão dos freios requerida para o trem manter a velocidade de equilíbrio para várias porcentagens de rampa descendente.

.FY2 - Este arquivo contém informações do trem com as helpers ociosas.

.TE2 - Este arquivo contém uma tabela de velocidades de equilíbrio com as helpers ociosas.

.DE2 - Este arquivo contém uma tabela de equilíbrio do esforço dinâmico com as belpers ociosas.

\section{A.3.4 O programa simulador (TEM)}

O programa simulador (TEM) requer que alguns arquivos estejam armazenados no computador. Há oito arquivos de entrada necessários para rodar o programa TEM: 
.DAT - Este arquivo contém os dados do trem pré-processados.

.TRK - Arquivo que contém dados da via, como elevação, porcentagem de rampa, grau de curva e posições específicas na via.

. WND - Este arquivo contém a direção e velocidade do vento, como também a temperatura e pressão ambiente para vários pontos ao longo da via.

.ATA - Este arquivo contém valores de parâmetros de ajustes requeridos pelo algoritmo automático de desempenho do trem (ATA) para controlar o trem durante a simulação.

.INI - Este arquivo contém informações para início da simulação incluindo a posição inicial do trem na via.

. STP- Este arquivo contém a posição e tempos de parada na via.

TEM. BIF - Este é o arquivo de iniciação do TEM. Este arquivo obtém informações do GOTEM. BAT para cada simulação a ser rodada.

A partir destes arquivos as simulações são executadas. Após as simulações do TEM dois arquivos de saída são gerados:

.RPT - Este arquivo contém o relatório reduzido da simulação, incluindo o consumo de combustível e energia.

.OUT - Este arquivo contém todos os dados da simulação para cada intervalo de tempo.

\section{A.3.5 O programa avaliador (EVA)}

O programa avaliador (EVA) é composto de dois outros arquivos de programas:

1. O programa tabulador (TAB)

2. O programa de visualização 
O programa tabulador (TAB) permite aos usuários elaborar várias tabelas a partir do arquivo .RPT. As tabelas (arquivos de saída) que podem ser geradas pelo TAB são:

1. Resumo sobre a composição

2. Resumo sobre a operação

3. Consumo de combustível por pontos de tração

4. Porcentagem do uso de pontos de tração

5. Consumo de combustível por intervalos de velocidade

6. Consumo de combustível para cada tipo de resistência

7. Trabalho de cada força

8. Tração do motor operando para baixar velocidades

O programa de visualização permite gerar através do arquivo de dados de saída (.OUT) vários gráficos relacionando variáveis como tempo, velocidade, aceleração, elevação, tração entre outras.

\section{A.4 Executando uma simulação}

O primeiro passo para gerar as simulações é criar os arquivos necessários para rodar os programas. Estes arquivos são gerados através das funções do arquivo editor e programa construtor (FEB).

Após a elaboração dos arquivos da composição e da via é necessário indicar o ponto de início e término da via em que a simulação deve ser efetuada. O ponto de inicio da simulação do trem está indicado nos parâmetros de configuração (.INI). E os pontos de parada na via bem como o tempo de espera está indicado no arquivo (.STP) construído. Todos os outros arquivos necessários para gerar simulações através do TEM 2.5 poder ser visualizados na Figura A.2. 
Com os arquivos criados, deve-se usar o procedimento para gerar as simulações:

- Executar a função 1 do programa BIF que faz parte do programa editor (EDI) e especificar o nome do arquivo da composição (.CON). Desta forma cria-se o arquivo GOAIR.BAT;

- Rodar o programa DRAG denominado “GOAIR”, criando os arquivos DRG;

- Executar a função 2 do programa BIF que faz parte do programa editor (EDI) e especificar o nome do arquivo da composição (.CON). Desta forma cria-se o arquivo GOPRE.BAT;

- Rodar o programa PRE através do arquivo denominado "GOPRE". Desta forma serão criados os arquivos .DAT, bem como os arquivos .FYI, .FY2, .TES, .TE2, .DES, .DE2 e .AER;

- Executar a função 2 do programa BIF e restaurar o grupo PRE. Isto deve ser efetuado sempre depois que o GOPRE for rodado;

- Executar a função 3 do programa BIF que faz parte do programa editor (EDI) e especificar o nome do arquivo da composição (.CON). Desta forma cria-se o arquivo GOTEM.BAT;

- Rodar o programa TEM através do arquivo denominado "GOTEM". Desta forma serão criados os arquivos .RPT e .OUT.

- Executar o programa TAB do programa avaliador (EVA) e indicar o nome do arquivo (.CON). Desta forma tabelas serão geradas com os dados do arquivo RPT. 
1.Geração do grupo de arquivos

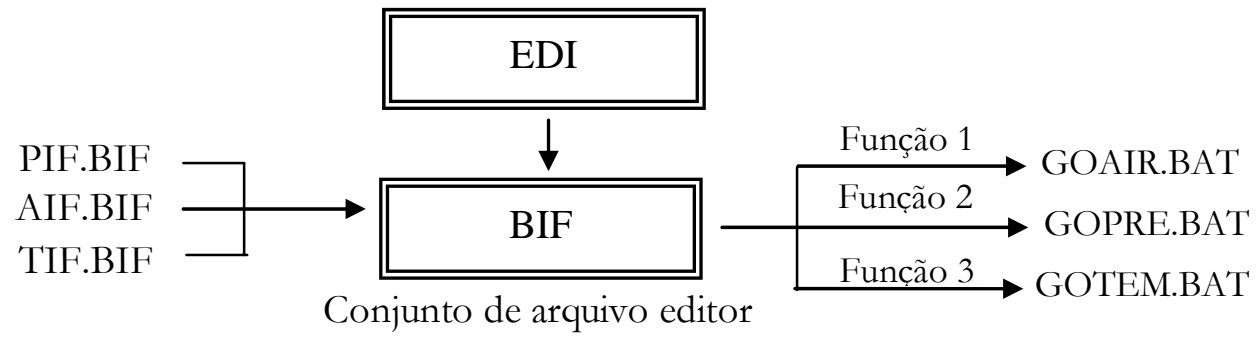

\section{Preprocessamento}

GOAIR.BAT $\longrightarrow$.AIF $\longrightarrow$ AIR.BIF

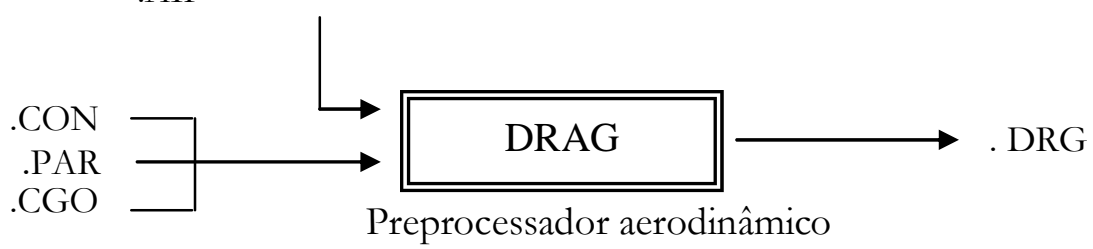

GOPRE.BAT $\longrightarrow$.PIF $\longrightarrow$ PRE.BIF
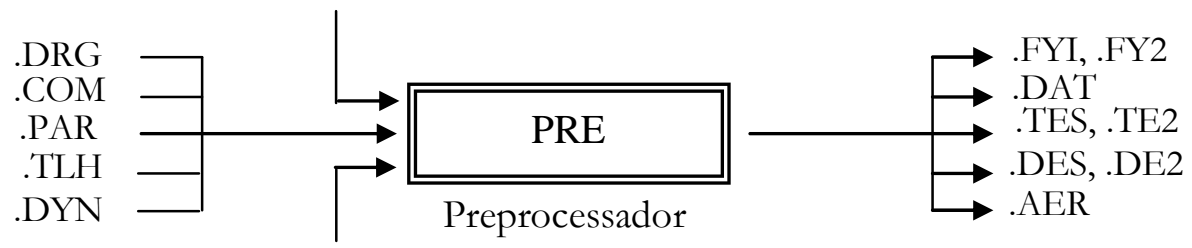

TEM.AIR

\section{Simulação}

GOTEM.BAT $\longrightarrow$.TIF $\longrightarrow$ TEM.BIF

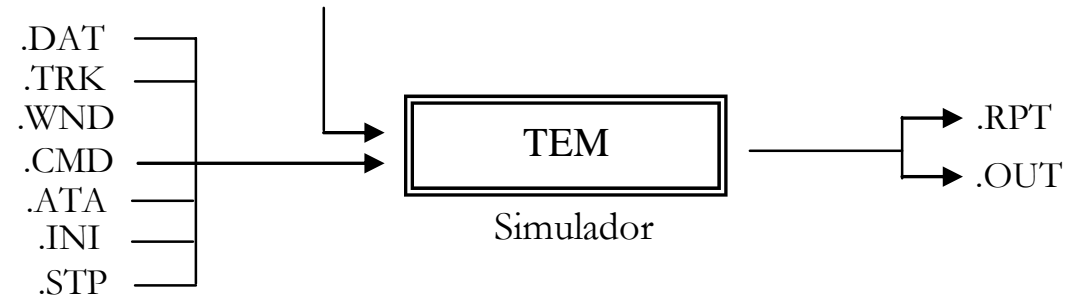

4. Visualização dos resultados

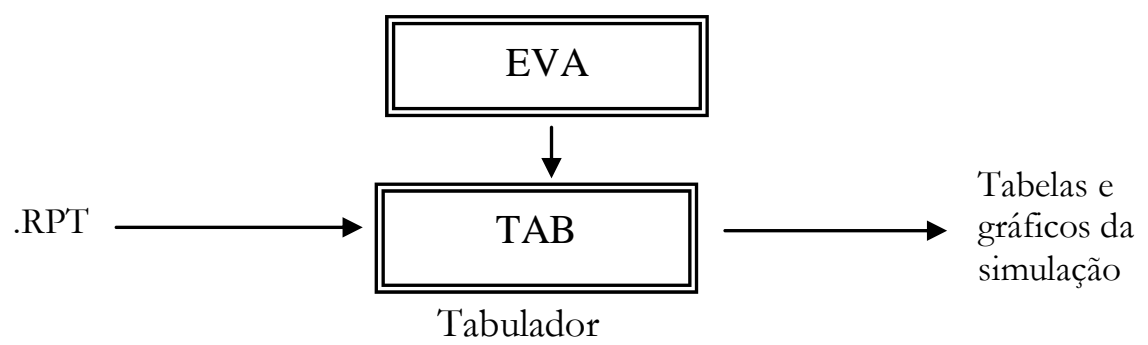

Figura A.2: Arquivos necessários para simular o movimento do trem usado o TEM 2.5 
O Simulador de desempenho do trem utilizado, o TEM 2.5, é um modelo complexo que possui uma interface pouco amigável. Porém, os dados resultantes do modelo permitem inúmeras análises sobre a movimentação das composições ferroviárias. 


\section{B MODELO DE LOCOMOÇÃO DE VEÍCULOS FERROVIÁRIOS}

Uma composição ferroviária de carga é composta de locomotivas e vagões. As locomotivas possuem um sistema para gerar, ou no caso das locomotivas elétricas, converter a energia que é transmitida para as rodas motrizes. A interação entre estas rodas e a linha férrea permite o movimento das locomotivas, que arrastam os vagões.

O movimento dos veículos ferroviários depende tanto da resultante das forças que atuam sobre o veículo como também das regras operacionais existentes, tais como sistema de controle e sinalização. Muitas vezes a velocidade máxima é limitada em função da via permanente, da sua conservação, do estado das obras de arte entre outros. Por questões de segurança os trens reduzem sua velocidade ao passarem em perímetro urbano ou em trechos em estados de conservação precário.

A previsão do desempenho do veículo ferroviário é muito importante para o planejamento e controle da operacional. A seguir inicia-se a descrição detalhada do modelo de locomoção ferroviária implementado pelo simulador da Association of american railroads, o TEM 2.5. As equações descritas, a nomenclatura e o sistema de unidades são provenientes do Train energy model version 2.0 user's manual (version 2.5 supplement) [ AAR, 1993].

\section{B.1 Equações do movimento}

O movimento ou desempenho das composições ferroviárias refere-se às forças que atuam sobre os veículos, que podem ser traduzidas em equações. Através destas equações de movimento é possivel determinar a posição, velocidade e aceleração do trem em um dado momento. Contudo a modelagem do movimento não é tão simples devido à muitas forças que agem sobre os veículos não se comportarem de forma linear.

De uma forma geral o movimento dos veículos, inclusive os veículos ferroviários, é previsto por modelos analíticos de desempenho baseados na segunda lei de Newton, em que as resultantes das forças aplicadas é igual a massa (W) multiplicada pela aceleração (A), como pode ser observado na eq. (1.1).

$$
F_{r}=W \cdot A
$$


Desta forma o veículo acelera quando as resultantes das forças forem positivas e desaceleram caso seja negativa. No TEM 2.5 a aceleração é determinada através da força máxima de aderência (fornecida pela locomotiva e o sistema de frenagem), resistências (incluindo o efeito do vento) e a força de rampa [AAR, 1993]:

$$
A=g \cdot(S-G-R \operatorname{sgn}(V)) / W
$$

em que: A: aceleração do trem $(\mathrm{mph} / \mathrm{s})$

g: aceleração da gravidade $(21,8 \mathrm{mph} / \mathrm{s})$

S: força total de aderência (lbs)

$\mathrm{G}$ : força total de rampa (lbs)

R: resistência total do trem (lbs)

$\mathrm{V}$ : velocidade do trem (mph)

W: peso total do trem (lbs)

A variável "sgn" representa o sinal da função. Por exemplo, $\operatorname{sgn}(V)=V /|V|$, se $V \neq 0$ e $\operatorname{sgn}(V)=0$, então $V=0$.

O valor total da resistência do trem, da força de rampa e da força de aderência será encontrada através do somatório do valor destas forças que atuam em cada veículo. Desta forma temos:

$$
\begin{aligned}
& S=\sum_{k=1}^{k=N} S_{k} \\
& G=\sum_{k=1}^{k=N} G_{k} \\
& R=\sum_{k=1}^{k=N} R_{k}
\end{aligned}
$$

em que: $\quad S_{k}$ : força motriz limitada pela aderência atuando no veículo $k$ (lbs)

$\mathrm{G}_{\mathrm{k}}$ : força de rampa atuando no veículo $\mathrm{k}$ (lbs) 
$\mathrm{R}_{\mathrm{k}}$ : resistência atuando no veículo k (lbs)

$\mathrm{N}$ : número do veículo da composição

k: número total de veículos da composição

\section{B.2 Esforço trator em locomotivas diesel-elétricas}

As locomotivas transformam energia em propulsão para colocar e manter a composição em movimento. Nas locomotivas diesel-elétricas a força produzida por um motor a diesel é transferida para as rodas motrizes através de uma transmissão elétrica. $\mathrm{Na}$ Figura B.1 é possível observar os principais componentes deste tipo de locomotiva.

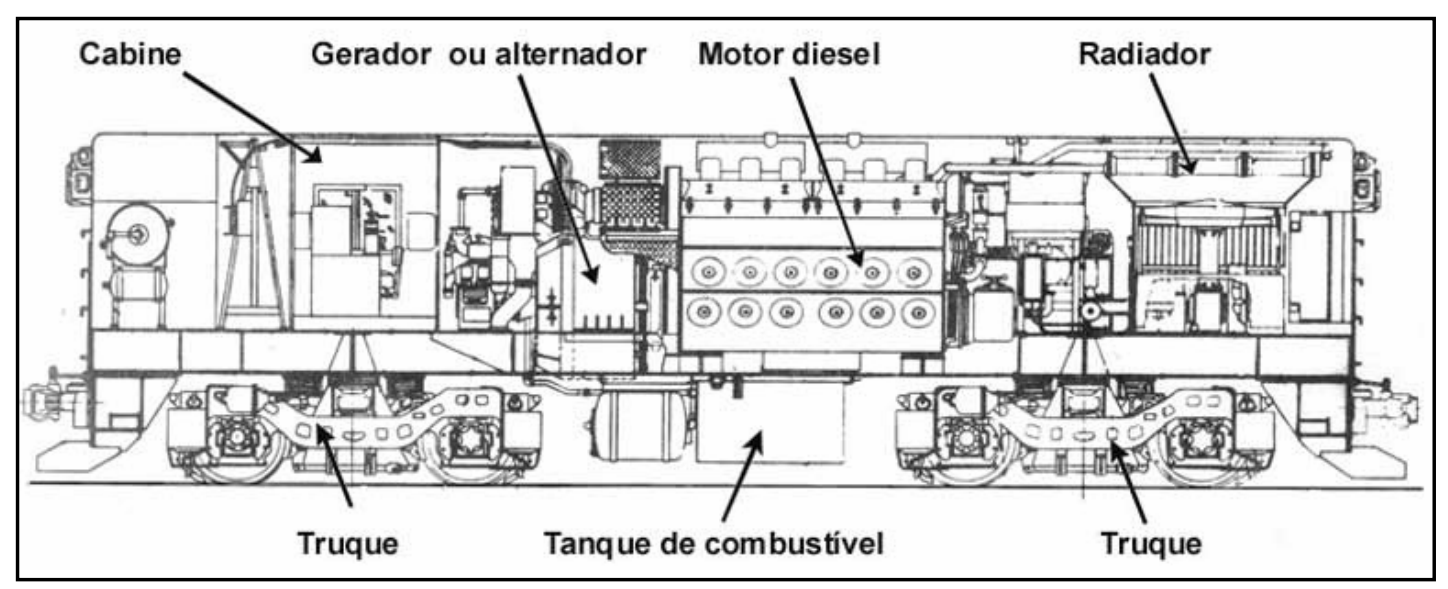

Figura B.1: Componentes de uma locomotiva diesel-elétrica

Esta força de propulsão, também conhecida como força motriz é obtida a partir do conceito de trabalho. A força motriz é diretamento proporcional a potência e inversamente proporcional a velocidade. Segundo Hay [1982] esta função pode ser expressa através da eq. (1.6).

$$
F_{t}=\frac{375 \cdot P \cdot \eta}{V}
$$

em que: $\quad F_{t}$ força motriz (lbs)

P: potência da locomotiva (hp)

$\mathrm{V}$ : velocidade (mph) 
$\eta$ : coeficiente de eficiência da transmissão

Os motores usam reguladores para aplicar a força ao trem. Estes reguladores numa locomotiva diesel-eletrica possuem 10 ajustes ou "pontos". Estes incluem um conjunto para a máquina inativa; um conjunto para quando está ociosa (ponto 0); e oito conjuntos para aumento de injeção de diesel no motor, "marcha 1"(ponto 1) até “marcha 8"( ponto 8).

O máximo esforço trator corresponde a marcha 8. A força pode ser aplicada em degraus, existem oito curvas de esforço trator para locomotivas diesel-elétricas. Para um dado conjunto de reguladores há um esforço trator diretamente proporcional a potência do motor diesel da locomotiva e inversamente proporcional a velocidade da locomotiva. A Figura B.2 mostra as curvas de esforço trator para a locomotiva Dash 9.

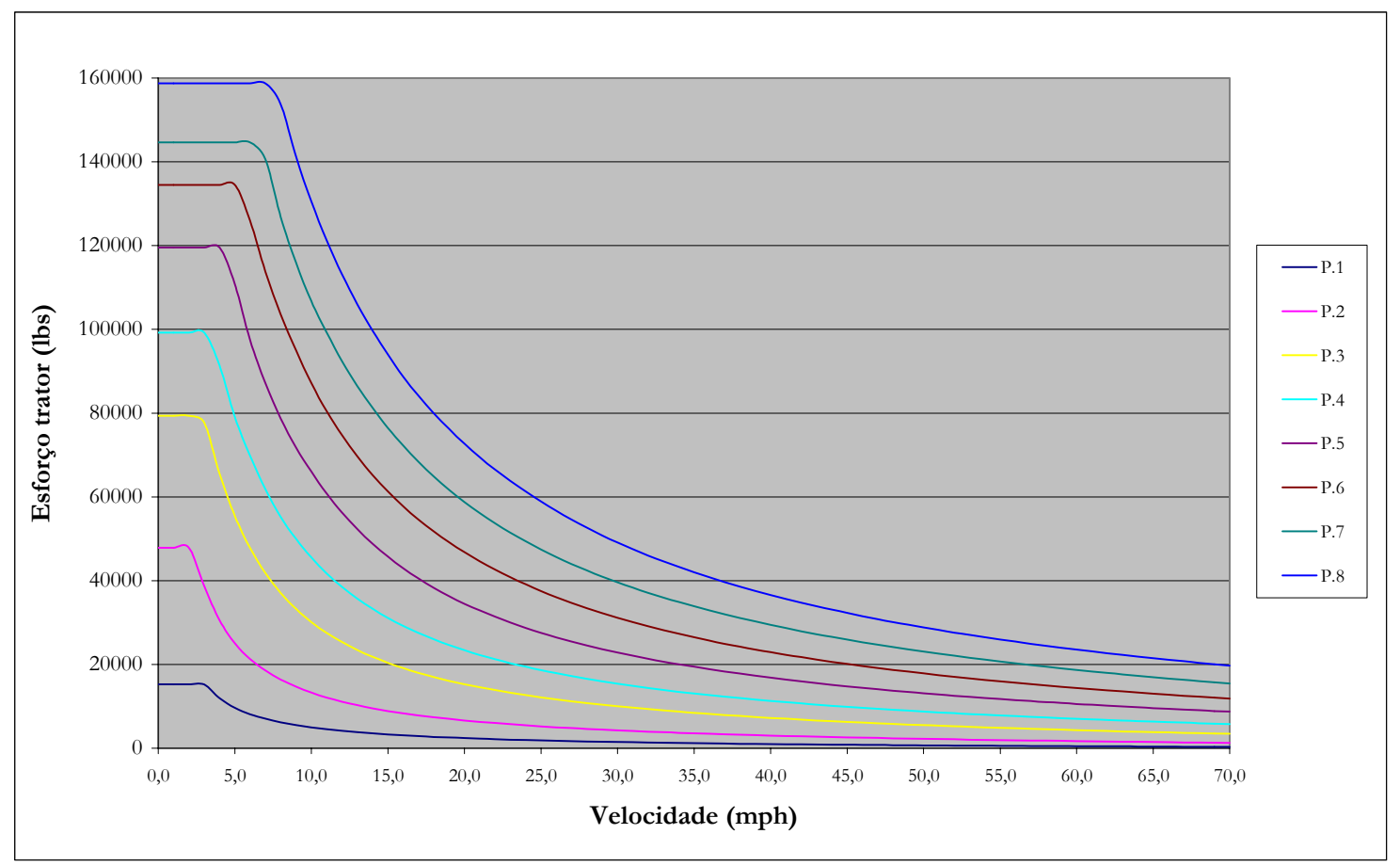

Figura B. 2: Curvas de tração da locomotiva diesel-elétrica Dash 9

\section{B.2.1 Limites de operação de motores elétricos}

Como se pode observar na Figura B.2 a força motriz ou esforço trator varia em função da velocidade segundo uma hipérbole, pois a potência da locomotiva é constante.

O funcionamento dos motores de tração limita a velocidade máxima e mínima em que a locomotiva pode operar sem que ocorram danos. O valor mínimo da velocidade é 
inversamente proporcional à corrente elétrica do motor, que deve ser operado nestas velocidades apenas no início do movimento. O valor máximo da velocidade é limitado pela voltagem máxima. A Figura B.3 apresenta esquematicamente os limites para operação dos motores elétricos de tração.



Figura B. 3: Limites de velocidade do motor elétrico

\section{B.2.2 Limites de tração por aderência}

Para que as composições ferroviárias consigam mover-se é necessário que exista atrito entre a roda e o trilho. Caso contrário, a roda patina e a locomotiva não consegue sair do lugar. Assim:

$$
\left|S_{k}\right| \leq W_{k} \cdot a_{k}(V)
$$

em que: $\quad S_{k}$ : força motriz limitada pela aderência atuando no veículo $k$ (lbs)

$\mathrm{W}_{\mathrm{k}}$ : peso total do veículo $\mathrm{k}(\mathrm{lbs})$

$a_{\mathrm{k}}$ : coeficiente de aderência do veículo $\mathrm{k}$

k: número total de veículos da composição

A ação da força limite de aderência no veículo é determinada pela comparação entre o esforço trator (esforço dinâmico) e a ação da força de frenagem aerodinâmica no veículo com o produto total do peso e o coeficiente de aderência do veículo, que varia com a velocidade do trem:

$$
S_{k}=E_{k}-B_{k} \operatorname{sgn}(V)
$$


em que: $\quad E_{k}$ : esforço trator ou esforço dinâmico atuando no veículo $k$ (lbs)

$\mathrm{B}_{\mathrm{k}}$ : resistência aerodinâmica atuando no veículo $\mathrm{k}(\mathrm{lbs})$

$\mathrm{V}$ : velocidade do trem (mph)

Portanto, a aderência limita a força tratora máxima que pode ser aplicada nas rodas, principalmente quando a locomotiva está iniciando o movimento ou está operando a baixa velocidade. Este coeficiente pode ser determinado pela eq.(1.9).

$$
a_{k}(V)=a_{0 k}-\Delta a\left(1-e^{-V / 10}\right)
$$

em que: $\quad a_{\mathrm{k}}$ : coeficiente de adesão para o veículo $\mathrm{k}$

$\mathrm{a}_{0 \mathrm{k}}$ : máximo coeficiente de aderência $($ velicidade $=0)$ para o veículo $\mathrm{k}$

$\Delta$ a: variação total no coeficiente de aderência $(0,05)$

K: número total de veículos da composição

O coeficiente de aderência máximo varia com o tipo de locomotiva. Para veículos não tratores o coeficiente de aderência máximo adotado deve ser igual a 0,235.

\section{B.3 Resistência ao movimento}

Quando um veículo está em movimento, existem forças que atuam no sentido contrário à força que propulsora ao movimento. O conjunto dessas forças é chamado de resistência.

A resistência ao movimento pode ser dividida em cinco componentes: resistência dos mancais, resistência de rolamento, resistência aerodinâmica, resistência de rampa e resistência de curva.

No modelo físico implementado no simulador o termo resistência é utilizado como forças que retardam o movimento do veículo. Assim no caso da resistência de rampa, será considerada uma categoria de força, distinta das resistências, já que pode estar a favor do movimento do veículo. A resistência total é dada pela eq. (1.10). 


$$
R_{T}=R_{B k}+R_{R k}+R_{A k}+G_{k}+R_{C k}
$$

em que: $\quad \mathrm{R}_{\mathrm{Bk}}$ : resistência de carregamento agindo no veículo $\mathrm{k}$ (lbs)

$\mathrm{R}_{\mathrm{Rk}}$ : resistência de rolamento no veículo $\mathrm{k}$ (lbs)

$\mathrm{R}_{\mathrm{Ak}}$ : resistência aerodinâmica atuando no veículo k (lbs)

$\mathrm{G}_{\mathrm{k}}$ : força total de rampa no veículo k (lbs)

$\mathrm{R}_{\mathrm{Ck}}$ : resistência de curva atuando no veículo k (lbs)

\section{B.3.1 Resistência dos mancais}

A resistência dos mancais é encontrada pelo produto do número de eixos do veículo e o coeficiente de resistência nos mancais (lbs/eixo). Este coeficiente depende de alguns fatores como temperatura ambiente e carregamento do veículo. Assim:

$$
R_{B K}=n_{k} \cdot C_{B K}
$$

em que: $\quad R_{B k}$ : resistência de carregamento agindo no veículo $k$ (lbs)

$\mathrm{n}_{\mathrm{k}}$ : número de eixos do veículo

$\mathrm{C}_{\mathrm{Bk}}$ : coeficiente de resistência nos mancais

k: número de veículos na composição

O coeficiente $C_{B k}$ é encontrado utilizando-se a eq. (1.12).

$$
C_{B k}=Q_{k} W_{k}^{P_{k}}
$$

em que: $\quad \mathrm{W}_{\mathrm{k}}$ : peso total do veículo em tons

$\mathrm{P}_{\mathrm{k}}$ : expoente empirico para o veículo $\mathrm{k}$

$\mathrm{Q}_{\mathrm{k}}:$ multiplicador empirico para o veículo $\mathrm{k}$

Sendo o expoente e o multiplicador baseado nas eq. (1.13) e (1.14) e a Tabela B.1: 


$$
\begin{aligned}
& P_{k}=b_{1}\left(i_{B k}\right)+b_{2}\left(i_{B k}\right) \cdot T+b_{3}\left(i_{B k}\right) \cdot T^{2} \\
& Q_{k}=b_{4}\left(i_{B k}\right)+b_{5}\left(i_{B k}\right) \cdot T+b_{6}\left(i_{B k}\right) \cdot T^{2}
\end{aligned}
$$

em que: T: temperatura ambiente em graus Fahrenheit

$\mathrm{b}_{1}\left(\mathrm{i}_{\mathrm{Bk}}\right), \mathrm{b}_{2}\left(\mathrm{i}_{\mathrm{Bk}}\right), \mathrm{b}_{3}\left(\mathrm{i}_{\mathrm{Bk}}\right):$ coeficientes dos expoentes empíricos para o veículo $\mathrm{k}$

$\mathrm{b}_{4}\left(\mathrm{i}_{\mathrm{Bk}}\right), \mathrm{b}_{5}\left(\mathrm{i}_{\mathrm{Bk}}\right), \mathrm{b}_{6}\left(\mathrm{i}_{\mathrm{Bk}}\right):$ coeficientes dos multiplicadores empíricos para o veículo $\mathrm{k}$ $\mathrm{i}_{\mathrm{Bk}}$ : índice do tipo de mancal

Tabela B.1: Valor do coeficiente b

\begin{tabular}{|l|c|c|l|l|l|l|l|}
\hline $\mathbf{i}_{\mathbf{B}}$ & mancal & $\mathbf{b}_{\mathbf{1}}$ & \multicolumn{1}{|c|}{$\mathbf{b}_{\mathbf{2}}$} & \multicolumn{1}{|c|}{$\mathbf{b}_{\mathbf{3}}$} & $\mathbf{b}_{\mathbf{4}}$ & $\mathbf{b}_{\mathbf{5}}$ & $\mathbf{b}_{\mathbf{6}}$ \\
\hline $\mathbf{1}$ & gasto "T" & 0.137 & 0.00282 & -0.0000275 & 8.70 & -0.1120 & 0.001000 \\
\hline $\mathbf{2}$ & novo "T" & 0.280 & -0.00343 & 0.0000169 & 4.47 & 0.0208 & 0.000893 \\
\hline $\mathbf{3}$ & gasto "B" & 0.106 & 0.00518 & -0.0000595 & 10.90 & -0.2290 & 0.002420 \\
\hline $\mathbf{4}$ & novo "B" & 0.291 & -0.00207 & 0.0000267 & 4.55 & 0.0271 & -0.000452 \\
\hline
\end{tabular}

\section{B.3.2 Resistência de rolamento}

A resistência de rolamento é o produto do peso do veículo, em tons, e o coeficiente de resistência de rolamento em lbs/ton como observado na eq. (1.15).

$$
R_{R k}=0.0005 \cdot W_{k} \cdot C_{R k}
$$

em que: $\quad \mathrm{R}_{\mathrm{Rk}}$ : resistência de rolamento no veículo $\mathrm{k}$ (lbs)

$$
\begin{aligned}
& \mathrm{W}_{\mathrm{k}} \text { : peso total do veículo } \mathrm{k}(\mathrm{lbs}) \\
& \mathrm{C}_{\mathrm{RK}} \text { : coeficiente da resistência de rolamento para o veículo } \mathrm{k} \text { em lbs/ton }
\end{aligned}
$$

Sendo o coeficiente de resistência de rolamento encontrado a partir da formulação e condições das eq.(1.16) e (1.17).

$$
\begin{gathered}
C_{R k}=\varepsilon\left(i_{T k}\right)-\left[\varepsilon\left(i_{T k}\right)-\lambda\left(i_{T k}\right)\right] \cdot\left[\frac{W_{k}-\tau_{k}}{\gamma_{k}-\tau_{k}}\right], \mathrm{W}_{\mathrm{k}}<\gamma_{\mathrm{k}} \\
C_{R k}=\lambda\left(i_{T k}\right), \mathrm{W}_{\mathrm{k}} \geq \gamma_{\mathrm{k}}
\end{gathered}
$$

em que: $\quad \gamma_{\mathrm{k}}$ : carga bruta para o veículo $\mathrm{k}$ (lbs) 
$\tau_{\mathrm{k}}$ : tara do veículo $\mathrm{k}(\mathrm{lbs})$

$\varepsilon\left(\mathrm{i}_{\mathrm{Tk}}\right)$ : coeficiente de resistência ao rolamento do veículo vazio (lbs/ton)

$\lambda\left(\mathrm{i}_{\mathrm{Tk}}\right):$ coeficiente de resistência ao rolamento do veículo carregado (lbs/ton)

$\mathrm{i}_{\mathrm{Tk}}$ é o tipo do truque do veículo $\mathrm{k}$.

Os coeficientes de resistência ao rolamento do veículo vazio e carregado, como pode ser observado na Tabela B.2:

Tabela B.2: Valor dos coeficientes $\varepsilon$ e $\lambda$

\begin{tabular}{|c|c|c|c|}
\hline $\mathbf{i}_{\mathbf{T}}$ & tipo do truque & $\begin{array}{c}\boldsymbol{\varepsilon} \\
\text { (lbs/ton) }\end{array}$ & $\begin{array}{c}\boldsymbol{\lambda} \\
\text { (lbs/ton) }\end{array}$ \\
\hline 1 & 3-peças gasto & 2.25 & 2.13 \\
\hline 2 & 3-peças novo & 2.25 & 1.57 \\
\hline 3 & radial & 1.48 & 1.43 \\
\hline 4 & estrutura-reforçada & 1.48 & 1.35 \\
\hline 5 & prêmio 2 eixos & 1.47 & 1.02 \\
\hline 6 & eixo simples & 4.25 & 1.89 \\
\hline
\end{tabular}

\section{B.3.3 Resistência aerodinâmica}

A resistência aerodinâmica é o produto da velocidade ao quadrado (relativa ao vento) do veículo e o coeficiente de resistência aerodinâmico:

$$
R_{A k}=v_{k}^{2} \cdot C_{A k}
$$

em que: $\quad \mathrm{R}_{\mathrm{Ak}}$ : resistência aerodinâmica atuando no veículo $\mathrm{k}$ (lbs)

$\mathrm{V}_{\mathrm{k}}$ : velocidade relativa do vento no veículo $\mathrm{k}(\mathrm{mph})$

$\mathrm{C}_{\mathrm{Ak}}:$ coeficiente de resistência aerodinâmico para o veículo $\mathrm{k}(\mathrm{lbs} / \mathrm{mph} / \mathrm{mph})$

k: número ordinal do veículo na composição

O coeficiente de resistência aerodinâmico é o produto do fator de densidade aéreo, que depende da pressão e temperatura ambiente e da área de arrasto do veículo, que por sua vez depende das características aerodinâmicas do veículo, sua posição e orientação com relação ao vento. 


$$
C_{A k}=0.5 \cdot r(P, T) \cdot A_{k}\left(Y_{k}\right)
$$

Onde:

$$
r(P, T)=0.04114 \cdot \frac{P}{(T+460)}
$$

em que: r: fator de densidade do ar

P: pressão barométrica (polegadas de mercúrio)

T: temperatura ambiente $\left({ }^{\circ} \mathrm{F}\right)$

$\mathrm{Y}_{\mathrm{k}}$ : ângulo de direção do veículo $\mathrm{k}$

$\mathrm{A}_{\mathrm{k}}$ : área de arrasto de veículo $\mathrm{k}\left(\mathrm{ft}^{2}\right)$

O coeficiente $A_{k}$ é em função do ângulo de direção, pois o mesmo veículo pode ter diferentes áreas de arrasto dependendo da posição do mesmo na composição.

\section{B.3.4 Força de Rampa}

Segundo AAR [1993], a força de rampa é o produto do peso do veículo e do grau instantâneo (em porcentagem) sobre o veículo em movimento:

$$
G_{k}=0.01 \cdot W_{k} \cdot \gamma_{k}
$$

em que: $\quad G_{k}$ : força total de rampa do veículo $k$ (lbs)

$\mathrm{W}_{\mathrm{k}}$ : peso total do veículo $\mathrm{k}(\mathrm{lbs})$

$\gamma_{k}$ : grau instantâneo do C.G. do veículo k (\%)

\section{B.3.5 Resistência de curva}

A resistência de curva é o produto do peso do veículo, em tons, e do coeficiente de resistência de curva (lbs/tons) O coeficiente de resistência de curva depende do tipo do truque e varia diretamente com a curva da via. Então:

$$
R_{C k}=W_{k} \cdot C_{C k}\left(i_{T k}, C_{k}\right)
$$


em que : $\quad \mathrm{R}_{\mathrm{Ck}}$ : resistência de curva atuando no veículo $\mathrm{k}$ (lbs)

$\mathrm{W}_{\mathrm{k}}$ : peso total do veículo $\mathrm{k}$ (tons)

$\mathrm{C}_{\mathrm{Ck}}$ : coeficiente de resistência de curva para cada veículo $\mathrm{k}$ (lbs/ton)

$\mathrm{i}_{\mathrm{Tk}}:$ tipo do truque do veículo $\mathrm{k}$

$\mathrm{c}_{\mathrm{k}}$ : curva instântanea entre o C.G. do veículo k e a via (graus)

Dependendo do tipo de truque e da curva instantânea da via, o coeficiente de resistência da curva é reduzido pela lubrificação da via. A partir do tipo de truque selecionado na Tabela B.3 e do grau da curva é encontrado através da Tabela B.4 o valor correspondente do coeficiente de resitência.

Tabela B.3: Valor numérico relativo ao tipo de truque

\begin{tabular}{|c|c|c|c|}
\hline $\mathbf{i}_{\mathbf{T}}$ & tipo do truque & lubrificado & não-lubrificado \\
\hline 1 & 3-peças gasto & 1 & 2 \\
\hline 2 & 3-peças novo & 1 & 2 \\
\hline 3 & radial & 3 & 4 \\
\hline 4 & estrutura-reforçada & 5 & 5 \\
\hline 5 & prêmio 2 eixos & 6 & 6 \\
\hline 6 & eixo simples & 7 & 7 \\
\hline
\end{tabular}

Tabela B.4: Coeficiente de resistência de curva

\begin{tabular}{|c|c|c|c|c|c|c|c|}
\hline $\mathbf{c}^{\mathbf{}} \mathbf{)}$ & $\mathbf{1}$ & $\mathbf{2}$ & $\mathbf{3}$ & $\mathbf{4}$ & $\mathbf{5}$ & $\mathbf{6}$ & $\mathbf{7}$ \\
\hline $\mathbf{0}$ & 0.000 & 0.000 & 0.000 & 0.000 & 0.000 & 0.000 & 0.000 \\
\hline $\mathbf{1}$ & 0.090 & 0.056 & 0.013 & 0.017 & 0.010 & 0.015 & 0.015 \\
\hline $\mathbf{2}$ & 0.731 & 0.339 & 0.018 & 0.020 & 0.055 & 0.120 & 0.055 \\
\hline $\mathbf{3}$ & 1.548 & 0.791 & 0.206 & 0.173 & 0.200 & 0.430 & 0.110 \\
\hline $\mathbf{4}$ & 2.465 & 1.335 & 0.624 & 0.448 & 0.320 & 0.800 & 0.220 \\
\hline $\mathbf{5}$ & 3.325 & 1.907 & 1.020 & 0.747 & 0.470 & 1.130 & 0.365 \\
\hline $\mathbf{6}$ & 4.106 & 2.468 & 1.315 & 1.073 & 0.760 & 1.520 & 0.675 \\
\hline $\mathbf{7}$ & 4.767 & 3.046 & 1.505 & 1.445 & 1.120 & 1.895 & 1.235 \\
\hline $\mathbf{8}$ & 5.816 & 3.664 & 2.016 & 1.824 & 1.555 & 2.375 & 2.135 \\
\hline $\mathbf{9}$ & 6.686 & 4.298 & 2.478 & 2.206 & 1.770 & 2.915 & 5.555 \\
\hline $\mathbf{1 0}$ & 7.557 & 4.933 & 2.926 & 2.588 & 2.410 & 3.560 & 11.625 \\
\hline $\mathbf{1 1}$ & 8.427 & 5.563 & 3.376 & 2.968 & 2.705 & 4.260 & 14.170 \\
\hline $\mathbf{1 2}$ & 9.297 & 6.193 & 3.826 & 3.348 & 3.330 & 5.020 & 16.905 \\
\hline $\mathbf{1 3}$ & 10.167 & 6.823 & 4.276 & 3.728 & 4.050 & 5.865 & 19.425 \\
\hline $\mathbf{1 4}$ & 11.037 & 7.453 & 4.726 & 4.108 & 4.815 & 6.755 & 22.310 \\
\hline $\mathbf{1 5}$ & 11.907 & 8.083 & 5.176 & 4.488 & 5.695 & 7.665 & 27.685 \\
\hline
\end{tabular}


Para o grau de curva não exato os valores da Tabela B.4 podem ser interpolados.

\section{B.4 Frenagem de composições ferroviárias}

\section{B.4.1 Frenagem dinâmica}

O motor usa o freio dinâmico para reduzir a velocidade do trem. Durante a frenagem dinâmica o comando elétrico para os motores de tração são revertidos, assim os motores de tração atuam como geradores, quando acionados sem alimentação elétrica.

Como o esforço trator e a frenagem dinâmica são em geral não lineares, o TEM 2.5 usa valores que são interpolados durante a simulação.

Se o veículo for uma locomotiva dentro do controle de marchas (ponto 1 ao 8), então:

$$
E_{k}=T_{k}\left(n_{T,} V\right)
$$

em que: $\quad \mathrm{E}_{\mathrm{k}}$ : força tratora atuando no veículo $\mathrm{k}(\mathrm{lbs})$

$\mathrm{T}_{\mathrm{k}}$ : esforço trator agindo no veículo $\mathrm{k}$ (lbs)

$\mathrm{n}_{\mathrm{T}}$ : conjunto de pontos de tração, variando de 1 a 8 .

Se o veículo estiver dentro de uma frenagem dinâmica, então:

$$
E_{k}=-D_{k}\left(n_{D}, V\right)
$$

em que: $\quad \mathrm{E}_{\mathrm{k}}$ : força de frenagem dinâmica atuando no veículo $\mathrm{k}$ (lbs)

$\mathrm{D}_{\mathrm{k}}$ : esforço de frenagem dinâmica agindo no veículo $\mathrm{k}$ (lbs)

$\mathrm{n}_{\mathrm{D}}$ : conjunto de pontos de frenagem, variando de 1 a 8.

Esta formulação pode ser verificada através da Figura B.4, que mostra as curvas da força de frenagem para uma locomotiva Dash 9. Diferentemente destes dois casos, se o veículo for um vagão ou uma locomotiva desligada, então:

$$
E_{k}=0
$$




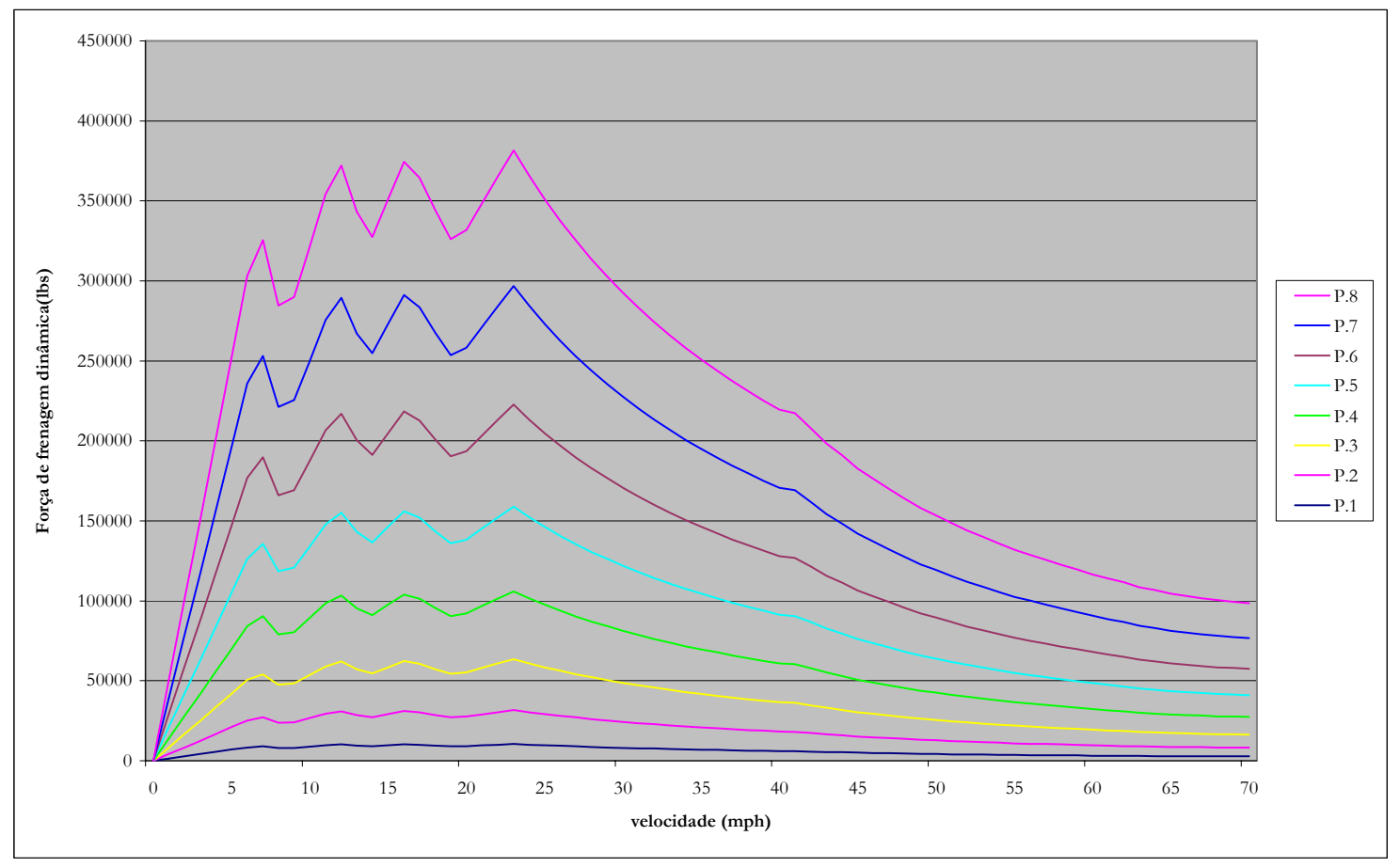

Figura B. 4: Frenagem dinâmica da locomotiva diesel-elétrica Dash 9

\section{B.4.2 Frenagem a ar comprimido}

O motor usa o freio automático aerodinâmico para reduzir a velocidade ou parar o trem, quando o freio dinâmico é ineficiente ou quando o seu uso não é recomendado. No sistema de frenagem mecânica a ar comprimido, cada roda possui uma sapata de freio e cada vagão possui um reservatório de ar comprimido. Cada vagão possui uma válvula para controlar os freios que é acionada por diferença de pressão. A redução da pressão nos tubos de freios causa o acionamento das sapatas e consequentemente um aumento da força retardadora.

\section{B.5 Estimativa da força no engate}

O simulador, o TEM 2.5, faz uma estimativa da força no engate de cada veículo. Este valor é calculado para cada intervalo de simulação seguindo a eq. (1.26) [AAR, 1993].

$$
F_{k}=S_{k}-G_{k}-R_{k} \operatorname{sgn}(V)-W_{k} \cdot(A / g)
$$

em que: $\quad F_{k}$ : força estimada no engate $k(\mathrm{lbs})$

$\mathrm{S}_{\mathrm{k}}$ : força total de aderência no engate $\mathrm{k}(\mathrm{lbs})$ 
$\mathrm{G}_{\mathrm{k}}$ : força total de rampa no engate $\mathrm{k}(\mathrm{lbs})$

$\mathrm{R}_{\mathrm{k}}$ : resistência total do trem no engate $\mathrm{k}(\mathrm{lbs})$

$\mathrm{V}$ : velocidade do trem (mph)

$\mathrm{W}_{\mathrm{k}}$ : peso total do trem no engate $\mathrm{k}(\mathrm{lbs})$

A: aceleração do trem $(\mathrm{mph} / \mathrm{s})$

g: aceleração da gravidade $(21,8 \mathrm{mph} / \mathrm{s})$

k: número total de veículos da composição

Caso a aceleração do trem seja diferente de zero, a força do engate estimada no engate $\mathrm{k}$ será igual a zero.

\section{B.6 Dados da via e do ambiente}

As seguintes informações são usadas para caracterizar a via: posição específica (ft), elevação da via (ft), rampa (porcentagem) e curva da via (graus).

As seguintes informações físicas são usadas para caracterizar o ambiente no simulador: velocidade do vento (mph), direção do vento (graus), temperatura ambiente $\left({ }^{\circ} \mathrm{F}\right)$, e pressão baromêtrica (polegadas de mercúrio). 


\section{RESULTADO DOS CENÁRIOS}

Nessas planilhas são lançados os resultados obtidos para cada cenário.

\section{C.1 Cenário 1}

\begin{tabular}{|c|c|c|c|c|c|c|c|}
\hline \multicolumn{8}{|c|}{ Cenário 1.1} \\
\hline Trecho & Estações & Localização & capacidade & Trecho & Estações & Localização & capacidade \\
\hline \multirow{4}{*}{1} & \multirow{4}{*}{ ZFS_ZJA } & 328.93 & 12 & \multirow{4}{*}{14} & \multirow{4}{*}{ ZRU_ZUC } & 546.18 & 10 \\
\hline & & 336.13 & 12 & & & 550.64 & 10 \\
\hline & & 363.99 & 12 & & & 561.17 & 10 \\
\hline & & 376.49 & 12 & & & 580.5 & 10 \\
\hline \multirow{4}{*}{2} & \multirow{4}{*}{ ZTF_ZED } & 336.13 & 11 & \multirow{4}{*}{15} & \multirow{4}{*}{ ZSP_ZCT } & 550.64 & 9 \\
\hline & & 363.99 & 11 & & & 561.17 & 9 \\
\hline & & 376.49 & 11 & & & 580.5 & 9 \\
\hline & & 392.59 & 11 & & & 597.77 & 9 \\
\hline \multirow{4}{*}{3} & \multirow{4}{*}{ ZUR_ZFN } & 363.99 & 13 & \multirow{4}{*}{16} & \multirow{4}{*}{ ZEH_ZCV } & 561.17 & 9 \\
\hline & & 376.49 & 13 & & & 580.5 & 9 \\
\hline & & 392.59 & 13 & & & 597.77 & 9 \\
\hline & & 410.61 & 13 & & & 611.25 & 9 \\
\hline \multirow{4}{*}{4} & \multirow{4}{*}{ ZJA_ZMR } & 376.49 & 13 & \multirow{4}{*}{17} & \multirow{4}{*}{ ZUC_ZPN } & 580.5 & 9 \\
\hline & & 392.59 & 13 & & & 597.77 & 9 \\
\hline & & 410.61 & 13 & & & 611.25 & 9 \\
\hline & & 421.08 & 13 & & & 621.78 & 9 \\
\hline \multirow{4}{*}{5} & & 392.59 & 14 & & & 597.77 & 14 \\
\hline & & 410.61 & 14 & 10 & ZCT & 611.25 & 14 \\
\hline & LED_LVG & 421.08 & 14 & 18 & $2 \mathrm{CI} / 2 \mathrm{SD}$ & 621.78 & 14 \\
\hline & & 434.93 & 14 & & & 634.71 & 14 \\
\hline & & 410.61 & 13 & & & 611.25 & 10 \\
\hline 6 & 7FN 7VP & 421.08 & 13 & 10 & $7 C V 7 C 7$ & 621.78 & 10 \\
\hline 0 & ZFN_ZVP & 434.93 & 13 & 19 & LCV_LCL & 634.71 & 10 \\
\hline & & 447.35 & 13 & & & 658.9 & 10 \\
\hline & & 421.08 & 7 & & & 621.78 & 10 \\
\hline 7 & & 434.93 & 7 & & & 634.71 & 10 \\
\hline 7 & ZMR_ZKY & 447.35 & 7 & 20 & $Z P N$ & 658.9 & 10 \\
\hline & & 471.83 & 7 & & & 674.76 & 10 \\
\hline & & 434.93 & 7 & & & 634.71 & 10 \\
\hline 8 & ZVG $7 \mathrm{~F} C$ & 447.35 & 7 & 21 & 7SD 7SH & 658.9 & 10 \\
\hline 8 & $\angle V G_{-} \angle E C$ & 471.83 & 7 & 21 & ZSD_LSH & 674.76 & 10 \\
\hline & & 486.35 & 7 & & & 690.58 & 10 \\
\hline & & 447.35 & 7 & & & 658.9 & 11 \\
\hline 0 & $7 \mathrm{VP} 7 \mathrm{~EB}$ & 471.83 & 7 & 22 & $7 C 7$ 7MA & 674.76 & 11 \\
\hline$y$ & ZVP_ZED & 486.35 & 7 & 22 & ZCZ_ZMA & 690.58 & 11 \\
\hline & & 504.09 & 7 & & & 706.84 & 11 \\
\hline & & 471.83 & 7 & & & 674.76 & 10 \\
\hline 10 & $7 \mathrm{KY} 7 \mathrm{M}$ & 486.35 & 7 & 23 &  & 690.58 & 10 \\
\hline 10 & $\angle \mathrm{KY} Z \mathrm{ZMO}$ & 504.09 & 7 & 23 & $\angle Z L$ & 706.84 & 10 \\
\hline & & 531.41 & 7 & & & 718.57 & 10 \\
\hline & & 486.35 & 7 & & & 690.58 & 10 \\
\hline 11 & $7 \mathrm{E} C$ 7RU & 504.09 & 7 & 24 & 7SH 7 7SH & 706.84 & 10 \\
\hline 11 & $\angle \mathrm{EC} \_\angle \mathrm{RU}$ & 531.41 & 7 & 24 & ZSH_ZDL & 718.57 & 10 \\
\hline & & 546.18 & 7 & & & 724.94 & 10 \\
\hline & & 504.09 & 6 & & & 706.84 & 13 \\
\hline 12 & ZEB ZSP & 531.41 & 6 & 25 & ZMA ZTO & 718.57 & 13 \\
\hline 12 & ZEB_ZSP & 546.18 & 6 & 25 & ZMA_Z1U & 724.94 & 13 \\
\hline & & 550.64 & 6 & & & 742.65 & 13 \\
\hline & & 531.41 & 14 & & & 718.57 & 13 \\
\hline 13 & $7 \mathrm{MO} 7 \mathrm{FH}$ & 546.18 & 14 & 26 & 771 & 724.94 & 13 \\
\hline & & 550.64 & 14 & 20 & ZZL_ZAK & 742.65 & 13 \\
\hline & & 561.17 & 14 & & & 749.91 & 13 \\
\hline
\end{tabular}




\begin{tabular}{|c|c|c|c|c|c|c|c|}
\hline \multicolumn{8}{|c|}{ Cenário 1.2} \\
\hline Trecho & Estações & Localização & capacidade & Trecho & Estações & Localização & capacidade \\
\hline \multirow{4}{*}{1} & \multirow{4}{*}{ ZFS_ZJA } & 328.93 & 13 & \multirow{4}{*}{14} & \multirow{4}{*}{ ZRU_ZUC } & 546.18 & 15 \\
\hline & & 336.13 & 13 & & & 550.64 & 15 \\
\hline & & 363.99 & 13 & & & 561.17 & 15 \\
\hline & & 376.49 & 13 & & & 580.5 & 15 \\
\hline \multirow{4}{*}{2} & \multirow{4}{*}{ ZTF_ZED } & 336.13 & 12 & \multirow{4}{*}{15} & \multirow{4}{*}{ ZSP_ZCT } & 550.64 & 14 \\
\hline & & 363.99 & 12 & & & 561.17 & 14 \\
\hline & & 376.49 & 12 & & & 580.5 & 14 \\
\hline & & 392.59 & 12 & & & 597.77 & 14 \\
\hline \multirow{4}{*}{3} & \multirow{4}{*}{ ZUR_ZFN } & 363.99 & 13 & \multirow{4}{*}{16} & \multirow{4}{*}{ ZEH_ZCV } & 561.17 & 13 \\
\hline & & 376.49 & 13 & & & 580.5 & 13 \\
\hline & & 392.59 & 13 & & & 597.77 & 13 \\
\hline & & 410.61 & 13 & & & 611.25 & 13 \\
\hline \multirow{4}{*}{4} & \multirow{4}{*}{ ZJA_ZMR } & 376.49 & 14 & \multirow{4}{*}{17} & \multirow{4}{*}{ ZUC_ZPN } & 580.5 & 13 \\
\hline & & 392.59 & 14 & & & 597.77 & 13 \\
\hline & & 410.61 & 14 & & & 611.25 & 13 \\
\hline & & 421.08 & 14 & & & 621.78 & 13 \\
\hline \multirow{4}{*}{5} & & 392.59 & 14 & & & 597.77 & 14 \\
\hline & 7ED $7 V$ & 410.61 & 14 & 18 & ZCT ZSD & 611.25 & 14 \\
\hline & $2 \mathrm{ED}+2 \mathrm{~V}$ & 421.08 & 14 & 10 & 2 CI_ZSD & 621.78 & 14 \\
\hline & & 434.93 & 14 & & & 634.71 & 14 \\
\hline & & 410.61 & 17 & & & 611.25 & 12 \\
\hline 6 & ZFN $7 \mathrm{VP}$ & 421.08 & 17 & 10 & $7 C \mathrm{~V} 7 C 7$ & 621.78 & 12 \\
\hline 0 & $2 \Gamma+2$ & 434.93 & 17 & 19 & $2 C v_{2} Z C Z$ & 634.71 & 12 \\
\hline & & 447.35 & 17 & & & 658.9 & 12 \\
\hline & & 421.08 & 11 & & & 621.78 & 13 \\
\hline 7 & ZMR ZKY & 434.93 & 11 & 20 & ZPN ZTO & 634.71 & 13 \\
\hline & & 447.35 & 11 & & $21102+2$ & 658.9 & 13 \\
\hline & & 471.83 & 11 & & & 674.76 & 13 \\
\hline & & 434.93 & 11 & & & 634.71 & 13 \\
\hline 8 & $7 \mathrm{VG}$ ZFE & 447.35 & 11 & 21 & $7 \mathrm{SD} 7 \mathrm{SH}$ & 658.9 & 13 \\
\hline 0 & $2 V U_{-} Z L$ & 471.83 & 11 & 21 & ZOH_ZOH & 674.76 & 13 \\
\hline & & 486.35 & 11 & & & 690.58 & 13 \\
\hline & & 447.35 & 11 & & & 658.9 & 13 \\
\hline 0 & 7VP $7 \mathrm{FB}$ & 471.83 & 11 & 22 & $7 C 7$ 7MA & 674.76 & 13 \\
\hline (3) & $2 \sqrt{18}-2 \mathrm{ED}$ & 486.35 & 11 & 22 & $2 C 2 \_Z 1 V A$ & 690.58 & 13 \\
\hline & & 504.09 & 11 & & & 706.84 & 13 \\
\hline & & 471.83 & 10 & & & 674.76 & 15 \\
\hline 10 & ZKY ZMO & 486.35 & 10 & 23 & ZTO ZZI & 690.58 & 15 \\
\hline & & 504.09 & 10 & & प1Q_ZLL & 706.84 & 15 \\
\hline & & 531.41 & 10 & & & 718.57 & 15 \\
\hline & & 486.35 & 10 & & & 690.58 & 13 \\
\hline 11 & $7 \mathrm{FC}$ 7RU & 504.09 & 10 & 24 & 7SH 7D7 & 706.84 & 13 \\
\hline 11 & ZЕL_ZNU & 531.41 & 10 & 24 & ZSH_ZDL & 718.57 & 13 \\
\hline & & 546.18 & 10 & & & 724.94 & 13 \\
\hline & & 504.09 & 10 & & & 706.84 & 15 \\
\hline 12 & ZEB ZSP & 531.41 & 10 & 25 & ZMA ZTO & 718.57 & 15 \\
\hline & & 546.18 & 10 & & & 724.94 & 15 \\
\hline & & 550.64 & 10 & & & 742.65 & 15 \\
\hline & & 531.41 & 14 & & & 718.57 & 14 \\
\hline 13 & $7 M O 7 F H$ & 546.18 & 14 & $26+2>$ & $77 \mathrm{I} 7 \mathrm{AR}$ & 724.94 & 14 \\
\hline 10 & EVIU_- & 550.64 & 14 & 20 & 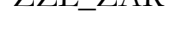 & 742.65 & 14 \\
\hline & & 561.17 & 14 & & & 749.91 & 14 \\
\hline
\end{tabular}




\section{C.2 Cenário 2}

\begin{tabular}{|c|c|c|c|c|c|c|c|}
\hline \multicolumn{8}{|c|}{ Cenário 2.1} \\
\hline Trecho & Estações & Localização & capacidade & Trecho & Estações & Localização & capacidade \\
\hline \multirow{4}{*}{1} & \multirow{4}{*}{ ZFS_ZJA } & 328.93 & 13 & \multirow{4}{*}{14} & \multirow{4}{*}{ ZRU_ZUC } & 546.18 & 11 \\
\hline & & 336.13 & 13 & & & 550.64 & 11 \\
\hline & & 363.99 & 13 & & & 561.17 & 11 \\
\hline & & 376.49 & 13 & & & 580.5 & 11 \\
\hline \multirow{4}{*}{2} & \multirow{4}{*}{ ZTF_ZED } & 336.13 & 13 & \multirow{4}{*}{15} & \multirow{4}{*}{ ZSP_ZCT } & 550.64 & 10 \\
\hline & & 363.99 & 13 & & & 561.17 & 10 \\
\hline & & 376.49 & 13 & & & 580.5 & 10 \\
\hline & & 392.59 & 13 & & & 597.77 & 10 \\
\hline \multirow{4}{*}{3} & \multirow{4}{*}{ ZUR_ZFN } & 363.99 & 15 & \multirow{4}{*}{16} & \multirow{4}{*}{ ZEH_ZCV } & 561.17 & 10 \\
\hline & & 376.49 & 15 & & & 580.5 & 10 \\
\hline & & 392.59 & 15 & & & 597.77 & 10 \\
\hline & & 410.61 & 15 & & & 611.25 & 10 \\
\hline \multirow{4}{*}{4} & \multirow{4}{*}{ ZJA_ZMR } & 376.49 & 14 & \multirow{4}{*}{17} & \multirow{4}{*}{ ZUC_ZPN } & 580.5 & 9 \\
\hline & & 392.59 & 14 & & & 597.77 & 9 \\
\hline & & 410.61 & 14 & & & 611.25 & 9 \\
\hline & & 421.08 & 14 & & & 621.78 & 9 \\
\hline \multirow{4}{*}{5} & & 392.59 & 16 & & & 597.77 & 15 \\
\hline & $7 \mathrm{FD} 7 \mathrm{~V}$ & 410.61 & 16 & 18 & 7CT 7SD & 611.25 & 15 \\
\hline & LED_ZV & 421.08 & 16 & 10 & 24 & 621.78 & 15 \\
\hline & & 434.93 & 16 & & & 634.71 & 15 \\
\hline & & 410.61 & 14 & & & 611.25 & 11 \\
\hline 6 & ZFN ZVP & 421.08 & 14 & 19 & ZCV ZCZ & 621.78 & 11 \\
\hline 0 & 211 & 434.93 & 14 & 19 & $\angle C V_{-} Z C Z$ & 634.71 & 11 \\
\hline & & 447.35 & 14 & & & 658.9 & 11 \\
\hline & & 421.08 & 8 & & & 621.78 & 11 \\
\hline 7 & $7 \mathrm{MR} \quad 7 \mathrm{KY}$ & 434.93 & 8 & 20 & 7PN 7TO & 634.71 & 11 \\
\hline 1 & LMR_ZN & 447.35 & 8 & 20 & ZPN_Z1Q & 658.9 & 11 \\
\hline & & 471.83 & 8 & & & 674.76 & 11 \\
\hline & & 434.93 & 8 & & & 634.71 & 11 \\
\hline 8 & $7 \mathrm{VG}, 7 \mathrm{E} C$ & 447.35 & 8 & 21 & 7SD 7SH & 658.9 & 11 \\
\hline 0 & 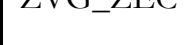 & 471.83 & 8 & 21 & ZOD_ZOII & 674.76 & 11 \\
\hline & & 486.35 & 8 & & & 690.58 & 11 \\
\hline & & 447.35 & 8 & & & 658.9 & 12 \\
\hline 9 & ZVP ZEB & 471.83 & 8 & 22 & $\mathrm{ZCZ} \mathrm{ZMA}$ & 674.76 & 12 \\
\hline & & 486.35 & 8 & & & 690.58 & 12 \\
\hline & & 504.09 & 8 & & & 706.84 & 12 \\
\hline & & 471.83 & 7 & & & 674.76 & 11 \\
\hline 10 & ZKKY ZMO & 486.35 & 7 & 23 & ZTO ZZI & 690.58 & 11 \\
\hline & & 504.09 & 7 & & Z1Q_ZZL & 706.84 & 11 \\
\hline & & 531.41 & 7 & & & 718.57 & 11 \\
\hline & & 486.35 & 7 & & & 690.58 & 11 \\
\hline 11 & 7Е厂 7RU & 504.09 & 7 & 24 & 7SH 707 & 706.84 & 11 \\
\hline 11 & ZLE_ZNO & 531.41 & 7 & 24 & ZOH_ZWL & 718.57 & 11 \\
\hline & & 546.18 & 7 & & & 724.94 & 11 \\
\hline & & 504.09 & 7 & & & 706.84 & 14 \\
\hline 12 & ZEB ZSP & 531.41 & 7 & 25 & ZMA ZTO & 718.57 & 14 \\
\hline & & 546.18 & 7 & & & 724.94 & 14 \\
\hline & & 550.64 & 7 & & & 742.65 & 14 \\
\hline & & 531.41 & 16 & & & 718.57 & 14 \\
\hline & $7 \mathrm{MO} 7 \mathrm{FH}$ & 546.18 & 16 & & $77 \mathrm{I} \quad 7 \mathrm{AR}$ & 724.94 & 14 \\
\hline 13 & ZMO_ZEH & 550.64 & 16 & 20 & ZZL_ZAR & 742.65 & 14 \\
\hline & & 561.17 & 16 & & & 749.91 & 14 \\
\hline
\end{tabular}




\begin{tabular}{|c|c|c|c|c|c|c|c|}
\hline \multicolumn{8}{|c|}{ Cenário 2.2} \\
\hline Trecho & Estações & \begin{tabular}{|l} 
Localização \\
\end{tabular} & capacidade & Trecho & Estações & Localização & capacidade \\
\hline \multirow{4}{*}{1} & \multirow{4}{*}{ ZFS_ZJA } & 328.93 & 11 & \multirow{4}{*}{14} & \multirow{4}{*}{ ZRU_ZUC } & 546.18 & 9 \\
\hline & & 336.13 & 11 & & & 550.64 & 9 \\
\hline & & 363.99 & 11 & & & 561.17 & 9 \\
\hline & & 376.49 & 11 & & & 580.5 & 9 \\
\hline \multirow{4}{*}{2} & \multirow{4}{*}{ ZTF_ZED } & 336.13 & 10 & \multirow{4}{*}{15} & \multirow{4}{*}{ ZSP_ZCT } & 550.64 & 9 \\
\hline & & 363.99 & 10 & & & 561.17 & 9 \\
\hline & & 376.49 & 10 & & & 580.5 & 9 \\
\hline & & 392.59 & 10 & & & 597.77 & 9 \\
\hline \multirow{4}{*}{3} & \multirow{4}{*}{ ZUR_ZFN } & 363.99 & 12 & \multirow{4}{*}{16} & \multirow{4}{*}{ ZEH_ZCV } & 561.17 & 8 \\
\hline & & 376.49 & 12 & & & 580.5 & 8 \\
\hline & & 392.59 & 12 & & & 597.77 & 8 \\
\hline & & 410.61 & 12 & & & 611.25 & 8 \\
\hline \multirow{4}{*}{4} & \multirow{4}{*}{ ZJA_ZMR } & 376.49 & 12 & \multirow{4}{*}{17} & \multirow{4}{*}{ ZUC_ZPN } & 580.5 & 8 \\
\hline & & 392.59 & 12 & & & 597.77 & 8 \\
\hline & & 410.61 & 12 & & & 611.25 & 8 \\
\hline & & 421.08 & 12 & & & 621.78 & 8 \\
\hline \multirow{4}{*}{5} & & 392.59 & 13 & & & 597.77 & 12 \\
\hline & $7 F D$ 7VG & 410.61 & 13 & 18 & ZCT 7SD & 611.25 & 12 \\
\hline & $\angle E D+Z V G$ & 421.08 & 13 & 10 & ZU_LDD & 621.78 & 12 \\
\hline & & 434.93 & 13 & & & 634.71 & 12 \\
\hline & & 410.61 & 12 & & & 611.25 & 9 \\
\hline( & משני נדים & 421.08 & 12 & 10 & 7Cע & 621.78 & 9 \\
\hline 0 & ZFIN_ZVI & 434.93 & 12 & 19 & $2 C v_{2} Z C Z$ & 634.71 & 9 \\
\hline & & 447.35 & 12 & & & 658.9 & 9 \\
\hline & & 421.08 & 7 & & & 621.78 & 9 \\
\hline 7 & $7 \mathrm{MR}$ ZKY & 434.93 & 7 & 20 & ZPN 7TO & 634.71 & 9 \\
\hline & ZMK_ZNY & 447.35 & 7 & & Z1N_LIQ & 658.9 & 9 \\
\hline & & 471.83 & 7 & & & 674.76 & 9 \\
\hline & & 434.93 & 7 & & & 634.71 & 9 \\
\hline 8 & ZVG 7ER & 447.35 & 7 & 21 & $7 \mathrm{SD} 7 \mathrm{SH}$ & 658.9 & 9 \\
\hline 0 & $2 V U_{-} Z E L$ & 471.83 & 7 & 21 & 2SD_ZSП & 674.76 & 9 \\
\hline & & 486.35 & 7 & & & 690.58 & 9 \\
\hline & & 447.35 & 7 & & & 658.9 & 10 \\
\hline 0 & 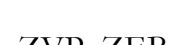 & 471.83 & 7 & 20 &  & 674.76 & 10 \\
\hline 9 & ZVP_ZEB & 486.35 & 7 & 22 & ZCZ_ZMA & 690.58 & 10 \\
\hline & & 504.09 & 7 & & & 706.84 & 10 \\
\hline & & 471.83 & 6 & & & 674.76 & 10 \\
\hline 10 & $7 \mathrm{KY} 7 \mathrm{M}$ & 486.35 & 6 & 23 & 7TO 77I & 690.58 & 10 \\
\hline & $2 \Lambda 1-2 M U$ & 504.09 & 6 & & Z1Q_ZLL & 706.84 & 10 \\
\hline & & 531.41 & 6 & & & 718.57 & 10 \\
\hline & & 486.35 & 6 & & & 690.58 & 9 \\
\hline 11 & ZEC $7 \mathrm{RU}$ & 504.09 & 6 & 24 & 7אH & 706.84 & 9 \\
\hline 11 & ZEL_ZNU & 531.41 & 6 & 24 & ZSП_ZDL & 718.57 & 9 \\
\hline & & 546.18 & 6 & & & 724.94 & 9 \\
\hline & & 504.09 & 6 & & & 706.84 & 11 \\
\hline 12 & ZEB ZSP & 531.41 & 6 & 25 & ZMA 7Т & 718.57 & 11 \\
\hline & ZED_ZSP & 546.18 & 6 & & ZMIA_ZIO & 724.94 & 11 \\
\hline & & 550.64 & 6 & & & 742.65 & 11 \\
\hline & & 531.41 & 13 & & & 718.57 & 12 \\
\hline 13 & $7 \mathrm{MO} 7 \mathrm{EH}$ & 546.18 & 13 & 26 & $77 \mathrm{I} \quad 7 \mathrm{AR}$ & 724.94 & 12 \\
\hline 13 & ZMU_ZГП & 550.64 & 13 & 20 & ZZL_ZAR & 742.65 & 12 \\
\hline & & 561.17 & 13 & & & 749.91 & 12 \\
\hline
\end{tabular}




\begin{tabular}{|c|c|c|c|c|c|c|c|}
\hline \multicolumn{8}{|c|}{ Cenário 2.3} \\
\hline Trecho & Estações & Localização & capacidade & Trecho & Estações & Localização & capacidade \\
\hline \multirow{4}{*}{1} & \multirow{4}{*}{ ZFS_ZJA } & 328.93 & 9 & \multirow{4}{*}{14} & \multirow{4}{*}{ ZRU_ZUC } & 546.18 & 8 \\
\hline & & 336.13 & 9 & & & 550.64 & 8 \\
\hline & & 363.99 & 9 & & & 561.17 & 8 \\
\hline & & 376.49 & 9 & & & 580.5 & 8 \\
\hline \multirow{4}{*}{2} & \multirow{4}{*}{ ZTF_ZED } & 336.13 & 9 & \multirow{4}{*}{15} & \multirow{4}{*}{ ZSP_ZCT } & 550.64 & 7 \\
\hline & & 363.99 & 9 & & & 561.17 & 7 \\
\hline & & 376.49 & 9 & & & 580.5 & 7 \\
\hline & & 392.59 & 9 & & & 597.77 & 7 \\
\hline \multirow{4}{*}{3} & \multirow{4}{*}{ ZUR_ZFN } & 363.99 & 10 & \multirow{4}{*}{16} & \multirow{4}{*}{ ZEH_ZCV } & 561.17 & 7 \\
\hline & & 376.49 & 10 & & & 580.5 & 7 \\
\hline & & 392.59 & 10 & & & 597.77 & 7 \\
\hline & & 410.61 & 10 & & & 611.25 & 7 \\
\hline \multirow{4}{*}{4} & \multirow{4}{*}{ ZJA_ZMR } & 376.49 & 10 & \multirow{4}{*}{17} & \multirow{4}{*}{ ZUC_ZPN } & 580.5 & 7 \\
\hline & & 392.59 & 10 & & & 597.77 & 7 \\
\hline & & 410.61 & 10 & & & 611.25 & 7 \\
\hline & & 421.08 & 10 & & & 621.78 & 7 \\
\hline \multirow{4}{*}{5} & & 392.59 & 11 & & & 597.77 & 10 \\
\hline & $7 \mathrm{FD} 7 \mathrm{~V}$ & 410.61 & 11 & 18 & 7CT 7SD & 611.25 & 10 \\
\hline & LED_ZVG & 421.08 & 11 & 18 & $2 C 1 \_Z S D$ & 621.78 & 10 \\
\hline & & 434.93 & 11 & & & 634.71 & 10 \\
\hline & & 410.61 & 10 & & & 611.25 & 8 \\
\hline 6 & 7FN ZVP & 421.08 & 10 & 10 & $7 C V \quad 7 C 7$ & 621.78 & 8 \\
\hline 0 & 210 -2Vi & 434.93 & 10 & 19 & $20 v \_\angle C Z$ & 634.71 & 8 \\
\hline & & 447.35 & 10 & & & 658.9 & 8 \\
\hline & & 421.08 & 6 & & & 621.78 & 8 \\
\hline 7 & ZMR ZKY & 434.93 & 6 & 20 & ZPN ZTO & 634.71 & 8 \\
\hline & & 447.35 & 6 & & & 658.9 & 8 \\
\hline & & 471.83 & 6 & & & 674.76 & 8 \\
\hline & & 434.93 & 6 & & & 634.71 & 8 \\
\hline 8 & $7 \mathrm{VG}, 7 \mathrm{EC}$ & 447.35 & 6 & 21 & $7 \mathrm{SD} 7 \mathrm{SH}$ & 658.9 & 8 \\
\hline 0 & ZVG_ZEC & 471.83 & 6 & 21 & ZSD_ZSH & 674.76 & 8 \\
\hline & & 486.35 & 6 & & & 690.58 & 8 \\
\hline & & 447.35 & 6 & & & 658.9 & 8 \\
\hline 0 & 7VP 7FB & 471.83 & 6 & 22 & $7 C 77 \mathrm{MA}$ & 674.76 & 8 \\
\hline () & ZVP_ZEB & 486.35 & 6 & 22 & ZCZ_ZMA & 690.58 & 8 \\
\hline & & 504.09 & 6 & & & 706.84 & 8 \\
\hline & & 471.83 & 6 & & & 674.76 & 8 \\
\hline 10 & $\mathrm{ZKY} 7 \mathrm{MO}$ & 486.35 & 6 & 23 & ZTO ZZI & 690.58 & 8 \\
\hline & & 504.09 & 6 & & & 706.84 & 8 \\
\hline & & 531.41 & 6 & & & 718.57 & 8 \\
\hline & & 486.35 & 6 & & & 690.58 & 8 \\
\hline 11 & ZFC ZRU & 504.09 & 6 & 24 & 7SH $7 \mathrm{DZ}$ & 706.84 & 8 \\
\hline 11 & ZLU_ZNU & 531.41 & 6 & 24 & ZOH_ZDL & 718.57 & 8 \\
\hline & & 546.18 & 6 & & & 724.94 & 8 \\
\hline & & 504.09 & 5 & & & 706.84 & 10 \\
\hline 12 & 7ER 7SP & 531.41 & 5 & 25 & 7MA 7T & 718.57 & 10 \\
\hline 12 & ZEB_ZSP & 546.18 & 5 & 25 & $2 M A+Z 1 U$ & 724.94 & 10 \\
\hline & & 550.64 & 5 & & & 742.65 & 10 \\
\hline & & 531.41 & 11 & & & 718.57 & 10 \\
\hline 13 & $7 \mathrm{MO} 7 \mathrm{FH}$ & 546.18 & 11 & 26 & $77 \mathrm{I} 7 \mathrm{AB}$ & 724.94 & 10 \\
\hline 15 & ZMO_ZЕН & 550.64 & 11 & 20 & ZZL_ZAK & 742.65 & 10 \\
\hline & & 561.17 & 11 & & & 749.91 & 10 \\
\hline
\end{tabular}




\section{C.3 Cenário 3}

\begin{tabular}{|c|c|c|c|c|c|c|c|}
\hline \multicolumn{4}{|c|}{ Cenário 3.1} & \multicolumn{4}{|c|}{ Cenário 3.2} \\
\hline Trecho & Estações & Localização & capacidade & Trecho & Estações & Localização & capacidade \\
\hline \multirow{4}{*}{1} & \multirow{4}{*}{ ZFS_ZFN } & 328.93 & 6 & \multirow{4}{*}{1} & \multirow{4}{*}{ ZFS_ZED } & 328.93 & 9 \\
\hline & & 376.49 & 6 & & & 363.99 & 9 \\
\hline & & 392.59 & 6 & & & 376.49 & 9 \\
\hline & & 410.61 & 6 & & & 392.59 & 9 \\
\hline \multirow{4}{*}{2} & \multirow{4}{*}{ ZJA_ZVG } & 376.49 & 12 & \multirow{4}{*}{2} & \multirow{4}{*}{ ZUR_ZFN } & 363.99 & 13 \\
\hline & & 392.59 & 12 & & & 376.49 & 13 \\
\hline & & 410.61 & 12 & & & 392.59 & 13 \\
\hline & & 434.93 & 12 & & & 410.61 & 13 \\
\hline \multirow{4}{*}{3} & \multirow{4}{*}{ ZED_ZVP } & 392.59 & 12 & \multirow{4}{*}{3} & \multirow{4}{*}{ ZJA_ZMR } & 376.49 & 13 \\
\hline & & 410.61 & 12 & & & 392.59 & 13 \\
\hline & & 434.93 & 12 & & & 410.61 & 13 \\
\hline & & 447.35 & 12 & & & 421.08 & 13 \\
\hline \multirow{4}{*}{4} & \multirow{4}{*}{ ZFN_ZRU } & 410.61 & 1 & \multirow{4}{*}{4} & \multirow{4}{*}{ ZED_ZVP } & 392.59 & 9 \\
\hline & & 434.93 & 1 & & & 410.61 & 9 \\
\hline & & 447.35 & 1 & & & 421.08 & 9 \\
\hline & & 546.18 & 1 & & & 447.35 & 9 \\
\hline & & 434.93 & 2 & & & 410.61 & 4 \\
\hline 5 & $7 \mathrm{VG}$ 7CV & 447.35 & 2 & 5 & ZEN $7 E C$ & 421.08 & 4 \\
\hline$J$ & $2 v u_{2} c \mathrm{v}$ & 546.18 & 2 & $J$ & 215_ZL & 447.35 & 4 \\
\hline & & 611.25 & 2 & & & 486.35 & 4 \\
\hline & & 447.35 & 1 & & & 421.08 & 4 \\
\hline 6 & 7VP $7 \mathrm{PN}$ & 546.18 & 1 & 6 & 7MR $7 \mathrm{MO}$ & 447.35 & 4 \\
\hline 0 & $2 \mathrm{VI}-21 \mathrm{~T}$ & 611.25 & 1 & 0 & 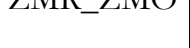 & 486.35 & 4 \\
\hline & & 621.78 & 1 & & & 531.41 & 4 \\
\hline & & 546.18 & 2 & & & 447.35 & 4 \\
\hline 7 & ZRU ZSD & 611.25 & 2 & 7 & ZVP ZSP & 486.35 & 4 \\
\hline 1 & ZNU_ZSD & 621.78 & 2 & 1 & $2 V P \_Z S P$ & 531.41 & 4 \\
\hline & & 634.71 & 2 & & & 550.64 & 4 \\
\hline & & 611.25 & 10 & & & 486.35 & 4 \\
\hline 8 & ZCV ZCZ & 621.78 & 10 & 8 & ZEC ZUC & 531.41 & 4 \\
\hline 0 & $20 v_{-} z \mathrm{CL}$ & 634.71 & 10 & & & 550.64 & 4 \\
\hline & & 658.9 & 10 & & & 580.5 & 4 \\
\hline & & 621.78 & 4 & & & 531.41 & 6 \\
\hline 9 & ZPN ZMA & 634.71 & 4 & 9 & $\mathrm{ZMO}$ ZCV & 550.64 & 6 \\
\hline () & ZPN_ZMA & 658.9 & 4 & (5) & ZMU_LCV & 580.5 & 6 \\
\hline & & 706.84 & 4 & & & 611.25 & 6 \\
\hline & & 634.71 & 5 & & & 550.64 & 6 \\
\hline 10 & 7SD 77I & 658.9 & 5 & 10 & 7SP 7SD & 580.5 & 6 \\
\hline 10 & ZSD_ZLL & 706.84 & 5 & 10 & ZSP_ZSD & 611.25 & 6 \\
\hline & & 718.57 & 5 & & & 634.71 & 6 \\
\hline & & 658.9 & 6 & & & 580.5 & 4 \\
\hline 11 & $7 C 7$ 7DC & 706.84 & 6 & 11 & $\mathrm{ZUC}$ ZSH & 611.25 & 4 \\
\hline & & 718.57 & 6 & & & 634.71 & 4 \\
\hline & & 724.94 & 6 & & & 690.58 & 4 \\
\hline & & 706.84 & 13 & & & 611.25 & 4 \\
\hline 12 & 7МА 7ТО & 718.57 & 13 & 12 & 7CV 77I & 634.71 & 4 \\
\hline 12 &  & 724.94 & 13 & 12 & $20 v_{-2 L L}$ & 690.58 & 4 \\
\hline & & 742.65 & 13 & & & 718.57 & 4 \\
\hline & & 531.41 & 16 & & & 690.58 & 7 \\
\hline 13 & $7 \mathrm{MO} 7 \mathrm{FH}$ & 546.18 & 16 & 14 & 7SH 7TO & 718.57 & 7 \\
\hline $1 J$ & ZN10_ZL11 & 550.64 & 16 & 14 & $2011+210$ & 724.94 & 7 \\
\hline & & 561.17 & 16 & & & 742.65 & 7 \\
\hline
\end{tabular}




\begin{tabular}{|c|c|c|c|c|c|c|c|}
\hline \multicolumn{4}{|c|}{ Cenário 3.3} & \multicolumn{4}{|c|}{ Cenário 3.4} \\
\hline Trecho & Estações & Localização & capacidade & Trecho & Estações & Localização & capacidade \\
\hline \multirow{4}{*}{1} & \multirow{4}{*}{ ZFS_ZMR } & 328.93 & 9 & \multirow{4}{*}{1} & \multirow{4}{*}{ ZFS_ZMR } & 328.93 & 9 \\
\hline & & 363.99 & 9 & & & 363.99 & 9 \\
\hline & & 392.59 & 9 & & & 392.59 & 9 \\
\hline & & 421.08 & 9 & & & 421.08 & 9 \\
\hline \multirow{4}{*}{2} & \multirow{4}{*}{ ZUR_ZVP } & 363.99 & 8 & \multirow{4}{*}{2} & \multirow{4}{*}{ ZUR_ZVP } & 363.99 & 8 \\
\hline & & 392.59 & 8 & & & 392.59 & 8 \\
\hline & & 421.08 & 8 & & & 421.08 & 8 \\
\hline & & 447.35 & 8 & & & 447.35 & 8 \\
\hline \multirow{4}{*}{3} & \multirow{4}{*}{ ZED_ZKY } & 392.59 & 7 & \multirow{4}{*}{3} & \multirow{4}{*}{ ZED_ZKY } & 392.59 & 10 \\
\hline & & 421.08 & 7 & & & 421.08 & 10 \\
\hline & & 447.35 & 7 & & & 447.35 & 10 \\
\hline & & 471.83 & 7 & & & 471.83 & 10 \\
\hline \multirow{4}{*}{4} & \multirow{4}{*}{ ZMR_ZEB } & 421.08 & 5 & \multirow{4}{*}{4} & \multirow{4}{*}{ ZMR_ZEB } & 421.08 & 11 \\
\hline & & 447.35 & 5 & & & 447.35 & 11 \\
\hline & & 471.83 & 5 & & & 471.83 & 11 \\
\hline & & 504.09 & 5 & & & 504.09 & 11 \\
\hline \multirow{4}{*}{5} & \multirow{4}{*}{ ZVP_ZMO } & 447.35 & 5 & & & 447.35 & 10 \\
\hline & & 471.83 & 5 & 5 & ZVP ZMO & 471.83 & 10 \\
\hline & & 504.09 & 5 & & ZVP_ZMO & 504.09 & 10 \\
\hline & & 531.41 & 5 & & & 531.41 & 10 \\
\hline & & 471.83 & 5 & & & 471.83 & 8 \\
\hline & & 504.09 & 5 & & $7 \mathrm{KY} 7 \mathrm{EH}$ & 504.09 & 8 \\
\hline 0 & ZKY_ZEH & 531.41 & 5 & 0 & ZKY_ZEH & 531.41 & 8 \\
\hline & & 561.17 & 5 & & & 561.17 & 8 \\
\hline & & 504.09 & 5 & & & 504.09 & 8 \\
\hline 7 & ZEB ZCT & 531.41 & 5 & 7 & ZEB ZCT & 531.41 & 8 \\
\hline & & 561.17 & 5 & & & 561.17 & 8 \\
\hline & & 597.77 & 5 & & & 597.77 & 8 \\
\hline & & 531.41 & 5 & & & 531.41 & 8 \\
\hline 8 & $7 \mathrm{MO} 7 \mathrm{PN}$ & 561.17 & 5 & 8 & ZMO ZPN & 561.17 & 8 \\
\hline 8 & ZMO_ZPN & 597.77 & 5 & & ZMU_ZPN & 597.77 & 8 \\
\hline & & 621.78 & 5 & & & 621.78 & 8 \\
\hline & & 561.17 & 5 & & & 561.17 & 8 \\
\hline 0 & & 597.77 & 5 & 0 & & 597.77 & 8 \\
\hline 9 & LEH_ZCZ & 621.78 & 5 & 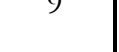 & ZEH_ZCZ & 621.78 & 8 \\
\hline & & 658.9 & 5 & & & 658.9 & 8 \\
\hline & & 597.77 & 6 & & & 597.77 & 8 \\
\hline 10 & ZCT ZSH & 621.78 & 6 & 10 & ZCT ZSH & 621.78 & 8 \\
\hline & & 658.9 & 6 & & & 658.9 & 8 \\
\hline & & 690.58 & 6 & & & 690.58 & 8 \\
\hline & & 621.78 & 6 & & & 621.78 & 8 \\
\hline 11 & ZPN ZZL & 658.9 & 6 & 11 & ZPN ZZL & 658.9 & 8 \\
\hline & & 690.58 & 6 & & & 690.58 & 8 \\
\hline & & 718.57 & 6 & & & 718.57 & 8 \\
\hline & & 658.9 & 7 & & & 658.9 & 8 \\
\hline 12 & ZCZ_ZTO & 690.58 & 7 & 12 & ZCZ ZTO & 690.58 & 8 \\
\hline & & 718.57 & 7 & & & 718.57 & 8 \\
\hline & & 742.65 & 7 & & & 742.65 & 8 \\
\hline
\end{tabular}




\section{C.4 Cenário 4}

\begin{tabular}{|c|c|c|c|c|c|c|c|}
\hline \multicolumn{8}{|c|}{ Cenário 4.1} \\
\hline Trecho & Estações & Localização & capacidade & Trecho & Estações & Localização & capacidade \\
\hline \multirow{4}{*}{1} & \multirow{4}{*}{ ZFS_ZJA } & 328.93 & 12 & \multirow{4}{*}{14} & \multirow{4}{*}{ ZRU_ZUC } & 546.18 & 11 \\
\hline & & 336.13 & 12 & & & 550.64 & 11 \\
\hline & & 363.99 & 12 & & & 561.17 & 11 \\
\hline & & 376.49 & 12 & & & 580.5 & 11 \\
\hline \multirow{4}{*}{2} & \multirow{4}{*}{ ZTF_ZED } & 336.13 & 11 & \multirow{4}{*}{15} & \multirow{4}{*}{ ZSP_ZCT } & 550.64 & 9 \\
\hline & & 363.99 & 11 & & & 561.17 & 9 \\
\hline & & 376.49 & 11 & & & 580.5 & 9 \\
\hline & & 392.59 & 11 & & & 597.77 & 9 \\
\hline \multirow{4}{*}{3} & \multirow{4}{*}{ ZUR_ZFN } & 363.99 & 15 & \multirow{4}{*}{16} & \multirow{4}{*}{ ZEH_ZCV } & 561.17 & 9 \\
\hline & & 376.49 & 15 & & & 580.5 & 9 \\
\hline & & 392.59 & 15 & & & 597.77 & 9 \\
\hline & & 410.61 & 15 & & & 611.25 & 9 \\
\hline \multirow{4}{*}{4} & \multirow{4}{*}{ ZJA_ZMR } & 376.49 & 13 & \multirow{4}{*}{17} & \multirow{4}{*}{ ZUC_ZPN } & 580.5 & 9 \\
\hline & & 392.59 & 13 & & & 597.77 & 9 \\
\hline & & 410.61 & 13 & & & 611.25 & 9 \\
\hline & & 421.08 & 13 & & & 621.78 & 9 \\
\hline \multirow{4}{*}{5} & & 392.59 & 15 & & & 597.77 & 15 \\
\hline & ZFD ZVG & 410.61 & 15 & 18 & ZCT ZSD & 611.25 & 15 \\
\hline & LED_LVG & 421.08 & 15 & 10 & LCI_LSD & 621.78 & 15 \\
\hline & & 434.93 & 15 & & & 634.71 & 15 \\
\hline & & 410.61 & 13 & & & 611.25 & 10 \\
\hline 6 & ZFN ZVP & 421.08 & 13 & 19 & ZCV ZCZ & 621.78 & 10 \\
\hline 0 & $\angle F N \_\angle V P$ & 434.93 & 13 & 19 & $2 C v_{-} \angle C Z$ & 634.71 & 10 \\
\hline & & 447.35 & 13 & & & 658.9 & 10 \\
\hline & & 421.08 & 8 & & & 621.78 & 10 \\
\hline 7 & 7MR ZKY & 434.93 & 8 & 20 & ZPN ZTO & 634.71 & 10 \\
\hline & ZNIN_ZN1 & 447.35 & 8 & 20 & Z1N_Z1Q & 658.9 & 10 \\
\hline & & 471.83 & 8 & & & 674.76 & 10 \\
\hline & & 434.93 & 7 & & & 634.71 & 10 \\
\hline 8 & ZVG ZFC & 447.35 & 7 & 21 & $\mathrm{ZSD} 7 \mathrm{SH}$ & 658.9 & 10 \\
\hline 0 &  & 471.83 & 7 & 21 & ZSD_ZSH & 674.76 & 10 \\
\hline & & 486.35 & 7 & & & 690.58 & 10 \\
\hline & & 447.35 & 7 & & & 658.9 & 11 \\
\hline 9 & ZVP ZEB & 471.83 & 7 & 22 & ZCZ ZMA & 674.76 & 11 \\
\hline & & 486.35 & 7 & & & 690.58 & 11 \\
\hline & & 504.09 & 7 & & & 706.84 & 11 \\
\hline & & 471.83 & 7 & & & 674.76 & 11 \\
\hline 10 & ZKY 7MO & 486.35 & 7 & 23 & 7TO 77L & 690.58 & 11 \\
\hline & & 504.09 & 7 & & & 706.84 & 11 \\
\hline & & 531.41 & 7 & & & 718.57 & 11 \\
\hline & & 486.35 & 7 & & & 690.58 & 11 \\
\hline 11 & ZEC ZRU & 504.09 & 7 & 24 & 7SH 7DZ & 706.84 & 11 \\
\hline & & 531.41 & 7 & & & 718.57 & 11 \\
\hline & & 546.18 & 7 & & & 724.94 & 11 \\
\hline & & 504.09 & 7 & & & 706.84 & 13 \\
\hline 12 & ZFB 7SP & 531.41 & 7 & 25 & 7MA 7TO & 718.57 & 13 \\
\hline 12 & ZEB_ZSP & 546.18 & 7 & 25 & ZIMA_LIU & 724.94 & 13 \\
\hline & & 550.64 & 7 & & & 742.65 & 13 \\
\hline & & 531.41 & 16 & & & 718.57 & 13 \\
\hline 13 & ZMO ZFH & 546.18 & 16 & 26 & 77I 7AR & 724.94 & 13 \\
\hline 13 & 210 & 550.64 & 16 & 20 & 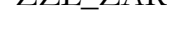 & 742.65 & 13 \\
\hline & & 561.17 & 16 & & & 749.91 & 13 \\
\hline
\end{tabular}




\begin{tabular}{|c|c|c|c|c|c|c|c|}
\hline \multicolumn{8}{|c|}{ Cenário 4.2} \\
\hline Trecho & Estações & Localização & capacidade & Trecho & Estações & Localização & capacidade \\
\hline \multirow{4}{*}{1} & \multirow{4}{*}{ ZFS_ZJA } & 328.93 & 14 & \multirow{4}{*}{14} & \multirow{4}{*}{ ZRU_ZUC } & 546.18 & 15 \\
\hline & & 336.13 & 14 & & & 550.64 & 15 \\
\hline & & 363.99 & 14 & & & 561.17 & 15 \\
\hline & & 376.49 & 14 & & & 580.5 & 15 \\
\hline \multirow{4}{*}{2} & \multirow{4}{*}{ ZTF_ZED } & 336.13 & 13 & \multirow{4}{*}{15} & \multirow{4}{*}{ ZSP_ZCT } & 550.64 & 15 \\
\hline & & 363.99 & 13 & & & 561.17 & 15 \\
\hline & & 376.49 & 13 & & & 580.5 & 15 \\
\hline & & 392.59 & 13 & & & 597.77 & 15 \\
\hline \multirow{4}{*}{3} & \multirow{4}{*}{ ZUR_ZFN } & 363.99 & 14 & \multirow{4}{*}{16} & \multirow{4}{*}{ ZEH_ZCV } & 561.17 & 15 \\
\hline & & 376.49 & 14 & & & 580.5 & 15 \\
\hline & & 392.59 & 14 & & & 597.77 & 15 \\
\hline & & 410.61 & 14 & & & 611.25 & 15 \\
\hline \multirow{4}{*}{4} & \multirow{4}{*}{ ZJA_ZMR } & 376.49 & 14 & \multirow{4}{*}{17} & \multirow{4}{*}{ ZUC_ZPN } & 580.5 & 14 \\
\hline & & 392.59 & 14 & & & 597.77 & 14 \\
\hline & & 410.61 & 14 & & & 611.25 & 14 \\
\hline & & 421.08 & 14 & & & 621.78 & 14 \\
\hline \multirow{4}{*}{5} & & 392.59 & 13 & & & 597.77 & 14 \\
\hline & $7 \mathrm{FD} 7 \mathrm{~V}$ & 410.61 & 13 & 18 & 7CT 7SD & 611.25 & 14 \\
\hline & LED_ZVG & 421.08 & 13 & 18 & $2 C 1 \_Z S D$ & 621.78 & 14 \\
\hline & & 434.93 & 13 & & & 634.71 & 14 \\
\hline & & 410.61 & 18 & & & 611.25 & 13 \\
\hline 6 & 7FN ZVP & 421.08 & 18 & 10 & $7 C V \quad 7 C 7$ & 621.78 & 13 \\
\hline 0 & 210 -2Vi & 434.93 & 18 & 19 & $20 v \_\angle C Z$ & 634.71 & 13 \\
\hline & & 447.35 & 18 & & & 658.9 & 13 \\
\hline & & 421.08 & 12 & & & 621.78 & 14 \\
\hline 7 & 7MR $7 \mathrm{KY}$ & 434.93 & 12 & 20 & ZPN 7TO & 634.71 & 14 \\
\hline & | & 447.35 & 12 & & $21+2+2$ & 658.9 & 14 \\
\hline & & 471.83 & 12 & & & 674.76 & 14 \\
\hline & & 434.93 & 11 & & & 634.71 & 14 \\
\hline 8 & $7 \mathrm{VG}, 7 \mathrm{EC}$ & 447.35 & 11 & 21 & $7 \mathrm{SD} 7 \mathrm{SH}$ & 658.9 & 14 \\
\hline 8 & ZVG_ZEC & 471.83 & 11 & 21 & ZSD_ZSH & 674.76 & 14 \\
\hline & & 486.35 & 11 & & & 690.58 & 14 \\
\hline & & 447.35 & 11 & & & 658.9 & 15 \\
\hline 0 & 7VP 7FB & 471.83 & 11 & 22 & $7 C 77 \mathrm{MA}$ & 674.76 & 15 \\
\hline () & ZVP_ZEB & 486.35 & 11 & 22 & ZCL_ZVIN & 690.58 & 15 \\
\hline & & 504.09 & 11 & & & 706.84 & 15 \\
\hline & & 471.83 & 10 & & & 674.76 & 15 \\
\hline 10 & $\mathrm{ZKY} 7 \mathrm{MO}$ & 486.35 & 10 & 23 & ZTO ZZI & 690.58 & 15 \\
\hline & & 504.09 & 10 & & & 706.84 & 15 \\
\hline & & 531.41 & 10 & & & 718.57 & 15 \\
\hline & & 486.35 & 10 & & & 690.58 & 15 \\
\hline 11 & ZFC ZRU & 504.09 & 10 & 24 & 7SH $7 \mathrm{DZ}$ & 706.84 & 15 \\
\hline 11 & ZLU_ZNU & 531.41 & 10 & 24 & ZOH_ZDL & 718.57 & 15 \\
\hline & & 546.18 & 10 & & & 724.94 & 15 \\
\hline & & 504.09 & 10 & & & 706.84 & 15 \\
\hline 12 & 7ER 7SP & 531.41 & 10 & 25 & 7MA 7T & 718.57 & 15 \\
\hline 12 & ZED_ZSI & 546.18 & 10 & 23 & СNA_L1U & 724.94 & 15 \\
\hline & & 550.64 & 10 & & & 742.65 & 15 \\
\hline & & 531.41 & 15 & & & 718.57 & 15 \\
\hline 13 & $7 \mathrm{MO} 7 \mathrm{FH}$ & 546.18 & 15 & 26 & $77 \mathrm{I} 7 \mathrm{AR}$ & 724.94 & 15 \\
\hline 15 & | ZNV_CZLII & 550.64 & 15 & 20 & ZZL_ZAK & 742.65 & 15 \\
\hline & & 561.17 & 15 & & & 749.91 & 15 \\
\hline
\end{tabular}




\begin{tabular}{|c|c|c|c|c|c|c|c|}
\hline \multicolumn{8}{|c|}{ Cenário 4.3} \\
\hline Trecho & Estações & Localização & capacidade & Trecho & Estações & Localização & capacidade \\
\hline \multirow{4}{*}{1} & \multirow{4}{*}{ ZFS_ZJA } & 328.93 & 14 & \multirow{4}{*}{14} & \multirow{4}{*}{ ZRU_ZUC } & 546.18 & 15 \\
\hline & & 336.13 & 14 & & & 550.64 & 15 \\
\hline & & 363.99 & 14 & & & 561.17 & 15 \\
\hline & & 376.49 & 14 & & & 580.5 & 15 \\
\hline \multirow{4}{*}{2} & \multirow{4}{*}{ ZTF_ZED } & 336.13 & 13 & \multirow{4}{*}{15} & \multirow{4}{*}{ ZSP_ZCT } & 550.64 & 15 \\
\hline & & 363.99 & 13 & & & 561.17 & 15 \\
\hline & & 376.49 & 13 & & & 580.5 & 15 \\
\hline & & 392.59 & 13 & & & 597.77 & 15 \\
\hline \multirow{4}{*}{3} & \multirow{4}{*}{ ZUR_ZFN } & 363.99 & 16 & \multirow{4}{*}{16} & \multirow{4}{*}{ ZEH_ZCV } & 561.17 & 15 \\
\hline & & 376.49 & 16 & & & 580.5 & 15 \\
\hline & & 392.59 & 16 & & & 597.77 & 15 \\
\hline & & 410.61 & 16 & & & 611.25 & 15 \\
\hline \multirow{4}{*}{4} & \multirow{4}{*}{ ZJA_ZMR } & 376.49 & 16 & \multirow{4}{*}{17} & \multirow{4}{*}{ ZUC_ZPN } & 580.5 & 16 \\
\hline & & 392.59 & 16 & & & 597.77 & 16 \\
\hline & & 410.61 & 16 & & & 611.25 & 16 \\
\hline & & 421.08 & 16 & & & 621.78 & 16 \\
\hline \multirow{4}{*}{5} & & 392.59 & 16 & & & 597.77 & 18 \\
\hline & $7 \mathrm{FD} 7 \mathrm{~V}$ & 410.61 & 16 & 18 & 7CT 7SD & 611.25 & 18 \\
\hline & LED_ZVG & 421.08 & 16 & 18 & $2 C 1 \_Z S D$ & 621.78 & 18 \\
\hline & & 434.93 & 16 & & & 634.71 & 18 \\
\hline & & 410.61 & 18 & & & 611.25 & 14 \\
\hline 6 & 7FN ZVP & 421.08 & 18 & 10 & $7 C V \quad 7 C 7$ & 621.78 & 14 \\
\hline 0 & 210 -2Vi & 434.93 & 18 & 19 & $20 v \_\angle C Z$ & 634.71 & 14 \\
\hline & & 447.35 & 18 & & & 658.9 & 14 \\
\hline & & 421.08 & 14 & & & 621.78 & 14 \\
\hline 7 & 7MR $7 \mathrm{KY}$ & 434.93 & 14 & 20 & ZPN 7TO & 634.71 & 14 \\
\hline & | & 447.35 & 14 & & $21+2+2$ & 658.9 & 14 \\
\hline & & 471.83 & 14 & & & 674.76 & 14 \\
\hline & & 434.93 & 14 & & & 634.71 & 14 \\
\hline 8 & $7 \mathrm{VG}, 7 \mathrm{EC}$ & 447.35 & 14 & 21 & $7 \mathrm{SD} 7 \mathrm{SH}$ & 658.9 & 14 \\
\hline 8 & ZVG_ZEC & 471.83 & 14 & 21 & ZSD_ZSH & 674.76 & 14 \\
\hline & & 486.35 & 14 & & & 690.58 & 14 \\
\hline & & 447.35 & 14 & & & 658.9 & 17 \\
\hline 0 & 7VP 7FB & 471.83 & 14 & 22 & $7 C 77 \mathrm{MA}$ & 674.76 & 17 \\
\hline () & ZVP_ZEB & 486.35 & 14 & 22 & ZCL_ZVIN & 690.58 & 17 \\
\hline & & 504.09 & 14 & & & 706.84 & 17 \\
\hline & & 471.83 & 13 & & & 674.76 & 18 \\
\hline 10 & $\mathrm{ZKY} 7 \mathrm{MO}$ & 486.35 & 13 & 23 & ZTO ZZI & 690.58 & 18 \\
\hline & & 504.09 & 13 & & & 706.84 & 18 \\
\hline & & 531.41 & 13 & & & 718.57 & 18 \\
\hline & & 486.35 & 13 & & & 690.58 & 16 \\
\hline 11 & ZFC ZRU & 504.09 & 13 & 24 & 7SH $7 \mathrm{DZ}$ & 706.84 & 16 \\
\hline 11 & ZLU_ZNU & 531.41 & 13 & 24 & ZOH_ZDL & 718.57 & 16 \\
\hline & & 546.18 & 13 & & & 724.94 & 16 \\
\hline & & 504.09 & 13 & & & 706.84 & 16 \\
\hline 12 & 7ER 7SP & 531.41 & 13 & 25 & 7MA 7T & 718.57 & 16 \\
\hline 12 & ZEB_ZSP & 546.18 & 13 & 25 & $2 M A+Z 1 U$ & 724.94 & 16 \\
\hline & & 550.64 & 13 & & & 742.65 & 16 \\
\hline & & 531.41 & 17 & & & 718.57 & 16 \\
\hline 13 & $7 \mathrm{MO} 7 \mathrm{FH}$ & 546.18 & 17 & 26 & $77 \mathrm{I} 7 \mathrm{AB}$ & 724.94 & 16 \\
\hline 15 & | ZNV_CZLII & 550.64 & 17 & 20 & ZZL_ZAK & 742.65 & 16 \\
\hline & & 561.17 & 17 & & & 749.91 & 16 \\
\hline
\end{tabular}




\section{C.5 Cenário 5}

\begin{tabular}{|c|c|c|c|c|c|c|c|}
\hline \multicolumn{8}{|c|}{ Cenário 5.1} \\
\hline Trecho & Estações & \begin{tabular}{|l|} 
Localização \\
\end{tabular} & capacidade & Trecho & Estações & Localização & capacidade \\
\hline \multirow{4}{*}{1} & \multirow{4}{*}{ ZFS_ZJA } & 328.93 & 15 & \multirow{4}{*}{14} & \multirow{4}{*}{ ZRU_ZUC } & 546.18 & 18 \\
\hline & & 336.13 & 15 & & & 550.64 & 18 \\
\hline & & 363.99 & 15 & & & 561.17 & 18 \\
\hline & & 376.49 & & & & 580.5 & 18 \\
\hline \multirow{4}{*}{2} & \multirow{4}{*}{ ZTF_ZED } & 336.13 & 15 & \multirow{4}{*}{15} & \multirow{4}{*}{ ZSP_ZCT } & 550.64 & 17 \\
\hline & & 363.99 & 15 & & & 561.17 & 17 \\
\hline & & 376.49 & 15 & & & 580.5 & 17 \\
\hline & & 392.59 & 15 & & & 597.77 & 17 \\
\hline \multirow{4}{*}{3} & \multirow{4}{*}{ ZUR_ZFN } & 363.99 & 19 & \multirow{4}{*}{16} & \multirow{4}{*}{ ZEH_ZCV } & 561.17 & 17 \\
\hline & & 376.49 & 19 & & & 580.5 & 17 \\
\hline & & 392.59 & 19 & & & 597.77 & 17 \\
\hline & & 410.61 & 19 & & & 611.25 & 17 \\
\hline \multirow{4}{*}{4} & \multirow{4}{*}{ ZJA_ZMR } & 376.49 & 19 & \multirow{4}{*}{17} & \multirow{4}{*}{ ZUC_ZPN } & 580.5 & 19 \\
\hline & & 392.59 & 19 & & & 597.77 & 19 \\
\hline & & 410.61 & 19 & & & 611.25 & 19 \\
\hline & & 421.08 & 19 & & & 621.78 & 19 \\
\hline \multirow{4}{*}{5} & & 392.59 & 19 & & & 597.77 & 20 \\
\hline & $7 \mathrm{FD} 7 \mathrm{VG}$ & 410.61 & 19 & 18 & 7CT 7SD & 611.25 & 20 \\
\hline & | ZED_ZVG & 421.08 & 19 & 10 & ZCI_ZSD & 621.78 & 20 \\
\hline & & 434.93 & 19 & & & 634.71 & 20 \\
\hline & & 410.61 & 21 & & & 611.25 & 16 \\
\hline 6 & ZFN ZVP & 421.08 & 21 & 19 & $\mathrm{ZCV}$ ZCZ & 621.78 & 16 \\
\hline & & 434.93 & 21 & & & 634.71 & 16 \\
\hline & & 447.35 & 21 & & & 658.9 & 16 \\
\hline & & 421.08 & 16 & & & 621.78 & 16 \\
\hline 7 & $7 \mathrm{MR} 7 \mathrm{KY}$ & 434.93 & 16 & 20 & 7PN 7TO & 634.71 & 16 \\
\hline & 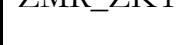 & 447.35 & 16 & & $211 \mathrm{v}-21 \mathrm{Q}$ & 658.9 & 16 \\
\hline & & 471.83 & 16 & & & 674.76 & 16 \\
\hline & & 434.93 & 16 & & & 634.71 & 16 \\
\hline 8 & 7VG 7EC & 447.35 & 16 & 21 & $7 \mathrm{SD} 7 \mathrm{SH}$ & 658.9 & 16 \\
\hline 0 & LVG_ZEC & 471.83 & 16 & 21 & ZSD_ZSH & 674.76 & 16 \\
\hline & & 486.35 & 16 & & & 690.58 & 16 \\
\hline & & 447.35 & 15 & & & 658.9 & 20 \\
\hline 9 & ZVP ZEB & 471.83 & 15 & 22 & $7 \mathrm{CZ} 7 \mathrm{MA}$ & 674.76 & 20 \\
\hline & & 486.35 & 15 & & & 690.58 & 20 \\
\hline & & 504.09 & 15 & & & 706.84 & 20 \\
\hline & & 471.83 & 15 & & & 674.76 & 20 \\
\hline 10 & $7 \mathrm{KY} 7 \mathrm{MO}$ & 486.35 & 15 & 23 & 7TO $77 \mathrm{I}$ & 690.58 & 20 \\
\hline & LNY_ZNG & 504.09 & 15 & & Z1Q_ZZL & 706.84 & 20 \\
\hline & & 531.41 & 15 & & & 718.57 & 20 \\
\hline & & 486.35 & 15 & & & 690.58 & 19 \\
\hline 11 & $75 C_{7 \mathrm{PU}}$ & 504.09 & 15 & $24+2$ & 78U 70 & 706.84 & 19 \\
\hline 11 & ZEU_ZKU & 531.41 & 15 & 24 & ZSH_ZDL & 718.57 & 19 \\
\hline & & 546.18 & 15 & & & 724.94 & 19 \\
\hline & & 504.09 & 14 & & & 706.84 & 18 \\
\hline 12 & ZEB ZSP & 531.41 & 14 & 25 & ZMA ZTO & 718.57 & 18 \\
\hline & & 546.18 & 14 & & & 724.94 & 18 \\
\hline & & 550.64 & 14 & & & 742.65 & 18 \\
\hline & & 531.41 & 20 & & & 718.57 & 18 \\
\hline 13 & 7790 & 546.18 & 20 & 26 & 771840 & 724.94 & 18 \\
\hline $1 J$ & | ZNH_ZLE & 550.64 & 20 & 20 & ZZL_ZAK & 742.65 & 18 \\
\hline & & 561.17 & 20 & & & 749.91 & 18 \\
\hline
\end{tabular}




\section{C.6 Cenário 6}

\begin{tabular}{|c|c|c|c|c|c|c|c|}
\hline \multicolumn{8}{|c|}{ Cenário 6.1} \\
\hline Trecho & Estações & Localização & capacidade & Trecho & Estações & Localização & capacidade \\
\hline \multirow{4}{*}{1} & \multirow{4}{*}{ ZFS_ZJA } & 328.93 & 15 & \multirow{4}{*}{14} & \multirow{4}{*}{ ZRU_ZUC } & 533.92 & 17 \\
\hline & & 344.82 & 15 & & & 550.64 & 17 \\
\hline & & 360.71 & 15 & & & 561.17 & 17 \\
\hline & & 376.49 & 15 & & & 580.5 & 17 \\
\hline \multirow{4}{*}{2} & \multirow{4}{*}{ ZTF_ZED } & 344.82 & 15 & \multirow{4}{*}{15} & \multirow{4}{*}{ ZSP_ZCT } & 550.64 & 17 \\
\hline & & 360.71 & 15 & & & 561.17 & 17 \\
\hline & & 376.49 & 15 & & & 580.5 & 17 \\
\hline & & 392.59 & 15 & & & 597.77 & 17 \\
\hline \multirow{4}{*}{3} & \multirow{4}{*}{ ZUR_ZFN } & 360.71 & 19 & \multirow{4}{*}{16} & \multirow{4}{*}{ ZEH_ZCV } & 561.17 & 17 \\
\hline & & 376.49 & 19 & & & 580.5 & 17 \\
\hline & & 392.59 & 19 & & & 597.77 & 17 \\
\hline & & 410.61 & 19 & & & 611.25 & 17 \\
\hline \multirow{4}{*}{4} & \multirow{4}{*}{ ZJA_ZMR } & 376.49 & 19 & \multirow{4}{*}{17} & \multirow{4}{*}{ ZUC_ZPN } & 580.5 & 19 \\
\hline & & 392.59 & 19 & & & 597.77 & 19 \\
\hline & & 410.61 & 19 & & & 611.25 & 19 \\
\hline & & 421.08 & 19 & & & 621.78 & 19 \\
\hline \multirow{4}{*}{5} & & 392.59 & 19 & & & 597.77 & 20 \\
\hline & ZFD ZVG & 410.61 & 19 & 18 & ZCT ZSD & 611.25 & 20 \\
\hline & LED_LVG & 421.08 & 19 & 10 & $2 \mathrm{Cl}-2 \mathrm{CD}$ & 621.78 & 20 \\
\hline & & 434.93 & 19 & & & 634.71 & 20 \\
\hline & & 410.61 & 21 & & & 611.25 & 16 \\
\hline 6 & ZFN ZVP & 421.08 & 21 & 19 & ZCV ZCZ & 621.78 & 16 \\
\hline 0 & $\angle F N \_\angle V P$ & 434.93 & 21 & 19 & $2 C v_{-} \angle C Z$ & 634.71 & 16 \\
\hline & & 447.35 & 21 & & & 658.9 & 16 \\
\hline & & 421.08 & 16 & & & 621.78 & 16 \\
\hline 7 & ZMR ZKY & 434.93 & 16 & 20 & ZPN ZTO & 634.71 & 16 \\
\hline & ZNIN_ZN1 & 447.35 & 16 & 20 & Z1N_Z1Q & 658.9 & 16 \\
\hline & & 464.84 & 16 & & & 674.76 & 16 \\
\hline & & 434.93 & 16 & & & 634.71 & 16 \\
\hline 8 & ZVG ZFC & 447.35 & 16 & 21 & ZSD $7 \mathrm{SH}$ & 658.9 & 16 \\
\hline 0 & 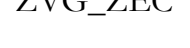 & 464.84 & 16 & 21 & ZSD_ZSH & 674.76 & 16 \\
\hline & & 481.98 & 16 & & & 690.58 & 16 \\
\hline & & 447.35 & 19 & & & 658.9 & 20 \\
\hline 9 & ZVP ZEB & 464.84 & 19 & 22 & $7 C 7$ 7MA & 674.76 & 20 \\
\hline & & 481.98 & 19 & 22 & ZU2_Z11 & 690.58 & 20 \\
\hline & & 499.29 & 19 & & & 706.84 & 20 \\
\hline & & 464.84 & 19 & & & 674.76 & 20 \\
\hline 10 & ZKY 7MO & 481.98 & 19 & 23 & 7TO 77L & 690.58 & 20 \\
\hline & & 499.29 & 19 & & & 706.84 & 20 \\
\hline & & 516.6 & 19 & & & 718.57 & 20 \\
\hline & & 481.98 & 19 & & & 690.58 & 19 \\
\hline 11 & ZEC ZRU & 499.29 & 19 & 24 & 7SH 7DZ & 706.84 & 19 \\
\hline & & 516.6 & 19 & & & 718.57 & 19 \\
\hline & & 533.92 & 19 & & & 724.94 & 19 \\
\hline & & 499.29 & 19 & & & 706.84 & 18 \\
\hline 12 & ZFB 7SP & 516.6 & 19 & 25 & 7MA 7TO & 718.57 & 18 \\
\hline 12 & ZEB_ZSP & 533.92 & 19 & 25 & ZIMA_LIU & 724.94 & 18 \\
\hline & & 550.64 & 19 & & & 742.65 & 18 \\
\hline & & 516.6 & 20 & & & 718.57 & 18 \\
\hline 13 & ZMO ZFH & 533.92 & 20 & 26 & 77I 7AR & 724.94 & 18 \\
\hline 13 & 210 & 550.64 & 20 & 20 & 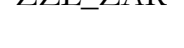 & 742.65 & 18 \\
\hline & & 561.17 & 20 & & & 749.91 & 18 \\
\hline
\end{tabular}




\begin{tabular}{|c|c|c|c|c|c|c|c|}
\hline \multicolumn{8}{|c|}{ Cenário 6.2} \\
\hline Trecho & Estações & Localização & capacidade & Trecho & Estações & Localização & capacidade \\
\hline \multirow{4}{*}{1} & \multirow{4}{*}{ ZFS_ZJA } & 328.93 & 20 & \multirow{4}{*}{14} & \multirow{4}{*}{ ZRU_ZUC } & 533.92 & 17 \\
\hline & & 344.82 & 20 & & & 550.64 & 17 \\
\hline & & 360.71 & 20 & & & 561.17 & 17 \\
\hline & & 376.49 & & & & 580.5 & 17 \\
\hline \multirow{4}{*}{2} & \multirow{4}{*}{ ZTF_ZED } & 344.82 & 19 & \multirow{4}{*}{15} & \multirow{4}{*}{ ZSP_ZCT } & 550.64 & 17 \\
\hline & & 360.71 & 19 & & & 561.17 & 17 \\
\hline & & 376.49 & 19 & & & 580.5 & 17 \\
\hline & & 392.59 & 19 & & & 597.77 & 17 \\
\hline \multirow{4}{*}{3} & \multirow{4}{*}{ ZUR_ZFN } & 360.71 & 19 & \multirow{4}{*}{16} & \multirow{4}{*}{ ZEH_ZCV } & 561.17 & 17 \\
\hline & & 376.49 & 19 & & & 580.5 & 17 \\
\hline & & 392.59 & 19 & & & 597.77 & 17 \\
\hline & & 410.61 & 19 & & & 611.25 & 17 \\
\hline \multirow{4}{*}{4} & \multirow{4}{*}{ ZJA_ZMR } & 376.49 & 19 & \multirow{4}{*}{17} & \multirow{4}{*}{ ZUC_ZPN } & 580.5 & 19 \\
\hline & & 392.59 & 19 & & & 597.77 & 19 \\
\hline & & 410.61 & 19 & & & 611.25 & 19 \\
\hline & & 421.08 & 19 & & & 621.78 & 19 \\
\hline \multirow{4}{*}{5} & & 392.59 & 19 & & & 597.77 & 20 \\
\hline & $7 \mathrm{FD} 7 \mathrm{VG}$ & 410.61 & 19 & 18 & ZCT ZSD & 611.25 & 20 \\
\hline & LED_ZVG & 421.08 & 19 & 10 & ZU_ZUD & 621.78 & 20 \\
\hline & & 434.93 & 19 & & & 634.71 & 20 \\
\hline & & 410.61 & 21 & & & 611.25 & 16 \\
\hline 6 & ZFN ZVP & 421.08 & 21 & 19 & $7 C \mathrm{CV} 7 \mathrm{CZ}$ & 621.78 & 16 \\
\hline 0 & $21+281$ & 434.93 & 21 & 17 & $201-202$ & 634.71 & 16 \\
\hline & & 447.35 & 21 & & & 658.9 & 16 \\
\hline & & 421.08 & 19 & & & 621.78 & 16 \\
\hline 7 & Z ZMR ZKY & 434.93 & 19 & 20 & ZPN ZTO & 634.71 & 16 \\
\hline & & 447.35 & 19 & & 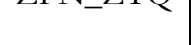 & 658.9 & 16 \\
\hline & & 464.84 & 19 & & & 674.76 & 16 \\
\hline & & 434.93 & 19 & & & 634.71 & 16 \\
\hline 8 & $7 \mathrm{VG}$ ZFC & 447.35 & 19 & 21 & 7SD $7 S H$ & 658.9 & 16 \\
\hline 0 & 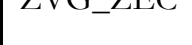 & 464.84 & 19 & 21 & ZDD_ZDח & 674.76 & 16 \\
\hline & & 481.98 & 19 & & & 690.58 & 16 \\
\hline & & 447.35 & 19 & & & 658.9 & 20 \\
\hline 9 & ZVP ZEB & 464.84 & 19 & 22 & ZCZ ZMA & 674.76 & 20 \\
\hline & & 481.98 & 19 & & & 690.58 & 20 \\
\hline & & 499.29 & 19 & & & 706.84 & 20 \\
\hline & & 464.84 & 19 & & & 674.76 & 20 \\
\hline 10 & ZKY ZMO & 481.98 & 19 & 23 & ZTO $77 \mathrm{I}$ & 690.58 & 20 \\
\hline & & 499.29 & 19 & & LQ_- & 706.84 & 20 \\
\hline & & 516.6 & 19 & & & 718.57 & 20 \\
\hline & & 481.98 & 19 & & & 690.58 & 19 \\
\hline 11 & 7FC ZRU & 499.29 & 19 & 24 & 7SH $7 D 7$ & 706.84 & 19 \\
\hline 11 & ZLE_ZNU & 516.6 & 19 & 24 & ZSH_ZDL & 718.57 & 19 \\
\hline & & 533.92 & 19 & & & 724.94 & 19 \\
\hline & & 499.29 & 19 & & & 706.84 & 18 \\
\hline 12 & ZEB ZSP & 516.6 & 19 & 25 & ZMA ZTO & 718.57 & 18 \\
\hline & & 533.92 & 19 & & & 724.94 & 18 \\
\hline & & 550.64 & 19 & & & 742.65 & 18 \\
\hline & & 516.6 & 20 & & & 718.57 & 18 \\
\hline 13 & $17 M 07 F H$ & 533.92 & 20 & 26 & $77 \mathrm{I} \quad 7 \mathrm{AR}$ & 724.94 & 18 \\
\hline 10 & 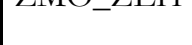 & 550.64 & 20 & 20 & ZЕL_L1 & 742.65 & 18 \\
\hline & & 561.17 & 20 & & & 749.91 & 18 \\
\hline
\end{tabular}


APÊNDICE D: ARQUIVO DA COMPOSIÇÃO 


\section{Arquivo da composição}

Neste arquivo é descrita a composição que é utilizada nas simulações. Na Figura D.1 temos a composição padrão usada na aplicação do modelo.

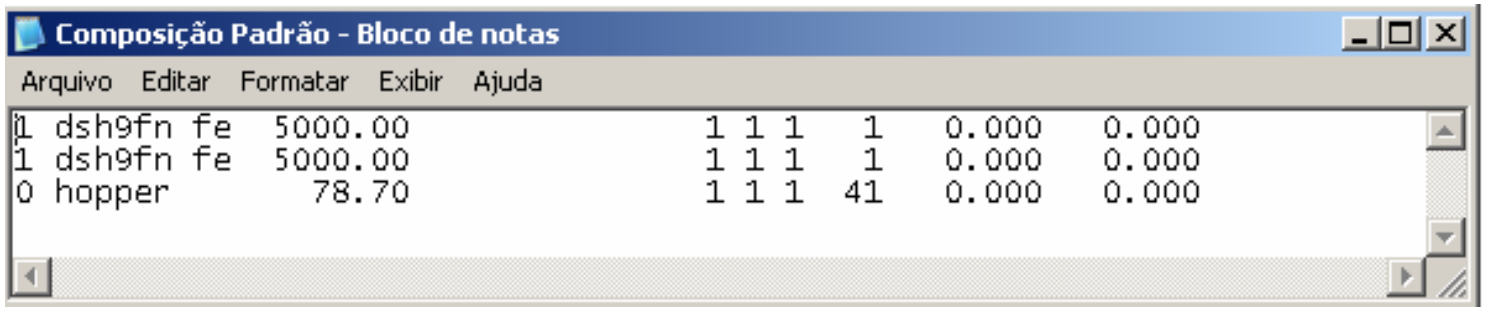

Figura D. 1 - Arquivo da composição

Cada linha do arquivo representa um bloco de veículos. As variáveis que fazem parte deste arquivo são apresentados a seguir, na Tabela B.1.

Tabela D.1: Descrição das variáveis do arquivo da composição (.CON)

\begin{tabular}{|l|}
\hline CÓDIGO DO VEÍCULO \\
1 para locomotivas \\
0 para vagões \\
\hline CÓDIGO IDENTIFICADOR DO VEÍCULO \\
6 caracteres para todos veículos \\
\hline TIPO DE FRENAGEM DINÂMICA \\
2 caracteres para locomotivas \\
2 espaços para vagões \\
\hline PESO DO COMBUSTÍVEL OU CARGA (tons) \\
\hline INDICADOR DE ORIENTAÇÃO DA LOCOMOTIVA \\
0 voltada para frente \\
1 cabine voltada para trás \\
Este valor é ignorado para os vagões \\
\hline IDENTIFICADOR PARA O TOPO DOS TRAILERS OU CONTEINERS \\
6 caracteres para carga intermodal \\
6 espaçOs para carga não intermodal \\
\hline IDENTIFICADOR PARA A BASE DOS TRAILERS OU CONTEINERS \\
6 caracteres para carga intermodal
\end{tabular}




\begin{tabular}{|l|}
\hline 6 espaços para carga não intermodal \\
\hline INDICAÇÃO DA CONDIÇÃO DA PORTA DO VAGÃO \\
1 para fechada \\
0 para aberta \\
\hline TIPO DO MANCAL DO VEÍCULO \\
1 para tipo T gasto \\
2 para tipo T novo \\
3 para tipo B gasto \\
4 para tipo B novo \\
\hline TIPO DO TRUQUE DO VEÍCULO \\
1 para 3-peças gasto \\
2 para 3-peças novo \\
3 para radial \\
4 estrutura-reforçada \\
5 para prêmio 2 eixos \\
6 para eixo simples \\
\hline NÚMERO DE VEÍCULOS POR BLOCO para cálculo interno do simulador \\
\hline COEFICIENTE DE RESISTÊNCIA DE RESISTÊNCIA NOS MANCAIS \\
COEFICIENTE DE RESISTÊNCIA DE ROLAMENTO \\
\hline
\end{tabular}


APÊNDICE E: PARÂMETROS DE CONFIGURAÇÃO 


\section{E Parâmetros de configuração}

Neste anexo é descrito o arquivo de parâmetros de configuração que é utilizada nas simulações. Cada subtrecho possui um arquivo de configuração com o início do percurso indicado. Na Figura E.1 observa-se como exemplo o arquivo de parâmetro de configuração do trecho de Rio Preto Paulista (ZRU) a Uchoa (ZUC).

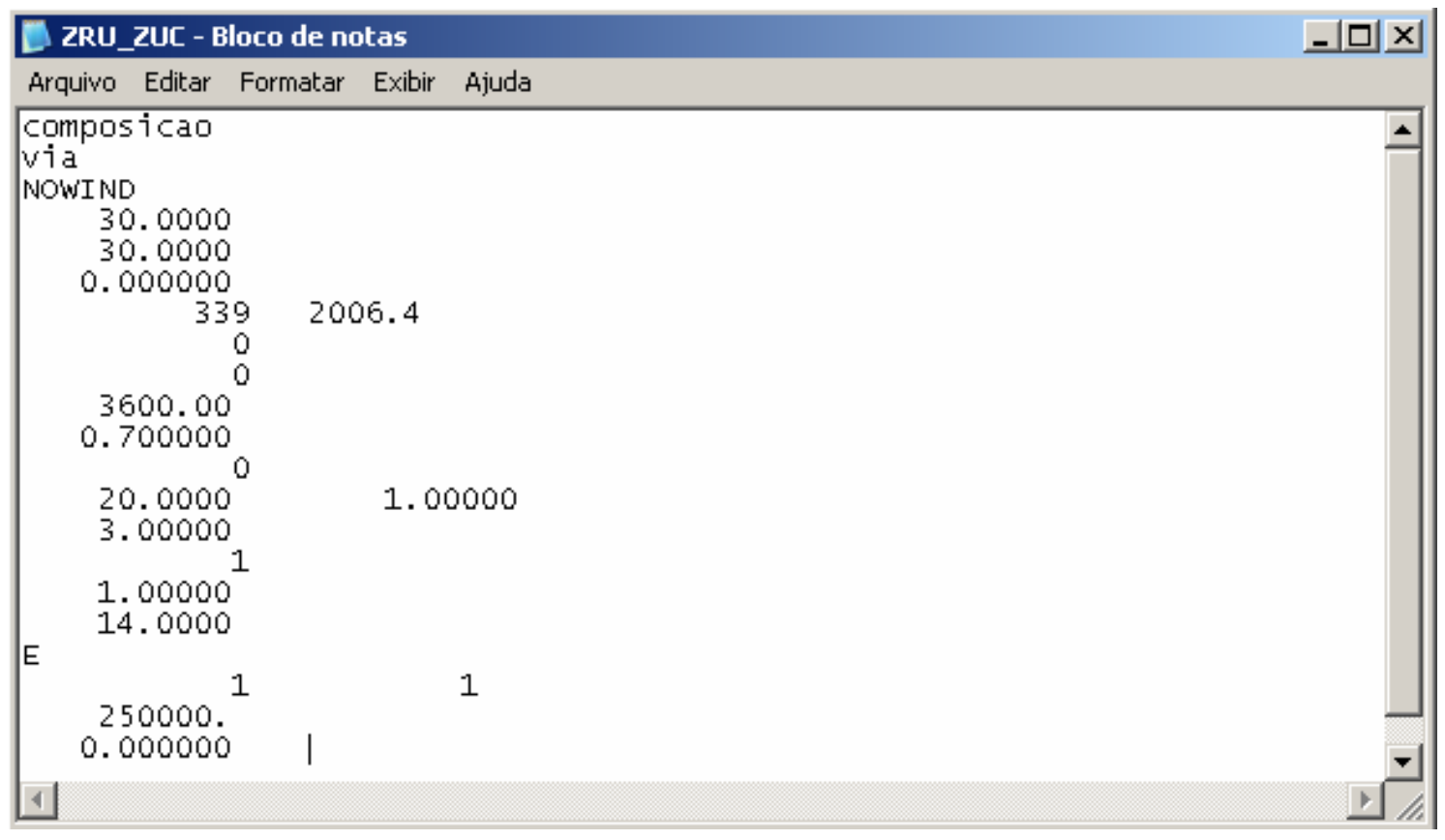

Figura E. 1 - Parâmetros de configuração para ZRU-ZUC

As variáveis que fazem parte deste arquivo são apresentados a seguir, na Tabela E.1.

Tabela E.1: Descrição do arquivo de parâmetros de configuração (.INI)

\begin{tabular}{|l|}
\hline NOME DO ARQUIVO DE DADOS DA COMPOSIÇÃO \\
\hline NOME DO ARQUIVO DE VIA \\
\hline NOME DO ARQUIVO DE DADOS AERODINÂMICOS \\
\hline INTERVALO DE TEMPO DO ARQUIVO DE SAÍDA EM SEGUNDOS \\
\hline INTERVALO DE TEMPO DE EXIBIÇÃO NA TELA EM SEGUNDOS \\
\hline DIREÇÃO INICIAL DO VEICULO LÍDER EM GRAUS \\
\hline \begin{tabular}{c} 
POSIÇÃO INICIAL DO VEÍCULO LÍDER \\
número em milhas (mi) e (ft) da posição inicial \\
\hline CONDIÇÃO DOS VEÍCULOS
\end{tabular} \\
\hline
\end{tabular}




\begin{tabular}{|l|}
\hline 0 para não lubrificados \\
1 para lubrificados \\
\hline CONDIÇÃO DO TRUQUE \\
0 para não lubrificados \\
1 para lubrificados \\
\hline DISTÂNCIA EFETIVA DE LUBRIFICAÇÃO EM ft \\
\hline REDUÇAO DA RESISTÊNCIA DE ROLAMENTO EM lbs/ton \\
\hline CONTROLE MANUAL DE INTERRUPÇÃO EM SEGUNDOS \\
\hline POSIÇÃO INICIAL DA COMPOSIÇÃO \\
E, NE, N, NW, W, SW, S ou SE \\
\hline PARÂMETROS DE EXIBIÇÃO \\
EFEITOS \\
0 sem som \\
1 com som \\
DISTÂNCIA DE VISIBILIDADE NA TELA EM MILHAS \\
VISUALIZAÇÃO DO HORA DO DIA NA SIMULAÇÃO INICIAL \\
1 para noite \\
0 para crepúsculo \\
-1 para dia \\
TEMPO ATÉ A CHEGADA DO CREPÚSCULO EM HORAS \\
DURAÇÃO INICIAL DO DIA EM HORAS \\
DISTRIBUIÇÃO DE FORÇAS NA TELA \\
0 para não exibir \\
VALOR MÁXIMOR DA DAR DERÇA EXIBA NA TELA EM LIBRAS \\
VELOCIDADE INSTÂNTANEA E LIMITE AO LONGO DA VIA \\
0 para não exibir \\
\hline
\end{tabular}


APÊNDICE F: ARQUIVO DE PARADAS 


\section{F Arquivo de paradas}

Neste anexo é descrito o arquivo de paradas usado para simulação de cada subtrecho. O simulador de marcha, TEM 2.5 permite a inserção de até 20 paradas. Na Figura F.1 observa-se como exemplo o arquivo de paradas do subtrecho de Rio Preto Paulista (ZRU) a Uchoa (ZUC).

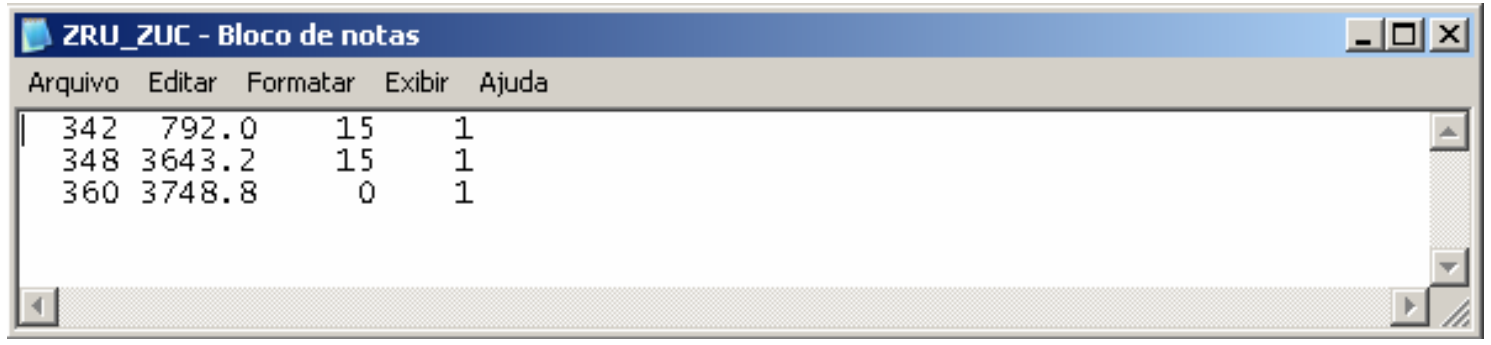

Figura F.1 - Arquivo de paradas do subtrecho ZRU-ZUC

Cada linha do arquivo representa uma parada e sua descrição detalhada é apresentada a seguir, na Tabela F.1.

Tabela F.1: Descrição do arquivo de paradas (.STP)

\begin{tabular}{|l|}
\hline $\begin{array}{l}\text { POSIÇÃO DA PARADA NA VIA FÉRREA } \\
\text { número em (mi) e (ft) }\end{array}$ \\
\hline TEMPO DE PARADA \\
Valor em minutos \\
CONDIÇÃO DA LOCOMOTIVA DURANTE A PARADA \\
0 se desligada \\
1 em espera
\end{tabular}


APÊNDICE G: RELATÓRIO DA SIMULAÇÃO 


\section{G Relatório da simulação}

Neste anexo é apresentado o relatório gerado após as simulações. Na Figura G.1 observa-se o relatório gerado para a simulação do subtrecho de Rio Preto Paulista (ZRU) a Uchoa (ZUC).

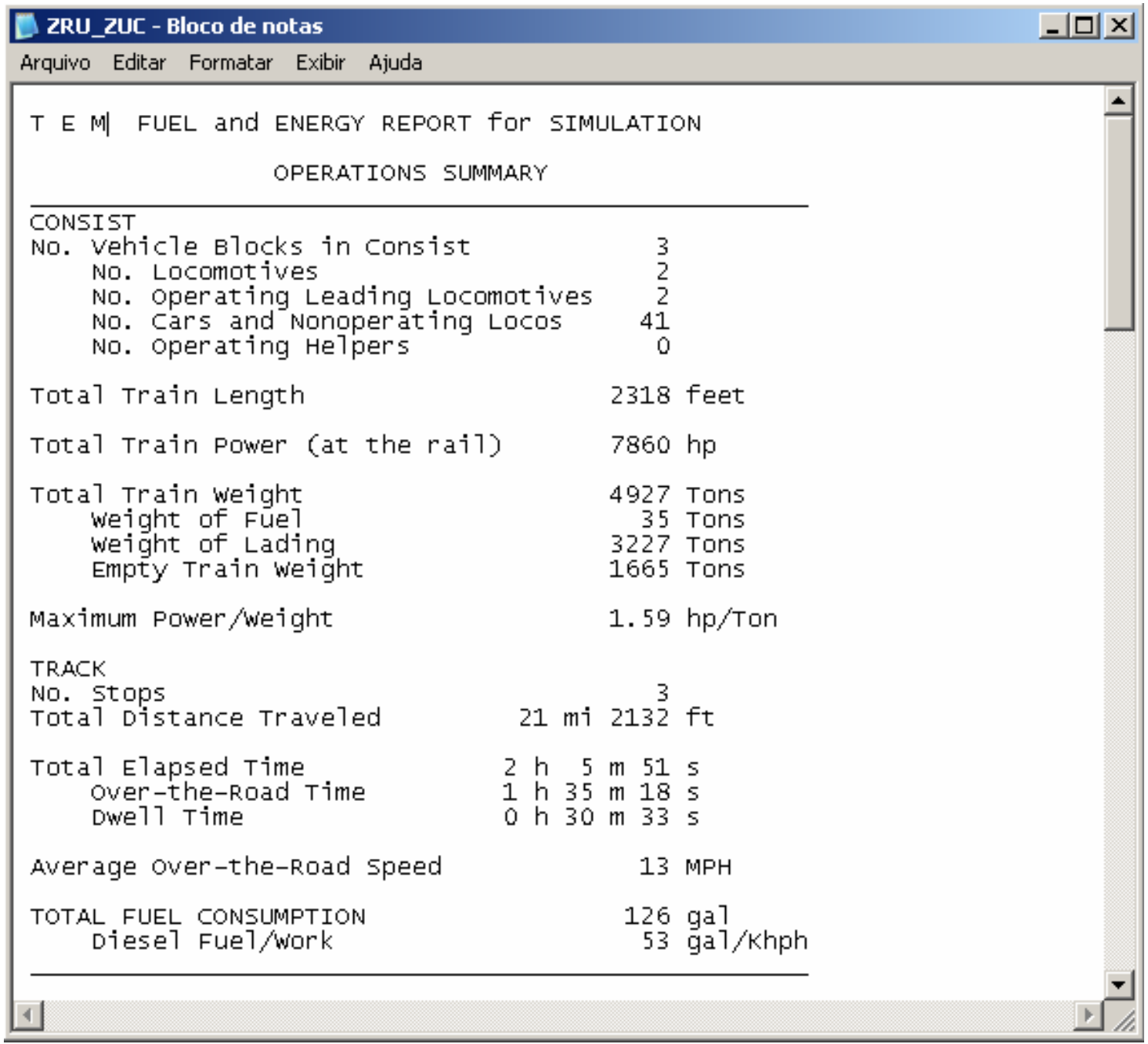

Figura G. 1 - Resumo da operação para o subtrecho ZRU-ZUC (.RPT)

O arquivo contém informações sobre a composição, o trecho simulado e o consumo de combustível. Nele também é descrito o número de locomotivas, incluindo locomotivas auxiliares(helpers), vagões, comprimento e pesos da composição. Em relação ao desempenho do trem é mostrado o número e tempo de paradas efetuadas, a distância total percorrida e a velocidade média.

Além do resumo sobre a composição e operação o arquivo completo permite verificar o consumo de combustível por pontos de tração, o ciclo de rendimento, o 
consumo de combustível por velocidade e por resistência, o trabalho realizado de cada força e a operação do motor de tração abaixo da velocidade contínua mínima (12.1 mph). 
APÊNDICE H: ARQUIVO DE SAÍDA DO SIMULADOR (20) 


\section{H Arquivo de saída}

O arquivo de saída contém dados da movimentação dos trens normalmente para um intervalo de simulação determinado, no caso da aplicação os dados foram gerados para cada 30 segundos de simulação.

As informações contidas no arquivo (Tabela H.1) podem ser usadas para avaliar vários fatores de desempenho do trem.

Tabela H.1: Descrição do arquivo de saída do simulador (.OUT)

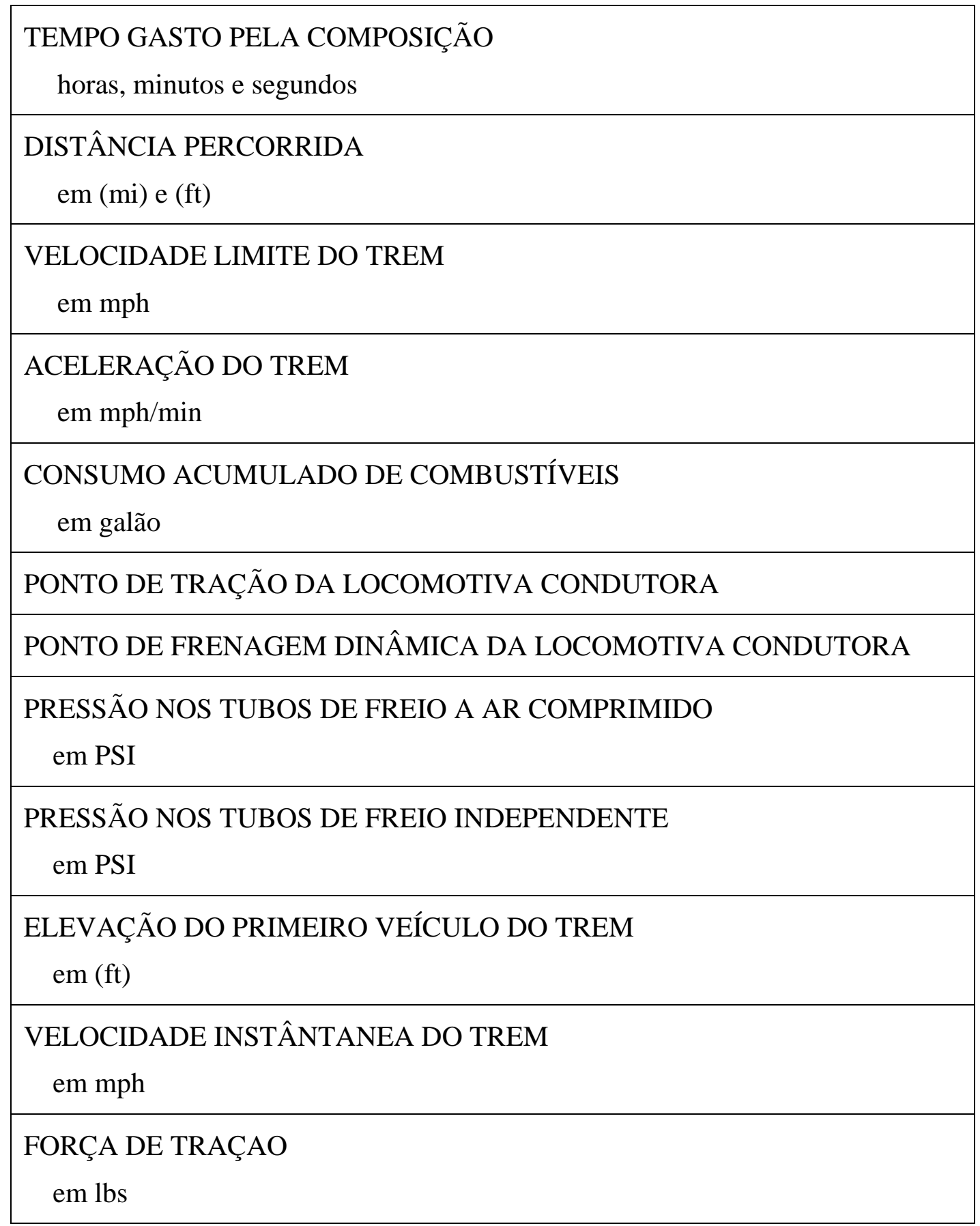




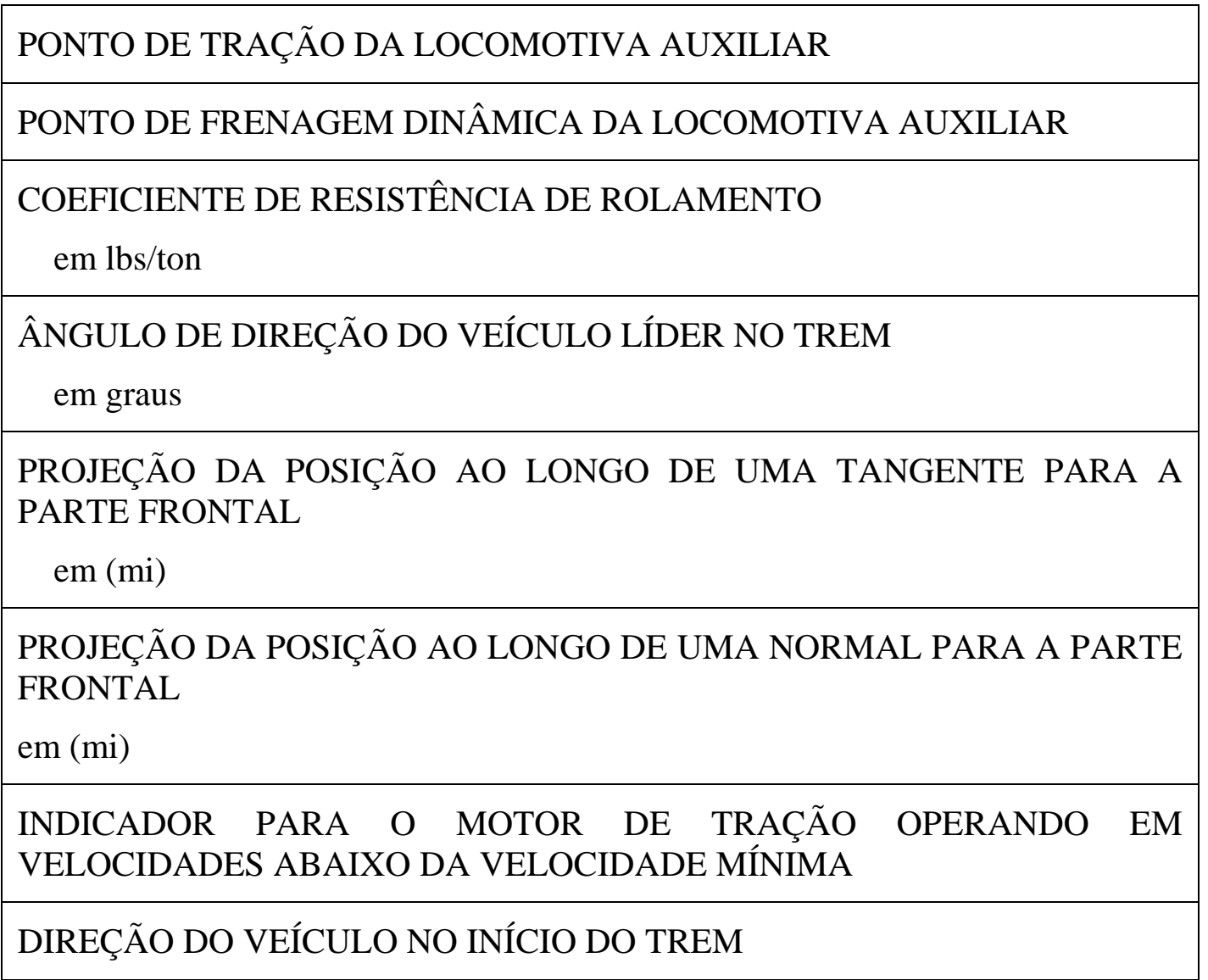


ANEXO A: ARQUIVO DA VIA 


\section{A Arquivo da via}

Este anexo contém todas as informações relativas à linha ferroviária de Santa Fé do Sul a Araraquara utilizada pelo simulador de desempenho do trem. As variáveis que fazem parte deste arquivo são apresentadas a seguir na Tabela A.1.

Alguns desses valores, como a posição, elevação, grau de curva e velocidade tiveram seus valores convertidos. Na Tabela A.1 são expostos também os valores respectivos para o código 1 (c 1) e o código 2 (c 2):

Código 1: código característico da instalação na via férrea
2 ponte
3 viaduto
5 passagem de nível
8 estação

Código 2: código característico do desvio
1 linha do desvio
2 chave direita do desvio
3 chave esquerda do desvio 
Tabela A.1: Arquivo da via (.TRK)

\begin{tabular}{|c|c|c|c|c|c|c|c|c|c|c|c|}
\hline \multicolumn{2}{|c|}{ Posição } & \multicolumn{2}{|c|}{ Elevação } & \multirow{2}{*}{$\begin{array}{c}\text { rampa } \\
(\%)\end{array}$} & \multicolumn{2}{|c|}{ curva } & \multicolumn{2}{|c|}{$\begin{array}{c}\text { Limite de } \\
\text { velocidade }\end{array}$} & \multirow[t]{2}{*}{ nome do local } & \multirow[t]{2}{*}{ C 1} & \multirow[t]{2}{*}{ C 2} \\
\hline (feet) & $(\mathrm{km})$ & (feet) & $(\mathrm{m})$ & & ${ }^{\circ}$ & $(\mathrm{m})$ & MPH & $\mathrm{km} / \mathrm{h}$ & & & \\
\hline 1076043,5 & 327,98 & \begin{tabular}{|l|}
1279,3 \\
\end{tabular} & 389,93 & |0,36 & 2,91 & \begin{tabular}{|c|}
600,19 \\
\end{tabular} & 12 & $\overline{19,31}$ & ZSF - FIM & 0 & 2 \\
\hline 1076286 & 328,05 & 1280,2 & 390,20 & 0,5 & 2,91 & 600,19 & 43 & 69,20 & & 0 & 1 \\
\hline 1076552 & 328,13 & 1281,5 & 390,60 & 0,5 & 0 & 0,00 & 43 & 69,20 & & 0 & 1 \\
\hline 1078320,3 & 328,67 & 1290,4 & 393,31 & 0,5 & $-1,52$ & 1148,96 & 43 & 69,20 & & 0 & 1 \\
\hline 1078323,5 & 328,67 & 1290,4 & 393,31 & 0,5 & 1,52 & 1148,96 & 43 & 69,20 & KM 421 & 0 & 1 \\
\hline 1079160 & 328,93 & 1294,6 & 394,59 & 0,5 & 1,52 & 1148,96 & 43 & 69,20 & & 0 & 1 \\
\hline 1079163,5 & 328,93 & 1294,6 & 394,59 & 0,5 & 1,52 & 1148,96 & 43 & 69,20 & SANTA FE DO SUL & 8 & 1 \\
\hline 1079406,3 & 329,00 & 1295,8 & 394,96 & 0,5 & 0 & 0,00 & 43 & 69,20 & & 0 & 1 \\
\hline 1080216,5 & 329,25 & 1299,9 & 396,21 & 0,5 & 0 & 0,00 & 43 & 69,20 & & 0 & 1 \\
\hline 1080269 & 329,27 & 1300,1 & 396,27 & 0,5 & 0 & 0,00 & 12 & 19,31 & ZSF - INICIO & 0 & 3 \\
\hline 1081079,5 & 329,51 & 1304,2 & 397,52 & 0,5 & 1,52 & 1148,96 & 43 & 69,20 & & 0 & 0 \\
\hline 1081601 & 329,67 & 1306,8 & 398,31 & 0,5 & 1,52 & 1148,96 & 43 & 69,20 & & 0 & 0 \\
\hline 1081604,5 & 329,67 & 1306,8 & 398,31 & 0,5 & 1,52 & 1148,96 & 43 & 69,20 & KM 420 & 0 & 0 \\
\hline 1082916,8 & 330,07 & 1313,4 & 400,32 & 0,5 & 0 & 0,00 & 43 & 69,20 & & 0 & 0 \\
\hline 1084147 & 330,45 & 1319,5 & 402,18 & 0,5 & $-2,79$ & 626,00 & 43 & 69,20 & & 0 & 0 \\
\hline 1084882 & 330,67 & 1323,2 & 403,31 & 0,5 & $-2,79$ & 626,00 & 43 & 69,20 & & 0 & 0 \\
\hline 1084885,3 & 330,67 & 1323,2 & 403,31 & 0,5 & $-2,79$ & 626,00 & 43 & 69,20 & KM 419 & 0 & $\overline{0}$ \\
\hline 1085650 & 330,91 & 1327 & 404,47 & 0,5 & $-2,79$ & 626,00 & 25 & 40,23 & & 0 & $\overline{0}$ \\
\hline 1086722,5 & 331,23 & 1332,4 & 406,12 & 0,5 & 0 & 0,00 & 25 & 40,23 & & 0 & 0 \\
\hline 1087706,8 & 331,53 & 1337,3 & 407,61 & 0,5 & 2,79 & 626,00 & 25 & 40,23 & & 0 & 0 \\
\hline 1088162,8 & 331,67 & 1339,6 & 408,31 & 0,5 & 2,79 & 626,00 & 25 & 40,23 & & 0 & 0 \\
\hline 1088166 & 331,67 & 1339,6 & 408,31 & 0,5 & 2,79 & 626,00 & 25 & 40,23 & KM 418 & 0 & 0 \\
\hline 1090922 & 332,51 & 1353,4 & 412,52 & 0,5 & 0 & 0,00 & 25 & 40,23 & & 0 & 0 \\
\hline 1091443,5 & 332,67 & 1356 & 413,31 & 0,5 & 0 & 0,00 & 25 & 40,23 & & 0 & 0 \\
\hline 1091447 & 332,67 & 1356 & 413,31 & 0,5 & 0 & 0,00 & 25 & 40,23 & KM 417 & 0 & $\overline{0}$ \\
\hline 1093021,8 & 333,15 & 1363,9 & 415,72 & 0,5 & $-2,24$ & 7779,68 & 25 & 40,23 & & 0 & 0 \\
\hline 1094724,5 & 333,67 & 1372,4 & 418,31 & 0,5 & $-2,24$ & 779,68 & 25 & 40,23 & & 0 & 0 \\
\hline 1094727,8 & 333,67 & 1372,4 & 418,31 & 0,5 & $-2,24$ & 779,68 & 25 & 40,23 & KM 416 & 0 & 0 \\
\hline 1095482,3 & 333,90 & 1376,2 & 419,47 & 0,5 & 0 & 0,00 & 25 & 40,23 & & 0 & 0 \\
\hline 1097916,5 & 334,64 & 1388,4 & 423,18 & 0,5 & 0 & 0,00 & 25 & 40,23 & & 0 & 0 \\
\hline 1098005,3 & 334,67 & 1388,8 & 423,31 & 0 & 0 & 0,00 & 43 & 69,20 & & 0 & 0 \\
\hline 1098008,5 & 334,67 & 1388,8 & 423,31 & 0 & 0 & 0,00 & 43 & 69,20 & KM 415 & 0 & 0 \\
\hline 1098080 & 334,69 & 1388,8 & 423,31 & 0 & 0 & 0,00 & 43 & 69,20 & & 0 & 0 \\
\hline 1098407,3 & 334,79 & 1388,8 & 423,31 & 0 & 0 & 0,00 & 19 & 30,58 & PN - Perímetro urbano & 5 & 0 \\
\hline 1098570,8 & 334,84 & 1388,8 & 423,31 & 0 & 0 & 0,00 & 25 & 40,23 & & 0 & 0 \\
\hline 1101286 & 335,67 & 1388,8 & 423,31 & 0 & 0 & 0,00 & 25 & 40,23 & & 0 & 0 \\
\hline 1101289,5 & 335,67 & 1388,8 & 423,31 & 0 & 0 & 0,00 & 25 & 40,23 & KM 414 & 0 & 0 \\
\hline 1101322,3 & 335,68 & 1388,8 & 423,31 & 0 & $-2,79$ & 626,00 & 25 & 40,23 & & 0 & 0 \\
\hline 1101486,3 & 335,73 & 1388,8 & 423,31 & 0,5 & $-2,79$ & 626,00 & 25 & 40,23 & & 0 & 0 \\
\hline 1101798 & 335,83 & 1390,4 & 423,79 & 0,5 & $-2,79$ & 626,00 & 25 & 40,23 & & 0 & 0 \\
\hline 1101850,5 & 335,84 & 1390,6 & 423,85 & 0,5 & $-2,79$ & 626,00 & 25 & 40,23 & ZTF - FIM & 0 & 2 \\
\hline 1102788,8 & 336,13 & 1395,3 & 425,29 & 0,5 & $-2,79$ & 626,00 & 25 & 40,23 & & 0 & 1 \\
\hline 1102792 & 336,13 & 1395,3 & 425,29 & 0,5 & $-2,79$ & 626,00 & 25 & 40,23 & TRES FRONTEIRAS & 8 & 1 \\
\hline 1103615,5 & 336,38 & 1399,5 & 426,57 & 0,5 & $-2,79$ & 626,00 & 25 & 40,23 & & 0 & 1 \\
\hline 1103668 & 336,40 & 1399,7 & 426,63 & 0,5 & $-2,79$ & 626,00 & 25 & 40,23 & ZTF - INICIO & 0 & 3 \\
\hline 1103717,3 & 336,41 & 1400 & 426,72 & 0,5 & 0 & 0,00 & 25 & 40,23 & & 0 & 0 \\
\hline 1104406,3 & 336,62 & 1403,4 & 427,76 & 0,5 & 2,79 & 626,00 & 25 & 40,23 & & 0 & 0 \\
\hline 1104567 & 336,67 & 1404,2 & 428,00 & 0,5 & 2,79 & 626,00 & 25 & 40,23 & & 0 & 0 \\
\hline 1104570,3 & 336,67 & 1404,2 & 428,00 & 0,5 & 2,79 & 626,00 & 25 & 40,23 & KM 413 & 0 & 0 \\
\hline 1106079,5 & 337,13 & 1411,8 & 430,32 & 0 & 2,79 & 626,00 & 25 & 40,23 & & 0 & 0 \\
\hline 1107195 & 337,47 & 1411,8 & 430,32 & 0 & 0 & 0,00 & 25 & 40,23 & & 0 & 0 \\
\hline 1107654,3 & 337,61 & 1411,8 & 430,32 & $-0,5$ & 0 & 0,00 & 25 & 40,23 & & 0 & 0 \\
\hline 1107847,8 & 337,67 & 1410,8 & 430,01 & \begin{tabular}{l|l}
$-0,5$ \\
\end{tabular} & 0 & 0,00 & 25 & 40,23 & & 0 & 0 \\
\hline 1107851 & 337,67 & 1410,8 & 430,01 & \begin{tabular}{l|l}
$-0,5$ \\
\end{tabular} & 0 & 0,00 & 25 & 40,23 & KM 412 & 0 & 0 \\
\hline 1107916,8 & 337,69 & 1410,5 & 429,92 & \begin{tabular}{l|l}
$-0,5$ \\
\end{tabular} & $-2,79$ & 626,00 & 25 & 40,23 & & 0 & 0 \\
\hline 1110213,3 & 338,39 & 1399 & 426,42 & $\begin{array}{ll}-0,5 \\
\end{array}$ & 0 & 0,00 & 25 & 40,23 & & 0 & 0 \\
\hline 1110869,5 & 338,59 & \begin{tabular}{l|l|}
1395,7 \\
\end{tabular} & 425,41 & \begin{tabular}{l|l}
$-0,5$ \\
\end{tabular} & 2,18 & 801,14 & 25 & 40,23 & & 0 & 0 \\
\hline 1111128,8 & 338,67 & 1394,4 & 425,01 & $-0,5$ & 2,18 & 801,14 & 25 & 40,23 & & 0 & 0 \\
\hline 11111132 & 338,67 & 1394,4 & 425,01 & $-0,5$ & 2,18 & 801,14 & 25 & 40,23 & KM 411 & 0 & 0 \\
\hline 1112636,5 & 339,13 & 1386,9 & 422,73 & $-0,5$ & 2,18 & 801,14 & 25 & 40,23 & & 0 & 0 \\
\hline 1112838 & 339,19 & 1385,9 & 422,42 & 0 & 2,18 & 801,14 & 43 & 69,20 & & 0 & 0 \\
\hline 1113494 & 339,39 & 1385,9 & 422,42 & 0,5 & 2,18 & 801,14 & 43 & 69,20 & & 0 & 0 \\
\hline 1114409,5 & 339,67 & 1390,4 & 423,79 & 0,5 & 2,18 & 801,14 & 43 & 69,20 & & 0 & 0 \\
\hline 1114412,8 & 339,67 & 1390,4 & 423,79 & 0,5 & 2,18 & 801,14 & 43 & 69,20 & KM 110 & 0 & 0 \\
\hline 1114937,8 & 339,83 & 1393,1 & 424,62 & 0,5 & 0 & 0,00 & 43 & 69,20 & & 0 & 0 \\
\hline 1116742,3 & 340,38 & 1402,1 & 427,36 & 0 & 0 & 0,00 & 43 & 69,20 & & 0 & 0 \\
\hline 1117690,3 & 340,67 & 1402,1 & 427,36 & 0 & 0 & 0,00 & 43 & 69,20 & & 0 & 0 \\
\hline 1117693,5 & 340,67 & 1402,1 & 427,36 & 0 & 0 & 0,00 & 43 & 69,20 & KM 409 & 0 & 0 \\
\hline 1118743,5 & 340,99 & 1402,1 & 427,36 & 0 & $-2,79$ & 626,00 & 43 & 69,20 & & 0 & 0 \\
\hline
\end{tabular}




\begin{tabular}{|c|c|c|c|c|c|c|c|c|c|c|c|}
\hline \multicolumn{2}{|c|}{ Posição } & \multicolumn{2}{|c|}{ Elevação } & \multirow{2}{*}{\begin{tabular}{c|} 
rampa \\
$(\%)$ \\
\end{tabular}} & \multicolumn{2}{|c|}{ curva } & \multicolumn{2}{|c|}{$\begin{array}{c}\text { Limite de } \\
\text { velocidade }\end{array}$} & \multirow[t]{2}{*}{ nome do local } & \multirow[t]{2}{*}{ C 1} & C 2 \\
\hline (feet) & $(\mathrm{km})$ & (feet) & $(\mathrm{m})$ & & ${ }^{\circ}$ & $(\mathrm{m})$ & $\mathrm{MPH}$ & $\mathrm{km} / \mathrm{h}$ & & & \\
\hline 11120971,3 & 341,67 & "1402,1 & 427,36 & 0 & \begin{tabular}{|c|}
$-2,79$ \\
\end{tabular} & 626,00 & 43 & 69,20 & & 0 & 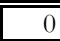 \\
\hline 1120974,5 & 341,67 & 1402,1 & 427,36 & 0 & $-2,79$ & 626,00 & 43 & 69,20 & KM 408 & 0 & 0 \\
\hline 1121499,5 & 341,83 & 1402,1 & 427,36 & 0 & 0 & 0,00 & \begin{tabular}{l|l}
43 \\
\end{tabular} & 69,20 & & 0 & 0 \\
\hline 1121958,8 & 341,97 & 1402,1 & 427,36 & 0,5 & 0 & 0,00 & 43 & 69,20 & & 0 & 0 \\
\hline 1122615 & 342,17 & 1405,4 & 428,37 & 0,5 & 2,79 & 626,00 & 43 & 69,20 & & 0 & 0 \\
\hline 1123369,5 & 342,40 & 1409,1 & 429,49 & 0,5 & 0 & 0,00 & 43 & 69,20 & & 0 & 0 \\
\hline 1124252 & 342,67 & 1413,6 & 430,87 & 0,5 & 0 & 0,00 & 43 & 69,20 & & 0 & 0 \\
\hline 1124255,3 & 342,67 & 1413,6 & 430,87 & 0,5 & 0 & 0,00 & 43 & 69,20 & KM 407 & 0 & 0 \\
\hline 1125108,3 & 342,93 & 1417,8 & 432,15 & 0,5 & 2,79 & 626,00 & 43 & 69,20 & & 0 & 0 \\
\hline 1127533 & 343,67 & 1430 & 435,86 & 0,5 & 2,79 & 626,00 & 43 & 69,20 & & 0 & 0 \\
\hline 1127536 & 343,67 & 1430 & 435,86 & 0,5 & 2,79 & 626,00 & 43 & 69,20 & KM 406 & 0 & 0 \\
\hline 1127864,3 & 343,77 & 1431,6 & 436,35 & \begin{tabular}{l|l|}
0,5 \\
\end{tabular} & 0 & 0,00 & 43 & 69,20 & & 0 & 0 \\
\hline 1129996,8 & 344,42 & 1442,3 & 439,61 & 0,5 & \begin{tabular}{|l|}
$-2,79$ \\
\end{tabular} & 626,00 & 43 & 69,20 & & 0 & 0 \\
\hline 1130813,8 & 344,67 & 1446,4 & 440,86 & 0,5 & $-2,79$ & 626,00 & 43 & 69,20 & & 0 & 0 \\
\hline 1130817 & 344,67 & 1446,4 & 440,86 & 0,5 & \begin{tabular}{l|}
$-2,79$ \\
\end{tabular} & 626,00 & 43 & 69,20 & KM 405 & 0 & 0 \\
\hline 1131538,8 & 344,89 & 1450 & 441,96 & 0,5 & 0 & 0,00 & 43 & 69,20 & & 0 & 0 \\
\hline 1134094,5 & 345,67 & 1462,8 & 445,86 & 0,5 & 0 & 0,00 & 43 & 69,20 & & 0 & 0 \\
\hline 1134097,8 & 345,67 & 1462,8 & 445,86 & 0,5 & 0 & 0,00 & \begin{tabular}{l|l}
43 \\
\end{tabular} & 69,20 & KM 404 & 0 & 0 \\
\hline 1135508,5 & 346,10 & 1469,8 & 448,00 & 0,5 & $-2,24$ & 779,68 & 43 & 69,20 & & 0 & 0 \\
\hline 1136624 & 346,44 & 1475,4 & 449,70 & 0,5 & 0 & 0,00 & \begin{tabular}{l|}
43 \\
\end{tabular} & 69,20 & & 0 & 0 \\
\hline 1137375,5 & 346,67 & 1479,2 & 450,86 & 0,5 & 0 & 0,00 & 43 & 69,20 & & 0 & 0 \\
\hline 1137378,8 & 346,67 & 1479,2 & 450,86 & 0,5 & 0 & 0,00 & 43 & 69,20 & KM 403 & 0 & 0 \\
\hline 1138231,8 & 346,93 & 1483,5 & 452,17 & 0,5 & $-2,24$ & 779,68 & 43 & 69,20 & & 0 & 0 \\
\hline 1139741 & 347,39 & 1491 & 454,46 & 0,5 & 0 & 0,00 & 43 & 69,20 & & 0 & 0 \\
\hline 1140656,3 & 347,67 & 1495,6 & 455,86 & \begin{tabular}{l|}
$-0,5$ \\
\end{tabular} & 0 & 0,00 & \begin{tabular}{l|}
43 \\
\end{tabular} & 69,20 & & 0 & 0 \\
\hline 1140659,5 & 347,67 & 1495,6 & 455,86 & 0,5 & 0 & 0,00 & 43 & 69,20 & KM 402 & 0 & 0 \\
\hline 1140823,5 & 347,72 & 1496,4 & 456,10 & 0 & 0 & 0,00 & \begin{tabular}{l|l}
43 \\
\end{tabular} & 69,20 & & 0 & 0 \\
\hline 1141840,5 & 348,03 & 1496,4 & 456,10 & 0 & 2,18 & 801,14 & 43 & 69,20 & & 0 & 0 \\
\hline 1142726,5 & 348,30 & 1496,4 & 456,10 & 0 & 0 & 0,00 & 43 & 69,20 & & 0 & 0 \\
\hline 1143937 & 348,67 & 1496,4 & 456,10 & 0 & 0 & 0,00 & 43 & 69,20 & & 0 & 0 \\
\hline 1143940,3 & 348,67 & 1496,4 & 456,10 & 0 & 0 & 0,00 & 43 & 69,20 & KM 401 & 0 & 0 \\
\hline 1145538 & 349,16 & 1496,4 & 456,10 & 0 & 0 & 0,00 & \begin{tabular}{l|}
43 \\
\end{tabular} & 69,20 & & 0 & 0 \\
\hline 1145541,5 & 349,16 & 1496,4 & 456,10 & 0 & 0 & 0,00 & 43 & 69,20 & $\begin{array}{l}\text { PIMENTA BUENO } \\
\text { (demolida) }\end{array}$ & 8 & 0 \\
\hline 1147218 & 349,67 & 1496,4 & 456,10 & 0 & 0 & 0,00 & \begin{tabular}{l|l}
43 \\
\end{tabular} & 69,20 & & 0 & 0 \\
\hline 1147221,3 & 349,67 & 1496,4 & 456,10 & 0 & 0 & 0,00 & 43 & 69,20 & KM 400 & 0 & 0 \\
\hline 1147352,5 & 349,71 & 1496,4 & 456,10 & 0,47 & 0 & 0,00 & 43 & 69,20 & & 0 & 0 \\
\hline 1149845,8 & 350,47 & 1508,1 & 459,67 & 0,47 & 2,79 & 626,00 & 43 & 69,20 & & 0 & 0 \\
\hline 1150498,8 & 350,67 & 1511,2 & 460,61 & 0,47 & 2,79 & 626,00 & 43 & 69,20 & & 0 & 0 \\
\hline 1150502 & 350,67 & 1511,2 & 460,61 & 0,47 & 2,79 & 626,00 & 43 & 69,20 & KM 399 & 0 & 0 \\
\hline 1150797,3 & 350,76 & 1512,6 & 461,04 & \begin{tabular}{l|}
0,47 \\
\end{tabular} & 0 & 0,00 & 43 & 69,20 & & 0 & 0 \\
\hline 1151486,3 & 350,97 & 1515,8 & 462,02 & 0,47 & \begin{tabular}{r|}
$-2,79$ \\
\end{tabular} & 626,00 & \begin{tabular}{l|l}
43 \\
\end{tabular} & 69,20 & & 0 & 0 \\
\hline 1152601,8 & 351,31 & 1521,1 & 463,63 & 0 & \begin{tabular}{l|}
$-2,79$ \\
\end{tabular} & 626,00 & 43 & 69,20 & & 0 & 0 \\
\hline 1153779,5 & 351,67 & 1521,1 & 463,63 & 0 & \begin{tabular}{l|}
$-2,79$ \\
\end{tabular} & 626,00 & 43 & 69,20 & & 0 & 0 \\
\hline 1153783 & 351,67 & 1521,1 & 463,63 & 0 & \begin{tabular}{r|}
$-2,79$ \\
\end{tabular} & 626,00 & 43 & 69,20 & KM 398 & 0 & 0 \\
\hline 1153848,5 & 351,69 & 1521,1 & 463,63 & 0 & 0 & 0,00 & 43 & 69,20 & & 0 & 0 \\
\hline 1154668,8 & 351,94 & 1521,1 & 463,63 & 0 & 2,79 & 626,00 & 43 & 69,20 & & 0 & 0 \\
\hline 1156309 & 352,44 & 1521,1 & 463,63 & 0 & 0 & 0,00 & 43 & 69,20 & & 0 & 0 \\
\hline 1157060,5 & 352,67 & 1521,1 & 463,63 & \begin{tabular}{l|l}
0 \\
\end{tabular} & 0 & 0,00 & 43 & 69,20 & & 0 & 0 \\
\hline 1157063,8 & 352,67 & 1521,1 & 463,63 & 0 & 0 & 0,00 & 43 & 69,20 & KM 397 & 0 & 0 \\
\hline 1158104,5 & 352,99 & 1521,1 & 463,63 & 0 & 0 & 0,00 & 25 & 40,23 & & 0 & 0 \\
\hline 1159524,3 & 353,42 & 1521,1 & 463,63 & 0 & 2,18 & 801,14 & 25 & 40,23 & & 0 & 0 \\
\hline 1160147,8 & 353,61 & 1521,1 & 463,63 & 0,5 & 2,18 & 801,14 & 25 & 40,23 & & 0 & 0 \\
\hline 1160341,3 & 353,67 & 1522 & 463,91 & 0,5 & 2,18 & 801,14 & 25 & 40,23 & & 0 & 0 \\
\hline 1160344,5 & 353,67 & 1522 & 463,91 & 0,5 & 2,18 & 801,14 & 25 & 40,23 & KM 396 & 0 & 0 \\
\hline 1160394,3 & 353,69 & 1522,3 & 464,00 & 0,5 & 2,18 & 801,14 & 25 & 40,23 & & 0 & 0 \\
\hline 1161492,8 & 354,02 & 1527,8 & 465,67 & 0,5 & 0 & 0,00 & 43 & 69,20 & & 0 & 0 \\
\hline 1163100,5 & 354,51 & 1535,8 & 468,11 & 0,5 & $-2,18$ & 801,14 & 43 & 69,20 & & 0 & 0 \\
\hline 1163622 & 354,67 & 1538,4 & 468,90 & 0,5 & $-2,18$ & 801,14 & \begin{tabular}{l|}
43 \\
\end{tabular} & 69,20 & & 0 & 0 \\
\hline 1163625,5 & 354,67 & 1538,4 & 468,90 & 0,5 & \begin{tabular}{r|}
$-2,18$ \\
\end{tabular} & 801,14 & 43 & 69,20 & KM 395 & 0 & 0 \\
\hline 1164084,8 & 354,81 & 1540,7 & 469,61 & 0 & \begin{tabular}{r|}
$-2,18$ \\
\end{tabular} & 801,14 & 43 & 69,20 & & 0 & 0 \\
\hline 1164576,8 & 354,96 & 1540,7 & 469,61 & \begin{tabular}{l|l}
0 \\
\end{tabular} & 0 & 0,00 & 43 & 69,20 & & 0 & 0 \\
\hline 1165265,8 & 355,17 & 1540,7 & 469,61 & \begin{tabular}{l|l}
0 \\
\end{tabular} & \begin{tabular}{|l|}
$-1,52$ \\
\end{tabular} & 1148,96 & 43 & 69,20 & & 0 & 0 \\
\hline 1166903 & 355,67 & 1540,7 & 469,61 & 0 & $-1,52$ & 1148,96 & 43 & 69,20 & & 0 & 0 \\
\hline 1166906,3 & 355,67 & 1540,7 & 469,61 & 0 & \begin{tabular}{l|}
$-1,52$ \\
\end{tabular} & 1148,96 & 43 & 69,20 & KM 394 & 0 & 0 \\
\hline 1167759,3 & 355,93 & 1540,7 & 469,61 & 0 & 0 & 0,00 & 43 & 69,20 & & 0 & 0 \\
\hline 1170183,8 & 356,67 & 1540,7 & 469,61 & 0 & 0 & 0,00 & 43 & 69,20 & & 0 & 0 \\
\hline 1170187 & 356,67 & 1540,7 & 469,61 & \begin{tabular}{l|l}
0 \\
\end{tabular} & 0 & 0,00 & 43 & 69,20 & KM 393 & 0 & 0 \\
\hline 1170958 & 356,91 & 1540,7 & 469,61 & \begin{tabular}{l|l}
0 \\
\end{tabular} & 2,24 & 779,68 & 43 & 69,20 & & 0 & 0 \\
\hline 1173464,5 & 357,67 & 1540,7 & 469,61 & 0 & 0 & 0,00 & 43 & 69,20 & & 0 & 0 \\
\hline 1173468 & 357,67 & 1540,7 & 469,61 & \begin{tabular}{l|l}
0 \\
\end{tabular} & 0 & 0,00 & \begin{tabular}{l|l}
43 \\
\end{tabular} & 69,20 & KM 392 & 0 & 0 \\
\hline
\end{tabular}




\begin{tabular}{|c|c|c|c|c|c|c|c|c|c|c|c|}
\hline \multicolumn{2}{|c|}{ Posição } & \multicolumn{2}{|c|}{ Elevação } & \multirow{2}{*}{$\begin{array}{c}\text { rampa } \\
(\%) \\
\end{array}$} & \multicolumn{2}{|c|}{ curva } & \multicolumn{2}{|c|}{$\begin{array}{c}\text { Limite de } \\
\text { velocidade }\end{array}$} & \multirow[t]{2}{*}{ nome do local } & \multirow[t]{2}{*}{ C 1} & C 2 \\
\hline (feet) & $(\mathrm{km})$ & (feet) & $(\mathrm{m})$ & & ${ }^{\circ}$ & $(\mathrm{m})$ & $\mathrm{MPH}$ & $\mathrm{km} / \mathrm{h}$ & & & \\
\hline 1174452 & 3557,97 & 1540,7 & 469,61| & 0 & \begin{tabular}{c|}
-18 \\
\end{tabular} & 801,14 & 433 & $\begin{array}{c}69,20 \\
\end{array}$ & & 0 & 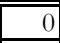 \\
\hline 1175994 & 358,44 & 1540,7 & 469,61 & 0 & 0 & 0,00 & 43 & 69,20 & & 0 & 0 \\
\hline 1176745,5 & 358,67 & 1540,7 & 469,61 & 0 & 0 & 0,00 & 43 & 69,20 & & 0 & 0 \\
\hline 1176748,8 & 358,67 & 1540,7 & 4469,61 & 0 & 0 & 0,00 & 43 & 69,20 & KM 391 & 0 & 0 \\
\hline 1176847,3 & 358,70 & 1540,7 & 4469,61 & 0 & 2,39 & 730,75 & 43 & 69,20 & & 0 & 0 \\
\hline 1178202 & 359,12 & 1540,7 & 469,61 & 0 & 2,39 & 730,75 & 43 & 69,20 & & 0 & 0 \\
\hline 1178205,5 & 359,12 & 1540,7 & 469,61 & 0 & 2,39 & 730,75 & 43 & 69,20 & SANTA SALETE (demolida) & 8 & 0 \\
\hline 1178553,3 & 359,22 & 1540,7 & 469,61 & 0 & 0 & 0,00 & 43 & 69,20 & & 0 & 0 \\
\hline 1179701,5 & 359,57 & 1540,7 & 469,61 & 0,5 & 0 & 0,00 & 43 & 69,20 & & 0 & 0 \\
\hline 1179734,3 & 359,58 & 1540,9 & 469,67 & 0,5 & $-2,79$ & 626,00 & 43 & 69,20 & & 0 & 0 \\
\hline 1180026,3 & 359,67 & 1542,4 & 470,12 & 0,5 & $-2,79$ & 626,00 & 43 & 69,20 & & 0 & 0 \\
\hline 1180029,5 & 359,67 & 1542,4 & 470,12 & 0,5 & $-2,79$ & 626,00 & 43 & 69,20 & KM 390 & 0 & 0 \\
\hline 1182654,3 & 360,47 & 1555,5 & 474,12 & 0 & $-2,79$ & 626,00 & 43 & 69,20 & & 0 & 0 \\
\hline 1182720 & 360,49 & 1555,5 & 474,12 & 0 & 0 & 0,00 & 43 & 69,20 & & 0 & 0 \\
\hline 1183307 & 360,67 & 1555,5 & 474,12 & 0 & 0 & 0,00 & 43 & 69,20 & & 0 & 0 \\
\hline 1183310,5 & 360,67 & 1555,5 & 474,12 & 0 & 0 & 0,00 & 43 & 69,20 & KM 389 & 0 & 0 \\
\hline 1183376 & 360,69 & 1555,5 & 474,12 & 0 & 2,79 & 626,00 & 43 & 69,20 & & 0 & 0 \\
\hline 1183966,5 & 360,87 & 1555,5 & 474,12 & 0,5 & 2,79 & 626,00 & 43 & 69,20 & & 0 & 0 \\
\hline 1186588 & 361,67 & 1568,6 & 478,11 & 0,5 & 2,79 & 626,00 & 43 & 69,20 & & 0 & 0 \\
\hline 1186591,3 & 361,67 & 1568,6 & 478,11 & 0,5 & 2,79 & 626,00 & 43 & 69,20 & KM 388 & 0 & 0 \\
\hline 1187969,3 & 362,09 & 1575,5 & 480,21 & 0,5 & 0 & 0,00 & 43 & 69,20 & & 0 & 0 \\
\hline 1188592,5 & 362,28 & 1578,6 & 481,16 & 0,5 & $-2,79$ & 626,00 & 43 & 69,20 & & 0 & 0 \\
\hline 1189868,8 & 362,67 & 1585 & 483,11 & 0 & $-2,79$ & 626,00 & 43 & 69,20 & & 0 & 0 \\
\hline 1189872 & 362,67 & 1585 & 483,11 & 0 & $-2,79$ & 626,00 & 43 & 69,20 & KM 387 & 0 & 0 \\
\hline 1190790,8 & 362,95 & 1585 & 483,11 & 0 & 0 & 0,00 & 43 & 69,20 & & 0 & 0 \\
\hline 1193126,8 & 363,67 & 1585 & 483,11 & 0 & 0 & 0,00 & 43 & 69,20 & & 0 & 0 \\
\hline 1193149,8 & 363,67 & 1585 & 483,11 & 0 & 0 & 0,00 & 43 & 69,20 & ZUR - FIM & 0 & 2 \\
\hline 1193153 & 363,67 & 1585 & 483,11 & $-0,5$ & 0 & 0,00 & 43 & 69,20 & KM 386 & 0 & 1 \\
\hline 1194199,5 & 363,99 & 1579,8 & 481,52 & $-0,5$ & 0 & 0,00 & 43 & 69,20 & & 0 & 1 \\
\hline 1194202,8 & 363,99 & 1579,8 & 481,52 & $-0,5$ & 0 & 0,00 & 43 & 69,20 & URANIA & 8 & 1 \\
\hline 1194413,8 & 364,06 & 1578,7 & 481,19 & $-0,5$ & 0 & 0,00 & 43 & 69,20 & & 0 & 1 \\
\hline 1195384 & 364,35 & 1573,9 & 479,72 & $-0,5$ & 1,73 & 1009,50 & 19 & 30,58 & PN - Perímetro urbano & 0 & 1 \\
\hline 1195387,3 & 364,35 & 1573,8 & 4779,69 & $-0,5$ & 1,73 & 1009,50 & 19 & 30,58 & PN - Perímetro urbano & 0 & 1 \\
\hline 1195439,8 & 364,37 & 1573,6 & 4479,63 & $-0,5$ & 1,73 & $\begin{array}{l}1009,50 \\
\end{array}$ & 19 & 30,58 & ZUR - INICIO & 0 & 3 \\
\hline 1195777,5 & 364,47 & 1571,9 & 4779,12 & 0 & 1,73 & 1009,50 & 19 & 30,58 & PN - Perímetro urbano & 0 & 0 \\
\hline 1196245,5 & 364,62 & 1571,9 & 479,12 & 0 & 1,73 & 1009,50 & 19 & 30,58 & PN - Perímetro urbano & 0 & 0 \\
\hline 1196430,5 & 364,67 & 1571,9 & 479,12 & 0,5 & 1,73 & 1009,50 & 43 & 69,20 & & 0 & 0 \\
\hline 1196433,8 & 364,67 & 1571,9 & 479,12 & 0,5 & 1,73 & 1009,50 & 43 & 69,20 & KM 385 & 0 & 0 \\
\hline 1197352,5 & 364,95 & 1576,5 & 480,52 & 0,5 & 0 & 0,00 & 43 & 69,20 & & 0 & 0 \\
\hline 1199711,3 & 365,67 & 1588,3 & 484,11 & 0,5 & 0 & 0,00 & 43 & 69,20 & & 0 & 0 \\
\hline 1199714,5 & 365,67 & 1588,3 & 484,11 & 0,5 & 0 & 0,00 & 43 & 69,20 & KM 384 & 0 & 0 \\
\hline 1200628,8 & 365,95 & 1592,9 & 485,52 & 0,5 & 0 & 0,00 & 31 & 49,89 & & 0 & 0 \\
\hline 1201610 & 366,25 & 1597,8 & \begin{tabular}{|l|l|}
487,01 \\
\end{tabular} & 0,5 & 0 & 0,00 & 31 & 49,89 & & 0 & 0 \\
\hline 1202992,3 & 366,67 & 1604,7 & 489,11 & 0,5 & 0 & 0,00 & 43 & 69,20 & & 0 & 0 \\
\hline 1202995,5 & 366,67 & 1604,7 & 489,11 & 0,5 & 0 & 0,00 & 43 & 69,20 & KM 383 & 0 & 0 \\
\hline 1204045,3 & 366,99 & 1610 & 490,73 & 0,5 & $-2,79$ & 626,00 & 43 & 69,20 & & 0 & 0 \\
\hline 1206273 & 367,67 & 1621,1 & 494,11 & 0,5 & $-2,79$ & 626,00 & 43 & 69,20 & & 0 & 0 \\
\hline 1206276,3 & 367,67 & 1621,1 & 494,11 & 0,5 & $-2,79$ & 626,00 & 43 & 69,20 & KM 382 & 0 & 0 \\
\hline 1206342 & 367,69 & 1621,5 & \begin{tabular}{|l|}
494,23 \\
\end{tabular} & 0,5 & 0 & 0,00 & 43 & 69,20 & & 0 & 0 \\
\hline 1207063,8 & 367,91 & 1625,1 & 495,33 & 0,5 & $-2,79$ & 626,00 & 43 & 69,20 & & 0 & 0 \\
\hline 1208146,5 & 368,24 & 1630,5 & 496,98 & 0,5 & 0 & 0,00 & 43 & 69,20 & & 0 & 0 \\
\hline 1209133,5 & 368,54 & 1635,4 & 4998,47 & 0,5 & 0 & 0,00 & 31 & 49,89 & & 0 & 0 \\
\hline 1209554 & 368,67 & 1637,5 & \begin{tabular}{|l|}
499,11 \\
\end{tabular} & 0,5 & 0 & 0,00 & 31 & 49,89 & & 0 & 0 \\
\hline 1209557 & 368,67 & 1637,5 & 4999,11 & 0,5 & 0 & 0,00 & 31 & 49,89 & KM 381 & 0 & 0 \\
\hline 1210769 & 369,04 & 1643,6 & 500,97 & 0,5 & 0 & 0,00 & 31 & 49,89 & & 0 & 0 \\
\hline 1212834,8 & 369,67 & 1653,9 & 504,11 & 0,5 & 0 & 0,00 & 43 & 69,20 & & 0 & 0 \\
\hline 1212838 & 369,67 & 1653,9 & 504,11 & 0,5 & 0 & 0,00 & 43 & 69,20 & KM 380 & 0 & 0 \\
\hline 1213002 & 369,72 & 1654,8 & 504,38 & 0,5 & $-2,79$ & 626,00 & 43 & 69,20 & & 0 & 0 \\
\hline 1214823 & 370,28 & 1663,9 & $\begin{array}{l}507,16 \\
\end{array}$ & 0 & $-2,79$ & 626,00 & 43 & 69,20 & & 0 & 0 \\
\hline 1215233 & 370,40 & 1663,9 & 507,16 & 0 & 0 & 0,00 & 43 & 69,20 & & 0 & 0 \\
\hline 1215790,8 & 370,57 & 1663,9 & 507,16 & 0,5 & 0 & 0,00 & 43 & 69,20 & & 0 & 0 \\
\hline 1216115,5 & 370,67 & 1665,5 & 507,64 & 0,5 & $-2,79$ & 626,00 & 43 & 69,20 & & 0 & 0 \\
\hline 1216118,8 & 370,67 & 1665,5 & 507,64 & 0,5 & 2,79 & 626,00 & 43 & 69,20 & KM 379 & 0 & 0 \\
\hline 1217431 & 371,07 & 1672,1 & 509,66 & 0,5 & 0 & 0,00 & 43 & 69,20 & & 0 & 0 \\
\hline 1219396,5 & 371,67 & 1681,9 & 512,64 & 0,5 & 0 & 0,00 & 43 & 69,20 & & 0 & 0 \\
\hline 1219399,8 & 371,67 & 1681,9 & \begin{tabular}{l|l}
512,64 \\
\end{tabular} & 0,5 & 0 & 0,00 & 43 & 69,20 & KM 378 & 0 & 0 \\
\hline 1219924,5 & 371,83 & 1684,5 & 513,44 & 0,5 & 2,79 & 626,00 & 43 & 69,20 & & 0 & 0 \\
\hline 1221565 & 372,33 & 1692,7 & 515,93 & 0,5 & 0 & 0,00 & 43 & 69,20 & & 0 & 0 \\
\hline 1222254 & 372,54 & 1696,2 & 517,00 & 0,5 & $-2,79$ & 626,00 & 43 & 69,20 & & 0 & 0 \\
\hline 1222677,3 & 372,67 & 1698,3 & 517,64 & 0,5 & $-2,79$ & 626,00 & 43 & 69,20 & & 0 & 0 \\
\hline 1222680,5 & 372,67 & 1698,3 & 517,64 & 0,5 & $-2,79$ & 626,00 & 43 & 69,20 & KM 377 & 0 & 0 \\
\hline
\end{tabular}




\begin{tabular}{|c|c|c|c|c|c|c|c|c|c|c|c|}
\hline \multicolumn{2}{|c|}{ Posição } & \multicolumn{2}{|c|}{ Elevação } & \multirow{2}{*}{\begin{tabular}{c|} 
rampa \\
$(\%)$ \\
\end{tabular}} & \multicolumn{2}{|c|}{ curva } & \multicolumn{2}{|c|}{$\begin{array}{c}\text { Limite de } \\
\text { velocidade }\end{array}$} & \multirow[t]{2}{*}{ nome do local } & \multirow[t]{2}{*}{ C 1} & C 2 \\
\hline (feet) & $(\mathrm{km})$ & (feet) & $(\mathrm{m})$ & & ${ }^{\circ}$ & $(\mathrm{m})$ & MPH & $\mathrm{km} / \mathrm{h}$ & & & \\
\hline 1223008,5 & 372,77 & \begin{tabular}{ll|}
1699,9 \\
\end{tabular} & 518,13 & 0 & \begin{tabular}{|c|}
$-2,79$ \\
\end{tabular} & 626,00 & 43 & 69,20 & & 0 & 0 \\
\hline 1223992,8 & 373,07 & 1699,9 & 518,13 & $-0,5$ & \begin{tabular}{|c|}
$-2,78$ \\
\end{tabular} & 628,25 & 43 & 69,20 & & 0 & 0 \\
\hline 1224419,3 & 373,20 & 1697,8 & 517,49 & $-0,5$ & 0 & 0,00 & 43 & 69,20 & & 0 & 0 \\
\hline 1225958 & 373,67 & 1690,1 & 515,14 & $-0,5$ & 0 & 0,00 & 43 & 69,20 & & 0 & 0 \\
\hline 1225961,3 & 373,67 & \begin{tabular}{c|}
1690,1 \\
\end{tabular} & 515,14 & $-0,5$ & 0 & 0,00 & 43 & 69,20 & KM 376 & 0 & 0 \\
\hline 1226617,5 & 373,87 & 1686,8 & 514,14 & 0 & 0 & 0,00 & 43 & 69,20 & & 0 & 0 \\
\hline 1227142,5 & 374,03 & 1686,8 & 514,14 & 0 & 1,52 & 1148,96 & 43 & 69,20 & & 0 & 0 \\
\hline 1228760 & 374,53 & 1686,8 & 514,14 & 0 & 1,52 & 1148,96 & 43 & 69,20 & & 0 & 0 \\
\hline 1228979,8 & 374,59 & 1686,8 & 514,14 & 0 & 0 & 0,00 & 19 & 30,58 & PN - Perímetro urbano & 0 & 0 \\
\hline 1229239 & 374,67 & 1686,8 & 514,14 & 0 & 0 & 0,00 & 19 & 30,58 & PN - Perímetro urbano & 0 & 0 \\
\hline 1229242,3 & 374,67 & 1686,8 & 514,14 & 0 & 0 & 0,00 & 19 & 30,58 & KM 375 & 0 & 0 \\
\hline 1231540,5 & 375,37 & 1686,8 & 514,14 & 0 & 0 & 0,00 & 19 & 30,58 & PN - Perímetro urbano & 0 & 0 \\
\hline 1232519,8 & 375,67 & 1686,8 & 514,14 & 0 & 0 & 0,00 & 43 & 69,20 & & 0 & 0 \\
\hline 1232523 & 375,67 & 1686,8 & 514,14 & 0 & 0 & 0,00 & 43 & 69,20 & KM 374 & 0 & 0 \\
\hline 1232613 & 375,70 & 1686,8 & 514,14 & 0 & 0 & 0,00 & 43 & 69,20 & & 0 & 0 \\
\hline 1233221,8 & 375,89 & 1686,8 & 514,14 & 0 & 0 & 0,00 & 19 & 30,58 & Perímetro urbano & 0 & 0 \\
\hline 1233274,3 & 375,90 & 1686,8 & 514,14 & 0 & 0 & 0,00 & 19 & 30,58 & ZJA - FIM & 0 & 2 \\
\hline 1235147,8 & 376,47 & 1686,8 & 514,14 & 0,5 & 0 & 0,00 & 19 & 30,58 & Perímetro urbano & 0 & 1 \\
\hline 1235193,5 & 376,49 & 1687,1 & 514,23 & 0,5 & 0 & 0,00 & 19 & 30,58 & Perímetro urbano & 0 & 1 \\
\hline 1235197 & 376,49 & 1687,1 & 514,23 & 0,5 & 0 & 0,00 & 19 & 30,58 & JALES & 8 & 1 \\
\hline 1235800,5 & 376,67 & 1690,1 & 515,14 & 0,5 & 0 & 0,00 & 19 & 30,58 & Perímetro urbano & 0 & 1 \\
\hline 1235804 & 376,67 & 1690,1 & 515,14 & 0,5 & 0 & 0,00 & 19 & 30,58 & KM 373 & 0 & 1 \\
\hline 1236342 & 376,84 & 1692,8 & 515,97 & 0,5 & 0 & 0,00 & 19 & 30,58 & Perímetro urbano & 0 & 1 \\
\hline 1236394,5 & 376,85 & 1693,1 & 516,06 & 0,5 & 0 & 0,00 & 19 & 30,58 & ZJA - INICIO & 0 & 3 \\
\hline 1236588,3 & 376,91 & 1694 & 516,33 & 0,5 & 0 & 0,00 & 19 & 30,58 & Perímetro urbano & 0 & 0 \\
\hline 1239081,5 & 377,67 & 1706,5 & 520,14 & 0,5 & 0 & 0,00 & 43 & 69,20 & & 0 & 0 \\
\hline 1239084,8 & 377,67 & 1706,5 & 520,14 & 0,5 & 0 & 0,00 & 43 & 69,20 & KM 372 & 0 & 0 \\
\hline 1239937,8 & 377,93 & 1710,8 & 521,45 & 0,5 & 2,79 & 626,00 & 43 & 69,20 & & 0 & 0 \\
\hline 1241479,8 & 378,40 & 1718,5 & 523,80 & 0,5 & 0 & 0,00 & 43 & 69,20 & & 0 & 0 \\
\hline 1242362,3 & 378,67 & 1722,9 & 525,14 & 0,5 & 0 & 0,00 & 43 & 69,20 & & 0 & 0 \\
\hline 1242365,5 & 378,67 & 1722,9 & 525,14 & 0,5 & 0 & 0,00 & 43 & 69,20 & KM 371 & 0 & 0 \\
\hline 1242628 & 378,75 & 1724,2 & 525,54 & 0,5 & \begin{tabular}{|l|}
$-2,79$ \\
\end{tabular} & 626,00 & 43 & 69,20 & & 0 & 0 \\
\hline 1243021,8 & 378,87 & 1726,2 & 526,15 & 0,5 & 0 & 0,00 & 43 & 69,20 & & 0 & 0 \\
\hline 1243678 & 379,07 & 1729,5 & 527,15 & 0,5 & $-2,79$ & 626,00 & 43 & 69,20 & & 0 & 0 \\
\hline 1245613,5 & 379,66 & 1739,2 & 530,11 & 0,5 & 0 & 0,00 & 43 & 69,20 & & 0 & 0 \\
\hline 1245643 & 379,67 & 1739,3 & 530,14 & 0,5 & 0 & 0,00 & 43 & 69,20 & & 0 & 0 \\
\hline 1245646,5 & 379,67 & 1739,3 & 530,14 & 0,5 & 0 & 0,00 & 43 & 69,20 & KM 370 & 0 & 0 \\
\hline 1248924 & 380,67 & 1755,7 & 535,14 & 0,5 & 0 & 0,00 & 43 & 69,20 & & 0 & 0 \\
\hline 1248927,3 & 380,67 & 1755,7 & 535,14 & 0,5 & 0 & 0,00 & 43 & 69,20 & KM 369 & 0 & 0 \\
\hline 1251945,5 & 381,59 & 1770,8 & 539,74 & 0 & 0 & 0,00 & 43 & 69,20 & & 0 & 0 \\
\hline 1252044 & 381,62 & 1770,8 & 539,74 & 0 & 2,79 & 626,00 & 43 & 69,20 & & 0 & 0 \\
\hline 1252204,8 & 381,67 & 1770,8 & 539,74 & 0 & 2,79 & 626,00 & 43 & 69,20 & & 0 & 0 \\
\hline 1252208 & 381,67 & 1770,8 & 539,74 & 0 & 2,79 & 626,00 & 43 & 69,20 & KM 368 & 0 & 0 \\
\hline 1252601,8 & 381,79 & 1770,8 & 539,74 & $-0,5$ & 2,79 & 626,00 & 43 & 69,20 & & 0 & 0 \\
\hline 1254078 & 382,24 & 1763,4 & 537,48 & $-0,5$ & 0 & 0,00 & 43 & 69,20 & & 0 & 0 \\
\hline 1254898,3 & 382,49 & 1759,3 & 536,23 & $-0,5$ & \begin{tabular}{l|l|}
$-2,79$ \\
\end{tabular} & 626,00 & 43 & 69,20 & & 0 & 0 \\
\hline 1255485,5 & 382,67 & 1756,4 & 535,35 & $-0,5$ & \begin{tabular}{|l|}
$-2,79$ \\
\end{tabular} & 626,00 & 43 & 69,20 & & 0 & 0 \\
\hline 1255489 & 382,67 & 1756,4 & 535,35 & $-0,5$ & \begin{tabular}{|l|}
$-2,79$ \\
\end{tabular} & 626,00 & 43 & 69,20 & KM 367 & 0 & 0 \\
\hline 1257457,5 & 383,27 & 1746,5 & 532,33 & $-0,5$ & \begin{tabular}{|l|}
$-2,79$ \\
\end{tabular} & 626,00 & 43 & 69,20 & & 0 & 0 \\
\hline 1258310,5 & 383,53 & 1742,3 & 531,05 & $-0,5$ & 2,79 & 626,00 & 43 & 69,20 & & 0 & 0 \\
\hline 1258766,5 & 383,67 & 1740 & 530,35 & $-0,5$ & 2,79 & 626,00 & 43 & 69,20 & & 0 & 0 \\
\hline 1258769,8 & 383,67 & 1740 & 530,35 & $-0,5$ & 2,79 & 626,00 & 43 & 69,20 & KM 366 & 0 & 0 \\
\hline 1259852,5 & 384,00 & \begin{tabular}{ll|}
1734,6 \\
\end{tabular} & 528,71 & $-0,5$ & 0 & 0,00 & 43 & 69,20 & & 0 & 0 \\
\hline 1261952 & 384,64 & 1724,1 & 525,51 & $-0,5$ & $\begin{array}{l}-2,18 \\
\end{array}$ & 801,14 & 43 & 69,20 & & 0 & 0 \\
\hline 1262047,3 & 384,67 & 1723,6 & 525,35 & $-0,5$ & $-2,18$ & 801,14 & 43 & 69,20 & & 0 & 0 \\
\hline 1262050,5 & 384,67 & 1723,6 & 525,35 & $-0,5$ & \begin{tabular}{|l|}
$-2,18$ \\
\end{tabular} & 801,14 & 43 & 69,20 & KM 365 & 0 & 0 \\
\hline 1262969,3 & 384,95 & 1719 & 523,95 & 0 & 0 & 0,00 & 43 & 69,20 & & 0 & 0 \\
\hline 1263428,5 & 385,09 & 1719 & 523,95 & $-0,53$ & 0 & 0,00 & 43 & 69,20 & & 0 & 0 \\
\hline 1265328 & 385,67 & 1708,9 & 520,87 & $-0,53$ & \begin{tabular}{l|l|}
$-2,18$ \\
\end{tabular} & 801,14 & 43 & 69,20 & & 0 & 0 \\
\hline 1265331,5 & 385,67 & 1708,9 & 520,87 & $-0,53$ & $\begin{array}{l}-2,18 \\
\end{array}$ & 801,14 & 43 & 69,20 & KM 364 & 0 & 0 \\
\hline 1266184,5 & 385,93 & 1704,4 & 519,50 & $-0,53$ & 0 & 0,00 & 43 & 69,20 & & 0 & 0 \\
\hline 1267334,5 & 386,28 & 1698,3 & 517,64 & $-0,53$ & 0 & 0,00 & 16 & 25,75 & & 0 & 0 \\
\hline 1268609 & 386,67 & 1691,5 & 515,57 & 0,53 & 0 & 0,00 & 16 & 25,75 & & 0 & 0 \\
\hline 1268612,3 & 386,67 & 1691,5 & 515,57 & 0,53 & \begin{tabular}{l|l}
0 \\
\end{tabular} & 0,00 & 16 & 25,75 & KM 363 & 0 & 0 \\
\hline 1268973 & 386,78 & 1693,4 & 516,15 & 0 & 0 & 0,00 & 16 & 25,75 & & 0 & 0 \\
\hline 1269544,5 & 386,96 & 1693,4 & 516,15 & 0 & 0 & 0,00 & 16 & 25,75 & & 0 & 0 \\
\hline 1269662 & 386,99 & 1693,4 & 516,15 & $-0,5$ & 0 & 0,00 & 43 & 69,20 & & 0 & 0 \\
\hline 1269793,5 & 387,03 & 1692,8 & 515,97 & $-0,5$ & 2,79 & 626,00 & 43 & 69,20 & & 0 & 0 \\
\hline 1271889,8 & 387,67 & 1682,3 & 512,77 & $-0,5$ & 2,79 & 626,00 & 43 & 69,20 & & 0 & 0 \\
\hline 1271893 & 387,67 & 1682,3 & 512,77 & $-0,5$ & 2,79 & 626,00 & 43 & 69,20 & KM 362 & 0 & 0 \\
\hline 1272024,3 & 387,71 & 1681,6 & 512,55 & $-0,5$ & 0 & 0,00 & 43 & 69,20 & & 0 & 0 \\
\hline
\end{tabular}




\begin{tabular}{|c|c|c|c|c|c|c|c|c|c|c|c|}
\hline \multicolumn{2}{|c|}{ Posição } & \multicolumn{2}{|c|}{ Elevação } & \multirow{2}{*}{$\begin{array}{c}\text { rampa } \\
(\%)\end{array}$} & \multicolumn{2}{|c|}{ curva } & \multicolumn{2}{|c|}{$\begin{array}{c}\text { Limite de } \\
\text { velocidade }\end{array}$} & \multirow[t]{2}{*}{ nome do local } & \multirow[t]{2}{*}{ C 1} & C 2 \\
\hline (feet) & $(\mathrm{km})$ & (feet) & $(\mathrm{m})$ & & $\mathrm{o}^{\circ}$ & $(\mathrm{m})$ & MPH & $\mathrm{km} / \mathrm{h}$ & & & \\
\hline \begin{tabular}{|l|}
1272877,3 \\
\end{tabular} & $\begin{array}{l}387,97 \\
\end{array}$ & $\mid 1677,4$ & \begin{tabular}{|l|}
511,27 \\
\end{tabular} & $\begin{array}{ll}-0,5 \\
\end{array}$ & \begin{tabular}{|l|}
$-2,18$ \\
\end{tabular} & 801,14 & 43 & 69,20 & & 0 & 0 \\
\hline 1275170,5 & 388,67 & 1665,9 & 507,77 & $-0,5$ & \begin{tabular}{|l|}
$-2,18$ \\
\end{tabular} & 801,14 & 43 & 69,20 & & 0 & 0 \\
\hline 1275174 & 388,67 & 1665,9 & $\begin{array}{l}507,77 \\
\end{array}$ & $-0,5$ & \begin{tabular}{|l|}
$-2,18$ \\
\end{tabular} & 801,14 & 43 & 69,20 & KM 361 & 0 & 0 \\
\hline 1275338 & 388,72 & 1665,1 & 507,52 & $-0,5$ & 0 & 0,00 & 43 & 69,20 & & 0 & 0 \\
\hline 1277667,5 & 389,43 & \begin{tabular}{ll|}
1653,4 \\
\end{tabular} & 503,96 & $-0,5$ & 1,52 & 1148,96 & 43 & 69,20 & & 0 & 0 \\
\hline 1278258 & 389,61 & 1650,5 & 503,07 & $-0,5$ & 0 & 0,00 & 43 & 69,20 & & 0 & 0 \\
\hline 1278451,5 & 389,67 & 1649,5 & 502,77 & $-0,5$ & 0 & 0,00 & 43 & 69,20 & & 0 & 0 \\
\hline 1278454,8 & 389,67 & 1649,5 & 502,77 & $-0,5$ & 0 & 0,00 & 43 & 69,20 & KM 360 & 0 & 0 \\
\hline 1278881,3 & 389,80 & 1647,3 & 502,10 & 0 & 0 & 0,00 & 43 & 69,20 & & 0 & 0 \\
\hline 1279832,8 & 390,09 & 1647,3 & 502,10 & 0,5 & 0 & 0,00 & 43 & 69,20 & & 0 & 0 \\
\hline 1281732,3 & 390,67 & 1656,8 & 504,99 & 0,5 & 0 & 0,00 & 43 & 69,20 & & 0 & 0 \\
\hline \begin{tabular}{l|l|}
1281735,5 \\
\end{tabular} & 390,67 & 1656,9 & 505,02 & 0,5 & 0 & 0,00 & 43 & 69,20 & KM 359 & 0 & 0 \\
\hline 1282490,3 & 390,90 & 1660,6 & 506,15 & 0 & 0 & 0,00 & 43 & 69,20 & & 0 & 0 \\
\hline 1283113,5 & 391,09 & 1660,6 & 506,15 & $-0,5$ & 0 & 0,00 & 43 & 69,20 & & 0 & 0 \\
\hline 1283638,5 & 391,25 & 1658 & 505,36 & $-0,5$ & \begin{tabular}{|l|}
$-2,79$ \\
\end{tabular} & 626,00 & 43 & 69,20 & & 0 & 0 \\
\hline 1285013,3 & 391,67 & 1651,1 & 503,26 & $-0,5$ & $\begin{array}{l}-2,79 \\
\end{array}$ & 626,00 & 43 & 69,20 & & 0 & 0 \\
\hline 1285016,5 & 391,67 & \begin{tabular}{ll|}
1651,1 \\
\end{tabular} & 503,26 & $-0,5$ & \begin{tabular}{|l|}
$-2,79$ \\
\end{tabular} & 626,00 & 43 & 69,20 & KM 358 & 0 & 0 \\
\hline 1285115 & 391,70 & 1650,6 & 503,10 & $-0,5$ & 0 & 0,00 & 43 & 69,20 & & 0 & 0 \\
\hline 1285410 & 391,79 & 1649,2 & 502,68 & 0 & 0 & 0,00 & 43 & 69,20 & & 0 & 0 \\
\hline 1287090 & 392,31 & 1649,2 & 502,68 & 0 & 0 & 0,00 & 43 & 69,20 & & 0 & 0 \\
\hline 1287142,5 & 392,32 & 1649,2 & 502,68 & 0 & 0 & 0,00 & 43 & 69,20 & ZED - FIM & 0 & 2 \\
\hline 1288021,8 & 392,59 & 1649,2 & 502,68 & 0 & 0 & 0,00 & 43 & 69,20 & & 0 & 1 \\
\hline 1288025 & 392,59 & 1649,2 & 502,68 & 0 & 0 & 0,00 & 43 & 69,20 & ESTRELA D'OESTE & 8 & 1 \\
\hline 1288294 & 392,67 & 1649,2 & 502,68 & 0 & 0 & 0,00 & 43 & 69,20 & & 0 & 1 \\
\hline 1288297,3 & 392,67 & 1649,2 & 502,68 & 0 & 0 & 0,00 & 43 & 69,20 & KM 357 & 0 & 1 \\
\hline 1289471,8 & 393,03 & 1649,2 & 502,68 & 0 & 0 & 0,00 & 43 & 69,20 & & 0 & 1 \\
\hline 1289524,3 & 393,05 & 1649,2 & 502,68 & 0 & 0 & 0,00 & 43 & 69,20 & ZED - INICIO & 0 & 3 \\
\hline 1290036 & 393,20 & 1649,2 & 502,68 & 0,5 & 0 & 0,00 & 43 & 69,20 & & 0 & 0 \\
\hline 1290200,3 & 393,25 & 1650 & 502,92 & 0,5 & \begin{tabular}{ll|}
$-2,79$ \\
\end{tabular} & 626,00 & 43 & 69,20 & & 0 & 0 \\
\hline 1290659,5 & 393,39 & 1652,3 & 503,62 & 0,5 & 0 & 0,00 & 43 & 69,20 & & 0 & 0 \\
\hline 1291414 & 393,62 & 1656 & 504,75 & 0,5 & 2,24 & 779,68 & 43 & 69,20 & & 0 & 0 \\
\hline 1292972,5 & 394,10 & 1663,8 & \begin{tabular}{|l|l|}
507,13 \\
\end{tabular} & 0 & 2,24 & 779,68 & 43 & 69,20 & & 0 & 0 \\
\hline 1293628,8 & 394,30 & 1663,8 & \begin{tabular}{|l|}
507,13 \\
\end{tabular} & $-0,5$ & 2,24 & 779,68 & 43 & 69,20 & & 0 & 0 \\
\hline 1295597,3 & 394,90 & 1654 & 504,14 & $-0,5$ & 0 & 0,00 & 43 & 69,20 & & 0 & 0 \\
\hline 1297106,3 & 395,36 & 1646,4 & \begin{tabular}{|l|}
501,82 \\
\end{tabular} & $-0,5$ & 2,79 & 626,00 & 43 & 69,20 & & 0 & 0 \\
\hline 1297254,5 & 395,40 & 1645,7 & 501,61 & $-0,5$ & 2,79 & 626,00 & 25 & 40,23 & & 0 & 0 \\
\hline 1298008,5 & 395,63 & 1641,9 & 500,45 & $-0,5$ & 0 & 0,00 & 25 & 40,23 & & 0 & 0 \\
\hline 1298205,5 & 395,69 & 1641 & 500,18 & 0 & 0 & 0,00 & 25 & 40,23 & & 0 & 0 \\
\hline 1298954,5 & 395,92 & 1641 & 500,18 & 0 & 0 & 0,00 & 25 & 40,23 & & 0 & 0 \\
\hline 1299189,8 & 395,99 & 1641 & 500,18 & 0,5 & 0 & 0,00 & 43 & 69,20 & & 0 & 0 \\
\hline 1300137,8 & 396,28 & 1645,7 & 501,61 & 0,5 & \begin{tabular}{|l|}
$-2,79$ \\
\end{tabular} & 626,00 & 43 & 69,20 & & 0 & 0 \\
\hline 1303471,3 & 397,30 & 1662,4 & 506,70 & 0,5 & 0 & 0,00 & 43 & 69,20 & & 0 & 0 \\
\hline 1305275,5 & 397,85 & 1671,4 & 509,44 & 0,5 & 2,79 & 626,00 & 43 & 69,20 & & 0 & 0 \\
\hline 1307326,3 & 398,47 & 1681,6 & 512,55 & 0,5 & 0 & 0,00 & 43 & 69,20 & & 0 & 0 \\
\hline 1309475 & 399,13 & 1692,4 & 515,84 & 0,5 & \begin{tabular}{|l|}
$-2,79$ \\
\end{tabular} & 626,00 & 43 & 69,20 & & 0 & 0 \\
\hline 1310344,5 & 399,39 & 1696,7 & 517,15 & 0 & \begin{tabular}{l|l|}
$-2,79$ \\
\end{tabular} & 626,00 & 43 & 69,20 & & 0 & 0 \\
\hline 1312122,8 & 399,94 & 1696,7 & 517,15 & 0 & 0 & 0,00 & 43 & 69,20 & & 0 & 0 \\
\hline 1313372,8 & 400,32 & 1696,7 & 517,15 & 0 & 2,79 & 626,00 & 43 & 69,20 & & 0 & 0 \\
\hline 1315282,3 & 400,90 & 1696,7 & 517,15 & 0 & 0 & 0,00 & 43 & 69,20 & & 0 & 0 \\
\hline 1316515,8 & 401,27 & 1696,7 & \begin{tabular}{|l|}
517,15 \\
\end{tabular} & 0 & 2,79 & 626,00 & 43 & 69,20 & & 0 & 0 \\
\hline 1317710 & 401,64 & \begin{tabular}{ll|}
1696,7 \\
\end{tabular} & 517,15 & 0 & 0 & 0,00 & 43 & 69,20 & & 0 & 0 \\
\hline 1318415,5 & 401,85 & 1696,7 & 517,15 & 0 & \begin{tabular}{|l|}
$-2,79$ \\
\end{tabular} & 626,00 & 43 & 69,20 & & 0 & 0 \\
\hline 1319337,3 & 402,13 & \begin{tabular}{l|l|}
1696,7 \\
\end{tabular} & 517,15 & 0 & 0 & 0,00 & 43 & 69,20 & & 0 & 0 \\
\hline 1321171,3 & 402,69 & 1696,7 & 517,15 & 0,5 & 0 & 0,00 & 43 & 69,20 & & 0 & 0 \\
\hline 1326420,5 & 404,29 & 1723 & 525,17 & 0 & 0 & 0,00 & 43 & 69,20 & & 0 & 0 \\
\hline 1330029,5 & 405,39 & 1723 & 525,17 & $-0,5$ & 0 & 0,00 & 43 & 69,20 & & 0 & 0 \\
\hline 1331998 & 405,99 & 1713,1 & 522,15 & 0 & 0 & 0,00 & 43 & 69,20 & & 0 & 0 \\
\hline 1334557 & 406,77 & 1713,1 & 522,15 & 0,5 & 0 & 0,00 & 43 & 69,20 & & 0 & 0 \\
\hline 1336394,5 & 407,33 & 1722,3 & 524,96 & 0,5 & \begin{tabular}{l|l|}
$-2,79$ \\
\end{tabular} & 626,00 & 43 & 69,20 & & 0 & 0 \\
\hline 1336813,5 & 407,46 & 1724,4 & 525,60 & 0,5 & \begin{tabular}{|l|}
$-2,79$ \\
\end{tabular} & 626,00 & 43 & 69,20 & & 0 & 0 \\
\hline 1336881,5 & 407,48 & 1724,8 & \begin{tabular}{|l|}
525,72 \\
\end{tabular} & 0,5 & $\begin{array}{l}-2,79 \\
\end{array}$ & 626,00 & 19 & 30,58 & PN - Rodovia & 5 & 0 \\
\hline 1338379,3 & 407,94 & 1732,2 & 527,97 & 0,5 & 0 & 0,00 & 43 & 69,20 & & 0 & 0 \\
\hline 1339068,3 & 408,15 & 1735,7 & 529,04 & 0,5 & 2,79 & 626,00 & 43 & 69,20 & & 0 & 0 \\
\hline 1340905,5 & 408,71 & 1744,9 & 531,85 & 0,5 & 0 & 0,00 & 43 & 69,20 & & 0 & 0 \\
\hline 1343743,5 & 409,57 & 1759,1 & 536,17 & 0,5 & 2,24 & 779,68 & 43 & 69,20 & & 0 & 0 \\
\hline 1344458,8 & 409,79 & \begin{tabular}{ll|}
1762,6 \\
\end{tabular} & 537,24 & 0 & 2,24 & 7779,68 & 43 & 69,20 & & 0 & 0 \\
\hline 1344859 & 409,91 & 1762,6 & 537,24 & 0 & 0 & 0,00 & 43 & 69,20 & & 0 & 0 \\
\hline 1345446,3 & 410,09 & 1762,6 & 537,24 & 0 & 0 & 0,00 & 43 & 69,20 & & 0 & 0 \\
\hline 1345498,8 & 410,11 & 1762,6 & 537,24 & 0 & 0 & 0,00 & 19 & 30,58 & ZFN - FIM & 0 & 2 \\
\hline 1347057 & 410,58 & 1762,6 & 537,24 & 0 & $-3,96$ & 441,09 & 43 & 69,20 & & 0 & 1 \\
\hline 1347122,8 & 410,60 & 1762,6 & 537,24 & 0 & \begin{tabular}{|c|}
$-3,96$ \\
\end{tabular} & 441,09 & 43 & 69,20 & & 0 & 1 \\
\hline
\end{tabular}




\begin{tabular}{|c|c|c|c|c|c|c|c|c|c|c|c|}
\hline \multicolumn{2}{|c|}{ Posição } & \multicolumn{2}{|c|}{ Elevação } & \multirow{2}{*}{$\frac{\text { rampa }}{(\%)}$} & \multicolumn{2}{|c|}{ curva } & \multicolumn{2}{|c|}{$\begin{array}{c}\text { Limite de } \\
\text { velocidade }\end{array}$} & \multirow[t]{2}{*}{ nome do local } & \multirow[t]{2}{*}{ C 1} & C 2 \\
\hline (feet) & $(\mathrm{km})$ & (feet) & $(\mathrm{m})$ & & o & $(\mathrm{m})$ & $\mathrm{MPH}$ & $\mathrm{km} / \mathrm{h}$ & & & \\
\hline 1347126 & 410,60 & 1762,6 & 537,24 & 0 & $-3,96$ & 441,09 & 43 & 69,20 & FERNANDOPOLIS & 8 & 1 \\
\hline 1347355,3 & 410,67 & 1762,6 & 537,24 & 0 & $-3,96$ & 441,09 & 19 & 30,58 & & 0 & 1 \\
\hline 1347586,3 & 410,74 & 1762,6 & 537,24 & 0 & $-3,96$ & $\begin{array}{ll}441,09 \\
\end{array}$ & 19 & 30,58 & & 0 & 1 \\
\hline 1347975,8 & 410,86 & 1762,6 & \begin{tabular}{l|l|}
537,24 \\
\end{tabular} & 0 & 0 & 0,00 & 43 & 69,20 & & 0 & 1 \\
\hline 1348107 & 410,90 & 1762,6 & 537,24 & 0 & 0 & 0,00 & 43 & 69,20 & & 0 & 1 \\
\hline 1348159,5 & 410,92 & 1762,6 & \begin{tabular}{|l|}
537,24 \\
\end{tabular} & 0 & 0 & 0,00 & 19 & 30,58 & ZFN - INICIO & 0 & 3 \\
\hline 1348792,8 & 411,11 & 1762,6 & 537,24 & $-0,5$ & 0 & 0,00 & 43 & 69,20 & & 0 & 0 \\
\hline 1350525 & 411,64 & 1754 & 534,62 & $-0,5$ & 3,35 & 521,38 & 43 & 69,20 & & 0 & 0 \\
\hline 1351430,5 & 411,92 & 1749,5 & 533,25 & $-0,5$ & 0 & 0,00 & 43 & 69,20 & & 0 & 0 \\
\hline 1351755,3 & 412,02 & 1747,8 & 532,73 & 0 & 0 & 0,00 & 43 & 69,20 & & 0 & 0 \\
\hline 1352342,5 & 412,19 & 1747,8 & 532,73 & 0 & $-3,35$ & 521,38 & 43 & 69,20 & & 0 & 0 \\
\hline 1354107,8 & 412,73 & 1747,8 & $\begin{array}{l}532,73 \\
\end{array}$ & 0 & 0 & 0,00 & 43 & 69,20 & & 0 & 0 \\
\hline 1355242,8 & 413,08 & 1747,8 & 532,73 & 0 & 3,35 & 521,38 & 43 & 69,20 & & 0 & 0 \\
\hline 1357716,5 & 413,83 & 1747,8 & 532,73 & $-0,5$ & 3,35 & 521,38 & 43 & 69,20 & & 0 & 0 \\
\hline 1358441,5 & 414,05 & 1744,2 & 531,63 & $-0,5$ & 0 & 0,00 & 43 & 69,20 & & 0 & 0 \\
\hline 1360994 & 414,83 & 1731,4 & \begin{tabular}{l|l|}
527,73 \\
\end{tabular} & $-0,5$ & \begin{tabular}{r|}
$-1,73$ \\
\end{tabular} & 1009,50 & 43 & 69,20 & & 0 & 0 \\
\hline 1361657 & 415,03 & 1728,1 & 526,72 & 0 & \begin{tabular}{|l|}
$-1,73$ \\
\end{tabular} & 1009,50 & 43 & 69,20 & & 0 & 0 \\
\hline 1361739 & 415,06 & 1728,1 & 526,72 & 0 & 0 & 0,00 & 43 & 69,20 & & 0 & 0 \\
\hline 1363110,3 & 415,48 & 1728,1 & 526,72 & 0 & $-2,18$ & 801,14 & 43 & 69,20 & & 0 & 0 \\
\hline 1364019 & 415,75 & 1728,1 & 526,72 & 0 & 0 & 0,00 & 43 & 69,20 & & 0 & 0 \\
\hline 1365922 & 416,33 & 1728,1 & \begin{tabular}{l|}
526,72 \\
\end{tabular} & $-0,5$ & 0 & 0,00 & 43 & 69,20 & & 0 & 0 \\
\hline 1366709,5 & 416,57 & 1724,2 & 525,54 & $-0,5$ & 3,96 & $\begin{array}{l}441,09 \\
\end{array}$ & 43 & 69,20 & & 0 & 0 \\
\hline 1368087,3 & 416,99 & 1717,3 & 523,43 & \begin{tabular}{l|}
$-0,5$ \\
\end{tabular} & 0 & 0,00 & 43 & 69,20 & & 0 & 0 \\
\hline 1369918 & 417,55 & 1708,1 & 520,63 & 0 & 0 & 0,00 & 43 & 69,20 & & 0 & 0 \\
\hline 1370197 & 417,64 & 1708,1 & 520,63 & 0 & $-4,32$ & 404,35 & 43 & 69,20 & & 0 & 0 \\
\hline 1371932,5 & 418,17 & 1708,1 & 520,63 & 0 & 0 & 0,00 & 43 & 69,20 & & 0 & 0 \\
\hline 1372211,3 & 418,25 & 1708,1 & 520,63 & 0,5 & 0 & 0,00 & \begin{tabular}{l|l}
43 \\
\end{tabular} & 69,20 & & 0 & 0 \\
\hline 1372690,3 & 418,40 & 1710,5 & 521,36 & 0,5 & 4,32 & 404,35 & 43 & 69,20 & & 0 & 0 \\
\hline 1373379,3 & \begin{tabular}{ll|}
418,61 \\
\end{tabular} & 1714 & 522,43 & 0,5 & 0 & 0,00 & 43 & 69,20 & & 0 & 0 \\
\hline 1374107,8 & 418,83 & 1717,6 & 523,52 & 0,5 & $-3,96$ & 441,09 & 43 & 69,20 & & 0 & 0 \\
\hline 1374179,8 & 418,85 & 1718 & 523,65 & 0 & $-3,96$ & 441,09 & 43 & 69,20 & & 0 & 0 \\
\hline 1375551,3 & 419,27 & 1718 & \begin{tabular}{l|}
523,65 \\
\end{tabular} & 0 & 0 & 0,00 & 43 & 69,20 & & 0 & 0 \\
\hline 1376387,8 & 419,52 & 1718 & 523,65 & 0 & 3,35 & 521,38 & 43 & 69,20 & & 0 & 0 \\
\hline 1377798,5 & 419,95 & 1718 & 523,65 & 0 & 0 & 0,00 & 43 & 69,20 & & 0 & 0 \\
\hline 1378661,5 & 420,22 & 1718 & 523,65 & 0 & $-4,32$ & 404,35 & 43 & 69,20 & & 0 & 0 \\
\hline 1379734,3 & 420,54 & 1718 & 523,65 & 0 & 0 & 0,00 & 43 & 69,20 & & 0 & 0 \\
\hline 1380495,5 & 420,78 & 1718 & 523,65 & 0 & 0 & 0,00 & 43 & 69,20 & & 0 & 0 \\
\hline 1380548 & 420,79 & 1718 & 523,65 & 0 & 0 & 0,00 & 43 & 69,20 & ZMR - FIM & 0 & 2 \\
\hline 1381151,5 & 420,97 & 1718 & 523,65 & 0 & 3,35 & 521,38 & 43 & 69,20 & & 0 & 1 \\
\hline 1381502,8 & 421,08 & 1718 & 523,65 & 0 & 3,35 & 521,38 & 28 & 45,06 & & 0 & 1 \\
\hline 1381506 & 421,08 & 1718 & 523,65 & 0 & 3,35 & 521,38 & 28 & 45,06 & MERIDIANO & 8 & 1 \\
\hline 1382805,3 & 421,48 & 1718 & 523,65 & 0 & 3,35 & 521,38 & 28 & 45,06 & & 0 & 1 \\
\hline 1382857,8 & 421,50 & 1718 & 523,65 & 0 & 3,35 & 521,38 & 28 & 45,06 & ZMR - INICIO & 0 & 3 \\
\hline 1383179,3 & 421,59 & 1718 & 523,65 & 0 & 0 & 0,00 & 28 & 45,06 & & 0 & 0 \\
\hline 1383468 & 421,68 & 1718 & 523,65 & $-0,5$ & 0 & 0,00 & 28 & 45,06 & & 0 & 0 \\
\hline 1384101 & 421,87 & 1714,8 & 522,67 & $-0,5$ & -3 & 582,19 & 28 & 45,06 & & 0 & 0 \\
\hline 1385466 & 422,29 & 1708 & 520,60 & 0 & -3 & 582,19 & 28 & 45,06 & & 0 & 0 \\
\hline 1385482,3 & 422,29 & 1708 & 520,60 & 0 & 0 & 0,00 & 28 & 45,06 & & 0 & 0 \\
\hline 1386269,8 & 422,54 & 1708 & \begin{tabular}{l|}
520,60 \\
\end{tabular} & 0 & 3,35 & 521,38 & 28 & 45,06 & & 0 & 0 \\
\hline 1387460,8 & 422,90 & 1708 & \begin{tabular}{|l|}
520,60 \\
\end{tabular} & 0 & 0 & 0,00 & 28 & 45,06 & & 0 & 0 \\
\hline 1388484,3 & 423,21 & 1708 & \begin{tabular}{l|}
520,60 \\
\end{tabular} & 0 & $-3,96$ & 441,09 & 28 & 45,06 & & 0 & 0 \\
\hline 1389741 & 423,59 & 1708 & \begin{tabular}{l|}
520,60 \\
\end{tabular} & $-0,5$ & \begin{tabular}{|l|}
$-3,96$ \\
\end{tabular} & 441,09 & 28 & 45,06 & & 0 & 0 \\
\hline 1390659,5 & 423,87 & 1703,4 & \begin{tabular}{l|}
519,20 \\
\end{tabular} & $-0,5$ & 0 & 0,00 & 28 & 45,06 & & 0 & 0 \\
\hline 1391443,5 & 424,11 & 1699,5 & \begin{tabular}{|l|}
518,01 \\
\end{tabular} & $-0,5$ & 4,32 & 404,35 & 28 & 45,06 & & 0 & 0 \\
\hline 1392365,5 & 424,39 & 1694,9 & 516,61 & 0 & 4,32 & 404,35 & 28 & 45,06 & & 0 & 0 \\
\hline 1393153 & 424,63 & 1694,9 & \begin{tabular}{|l|}
516,61 \\
\end{tabular} & 0,5 & 4,32 & 404,35 & 28 & 45,06 & & 0 & 0 \\
\hline 1393290,8 & 424,68 & 1695,6 & \begin{tabular}{l|l|}
516,82 \\
\end{tabular} & 0,5 & 0 & 0,00 & 28 & 45,06 & & 0 & 0 \\
\hline 1395200,3 & 425,26 & 1705,1 & \begin{tabular}{|l|}
519,71 \\
\end{tabular} & 0,5 & $-2,18$ & 801,14 & 28 & 45,06 & & 0 & 0 \\
\hline 1396762 & 425,73 & 1712,9 & 522,09 & 0,5 & 0 & 0,00 & 28 & 45,06 & & 0 & 0 \\
\hline 1397418 & 425,93 & 1716,2 & 523,10 & 0 & 0 & 0,00 & 28 & 45,06 & & 0 & 0 \\
\hline 1399055,3 & 426,43 & 1716,2 & 523,10 & $-0,5$ & 0 & 0,00 & 28 & 45,06 & & 0 & 0 \\
\hline 1401873,5 & 427,29 & 1702,1 & \begin{tabular}{|l|}
518,80 \\
\end{tabular} & $-0,5$ & $-2,18$ & 801,14 & 28 & 45,06 & & 0 & 0 \\
\hline 1403192,3 & 427,69 & 1695,5 & $\begin{array}{l}516,79 \\
\end{array}$ & $-0,5$ & 0 & 0,00 & 28 & 45,06 & & 0 & 0 \\
\hline 1406866,8 & 428,81 & 1677,1 & 511,18 & $-0,5$ & 3,35 & 521,38 & 28 & 45,06 & & 0 & 0 \\
\hline 1408244,8 & 429,23 & 1670,3 & 509,11 & 0 & 3,35 & 521,38 & 28 & 45,06 & & 0 & 0 \\
\hline 1409042 & 429,48 & 1670,3 & \begin{tabular}{|l|}
509,11 \\
\end{tabular} & 0 & 0 & 0,00 & 28 & 45,06 & & 0 & 0 \\
\hline 1410180,5 & 429,82 & 1670,3 & \begin{tabular}{|l|}
509,11 \\
\end{tabular} & 0 & $\begin{array}{l}-2,96 \\
\end{array}$ & 590,06 & 28 & $\begin{array}{l}45,06 \\
\end{array}$ & & 0 & 0 \\
\hline 1411289,5 & 430,16 & 1670,3 & \begin{tabular}{|l|}
509,11 \\
\end{tabular} & 0 & 0 & 0,00 & 28 & 45,06 & & 0 & 0 \\
\hline 1413694,3 & 430,89 & 1670,3 & \begin{tabular}{|l|}
509,11 \\
\end{tabular} & 0 & 2,18 & 801,14 & 28 & 45,06 & & 0 & 0 \\
\hline 1413815,8 & 430,93 & 1670,3 & 509,11 & 0,5 & 2,18 & 801,14 & 28 & 45,06 & & 0 & 0 \\
\hline 1414609,5 & 431,17 & 1674,2 & 510,30 & 0,5 & 0 & 0,00 & 28 & 45,06 & & 0 & 0 \\
\hline
\end{tabular}




\begin{tabular}{|c|c|c|c|c|c|c|c|c|c|c|c|}
\hline \multicolumn{2}{|c|}{ Posição } & \multicolumn{2}{|c|}{ Elevação } & \multirow{2}{*}{$\begin{array}{c}\text { rampa } \\
(\%) \\
\end{array}$} & \multicolumn{2}{|c|}{ curva } & \multicolumn{2}{|c|}{$\begin{array}{c}\text { Limite de } \\
\text { velocidade }\end{array}$} & \multirow[t]{2}{*}{ nome do local } & \multirow[t]{2}{*}{ C 1} & C 2 \\
\hline (feet) & $(\mathrm{km})$ & (feet) & $(\mathrm{m})$ & & ${ }^{\circ}$ & $(\mathrm{m})$ & MPH & $\mathrm{km} / \mathrm{h}$ & & & \\
\hline 1417431 & $\begin{array}{l}432,03 \\
\end{array}$ & 1688,3 & $\begin{array}{l}514,59 \\
\end{array}$ & 0,5 & 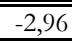 & 590,06 & 28 & 45,06 & & 0 & 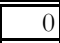 \\
\hline 1419537,5 & 432,68 & 1698,9 & 517,82 & 0,5 & 0 & 0,00 & 28 & 45,06 & & 0 & 0 \\
\hline 1420049,3 & 432,83 & 1701,4 & 518,59 & 0 & 0 & 0,00 & 28 & 45,06 & & 0 & 0 \\
\hline 1420974,5 & 433,11 & 1701,4 & 518,59 & 0 & 2,9 & 602,26 & 28 & 45,06 & & 0 & 0 \\
\hline 1422861 & 433,69 & 1701,4 & 518,59 & 0 & 0 & 0,00 & 28 & 45,06 & & 0 & 0 \\
\hline 1425744,8 & 434,57 & 1701,4 & 518,59 & 0 & 0 & 0,00 & 28 & 45,06 & & 0 & 0 \\
\hline 1425797,3 & 434,58 & 1701,4 & 518,59 & 0 & 0 & 0,00 & 28 & 45,06 & ZVG - FIM & 0 & 2 \\
\hline 1425960,5 & 434,63 & 1701,4 & 518,59 & 0 & 0 & 0,00 & 28 & 45,06 & & 0 & 1 \\
\hline 1426157,5 & 434,69 & 1701,4 & 518,59 & 0 & 0 & 0,00 & 19 & 30,58 & PN - Perímetro urbano & 5 & 1 \\
\hline 1426486,3 & 434,79 & 1701,4 & 518,59 & 0 & $-4,32$ & 404,35 & 28 & 45,06 & & 0 & 1 \\
\hline 1426627,3 & 434,84 & 1701,4 & 518,59 & 0,4 & $-4,32$ & 404,35 & 28 & 45,06 & & 0 & 1 \\
\hline 1426919,3 & 434,92 & 1702,6 & 518,95 & 0,4 & $-4,32$ & 404,35 & 28 & 45,06 & & 0 & 1 \\
\hline 1426922,5 & 434,93 & 1702,6 & 518,95 & 0,4 & $-4,32$ & 404,35 & 28 & 45,06 & VALENTIM GENTIL & 8 & 1 \\
\hline 1428130 & 435,29 & 1707,4 & 520,42 & 0,4 & $-4,32$ & 404,35 & 28 & 45,06 & & 0 & 1 \\
\hline 1428182,5 & 435,31 & 1707,6 & 520,48 & 0,4 & $-4,32$ & 404,35 & 28 & 45,06 & ZVG - INICIO & 0 & 3 \\
\hline 1428586 & 435,43 & 1709,3 & 520,99 & 0,4 & 0 & 0,00 & 28 & 45,06 & & 0 & 0 \\
\hline 1429924,5 & 435,84 & 1714,6 & 522,61 & 0 & 0 & 0,00 & 28 & 45,06 & & 0 & 0 \\
\hline 1430288,8 & 435,95 & 1714,6 & 522,61 & 0 & 3,96 & 441,09 & 28 & 45,06 & & 0 & 0 \\
\hline 1431440,3 & 436,30 & 1714,6 & 522,61 & 0 & 0 & 0,00 & 28 & 45,06 & & 0 & 0 \\
\hline 1433838,5 & 437,03 & 1714,6 & 522,61 & 0,5 & 0 & 0,00 & 28 & 45,06 & & 0 & 0 \\
\hline 1434294,8 & 437,17 & 1716,9 & 523,31 & 0,5 & 3,96 & 441,09 & 28 & 45,06 & & 0 & 0 \\
\hline 1434852,5 & 437,34 & 1719,7 & 524,16 & 0,5 & 0 & 0,00 & 28 & 45,06 & & 0 & 0 \\
\hline 1436391 & 437,81 & 1727,4 & 526,51 & 0,5 & $-2,79$ & 626,00 & 16 & 25,75 & & 0 & 0 \\
\hline 1436755,3 & 437,92 & 1729,2 & 527,06 & 0,5 & 0 & 0,00 & 16 & 25,75 & & 0 & 0 \\
\hline 1440659,5 & 439,11 & 1748,7 & 533,00 & 0 & 0 & 0,00 & 16 & 25,75 & & 0 & 0 \\
\hline 1441512,5 & 439,37 & 1748,7 & 533,00 & 0 & $-4,32$ & 404,35 & 16 & 25,75 & & 0 & 0 \\
\hline 1442726,5 & 439,74 & 1748,7 & 533,00 & 0 & 0 & 0,00 & 16 & 25,75 & & 0 & 0 \\
\hline 1443251,5 & 439,90 & 1748,7 & 533,00 & $-0,5$ & 0 & 0,00 & 16 & 25,75 & & 0 & 0 \\
\hline 1443504 & 439,98 & 1747,5 & 532,64 & $-0,5$ & 4,32 & 404,35 & 16 & 25,75 & & 0 & 0 \\
\hline 1444990,3 & 440,43 & 1740 & 530,35 & $-0,5$ & 0 & 0,00 & 16 & 25,75 & & 0 & 0 \\
\hline 1446368,3 & 440,85 & 1733,1 & 528,25 & 0 & 0 & 0,00 & 16 & 25,75 & & 0 & 0 \\
\hline 1446581,5 & 440,92 & 1733,1 & 528,25 & 0 & $-3,45$ & 506,27 & 16 & 25,75 & & 0 & 0 \\
\hline 1447992,3 & 441,35 & 1733,1 & 528,25 & 0 & 0 & 0,00 & 16 & 25,75 & & 0 & 0 \\
\hline 1449140,5 & 441,70 & 1733,1 & 528,25 & 0 & 4,32 & 404,35 & 16 & 25,75 & & 0 & 0 \\
\hline 1450567,5 & 442,13 & 1733,1 & 528,25 & $-0,5$ & 4,32 & 404,35 & 16 & 25,75 & & 0 & 0 \\
\hline 1450577,5 & 442,14 & 1733,1 & 528,25 & $-0,5$ & 0 & 0,00 & 16 & 25,75 & & 0 & 0 \\
\hline 1451552 & 442,43 & 1728,2 & 526,76 & $-0,5$ & $-4,32$ & 404,35 & 16 & 25,75 & & 0 & 0 \\
\hline 1452815 & 442,82 & 1721,9 & 524,84 & $-0,5$ & 0 & 0,00 & 16 & 25,75 & & 0 & 0 \\
\hline 1453661,5 & 443,08 & 1717,7 & 523,55 & $-0,5$ & 4,32 & 404,35 & 28 & 45,06 & & 0 & 0 \\
\hline 1455767,8 & 443,72 & 1707,1 & 520,32 & $-0,5$ & 0 & 0,00 & 28 & 45,06 & & 0 & 0 \\
\hline 1456883,3 & 444,06 & 1701,6 & 518,65 & $-0,5$ & $-4,32$ & 404,35 & 28 & 45,06 & & 0 & 0 \\
\hline 1458317 & 444,50 & 1694,4 & 516,45 & $-0,5$ & 0 & 0,00 & 28 & 45,06 & & 0 & 0 \\
\hline 1460082 & 445,03 & 1685,6 & 513,77 & $-0,5$ & $-4,32$ & 404,35 & 28 & 45,06 & & 0 & 0 \\
\hline 1460141 & 445,05 & 1685,3 & 513,68 & 0 & $-4,32$ & 404,35 & 28 & 45,06 & & 0 & 0 \\
\hline 1460853 & 445,27 & 1685,3 & 513,68 & 0 & 0 & 0,00 & 28 & 45,06 & & 0 & 0 \\
\hline 1461128,8 & 445,35 & 1685,3 & 513,68 & 0,5 & 0 & 0,00 & 28 & 45,06 & & 0 & 0 \\
\hline 1461617,5 & 445,50 & 1687,7 & 514,41 & 0,5 & 4,32 & 404,35 & 28 & 45,06 & & 0 & 0 \\
\hline 1462713,3 & 445,83 & 1693,2 & 516,09 & 0,5 & 0 & 0,00 & 28 & 45,06 & & 0 & 0 \\
\hline 1463461,3 & 446,06 & 1696,9 & 517,22 & 0,5 & $-4,32$ & 404,35 & 28 & 45,06 & & 0 & 0 \\
\hline 1464412,8 & 446,35 & 1701,7 & 518,68 & 0 & 0 & 0,00 & 28 & 45,06 & & 0 & 0 \\
\hline 1466082,8 & 446,86 & 1701,7 & 518,68 & 0 & 0 & 0,00 & 16 & 25,75 & & 0 & 0 \\
\hline 1466135,3 & 446,88 & 1701,7 & 518,68 & 0 & 0 & 0,00 & 12 & 19,31 & ZVP - FIM & 0 & 2 \\
\hline 1466709,5 & 447,05 & $\begin{array}{ll}1701,7 \\
\end{array}$ & 518,68 & 0,5 & 0 & 0,00 & 16 & 25,75 & & 0 & 1 \\
\hline 1467680,5 & 447,35 & 1706,5 & 520,14 & 0,5 & 0 & 0,00 & 16 & 25,75 & & 0 & 1 \\
\hline 1467683,8 & 447,35 & 1706,6 & 520,17 & 0,5 & 0 & 0,00 & 16 & 25,75 & VOTUPORANGA & 8 & 1 \\
\hline 1469055,3 & 447,77 & 1713,4 & 522,24 & 0,5 & 0 & 0,00 & 16 & 25,75 & & 0 & 1 \\
\hline 1469107,8 & 447,78 & 1713,7 & 522,34 & 0,5 & 0 & 0,00 & 12 & 19,31 & ZVP - INICIO & 0 & 3 \\
\hline 1470187 & 448,11 & 1719,1 & 523,98 & 0,5 & 4,32 & 404,35 & 16 & 25,75 & & 0 & 0 \\
\hline 1471788 & 448,60 & 1727,1 & 526,42 & 0,5 & 0 & 0,00 & 16 & 25,75 & & 0 & 0 \\
\hline 1472601,8 & 448,85 & 1731,1 & 527,64 & 0,5 & $-4,32$ & 404,35 & 16 & 25,75 & & 0 & 0 \\
\hline 1472611,5 & 448,85 & 1731,2 & \begin{tabular}{|l|}
527,67 \\
\end{tabular} & 0 & $-4,32$ & 404,35 & 16 & 25,75 & & 0 & 0 \\
\hline 1473796 & 449,21 & 1731,2 & 527,67 & 0 & 0 & 0,00 & 16 & 25,75 & & 0 & 0 \\
\hline 1477634,5 & 450,38 & 1731,2 & 527,67 & 0 & 4,32 & 404,35 & 16 & 25,75 & & 0 & 0 \\
\hline 1478487,5 & 450,64 & 1731,2 & \begin{tabular}{|l|}
527,67 \\
\end{tabular} & 0 & 0 & 0,00 & 16 & 25,75 & & 0 & 0 \\
\hline 1479373,5 & 450,91 & 1731,2 & \begin{tabular}{|l|}
527,67 \\
\end{tabular} & 0 & $-4,32$ & 404,35 & 16 & 25,75 & & 0 & 0 \\
\hline 1480571 & 451,28 & 1731,2 & 527,67 & 0 & 0 & 0,00 & 16 & 25,75 & & 0 & 0 \\
\hline 1482113 & 451,75 & 1731,2 & 527,67 & 0 & 3,96 & 441,09 & 16 & 25,75 & & 0 & 0 \\
\hline 1484229 & 452,39 & 1731,2 & \begin{tabular}{|l|}
527,67 \\
\end{tabular} & 0 & 0 & 0,00 & 16 & 25,75 & & 0 & 0 \\
\hline 1484422,5 & 452,45 & 1731,2 & 527,67 & 0,5 & 0 & 0,00 & 16 & 25,75 & & 0 & 0 \\
\hline 1485213,3 & 452,69 & 1735,1 & 528,86 & 0,5 & $-4,32$ & 404,35 & 16 & 25,75 & & 0 & 0 \\
\hline 1485823,8 & 452,88 & 1738,2 & 529,80 & 0,5 & $-4,32$ & 404,35 & 16 & 25,75 & & 0 & 0 \\
\hline
\end{tabular}




\begin{tabular}{|c|c|c|c|c|c|c|c|c|c|c|c|}
\hline \multicolumn{2}{|c|}{ Posição } & \multicolumn{2}{|c|}{ Elevação } & \multirow{2}{*}{$\begin{array}{c}\text { rampa } \\
(\%) \\
\end{array}$} & \multicolumn{2}{|c|}{ curva } & \multicolumn{2}{|c|}{$\begin{array}{c}\text { Limite de } \\
\text { velocidade }\end{array}$} & \multirow[t]{2}{*}{ nome do local } & \multirow[t]{2}{*}{ C 1} & C 2 \\
\hline (feet) & $(\mathrm{km})$ & (feet) & $(\mathrm{m})$ & & ${ }^{\circ}$ & $(\mathrm{m})$ & $\mathrm{MPH}$ & $\mathrm{km} / \mathrm{h}$ & & & \\
\hline 1485956,5 & 4452,92 & 1738,9 & $\begin{array}{l}530,02 \\
\end{array}$ & 0,5 & \begin{tabular}{c|}
$-4,32$ \\
\end{tabular} & $\begin{array}{l}404,35 \\
\end{array}$ & 16 & 25,75 & PN - Rodovia & 5 & $\overline{0}$ \\
\hline 1486716 & 453,15 & 1742,7 & 531,17 & 0,5 & 0 & 0,00 & 16 & 25,75 & & 0 & 0 \\
\hline 1487838 & 453,49 & 1748,3 & 532,88 & 0,5 & $-3,96$ & 441,09 & 16 & 25,75 & & 0 & 0 \\
\hline 1488313,8 & 453,64 & 1750,6 & \begin{tabular}{|l|}
533,58 \\
\end{tabular} & 0 & $-3,96$ & 441,09 & 16 & 25,75 & & 0 & $\overline{0}$ \\
\hline 1488825,5 & 453,79 & 1750,6 & 533,58 & 0 & 0 & 0,00 & 16 & 25,75 & & 0 & 0 \\
\hline 1492044 & 454,77 & 1750,6 & 533,58 & 0 & $-3,35$ & 521,38 & 16 & 25,75 & & 0 & 0 \\
\hline 1493540 & 455,23 & 1750,6 & 533,58 & 0 & 0 & 0,00 & 16 & 25,75 & & 0 & 0 \\
\hline 1494366,8 & 455,48 & 1750,6 & 533,58 & 0 & 4,32 & 404,35 & 16 & 25,75 & & 0 & 0 \\
\hline 1497155,5 & 456,33 & 1750,6 & 533,58 & $-0,5$ & 4,32 & 404,35 & 16 & 25,75 & & 0 & 0 \\
\hline 1497811,8 & 456,53 & 1747,4 & 532,61 & $-0,5$ & 0 & 0,00 & 16 & 25,75 & & 0 & 0 \\
\hline 1498582,8 & 456,77 & 1743,5 & 531,42 & $-0,5$ & $-4,32$ & 404,35 & 16 & 25,75 & & 0 & 0 \\
\hline 1500272,5 & 457,28 & 1735,1 & 528,86 & $-0,5$ & 0 & 0,00 & 16 & 25,75 & & 0 & 0 \\
\hline 1500994 & 457,50 & 1731,5 & 527,76 & $-0,5$ & 4,32 & 404,35 & 16 & 25,75 & & 0 & 0 \\
\hline 1501092,5 & 457,53 & 1731 & 527,61 & 0 & 4,32 & 404,35 & 16 & 25,75 & & 0 & 0 \\
\hline 1501883,3 & 457,77 & 1731 & 527,61 & 0 & 0 & 0,00 & 16 & 25,75 & & 0 & 0 \\
\hline 1502605 & 457,99 & 1731 & 527,61 & 0 & $-4,32$ & 404,35 & 16 & 25,75 & & 0 & 0 \\
\hline 1502729,8 & 458,03 & 1731 & 527,61 & 0 & $-4,32$ & 404,35 & 16 & 25,75 & & 0 & 0 \\
\hline 1502733 & 458,03 & 1731 & 527,61 & 0 & $-4,32$ & 404,35 & 16 & 25,75 & SIMONSEM (demolida) & 8 & 0 \\
\hline 1503192,3 & 458,17 & 1731 & 527,61 & 0 & 0 & 0,00 & 16 & 25,75 & & 0 & 0 \\
\hline 1503920,5 & 458,39 & 1731 & 527,61 & 0,5 & 0 & 0,00 & 16 & 25,75 & & 0 & 0 \\
\hline 1505095,3 & 458,75 & 1736,8 & 529,38 & 0,5 & 4,32 & 404,35 & 16 & 25,75 & & 0 & 0 \\
\hline 1506801,3 & 459,27 & 1745,4 & 532,00 & 0,5 & 0 & 0,00 & 16 & 25,75 & & 0 & 0 \\
\hline 1507621,5 & 459,52 & 1749,5 & 533,25 & 0,5 & $-3,35$ & 521,38 & 16 & 25,75 & & 0 & 0 \\
\hline 1509304,5 & 460,04 & 1757,9 & 535,81 & 0,5 & 0 & 0,00 & 16 & 25,75 & & 0 & 0 \\
\hline 1511653,5 & 460,75 & 1769,6 & 539,37 & 0,5 & 3,35 & 521,38 & 16 & 25,75 & & 0 & 0 \\
\hline 1512214,5 & 460,92 & 1772,4 & 540,23 & 0,5 & 0 & 0,00 & 16 & 25,75 & & 0 & 0 \\
\hline 1513002 & 461,16 & 1776,4 & 541,45 & 0,5 & $-4,32$ & 404,35 & 16 & 25,75 & & 0 & 0 \\
\hline 1514931 & 461,75 & 1786 & 544,37 & 0,5 & 0 & 0,00 & 16 & 25,75 & & 0 & 0 \\
\hline 1515626,8 & 461,96 & 1789,5 & 545,44 & 0,5 & $-4,32$ & 404,35 & 16 & 25,75 & & 0 & 0 \\
\hline 1516233,5 & 462,15 & 1792,5 & 546,35 & 0,5 & 0 & 0,00 & 16 & 25,75 & & 0 & 0 \\
\hline 1517040,8 & 462,39 & 1796,6 & 547,60 & 0 & 0 & 0,00 & 16 & 25,75 & & 0 & 0 \\
\hline 1519140,5 & 463,03 & 1796,6 & 547,60 & $-0,5$ & 0 & 0,00 & 16 & 25,75 & & 0 & 0 \\
\hline 1519432,5 & 463,12 & 1795,1 & 547,15 & $-0,5$ & $-4,32$ & 404,35 & 16 & 25,75 & & 0 & 0 \\
\hline 1519836 & 463,25 & 1793,1 & 546,54 & $-0,5$ & 0 & 0,00 & 16 & 25,75 & & 0 & 0 \\
\hline 1520482,3 & 463,44 & 1789,9 & 545,56 & $-0,5$ & 3,96 & 441,09 & 16 & 25,75 & & 0 & 0 \\
\hline 1522805,3 & 464,15 & 1778,2 & 542,00 & $-0,5$ & 0 & 0,00 & 16 & 25,75 & & 0 & 0 \\
\hline 1524393 & 464,63 & 1770,3 & 539,59 & 0 & 0 & 0,00 & 16 & 25,75 & & 0 & 0 \\
\hline 1524967,3 & 464,81 & 1770,3 & 539,59 & 0 & $-3,35$ & 521,38 & 16 & 25,75 & & 0 & 0 \\
\hline 1525761,3 & 465,05 & 1770,3 & 539,59 & 0 & 0 & 0,00 & 16 & 25,75 & & 0 & 0 \\
\hline 1526223,8 & 465,19 & 1770,3 & 539,59 & 0,5 & 0 & 0,00 & 16 & 25,75 & & 0 & 0 \\
\hline 1528320,3 & 465,83 & 1780,8 & 542,79 & 0 & 0 & 0,00 & 16 & 25,75 & & 0 & 0 \\
\hline 1529022,5 & 466,05 & 1780,8 & 542,79 & 0 & $-3,35$ & 521,38 & 16 & 25,75 & & 0 & 0 \\
\hline 1529586,8 & 466,22 & 1780,8 & 542,79 & 0 & 0 & 0,00 & 16 & 25,75 & & 0 & 0 \\
\hline 1532244 & 467,03 & 1780,8 & 542,79 & 0 & $-3,96$ & 441,09 & 16 & 25,75 & & 0 & 0 \\
\hline 1532654,3 & 467,15 & 1780,8 & 542,79 & 0 & 0 & 0,00 & 16 & 25,75 & & 0 & 0 \\
\hline 1533179,3 & 467,31 & 1780,8 & 542,79 & 0,5 & 0 & 0,00 & 16 & 25,75 & & 0 & 0 \\
\hline 1535065,8 & 467,89 & 1790,2 & 545,65 & 0,5 & $-4,32$ & 404,35 & 16 & 25,75 & & 0 & 0 \\
\hline 1536771,8 & 468,41 & 1798,7 & 548,24 & 0,5 & 0 & 0,00 & 16 & 25,75 & & 0 & 0 \\
\hline 1537477 & 468,62 & 1802,3 & 549,34 & 0,5 & 4,11 & 425,00 & 16 & 25,75 & & 0 & 0 \\
\hline 1539143,8 & 469,13 & 1810,6 & 551,87 & 0,5 & 0 & 0,00 & 16 & 25,75 & & 0 & 0 \\
\hline 1539609,5 & 469,27 & 1812,9 & 552,57 & 0 & 0 & 0,00 & 16 & 25,75 & & 0 & 0 \\
\hline 1541020,5 & 469,70 & 1812,9 & 552,57 & 0 & $-3,35$ & 521,38 & 16 & 25,75 & & 0 & 0 \\
\hline 1542756 & 470,23 & 1812,9 & 552,57 & 0 & 0 & 0,00 & 16 & 25,75 & & 0 & 0 \\
\hline 1544658,8 & 470,81 & 1812,9 & 552,57 & 0 & 4,32 & 404,35 & 16 & 25,75 & & 0 & 0 \\
\hline 1545849,8 & 471,18 & 1812,9 & 552,57 & 0 & 0 & 0,00 & 16 & 25,75 & & 0 & 0 \\
\hline 1546886,5 & 471,49 & 1812,9 & 552,57 & 0 & 0 & 0,00 & 16 & 25,75 & & 0 & 0 \\
\hline 1546939 & 471,51 & 1812,9 & 552,57 & 0 & 0 & 0,00 & 16 & 25,75 & ZKY - INICIO & 0 & 3 \\
\hline 1547221,3 & 471,59 & 1812,9 & 552,57 & $-0,5$ & 0 & 0,00 & 16 & 25,75 & & 0 & 1 \\
\hline 1547992,3 & 471,83 & 1809,1 & 551,41 & $-0,5$ & 0 & 0,00 & 16 & 25,75 & & 0 & 1 \\
\hline 1547995,5 & 471,83 & 1809,1 & 551,41 & $-0,5$ & 0 & 0,00 & 16 & 25,75 & COSMORAMA & 8 & 1 \\
\hline 1548550 & 472,00 & 1806,3 & 550,56 & $-0,5$ & 2,9 & 602,26 & 16 & 25,75 & & 0 & 1 \\
\hline 1549127,3 & 472,17 & 1803,4 & 549,68 & $-0,5$ & 0 & 0,00 & 16 & 25,75 & & 0 & 1 \\
\hline 1549166,8 & 472,19 & 1803,2 & 549,62 & $-0,5$ & 0 & 0,00 & 16 & 25,75 & ZKY- FIM & 0 & 3 \\
\hline 1550462,5 & 472,58 & 1796,7 & 547,63 & $-0,5$ & $-2,29$ & 762,66 & 16 & 25,75 & & 0 & 0 \\
\hline 1552076,8 & 473,07 & 1788,7 & 545,20 & $-0,5$ & 0 & 0,00 & 16 & 25,75 & & 0 & 0 \\
\hline 1553290,8 & 473,44 & 1782,6 & 543,34 & $-0,5$ & 4,32 & 404,35 & 28 & 45,06 & & 0 & 0 \\
\hline 1554675,3 & 473,87 & 1775,7 & 541,23 & $-0,5$ & 0 & 0,00 & 28 & 45,06 & & 0 & 0 \\
\hline 1555482,3 & 474,11 & 1771,6 & 539,98 & $-0,5$ & $-4,32$ & 404,35 & 28 & 45,06 & & 0 & 0 \\
\hline 1556407,5 & 474,39 & 1767 & 538,58 & 0 & $-4,32$ & 404,35 & 28 & 45,06 & & 0 & 0 \\
\hline 1557391,8 & 474,69 & 1767 & 538,58 & 0,5 & $-4,32$ & 404,35 & 28 & 45,06 & & 0 & 0 \\
\hline 1558786 & 475,12 & 1774 & 540,72 & 0,5 & 0 & 0,00 & 28 & 45,06 & & 0 & 0 \\
\hline
\end{tabular}




\begin{tabular}{|c|c|c|c|c|c|c|c|c|c|c|c|}
\hline \multicolumn{2}{|c|}{ Posição } & \multicolumn{2}{|c|}{ Elevação } & \multirow{2}{*}{$\begin{array}{c}\text { rampa } \\
(\%)\end{array}$} & \multicolumn{2}{|c|}{ curva } & \multicolumn{2}{|c|}{$\begin{array}{c}\text { Limite de } \\
\text { velocidade }\end{array}$} & \multirow[t]{2}{*}{ nome do local } & \multirow[t]{2}{*}{ C 1} & C 2 \\
\hline (feet) & $(\mathrm{km})$ & (feet) & $(\mathrm{m})$ & & ${ }^{\circ}$ & $(\mathrm{m})$ & $\mathrm{MPH}$ & $\mathrm{km} / \mathrm{h}$ & & & \\
\hline 1559819,5 & $\begin{array}{l}475,43 \\
\end{array}$ & 1779,1 & "542,27| & 0,5 & $4,3,32$ & 4404,35 & 28 & 45,06 & & 0 & 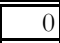 \\
\hline 1560279 & 475,57 & 1781,4 & 542,97 & 0 & 4,32 & 404,35 & 28 & 45,06 & & 0 & 0 \\
\hline 1560902,3 & 475,76 & 1781,4 & 542,97 & 0 & 0 & 0,00 & 28 & 45,06 & & 0 & 0 \\
\hline 1561591,3 & 475,97 & 1781,4 & 542,97 & 0 & $-4,32$ & 404,35 & 28 & 45,06 & & 0 & 0 \\
\hline 1563149,8 & 476,45 & 1781,4 & \begin{tabular}{|l|}
542,97 \\
\end{tabular} & 0 & 0 & 0,00 & 28 & 45,06 & & 0 & 0 \\
\hline 1563828,8 & 476,66 & 1781,4 & 542,97 & 0 & 4,32 & 404,35 & 28 & 45,06 & & 0 & 0 \\
\hline 1564015,8 & 476,71 & 1781,4 & \begin{tabular}{|l|}
542,97 \\
\end{tabular} & $-0,5$ & 4,32 & 404,35 & 28 & 45,06 & & 0 & 0 \\
\hline 1564547,3 & 476,87 & 1778,8 & 542,18 & $-0,5$ & 0 & 0,00 & 28 & 45,06 & & 0 & 0 \\
\hline 1565331,5 & 477,11 & 1774,9 & 540,99 & $-0,5$ & $-4,32$ & 404,35 & 28 & 45,06 & & 0 & 0 \\
\hline 1565590,5 & 477,19 & 1773,6 & 540,59 & 0 & $-4,32$ & 404,35 & 28 & 45,06 & & 0 & 0 \\
\hline 1566184,5 & 477,37 & 1773,6 & 540,59 & 0 & 0 & 0,00 & 28 & 45,06 & & 0 & 0 \\
\hline 1566939 & 477,60 & 1773,6 & 540,59 & 0 & 4,32 & 404,35 & 16 & 25,75 & & 0 & 0 \\
\hline 1567234,3 & 477,69 & 1773,6 & 540,59 & $-0,5$ & 4,32 & 404,35 & 16 & 25,75 & & 0 & 0 \\
\hline 1568497,5 & 478,08 & 1767,3 & $\begin{array}{l}538,67 \\
\end{array}$ & $-0,5$ & 0 & 0,00 & 16 & 25,75 & & 0 & 0 \\
\hline 1569268,5 & 478,31 & 1763,4 & 537,48 & $-0,5$ & $-4,32$ & 404,35 & 16 & 25,75 & & 0 & 0 \\
\hline 1570318,3 & 478,63 & 1758,1 & 535,87 & $-0,5$ & 0 & 0,00 & 16 & 25,75 & & 0 & 0 \\
\hline 1571056,5 & 478,86 & 1754,5 & 534,77 & \begin{tabular}{l|l|}
$-0,5$ \\
\end{tabular} & 4,32 & 404,35 & 16 & 25,75 & & 0 & 0 \\
\hline 1571499,5 & 478,99 & 1752,2 & 534,07 & 0 & 4,32 & 404,35 & 16 & 25,75 & & 0 & 0 \\
\hline 1572516,5 & 479,30 & 1752,2 & 534,07 & 0 & 0 & 0,00 & 16 & 25,75 & & 0 & 0 \\
\hline 1573271 & 479,53 & 1752,2 & 534,07 & 0 & $-4,32$ & 404,35 & 16 & 25,75 & & 0 & 0 \\
\hline 1573599 & 479,63 & 1752,2 & 534,07 & 0,5 & $-4,32$ & 404,35 & 16 & 25,75 & & 0 & 0 \\
\hline 1575167,5 & 480,11 & 1760,1 & 536,48 & 0,5 & 0 & 0,00 & 16 & 25,75 & & 0 & 0 \\
\hline 1576507,5 & 480,52 & 1766,8 & 538,52 & 0,5 & 0 & 0,00 & 9 & 14,48 & & 0 & 0 \\
\hline 1577332,8 & 480,77 & 1770,9 & 539,77 & 0,5 & 4,32 & 404,35 & 9 & 14,48 & & 0 & 0 \\
\hline 1577503,3 & 480,82 & 1771,8 & 540,04 & 0,5 & 4,32 & 404,35 & 9 & 14,48 & & 0 & 0 \\
\hline 1578002 & 480,97 & 1774,3 & 540,81 & 0,5 & 0 & 0,00 & 16 & 25,75 & & 0 & 0 \\
\hline 1578924 & 481,26 & 1778,9 & 542,21 & 0,5 & 3,96 & 441,09 & 16 & 25,75 & & 0 & 0 \\
\hline 1579570,3 & 481,45 & 1782,1 & 543,18 & 0,5 & 0 & 0,00 & 16 & 25,75 & & 0 & 0 \\
\hline 1580810,5 & 481,83 & 1788,3 & 545,07 & 0,5 & $-3,96$ & 441,09 & 16 & 25,75 & & 0 & 0 \\
\hline 1581591,3 & 482,07 & 1792,2 & 546,26 & 0,5 & 0 & 0,00 & 16 & 25,75 & & 0 & 0 \\
\hline 1581702,8 & 482,10 & 1792,8 & 546,45 & 0 & 0 & 0,00 & 16 & 25,75 & & 0 & 0 \\
\hline 1582352,5 & 482,30 & 1792,8 & 546,45 & 0 & 2,9 & 602,26 & 16 & 25,75 & & 0 & 0 \\
\hline 1583366,3 & 482,61 & 1792,8 & 546,45 & 0 & 0 & 0,00 & 16 & 25,75 & & 0 & 0 \\
\hline 1585377,3 & 483,22 & 1792,8 & $\begin{array}{l}546,45 \\
\end{array}$ & 0 & $-2,9$ & 602,26 & 16 & 25,75 & & 0 & 0 \\
\hline 1586460 & 483,55 & 1792,8 & 546,45 & 0 & 0 & 0,00 & 16 & 25,75 & & 0 & 0 \\
\hline 1587513,3 & 483,87 & 1792,8 & 546,45 & 0 & 3,96 & 441,09 & 16 & 25,75 & & 0 & 0 \\
\hline 1588051,3 & 484,04 & 1792,8 & 546,45 & 0 & 0 & 0,00 & 16 & 25,75 & & 0 & 0 \\
\hline 1589068,3 & 484,35 & 1792,8 & 546,45 & 0 & 3,96 & 441,09 & 16 & 25,75 & & 0 & 0 \\
\hline 1589806,5 & 484,57 & 1792,8 & 546,45 & 0 & 0 & 0,00 & 16 & 25,75 & & 0 & 0 \\
\hline 1590987,5 & 484,93 & 1792,8 & 546,45 & 0 & 4,32 & 404,35 & 16 & 25,75 & & 0 & 0 \\
\hline 1592555,8 & 485,41 & 1792,8 & 546,45 & 0 & 0 & 0,00 & 16 & 25,75 & & 0 & 0 \\
\hline 1594403 & 485,97 & 1792,8 & 546,45 & 0 & $-3,96$ & 441,09 & 16 & 25,75 & & 0 & 0 \\
\hline 1594488,3 & 486,00 & 1792,8 & 546,45 & 0 & $-3,96$ & 441,09 & 16 & 25,75 & & 0 & 0 \\
\hline 1594540,8 & 486,02 & 1792,8 & 546,45 & 0 & $-3,96$ & 441,09 & 12 & 19,31 & ZEC - FIM & 0 & 2 \\
\hline 1595239,5 & 486,23 & 1792,8 & 546,45 & $-0,5$ & $-3,96$ & 441,09 & 16 & 25,75 & & 0 & 1 \\
\hline 1595525 & 486,32 & 1791,3 & 545,99 & $-0,5$ & 0 & 0,00 & 16 & 25,75 & & 0 & 1 \\
\hline 1595643 & 486,35 & 1790,7 & 545,81 & $-0,5$ & 0 & 0,00 & 16 & 25,75 & & 0 & 1 \\
\hline 1595646,5 & 486,35 & 1790,7 & 545,81 & $\begin{array}{ll}-0,5 \\
\end{array}$ & 0 & 0,00 & 16 & 25,75 & ECATU & 8 & 1 \\
\hline 1596565 & 486,63 & 1786,1 & 544,40 & $-0,5$ & 2,9 & 602,26 & 16 & 25,75 & & 0 & 1 \\
\hline 1596581,5 & 486,64 & 1786 & 544,37 & $-0,5$ & 2,9 & 602,26 & 16 & 25,75 & & 0 & 1 \\
\hline 1596634 & 486,65 & 1785,8 & 544,31 & $-0,5$ & 2,9 & 602,26 & 12 & 19,31 & ZEC - INICIO & 0 & 3 \\
\hline 1597155,5 & 486,81 & 1783,2 & 543,52 & $-0,5$ & 0 & 0,00 & 16 & 25,75 & & 0 & 0 \\
\hline 1599140,5 & 487,42 & 1773,3 & 540,50 & \begin{tabular}{l|l}
$-0,5$ \\
\end{tabular} & $-3,36$ & 519,83 & 16 & 25,75 & & 0 & 0 \\
\hline 1599852,5 & 487,64 & 1769,7 & 539,40 & $-0,5$ & 0 & 0,00 & 16 & 25,75 & & 0 & 0 \\
\hline 1600502 & 487,83 & 1766,4 & 538,40 & 0 & 0 & 0,00 & 16 & 25,75 & & 0 & 0 \\
\hline 1601371,5 & 488,10 & 1766,4 & 538,40 & 0,5 & 0 & 0,00 & 16 & 25,75 & & 0 & 0 \\
\hline 1603963,3 & 488,89 & 1779,4 & 542,36 & 0 & 0 & 0,00 & 16 & 25,75 & & 0 & 0 \\
\hline 1606424 & 489,64 & 1779,4 & 542,36 & 0 & 3 & 582,19 & 16 & 25,75 & & 0 & 0 \\
\hline 1607391,8 & 489,93 & 1779,4 & $\begin{array}{l}542,36 \\
\end{array}$ & 0 & 0 & 0,00 & 16 & 25,75 & & 0 & 0 \\
\hline 1607588,5 & 489,99 & 1779,4 & 542,36 & 0,5 & 0 & 0,00 & 16 & 25,75 & & 0 & 0 \\
\hline 1612067 & 491,36 & 1801,8 & 549,19 & 0,5 & $-3,35$ & 521,38 & 16 & 25,75 & & 0 & 0 \\
\hline 1613635,3 & 491,84 & 1809,6 & 551,57 & 0,5 & 0 & 0,00 & 16 & 25,75 & & 0 & 0 \\
\hline 1616906,3 & 492,83 & 1826 & 556,56 & 0,5 & 3,96 & 441,09 & 16 & 25,75 & & 0 & 0 \\
\hline 1617431 & 492,99 & 1828,6 & 557,36 & 0 & 3,96 & 441,09 & 16 & 25,75 & & 0 & 0 \\
\hline 1618743,5 & 493,39 & 1828,6 & 557,36 & $-0,5$ & 3,96 & 441,09 & 16 & 25,75 & & 0 & 0 \\
\hline 1618822,3 & 493,42 & 1828,2 & \begin{tabular}{|l|}
557,24 \\
\end{tabular} & \begin{tabular}{l|l|}
$-0,5$ \\
\end{tabular} & 0 & 0,00 & 16 & 25,75 & & 0 & 0 \\
\hline 1621433,8 & 494,21 & 1815,2 & 553,27 & $-0,5$ & 2,18 & 801,14 & 16 & 25,75 & & 0 & 0 \\
\hline 1622024,3 & 494,39 & 1812,2 & 552,36 & 0 & 2,18 & 801,14 & 16 & 25,75 & & 0 & 0 \\
\hline 1622418 & 494,51 & 1812,2 & 552,36 & 0 & 0 & 0,00 & 16 & 25,75 & & 0 & 0 \\
\hline 1626611 & 495,79 & 1812,2 & 552,36 & 0 & -3 & 582,19 & 16 & 25,75 & & 0 & 0 \\
\hline 1628996 & 496,52 & 1812,2 & 552,36 & 0 & 0 & 0,00 & 16 & 25,75 & & 0 & 0 \\
\hline
\end{tabular}




\begin{tabular}{|c|c|c|c|c|c|c|c|c|c|c|c|}
\hline \multicolumn{2}{|c|}{ Posição } & \multicolumn{2}{|c|}{ Elevação } & \multirow{2}{*}{$\begin{array}{c}\text { rampa } \\
(\%) \\
\end{array}$} & \multicolumn{2}{|c|}{ curva } & \multicolumn{2}{|c|}{$\begin{array}{c}\text { Limite de } \\
\text { velocidade }\end{array}$} & \multirow[t]{2}{*}{ nome do local } & \multirow[t]{2}{*}{ C 1} & C 2 \\
\hline (feet) & $(\mathrm{km})$ & (feet) & $(\mathrm{m})$ & & ${ }^{\circ}$ & $(\mathrm{m})$ & MPH & $\mathrm{km} / \mathrm{h}$ & & & \\
\hline 1632195 & 497,49 & 1812,2 & \begin{tabular}{ll|}
552,36 \\
\end{tabular} & 0,5 & 0 & 0,00 & 16 & 25,75 & & 0 & $\overline{0}$ \\
\hline 1636794,8 & 498,90 & 1835,2 & 559,37 & 0 & 0 & 0,00 & 16 & 25,75 & & 0 & 0 \\
\hline 1637585,3 & 499,14 & 1835,2 & 559,37 & $-0,5$ & 0 & 0,00 & 16 & 25,75 & & 0 & 0 \\
\hline 1638756,5 & 499,49 & 1829,4 & 557,60 & \begin{tabular}{l|l}
$-0,5$ \\
\end{tabular} & 4,32 & 404,35 & 16 & 25,75 & & 0 & $\overline{0}$ \\
\hline 1639688,5 & 499,78 & 1824,7 & \begin{tabular}{|l|}
556,17 \\
\end{tabular} & \begin{tabular}{l|}
$-0,5$ \\
\end{tabular} & 0 & 0,00 & 16 & 25,75 & & 0 & 0 \\
\hline 1640863 & 500,14 & 1818,8 & 554,37 & 0 & 0 & 0,00 & 16 & 25,75 & & 0 & 0 \\
\hline 1642890,5 & 500,75 & 1818,8 & 554,37 & 0,5 & 0 & 0,00 & 16 & 25,75 & & 0 & 0 \\
\hline 1644038,8 & 501,10 & 1824,6 & 556,14 & 0,5 & $-3,96$ & 441,09 & 16 & 25,75 & & 0 & 0 \\
\hline 1645118,3 & 501,43 & 1830 & 557,78 & 0,5 & 0 & 0,00 & 16 & 25,75 & & 0 & 0 \\
\hline 1645528,3 & 501,56 & 1832 & 558,39 & 0 & 0 & 0,00 & 16 & 25,75 & & 0 & 0 \\
\hline 1645984,3 & 501,70 & 1832 & 558,39 & 0 & 3,96 & $\begin{array}{l}441,09 \\
\end{array}$ & 16 & 25,75 & & 0 & 0 \\
\hline 1646483 & 501,85 & 1832 & 558,39 & 0 & 0 & 0,00 & 16 & 25,75 & & 0 & 0 \\
\hline 1647483,5 & 502,15 & 1832 & \begin{tabular}{|l|}
558,39 \\
\end{tabular} & 0 & $-3,96$ & \begin{tabular}{|l|l|}
441,09 \\
\end{tabular} & 16 & 25,75 & & 0 & 0 \\
\hline 1648386 & 502,43 & 1832 & 558,39 & 0 & 0 & 0,00 & 16 & 25,75 & & 0 & 0 \\
\hline 1649403 & 502,74 & 1832 & \begin{tabular}{|l|}
558,39 \\
\end{tabular} & 0 & 3,96 & \begin{tabular}{|l|l|}
441,09 \\
\end{tabular} & 16 & 25,75 & & 0 & 0 \\
\hline 1650715,3 & 503,14 & 1832 & \begin{tabular}{l|l|}
558,39 \\
\end{tabular} & 0 & 0 & 0,00 & 16 & 25,75 & & 0 & 0 \\
\hline 1651529 & 503,39 & 1832 & 558,39 & 0 & 0 & 0,00 & 9 & 14,48 & & 0 & $\overline{0}$ \\
\hline 1652273,8 & 503,61 & 1832 & 558,39 & 0 & $-3,96$ & 441,09 & 9 & 14,48 & & 0 & 0 \\
\hline 1652674 & 503,74 & 1832 & 558,39 & 0 & $-3,96$ & $\begin{array}{l}441,09 \\
\end{array}$ & 9 & 14,48 & & 0 & $\overline{0}$ \\
\hline 1652726,5 & 503,75 & 1832 & $\begin{array}{l}558,39 \\
\end{array}$ & 0 & $-3,96$ & \begin{tabular}{|l|l|}
441,09 \\
\end{tabular} & 9 & 14,48 & ZEB - FIM & 0 & 2 \\
\hline 1653825,5 & 504,09 & 1832 & 558,39 & 0 & $-3,96$ & 441,09 & 9 & 14,48 & & 0 & 1 \\
\hline 1653828,8 & 504,09 & 1832 & 558,39 & 0 & $-3,96$ & 4441,09 & 9 & 14,48 & ENG. BALDUINO & 8 & 1 \\
\hline 1653914 & 504,11 & 1832 & 558,39 & \begin{tabular}{l|l}
$-0,5$ \\
\end{tabular} & $-3,96$ & \begin{tabular}{ll|}
441,09 \\
\end{tabular} & 9 & 14,48 & & 0 & 1 \\
\hline 1654193 & 504,20 & 1830,6 & 557,97 & $-0,5$ & $-3,96$ & 4441,09 & 9 & 14,48 & & 0 & 1 \\
\hline 1654432,5 & 504,27 & 1829,4 & 557,60 & $-0,5$ & 0 & 0,00 & 16 & 25,75 & & 0 & 1 \\
\hline 1654954 & 504,43 & 1826,8 & 556,81 & $-0,5$ & 0 & 0,00 & 16 & 25,75 & & 0 & 1 \\
\hline 1655006,5 & 504,45 & 1826,6 & 556,75 & $-0,5$ & 0 & 0,00 & 16 & 25,75 & ZEB - INICIO & 0 & 3 \\
\hline 1657195 & 505,11 & 1815,6 & 553,39 & 0 & 0 & 0,00 & 16 & 25,75 & & 0 & 0 \\
\hline 1658179,3 & 505,41 & 1815,6 & 553,39 & 0,5 & 0 & 0,00 & 16 & 25,75 & & 0 & 0 \\
\hline 1660475,8 & 506,11 & 1827,1 & 556,90 & 0 & 0 & 0,00 & 16 & 25,75 & & 0 & 0 \\
\hline 1661132 & 506,31 & 1827,1 & 556,90 & $-0,5$ & 0 & 0,00 & 16 & 25,75 & & 0 & 0 \\
\hline 1662116,3 & 506,61 & 1822,2 & 555,41 & 0 & 0 & 0,00 & 16 & 25,75 & & 0 & 0 \\
\hline 1663428,5 & 507,01 & 1822,2 & 555,41 & 0,5 & 0 & 0,00 & 16 & 25,75 & & 0 & 0 \\
\hline 1665397 & 507,61 & 1832 & $\begin{array}{l}558,39 \\
\end{array}$ & 0 & 0 & 0,00 & 16 & 25,75 & & 0 & 0 \\
\hline 1665413,5 & 507,62 & 1832 & $\begin{array}{l}558,39 \\
\end{array}$ & 0 & 2,49 & 701,41 & 16 & 25,75 & & 0 & 0 \\
\hline 1666387,8 & 507,91 & 1832 & 558,39 & $-0,5$ & 2,49 & 701,41 & 16 & 25,75 & & 0 & 0 \\
\hline 1667244 & 508,18 & 1827,7 & 557,08 & $-0,5$ & 0 & 0,00 & 16 & 25,75 & & 0 & 0 \\
\hline 1668349,8 & 508,51 & 1822,2 & \begin{tabular}{|l|}
555,41 \\
\end{tabular} & 0 & 0 & 0,00 & 16 & 25,75 & & 0 & 0 \\
\hline 1669990,3 & 509,01 & 1822,2 & 555,41 & 0,5 & 0 & 0,00 & 16 & 25,75 & & 0 & 0 \\
\hline 1670121,5 & 509,05 & 1822,9 & $\begin{array}{l}555,62 \\
\end{array}$ & 0,5 & $-2,29$ & 762,66 & 16 & 25,75 & & 0 & 0 \\
\hline 1672877,3 & 509,89 & 1836,6 & 559,80 & 0,5 & 0 & 0,00 & 16 & 25,75 & & 0 & 0 \\
\hline 1673566,3 & 510,10 & 1840,1 & 560,86 & 0,5 & 2,29 & 762,66 & 16 & 25,75 & & 0 & 0 \\
\hline 1675233 & 510,61 & 1848,4 & 563,39 & 0 & 2,29 & 762,66 & 16 & 25,75 & & 0 & 0 \\
\hline 1675492,3 & 510,69 & 1848,4 & 563,39 & 0 & 0 & 0,00 & 16 & 25,75 & & 0 & 0 \\
\hline 1675889,3 & 510,81 & 1848,4 & 563,39 & \begin{tabular}{l|}
$-0,5$ \\
\end{tabular} & 0 & 0,00 & 16 & 25,75 & & 0 & $\overline{0}$ \\
\hline 1677857,8 & 511,41 & 1838,6 & 560,41 & 0 & 0 & 0,00 & 16 & 25,75 & & 0 & 0 \\
\hline 1678513,8 & 511,61 & 1838,6 & 560,41 & 0,5 & 0 & 0,00 & 16 & 25,75 & & 0 & 0 \\
\hline 1679619,5 & 511,95 & 1844,1 & 562,08 & 0,5 & $-3,35$ & 521,38 & 16 & 25,75 & & 0 & 0 \\
\hline 1680324,8 & 512,16 & 1847,6 & 563,15 & 0,5 & 0 & 0,00 & 16 & 25,75 & & 0 & 0 \\
\hline 1681899,8 & 512,64 & 1855,5 & 565,56 & 0,5 & $-3,35$ & 521,38 & 16 & 25,75 & & 0 & 0 \\
\hline 1682457,5 & 512,81 & 1858,3 & 566,41 & 0 & $-3,35$ & \begin{tabular}{|l|}
521,38 \\
\end{tabular} & 16 & 25,75 & & 0 & 0 \\
\hline 1683107 & 513,01 & 1858,3 & 566,41 & $-0,5$ & 0 & 0,00 & 16 & 25,75 & & 0 & 0 \\
\hline 1683763,3 & 513,21 & 1855 & 565,40 & \begin{tabular}{l|l|}
$-0,5$ \\
\end{tabular} & 4,11 & 425,00 & 16 & 25,75 & & 0 & 0 \\
\hline 1685082 & 513,61 & 1848,4 & 563,39 & 0 & 4,11 & 425,00 & 16 & 25,75 & & 0 & 0 \\
\hline 1686657 & 514,09 & 1848,4 & 563,39 & 0 & 0 & 0,00 & 16 & 25,75 & & 0 & 0 \\
\hline 1687395 & 514,32 & 1848,4 & 563,39 & 0 & $-2,79$ & 626,00 & 16 & 25,75 & & 0 & 0 \\
\hline 1688038 & 514,51 & 1848,4 & 563,39 & \begin{tabular}{l|}
$-0,5$ \\
\end{tabular} & $-2,79$ & 626,00 & 16 & 25,75 & & 0 & 0 \\
\hline 1689281,5 & 514,89 & 1842,2 & 561,50 & $-0,5$ & 0 & 0,00 & 16 & 25,75 & & 0 & 0 \\
\hline 1690600,5 & 515,30 & 1835,6 & 559,49 & 0 & 0 & 0,00 & 16 & 25,75 & & 0 & 0 \\
\hline 1691971,8 & 515,71 & 1835,6 & 559,49 & 0,5 & 0 & 0,00 & 16 & 25,75 & & 0 & $\overline{0}$ \\
\hline 1693940,3 & 516,31 & 1845,4 & 562,48 & 0 & 0 & 0,00 & 16 & 25,75 & & 0 & 0 \\
\hline 1694599,8 & 516,51 & 1845,4 & 562,48 & $-0,5$ & 0 & 0,00 & 16 & 25,75 & & 0 & 0 \\
\hline 1695974,5 & 516,93 & 1838,6 & 560,41 & $-0,5$ & $-3,96$ & \begin{tabular}{|l|l|}
441,09 \\
\end{tabular} & 16 & 25,75 & & 0 & 0 \\
\hline 1696657 & 517,14 & 1835,2 & 559,37 & \begin{tabular}{l|}
$-0,5$ \\
\end{tabular} & 0 & 0,00 & 16 & 25,75 & & 0 & 0 \\
\hline 1697277 & 517,33 & 1832,1 & \begin{tabular}{|l|}
558,42 \\
\end{tabular} & 0 & 0 & 0,00 & 16 & 25,75 & & 0 & 0 \\
\hline 1697421,3 & $\begin{array}{r}517,37 \\
\end{array}$ & 1832,1 & \begin{tabular}{|l|}
558,42 \\
\end{tabular} & 0 & 3,96 & $\begin{array}{l}441,09 \\
\end{array}$ & 16 & 25,75 & & 0 & 0 \\
\hline 1697874 & 517,51 & 1832,1 & \begin{tabular}{|l|}
558,42 \\
\end{tabular} & 0 & 0 & 0,00 & 16 & 25,75 & & 0 & 0 \\
\hline 1698481,8 & 517,70 & 1832,1 & 558,42 & 0 & 0 & 0,00 & 16 & 25,75 & & 0 & 0 \\
\hline 1698648,3 & 517,75 & 1832,1 & \begin{tabular}{|l|}
558,42 \\
\end{tabular} & 0 & 0 & 0,00 & 12 & 19,31 & PN - Perímetro urbano & 5 & 0 \\
\hline 1699429,3 & 517,99 & 1832,1 & 558,42 & 0 & 0 & 0,00 & 16 & 25,75 & & 0 & 0 \\
\hline 1699432,5 & 517,99 & 1832,1 & 558,42 & 0 & 0 & 0,00 & 16 & 25,75 & BALSAMO (demolida) & 8 & $\overline{0}$ \\
\hline
\end{tabular}




\begin{tabular}{|c|c|c|c|c|c|c|c|c|c|c|c|}
\hline \multicolumn{2}{|c|}{ Posição } & \multicolumn{2}{|c|}{ Elevação } & \multirow{2}{*}{$\begin{array}{c}\text { rampa } \\
(\%) \\
\end{array}$} & \multicolumn{2}{|c|}{ curva } & \multicolumn{2}{|c|}{$\begin{array}{c}\text { Limite de } \\
\text { velocidade }\end{array}$} & \multirow[t]{2}{*}{ nome do local } & \multirow[t]{2}{*}{ C 1} & C 2 \\
\hline (feet) & $(\mathrm{km})$ & (feet) & $(\mathrm{m})$ & & ${ }^{\circ}$ & $(\mathrm{m})$ & $\mathrm{MPH}$ & $\mathrm{km} / \mathrm{h}$ & & & \\
\hline 1700229,8 & 518,23 & 1832,1 & 558,42 & 0,58 & 0 & 0,00 & 16 & 25,75 & & 0 & 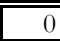 \\
\hline 1701470 & 518,61 & 1839,3 & 560,62 & 0,58 & 2,29 & 762,66 & 16 & 25,75 & & 0 & 0 \\
\hline 1702070,3 & 518,79 & 1842,7 & 561,65 & 0,58 & 0 & 0,00 & 16 & 25,75 & & 0 & 0 \\
\hline 1702208 & 518,83 & 1843,5 & 561,90 & 0 & 0 & 0,00 & 16 & 25,75 & & 0 & 0 \\
\hline 1704488,3 & 519,53 & 1843,5 & 561,90 & 0 & 2,29 & 762,66 & 16 & 25,75 & & 0 & 0 \\
\hline 1704832,8 & 519,63 & 1843,5 & 561,90 & 0,5 & 2,37 & 736,92 & 16 & 25,75 & & 0 & 0 \\
\hline 1706194,3 & 520,05 & 1850,3 & 563,97 & 0,5 & 0 & 0,00 & 16 & 25,75 & & 0 & 0 \\
\hline 1708051,3 & 520,61 & 1859,6 & 566,81 & 0,5 & 4,11 & 425,00 & 16 & 25,75 & & 0 & 0 \\
\hline 1708661,5 & 520,80 & 1862,7 & 567,75 & 0,5 & 0 & 0,00 & 16 & 25,75 & & 0 & 0 \\
\hline 1709376,8 & 521,02 & 1866,3 & 568,85 & 0,5 & $-3,2$ & 545,81 & 16 & 25,75 & & 0 & 0 \\
\hline 1711394,5 & 521,63 & 1876,3 & 571,90 & 0,5 & 0 & 0,00 & 16 & 25,75 & & 0 & 0 \\
\hline 1712572,3 & 521,99 & 1882,2 & 573,69 & 0,5 & 3,96 & 441,09 & 16 & 25,75 & & 0 & 0 \\
\hline 1713822,3 & 522,37 & 1888,5 & 575,61 & 0,5 & 0 & 0,00 & 16 & 25,75 & & 0 & 0 \\
\hline 1714675,3 & 522,63 & 1892,7 & 576,89 & 0 & 0 & 0,00 & 16 & 25,75 & & 0 & 0 \\
\hline 1715413,5 & 522,86 & 1892,7 & 576,89 & 0 & $-3,35$ & 521,38 & 16 & 25,75 & & 0 & 0 \\
\hline 1715643 & 522,93 & 1892,7 & 576,89 & $-0,5$ & $-3,35$ & 521,38 & 16 & 25,75 & & 0 & 0 \\
\hline 1718317 & 523,74 & 1879,4 & 572,84 & $-0,5$ & 0 & 0,00 & 16 & 25,75 & & 0 & 0 \\
\hline 1719265 & 524,03 & 1874,6 & 571,38 & 0 & 0 & 0,00 & 16 & 25,75 & & 0 & 0 \\
\hline 1720925,3 & 524,54 & 1874,6 & 571,38 & 0,5 & 2,79 & 626,00 & 16 & 25,75 & & 0 & 0 \\
\hline 1721401 & 524,68 & 1877 & 572,11 & 0,5 & 0 & 0,00 & 25 & 40,23 & & 0 & 0 \\
\hline 1722549,3 & 525,03 & 1882,8 & 573,88 & 0 & 0 & 0,00 & 25 & 40,23 & & 0 & 0 \\
\hline 1723205,5 & 525,23 & 1882,8 & 573,88 & $-0,5$ & 0 & 0,00 & 25 & 40,23 & & 0 & 0 \\
\hline 1723471,3 & 525,31 & 1881,4 & 573,45 & $-0,5$ & 2,79 & 626,00 & 25 & 40,23 & & 0 & 0 \\
\hline 1724501,5 & 525,63 & 1876,3 & 571,90 & 0 & 2,79 & 626,00 & 25 & 40,23 & & 0 & 0 \\
\hline 1725495,5 & 525,93 & 1876,3 & 571,90 & 0 & 0 & 0,00 & 25 & 40,23 & & 0 & 0 \\
\hline 1727437,8 & 526,52 & 1876,3 & 571,90 & 0,5 & 0 & 0,00 & 25 & 40,23 & & 0 & 0 \\
\hline 1729839,3 & 527,26 & 1888,3 & 575,55 & 0,5 & $\begin{array}{r}-3,76 \\
\end{array}$ & 464,54 & 25 & 40,23 & & 0 & 0 \\
\hline 1730718,5 & 527,52 & 1892,7 & 576,89 & 0 & $-3,76$ & 464,54 & 25 & 40,23 & & 0 & 0 \\
\hline 1731178 & 527,66 & 1892,7 & 576,89 & 0 & 0 & 0,00 & 25 & 40,23 & & 0 & 0 \\
\hline 1731404,3 & 527,73 & 1892,7 & 576,89 & $-0,5$ & 0 & 0,00 & 25 & 40,23 & & 0 & 0 \\
\hline 1732031 & 527,92 & 1889,5 & 575,92 & 0 & 0 & 0,00 & 25 & 40,23 & & 0 & 0 \\
\hline 1733304 & 528,31 & 1889,5 & 575,92 & $-0,5$ & 0 & 0,00 & 25 & 40,23 & & 0 & 0 \\
\hline 1733376 & 528,33 & 1889,2 & 575,83 & $-0,5$ & $\begin{array}{r}-3,96 \\
\end{array}$ & 441,09 & 25 & 40,23 & & 0 & 0 \\
\hline 1734288 & 528,61 & 1884,6 & 574,43 & 0 & $-3,96$ & 441,09 & 25 & 40,23 & & 0 & 0 \\
\hline 1734360,3 & 528,63 & 1884,6 & 574,43 & 0 & 0 & 0,00 & 25 & 40,23 & & 0 & 0 \\
\hline 1734950,8 & 528,81 & 1884,6 & 574,43 & 0,5 & 0 & 0,00 & 25 & 40,23 & & 0 & 0 \\
\hline 1735279 & 528,91 & 1886,3 & 574,94 & 0,5 & 4,11 & 425,00 & 25 & 40,23 & & 0 & 0 \\
\hline 1737411,5 & 529,56 & 1896,9 & 578,18 & 0,5 & 0 & 0,00 & 25 & 40,23 & & 0 & 0 \\
\hline 1738756,5 & 529,97 & 1903,7 & 580,25 & $-0,5$ & \begin{tabular}{|l|}
$-5,64$ \\
\end{tabular} & 309,77 & 25 & 40,23 & & 0 & 0 \\
\hline 1738956,8 & 530,03 & 1902,7 & 579,94 & 0 & $-5,64$ & 309,77 & 25 & 40,23 & & 0 & 0 \\
\hline 1740469,3 & 530,50 & 1902,7 & 579,94 & 0 & 0 & 0,00 & 25 & 40,23 & & 0 & 0 \\
\hline 1741105,8 & 530,69 & 1902,7 & 579,94 & 0 & 0 & 0,00 & 25 & 40,23 & & 0 & 0 \\
\hline 1741939 & 530,94 & 1902,7 & 579,94 & 0 & 5,64 & 309,77 & 19 & 30,58 & Perímetro urbano & 0 & 0 \\
\hline 1742293,5 & 531,05 & 1902,7 & 579,94 & 0 & 5,64 & 309,77 & 19 & 30,58 & Perímetro urbano & 0 & 0 \\
\hline 1742345,8 & 531,07 & 1902,7 & 579,94 & 0 & 5,64 & 309,77 & 19 & 30,58 & ZMO - FIM & 0 & 2 \\
\hline 1742900,3 & 531,24 & 1902,7 & 579,94 & 0 & 0 & 0,00 & 19 & 30,58 & Perímetro urbano & 0 & 1 \\
\hline 1743471,3 & 531,41 & 1902,7 & 579,94 & 0 & 0 & 0,00 & 19 & 30,58 & Perímetro urbano & 0 & 1 \\
\hline 1743474,5 & 531,41 & 1902,7 & 579,94 & 0 & 0 & 0,00 & 19 & 30,58 & MIRASSOL & 8 & 1 \\
\hline 1744435,8 & 531,70 & 1902,7 & 579,94 & 0 & 0 & 0,00 & 19 & 30,58 & Perímetro urbano & 0 & 1 \\
\hline 1744504,5 & 531,72 & 1902,7 & 579,94 & 0 & 0 & 0,00 & 19 & 30,58 & Perímetro urbano & 0 & 1 \\
\hline 1744557 & 531,74 & 1902,7 & 579,94 & 0 & 0 & 0,00 & 19 & 30,58 & ZMO - INICIO & 0 & 3 \\
\hline 1745843,3 & 532,13 & 1902,7 & 579,94 & -1 & 0 & 0,00 & 19 & 30,58 & Perímetro urbano & 0 & 0 \\
\hline 1749430,8 & 533,23 & 1866,8 & 569,00 & -1 & 0 & 0,00 & 19 & 30,58 & Perímetro urbano & 0 & 0 \\
\hline 1753057,8 & 534,33 & 1830,5 & 557,94 & 0 & 0 & 0,00 & 25 & 40,23 & & 0 & 0 \\
\hline 1754498 & 534,77 & 1830,5 & 557,94 & 0 & $-3,56$ & 490,63 & 25 & 40,23 & & 0 & 0 \\
\hline 1754698,3 & 534,83 & 1830,5 & 557,94 & -1 & $-3,56$ & 490,63 & 25 & 40,23 & & 0 & 0 \\
\hline 1755154,3 & 534,97 & 1825,9 & 556,53 & -1 & 0 & 0,00 & 25 & 40,23 & & 0 & 0 \\
\hline 1758359,5 & 535,95 & 1793,9 & 546,78 & -1 & 4,57 & 382,24 & 25 & 40,23 & & 0 & 0 \\
\hline 1759232,3 & 536,21 & 1785,2 & 544,13 & -1 & 0 & 0,00 & 25 & 40,23 & & 0 & 0 \\
\hline 1759852,5 & 536,40 & 1779 & 542,24 & -1 & \begin{tabular}{r|}
$-5,64$ \\
\end{tabular} & 309,77 & 25 & 40,23 & & 0 & 0 \\
\hline 1760610,3 & 536,63 & 1771,4 & 539,92 & -1 & 0 & 0,00 & 25 & 40,23 & & 0 & 0 \\
\hline 1761558,5 & 536,92 & 1761,9 & 537,03 & -1 & \begin{tabular}{r|}
$-5,64$ \\
\end{tabular} & 309,77 & 25 & 40,23 & & 0 & 0 \\
\hline 1762592 & 537,24 & 1751,6 & $\begin{array}{l}533,89 \\
\end{array}$ & -1 & 0 & 0,00 & 25 & 40,23 & & 0 & 0 \\
\hline 1763182,5 & 537,42 & 1745,7 & 532,09 & -1 & 5,64 & 309,77 & 25 & 40,23 & & 0 & 0 \\
\hline 1764278,3 & 537,75 & 1734,7 & 528,74 & -1 & \begin{tabular}{r|}
$-5,64$ \\
\end{tabular} & 309,77 & 25 & 40,23 & & 0 & 0 \\
\hline 1764544 & 537,83 & 1732,1 & 527,94 & 0 & 0 & 0,00 & 25 & 40,23 & & 0 & 0 \\
\hline 1764773,8 & 537,90 & 1732,1 & 527,94 & 0 & \begin{tabular}{r|}
$-5,64$ \\
\end{tabular} & 309,77 & 25 & 40,23 & & 0 & 0 \\
\hline 1765456 & 538,11 & 1732,1 & 527,94 & -1 & $-5,64$ & 309,77 & 25 & 40,23 & & 0 & 0 \\
\hline 1766122 & 538,31 & 1725,4 & 525,90 & -1 & 0 & 0,00 & 25 & 40,23 & & 0 & 0 \\
\hline 1766660 & 538,48 & 1720 & 524,26 & -1 & 5,64 & 309,77 & 25 & 40,23 & & 0 & 0 \\
\hline 1767956 & 538,87 & 1707,1 & 520,32 & -1 & 0 & 0,00 & 25 & 40,23 & & 0 & 0 \\
\hline
\end{tabular}




\begin{tabular}{|c|c|c|c|c|c|c|c|c|c|c|c|}
\hline \multicolumn{2}{|c|}{ Posição } & \multicolumn{2}{|c|}{ Elevação } & \multirow{2}{*}{$\begin{array}{c}\text { rampa } \\
(\%) \\
\end{array}$} & \multicolumn{2}{|c|}{ curva } & \multicolumn{2}{|c|}{$\begin{array}{c}\text { Limite de } \\
\text { velocidade }\end{array}$} & \multirow[t]{2}{*}{ nome do local } & \multirow[t]{2}{*}{ C 1} & C 2 \\
\hline (feet) & $(\mathrm{km})$ & (feet) & $(\mathrm{m})$ & & ${ }^{\circ}$ & $(\mathrm{m})$ & MPH & $\mathrm{km} / \mathrm{h}$ & & & \\
\hline 1768513,8 & 539,04 & 1701,5 & \begin{tabular}{|l|}
518,62 \\
\end{tabular} & -1 & $-5,64$ & \begin{tabular}{|c|}
309,77 \\
\end{tabular} & 25 & 40,23 & & 0 & 0 \\
\hline 1769918 & 539,47 & 1687,4 & 514,32 & -1 & 0 & 0,00 & 25 & 40,23 & & 0 & 0 \\
\hline 1771506 & 539,96 & 1671,6 & 509,50 & -1 & 4,06 & 430,23 & 25 & 40,23 & & 0 & 0 \\
\hline 1772057 & 540,12 & 1666 & 507,80 & -1 & 0 & 0,00 & 25 & 40,23 & & 0 & 0 \\
\hline 1772647,8 & 540,30 & 1660,1 & $\begin{array}{l}506,00 \\
\end{array}$ & -1 & $-4,57$ & \begin{tabular}{l|l|}
382,24 \\
\end{tabular} & 25 & 40,23 & & 0 & 0 \\
\hline 1773146,5 & 540,46 & 1655,1 & 504,47 & -1 & 0 & 0,00 & 25 & 40,23 & & 0 & 0 \\
\hline 1773960 & 540,70 & 1647 & 502,01 & -1 & 5,64 & 309,77 & 25 & 40,23 & & 0 & 0 \\
\hline 1775174 & 541,07 & 1634,9 & 498,32 & -1 & 0 & 0,00 & 25 & 40,23 & & 0 & 0 \\
\hline 1775315 & 541,12 & 1633,5 & \begin{tabular}{|l|}
497,89 \\
\end{tabular} & 0 & 0 & 0,00 & 25 & 40,23 & & 0 & 0 \\
\hline 1775699 & 541,23 & 1633,5 & 497,89 & 0 & $-5,64$ & 309,77 & 25 & 40,23 & & 0 & 0 \\
\hline 1776748,8 & 541,55 & 1633,5 & \begin{tabular}{|l|}
497,89 \\
\end{tabular} & 0 & 0 & 0,00 & 25 & 40,23 & & 0 & 0 \\
\hline 1777595,3 & 541,81 & 1633,5 & 497,89 & 0 & 4,57 & 382,24 & 25 & 40,23 & & 0 & 0 \\
\hline 1778126,8 & 541,97 & 1633,5 & \begin{tabular}{|l|l|}
497,89 \\
\end{tabular} & 0 & 0 & 0,00 & 25 & 40,23 & & 0 & 0 \\
\hline 1778970 & 542,23 & 1633,5 & 497,89 & 0 & 0 & 0,00 & 25 & 40,23 & & 0 & 0 \\
\hline 1778973 & 542,23 & 1633,5 & \begin{tabular}{|l|l|}
497,89 \\
\end{tabular} & 0 & 0 & 0,00 & 25 & 40,23 & G. DE CAMPOS (demolida) & 8 & 0 \\
\hline 1781023,8 & 542,86 & 1633,5 & 4497,89 & 0 & 3,56 & 490,63 & 25 & 40,23 & & 0 & 0 \\
\hline 1782506,5 & 543,31 & 1633,5 & 4497,89 & 0 & 0 & 0,00 & 25 & 40,23 & & 0 & 0 \\
\hline 1783212 & 543,52 & 1633,5 & 4497,89 & 0 & $-2,54$ & 687,61 & 25 & 40,23 & & 0 & 0 \\
\hline 1784819,5 & 544,01 & 1633,5 & 497,89 & $-0,3$ & $-2,54$ & 687,61 & 25 & 40,23 & & 0 & 0 \\
\hline 1784983,5 & 544,06 & 1633 & 4997,74 & $-0,3$ & 0 & 0,00 & 25 & 40,23 & & 0 & 0 \\
\hline 1786460 & 544,51 & 1628,5 & 496,37 & 0 & 0 & 0,00 & 25 & 40,23 & & 0 & 0 \\
\hline 1787782,3 & 544,92 & 1628,5 & 496,37 & 0 & $-2,79$ & 626,00 & 25 & 40,23 & & 0 & 0 \\
\hline 1788248 & 545,06 & 1628,5 & 496,37 & 0 & 0 & 0,00 & 25 & 40,23 & & 0 & 0 \\
\hline 1789557 & 545,46 & 1628,5 & 496,37 & 0 & 0 & 0,00 & 25 & 40,23 & & 0 & 0 \\
\hline 1789609,5 & 545,47 & 1628,5 & 496,37 & 0 & 0 & 0,00 & 12 & 19,31 & ZRU - FIM & 0 & 2 \\
\hline 1791926 & 546,18 & 1628,5 & 496,37 & 0 & 0 & 0,00 & 25 & 40,23 & & 0 & 1 \\
\hline 1791929,3 & 546,18 & 1628,5 & 4496,37 & 0 & 0 & 0,00 & 25 & 40,23 & RIO PRETO PAULIS & 8 & 1 \\
\hline 1792808,5 & 546,45 & 1628,5 & 496,37 & 0 & 2,79 & 626,00 & 25 & 40,23 & & 0 & 1 \\
\hline 1793087,3 & 546,53 & 1628,5 & 496,37 & 0 & 0 & 0,00 & 25 & 40,23 & & 0 & 1 \\
\hline 1793612,3 & 546,69 & 1628,5 & 496,37 & -1 & 0 & 0,00 & 25 & 40,23 & & 0 & 1 \\
\hline 1794163,5 & 546,86 & 1623 & 4494,69 & -1 & 0 & 0,00 & 25 & 40,23 & & 0 & 1 \\
\hline 1794216 & 546,88 & 1622,5 & 494,54 & -1 & 0 & 0,00 & 12 & 19,31 & ZRU - INICIO & 0 & 3 \\
\hline 1794288 & 546,90 & 1621,8 & 494,32 & 0 & 0 & 0,00 & 25 & 40,23 & & 0 & 0 \\
\hline 1795800,5 & 547,36 & 1621,8 & 494,32 & 0 & 5,64 & 309,77 & 25 & 40,23 & & 0 & 0 \\
\hline 1797155,5 & 547,77 & 1621,8 & 494,32 & $-0,6$ & 5,64 & 309,77 & 25 & 40,23 & & 0 & 0 \\
\hline 1797493,5 & 547,88 & 1619,8 & 493,72 & $-0,6$ & 0 & 0,00 & 25 & 40,23 & & 0 & 0 \\
\hline 1798599 & 548,21 & 1613,1 & 4991,67 & $-0,6$ & 3,56 & 490,63 & 25 & 40,23 & & 0 & 0 \\
\hline 1798796 & 548,27 & 1611,9 & 491,31 & -1 & 3,56 & 490,63 & 25 & 40,23 & & 0 & 0 \\
\hline 1799748,5 & 548,56 & 1602,4 & 488,41 & -1 & 3,56 & 490,63 & 25 & 40,23 & & 0 & 0 \\
\hline 1799780,3 & 548,57 & 1602,1 & 488,32 & -1 & 0 & 0,00 & 22 & 35,41 & PN - Perímetro urbano & 0 & 0 \\
\hline 1799912 & 548,61 & 1600,8 & 487,92 & -1 & 0 & 0,00 & 22 & 35,41 & PN - Perímetro urbano & 5 & 0 \\
\hline 1801420,5 & 549,07 & 1585,7 & 483,32 & -1 & $-4,57$ & 382,24 & 25 & 40,23 & & 0 & 0 \\
\hline 1801748,8 & 549,17 & 1582,4 & 482,32 & $-0,3$ & $-4,57$ & 382,24 & 25 & 40,23 & & 0 & 0 \\
\hline 1801781,5 & 549,18 & 1582,3 & 482,29 & $-0,3$ & 0 & 0,00 & 25 & 40,23 & & 0 & 0 \\
\hline 1803192,3 & 549,61 & 1578,1 & 481,00 & $-0,3$ & $-5,64$ & 309,77 & 25 & 40,23 & & 0 & 0 \\
\hline 1803389,3 & 549,67 & 1577,5 & 480,82 & 0 & $-5,64$ & 309,77 & 25 & 40,23 & & 0 & 0 \\
\hline 1803979,8 & 549,85 & 1577,5 & 480,82 & 0 & 0 & 0,00 & 25 & 40,23 & & 0 & 0 \\
\hline 1805735 & 550,39 & 1577,5 & 480,82 & 0 & $-7,21$ & 242,38 & 25 & 40,23 & & 0 & 0 \\
\hline 1805772 & 550,40 & 1577,5 & 480,82 & 0 & $-7,21$ & 242,38 & 25 & 40,23 & & 0 & 0 \\
\hline 1806079,5 & 550,49 & 1577,5 & 480,82 & 0,46 & $-7,21$ & 242,38 & 12 & 19,31 & PN - Perímetro urbano & 0 & 0 \\
\hline 1806276,3 & 550,55 & 1578,4 & 481,10 & 0,46 & $-7,21$ & 242,38 & 12 & 19,31 & PN - Perímetro urbano & 0 & 0 \\
\hline 1806309 & 550,56 & 1578,5 & 481,13 & 0,46 & 0 & 0,00 & 12 & 19,31 & ZSP - FIM & 0 & 2 \\
\hline 1806548,5 & 550,64 & 1579,6 & 481,46 & 0,46 & 0 & 0,00 & 12 & 19,31 & PN - Perímetro urbano & 0 & 1 \\
\hline 1806552 & 550,64 & 1579,7 & 481,49 & 0,46 & 0 & 0,00 & 12 & 19,31 & S. JOSE DO RIO PRETO & 8 & 1 \\
\hline 1806590,3 & 550,65 & 1579,8 & 481,52 & 0,46 & 0 & 0,00 & 12 & 19,31 & PN - Perímetro urbano & 0 & 1 \\
\hline 1807129,3 & 550,81 & 1582,3 & 482,29 & 0,46 & 4,32 & 404,35 & 25 & 40,23 & & 0 & 1 \\
\hline 1807555,8 & 550,94 & 1584,3 & 482,89 & 0,46 & 0 & 0,00 & 25 & 40,23 & & 0 & 1 \\
\hline 1807680,5 & 550,98 & 1584,9 & 483,08 & 0,46 & 0 & 0,00 & 25 & 40,23 & & 0 & 1 \\
\hline 1807733 & 551,00 & 1585,1 & 483,14 & 0,46 & 0 & 0,00 & 12 & 19,31 & ZSP - INICIO & 0 & 3 \\
\hline 1808080,8 & 551,10 & 1586,7 & 483,63 & 0,46 & $-4,32$ & 404,35 & 25 & 40,23 & & 0 & 0 \\
\hline 1808638,5 & 551,27 & 1589,3 & 484,42 & 0,46 & 0 & 0,00 & 25 & 40,23 & & 0 & 0 \\
\hline 1809852,5 & 551,64 & 1594,8 & 486,10 & 0,46 & 1,52 & 1148,96 & 25 & 40,23 & & 0 & 0 \\
\hline 1810027,5 & 551,70 & 1595,7 & 486,37 & 0,46 & 1,52 & 1148,96 & 25 & 40,23 & & 0 & 0 \\
\hline 1813805,8 & 552,85 & 1613 & 491,64 & 0,46 & 0 & 0,00 & 22 & 35,41 & Perímetro urbano & 0 & 0 \\
\hline 1813956 & 552,89 & 1613,7 & 491,86 & 0,46 & 0 & 0,00 & 22 & 35,41 & Perímetro urbano & 0 & 0 \\
\hline 1814340,6 & 553,01 & 1615,5 & 4992,40 & 0 & 0 & 0,00 & 25 & 40,23 & & 0 & 0 \\
\hline 1814642,4 & 553,10 & 1615,5 & 492,40 & 0 & 1,52 & 1148,96 & 25 & 40,23 & & 0 & 0 \\
\hline 1816738,6 & 553,74 & 1615,5 & 492,40 & 0 & 1,52 & 1148,96 & 25 & 40,23 & & 0 & 0 \\
\hline 1816804,1 & 553,76 & 1615,5 & 492,40 & 0 & 1,52 & 1148,96 & 19 & 30,58 & PN - Escola & 5 & 0 \\
\hline 1817299,9 & 553,91 & 1615,5 & 492,40 & 0 & 0 & 0,00 & 25 & 40,23 & & 0 & 0 \\
\hline 1819202,8 & 554,49 & 1615,5 & 492,40 & 0 & $-1,52$ & 1148,96 & 25 & 40,23 & & 0 & 0 \\
\hline
\end{tabular}




\begin{tabular}{|c|c|c|c|c|c|c|c|c|c|c|c|}
\hline \multicolumn{2}{|c|}{ Posição } & \multicolumn{2}{|c|}{ Elevação } & \multirow{2}{*}{$\begin{array}{c}\text { rampa } \\
(\%) \\
\end{array}$} & \multicolumn{2}{|c|}{ curva } & \multicolumn{2}{|c|}{$\begin{array}{c}\text { Limite de } \\
\text { velocidade }\end{array}$} & \multirow[t]{2}{*}{ nome do local } & \multirow[t]{2}{*}{ C 1} & C 2 \\
\hline (feet) & $(\mathrm{km})$ & (feet) & (m) & & ${ }^{\circ}$ & $(\mathrm{m})$ & $\mathrm{MPH}$ & $\mathrm{km} / \mathrm{h}$ & & & \\
\hline 1819268,4 & 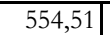 & 1615,5 & 492,40 & \begin{tabular}{l|l|}
$-0,5$ \\
\end{tabular} & \begin{tabular}{l|}
$-1,52$ \\
\end{tabular} & 1148,96 & 25 & 40,23 & & \begin{tabular}{l|l}
0 \\
\end{tabular} & $\overline{0}$ \\
\hline 1821893,1 & 555,31 & 1602,4 & 488,41 & 0 & $-1,52$ & 1148,96 & 25 & 40,23 & & 0 & 0 \\
\hline 1822549,3 & 555,51 & 1602,4 & 488,41 & 0,5 & \begin{tabular}{l|}
$-1,52$ \\
\end{tabular} & 1148,96 & 25 & 40,23 & & 0 & 0 \\
\hline 1822877,3 & 555,61 & 1604 & 488,90 & 0,5 & 0 & 0,00 & 25 & 40,23 & & 0 & 0 \\
\hline 1825331,4 & 556,36 & 1616,3 & 492,65 & 0,5 & 1,52 & 1148,96 & 25 & 40,23 & & 0 & $\overline{0}$ \\
\hline 1827651 & \begin{tabular}{l|}
557,07 \\
\end{tabular} & 1627,9 & 496,18 & 0,5 & 0 & 0,00 & 25 & 40,23 & & 0 & 0 \\
\hline 1828471,3 & \begin{tabular}{l|l|}
557,32 \\
\end{tabular} & 1632 & 497,43 & 0 & 0 & 0,00 & 25 & 40,23 & & 0 & 0 \\
\hline 1828684,4 & 557,38 & 1632 & 497,43 & 0 & $-1,52$ & 1148,96 & 25 & 40,23 & & 0 & 0 \\
\hline 1830360,9 & 557,89 & 1632 & 497,43 & 0 & 0 & 0,00 & 25 & 40,23 & & 0 & 0 \\
\hline 1834065 & 559,02 & 1632 & 497,43 & 0,5 & 0 & 0,00 & 25 & 40,23 & & 0 & 0 \\
\hline 1837181,8 & 559,97 & 1647,6 & 502,19 & 0,5 & \begin{tabular}{l|l}
1,52 \\
\end{tabular} & 1148,96 & 25 & 40,23 & & 0 & 0 \\
\hline 1837559,1 & \begin{tabular}{l|l}
560,09 \\
\end{tabular} & 1649,4 & 502,74 & 0 & 1,52 & 1148,96 & 25 & 40,23 & & 0 & 0 \\
\hline 1837673,9 & 560,12 & 1649,4 & 502,74 & 0 & 0 & 0,00 & 25 & 40,23 & & 0 & 0 \\
\hline 1840400,3 & 560,95 & 1649,4 & 502,74 & 0 & 0 & 0,00 & 25 & 40,23 & & 0 & 0 \\
\hline 1840452,8 & 560,97 & 1649,4 & 502,74 & 0 & 0 & 0,00 & 19 & 30,58 & ZEH - FIM & 0 & 2 \\
\hline 1840675,9 & 561,04 & 1649,4 & 502,74 & 1 & 0 & 0,00 & 19 & 30,58 & PN - Perímetro urbano & 5 & 1 \\
\hline 1841105,8 & \begin{tabular}{l|l}
561,17 \\
\end{tabular} & 1653,7 & 504,05 & 1 & 0 & 0,00 & 25 & 40,23 & & 0 & 1 \\
\hline 1841109 & 561,17 & 1653,8 & 504,08 & 1 & 0 & 0,00 & 25 & 40,23 & ENG. SCHIMITTT & 8 & 1 \\
\hline 1841939 & \begin{tabular}{l|l|}
561,42 \\
\end{tabular} & 1662,1 & 506,61 & 1 & 1,52 & 1148,96 & 25 & 40,23 & & 0 & 1 \\
\hline 1841962 & 561,43 & 1662,3 & 506,67 & 1 & 1,52 & 1148,96 & 25 & 40,23 & ZEH - INICIO & 0 & 3 \\
\hline 1843038,1 & 561,76 & 1673,1 & 509,96 & 1 & 0 & 0,00 & 25 & 40,23 & & 0 & 0 \\
\hline 1843825,5 & 562,00 & 1680,9 & 512,34 & 1 & \begin{tabular}{l|l|}
$-1,52$ \\
\end{tabular} & 1148,96 & 25 & 40,23 & & 0 & 0 \\
\hline 1846040,1 & 562,67 & 1703,1 & 519,10 & 1 & 0 & 0,00 & 25 & 40,23 & & 0 & 0 \\
\hline 1850502 & 564,03 & 1747,7 & 532,70 & 1 & 1,52 & 1148,96 & 25 & 40,23 & & 0 & 0 \\
\hline 1851880 & 564,45 & 1761,5 & 536,91 & 1 & 0 & 0,00 & 25 & 40,23 & & 0 & $\overline{0}$ \\
\hline 1853526,9 & 564,95 & 1778 & 541,93 & 1 & \begin{tabular}{l|}
$-1,52$ \\
\end{tabular} & 1148,96 & 25 & 40,23 & & 0 & 0 \\
\hline 1855554,5 & 565,57 & 1798,2 & 548,09 & 1 & 0 & 0,00 & 25 & 40,23 & & 0 & 0 \\
\hline 1856349,8 & 565,82 & 1806,2 & 550,53 & 1 & 0 & 0,00 & 16 & 25,75 & & 0 & 0 \\
\hline 1857168,1 & 566,06 & 1814,4 & 553,03 & 1 & 0 & 0,00 & 16 & 25,75 & & 0 & 0 \\
\hline 1859918 & 566,90 & 1841,9 & 561,41 & 1 & 0 & 0,00 & 25 & 40,23 & & 0 & 0 \\
\hline 1859921,3 & 566,90 & 1841,9 & 561,41 & 1 & 0 & 0,00 & 25 & 40,23 & CEDRAL PASS. (demolida) & 8 & $\overline{0}$ \\
\hline 1860515,1 & 567,08 & 1847,8 & 563,21 & 1 & 1,52 & 1148,96 & 25 & 40,23 & & 0 & 0 \\
\hline 1863231,8 & 567,91 & 1875 & 571,50 & 1 & 0 & 0,00 & 25 & 40,23 & & 0 & 0 \\
\hline 1865003,3 & 568,45 & 1892,7 & 576,89 & 0 & 0 & 0,00 & 25 & 40,23 & & 0 & 0 \\
\hline 1866916,1 & 569,04 & 1892,7 & 576,89 & -1 & 1,52 & 1148,96 & 25 & 40,23 & & 0 & 0 \\
\hline 1867306,5 & 569,16 & 1888,8 & 575,71 & -1 & 1,52 & 1148,96 & 25 & 40,23 & & 0 & 0 \\
\hline 1867309,8 & 569,16 & 1888,8 & 575,71 & -1 & 1,52 & 1148,96 & 25 & 40,23 & CEDRAL MERC. (demolida) & 8 & 0 \\
\hline 1868431,8 & 569,50 & 1877,6 & 572,29 & -1 & 0 & 0,00 & 25 & 40,23 & & 0 & 0 \\
\hline 1869235,6 & 569,74 & 1869,5 & 569,82 & \begin{tabular}{l|l}
-1 \\
\end{tabular} & \begin{tabular}{l|}
$-1,52$ \\
\end{tabular} & 1148,96 & 25 & 40,23 & & 0 & 0 \\
\hline 1873107 & 570,92 & 1830,8 & 558,03 & -1 & 0 & 0,00 & 25 & 40,23 & & 0 & 0 \\
\hline 1880971,3 & \begin{tabular}{l|l|}
573,32 \\
\end{tabular} & 1752,2 & 534,07 & \begin{tabular}{l|}
-1 \\
\end{tabular} & \begin{tabular}{l|}
$-1,52$ \\
\end{tabular} & 1148,96 & 25 & 40,23 & & 0 & 0 \\
\hline 1881393 & 573,45 & 1748 & 532,79 & -1 & $-1,52$ & 1148,96 & 9 & 14,48 & & 0 & 0 \\
\hline 1882702,5 & 573,85 & 1734,9 & 528,80 & -1 & \begin{tabular}{l|}
$-1,52$ \\
\end{tabular} & 1148,96 & 9 & 14,48 & & 0 & 0 \\
\hline 1885803,9 & \begin{tabular}{l|}
574,79 \\
\end{tabular} & 1703,8 & 519,32 & -1 & 0 & 0,00 & 25 & 40,23 & & 0 & 0 \\
\hline 1886985 & 575,15 & 1692 & 515,72 & -1 & \begin{tabular}{l|}
1,52 \\
\end{tabular} & 1148,96 & 25 & 40,23 & & 0 & 0 \\
\hline 1889019,1 & \begin{tabular}{l|l|}
575,77 \\
\end{tabular} & 1671,7 & 509,53 & \begin{tabular}{l|}
-1 \\
\end{tabular} & 0 & 0,00 & 25 & 40,23 & & 0 & 0 \\
\hline 1891184,4 & $\begin{array}{l}576,43 \\
\end{array}$ & 1650 & 502,92 & 0 & 0 & 0,00 & 25 & 40,23 & & 0 & 0 \\
\hline 1893284,3 & \begin{tabular}{l|l|}
577,07 \\
\end{tabular} & 1650 & 502,92 & \begin{tabular}{l|}
$-0,5$ \\
\end{tabular} & 0 & 0,00 & 25 & 40,23 & & 0 & 0 \\
\hline 1893973,1 & $\begin{array}{l}577,28 \\
\end{array}$ & 1646,6 & 501,88 & $-0,5$ & 1,52 & 1148,96 & 25 & 40,23 & & 0 & 0 \\
\hline 1896451,8 & \begin{tabular}{l|l}
578,04 \\
\end{tabular} & 1634,2 & 498,10 & \begin{tabular}{l|l|}
$-0,5$ \\
\end{tabular} & 1,52 & 1148,96 & 16 & 25,75 & & 0 & 0 \\
\hline 1896565 & \begin{tabular}{|l|}
578,07 \\
\end{tabular} & 1633,6 & 497,92 & $-0,5$ & 0 & 0,00 & 16 & 25,75 & & 0 & 0 \\
\hline 1897106,5 & \begin{tabular}{l|}
578,24 \\
\end{tabular} & 1630,9 & 497,10 & \begin{tabular}{l|}
$-0,5$ \\
\end{tabular} & 0 & 0,00 & 16 & 25,75 & & 0 & 0 \\
\hline 1898983 & 578,81 & 1621,5 & 494,23 & \begin{tabular}{l|}
$-0,5$ \\
\end{tabular} & $-0,66$ & 2646,04 & 25 & 40,23 & & 0 & 0 \\
\hline 1900173,9 & 579,17 & 1615,6 & 492,43 & 0 & $-0,66$ & 2646,04 & 25 & 40,23 & & 0 & 0 \\
\hline 1902093,3 & 579,76 & 1615,6 & 492,43 & 0 & 0 & 0,00 & 25 & 40,23 & & 0 & 0 \\
\hline 1903162,8 & 580,08 & 1615,6 & 492,43 & 0 & 0 & 0,00 & 25 & 40,23 & & 0 & 0 \\
\hline 1903215,3 & 580,10 & 1615,6 & 492,43 & \begin{tabular}{l|l}
0 \\
\end{tabular} & 0 & 0,00 & 19 & 30,58 & ZUC - FIM & 0 & 2 \\
\hline 1903323,5 & 580,13 & 1615,6 & 492,43 & \begin{tabular}{l|}
$-0,5$ \\
\end{tabular} & 0 & 0,00 & 25 & 40,23 & & 0 & 1 \\
\hline 1903733,6 & 580,26 & 1613,5 & 491,79 & \begin{tabular}{l|}
$-0,5$ \\
\end{tabular} & \begin{tabular}{l|}
1,52 \\
\end{tabular} & 1148,96 & 25 & 40,23 & & 0 & 1 \\
\hline 1904530,9 & 580,50 & 1609,6 & 490,61 & $-0,5$ & 1,52 & 1148,96 & 25 & 40,23 & & 0 & 1 \\
\hline 1904534,3 & 580,50 & 1609,5 & 490,58 & \begin{tabular}{l|l|}
$-0,5$ \\
\end{tabular} & 1,52 & 1148,96 & 25 & 40,23 & $\mathrm{UCHOA}$ & 8 & 1 \\
\hline 1904635,9 & 580,53 & 1609 & 490,42 & 0,5 & 1,52 & 1148,96 & 25 & 40,23 & & 0 & 1 \\
\hline 1905443 & 580,78 & 1613,1 & 491,67 & 0,5 & 1,52 & 1148,96 & 25 & 40,23 & & 0 & 1 \\
\hline 1905495,5 & 580,80 & 1613,3 & 491,73 & 0,5 & 1,52 & 1148,96 & 19 & 30,58 & ZUC - INICIO & 0 & 3 \\
\hline 1906506 & 581,10 & 1618,4 & 493,29 & 0,5 & 0 & 0,00 & 25 & 40,23 & & 0 & 0 \\
\hline 1908566,3 & 581,73 & 1628,7 & 496,43 & $-0,5$ & 0 & 0,00 & 25 & 40,23 & & 0 & 0 \\
\hline 1910338 & 582,27 & 1619,8 & 493,72 & \begin{tabular}{l|l}
$-0,5$ \\
\end{tabular} & $-1,52$ & 1148,96 & 25 & 40,23 & & 0 & 0 \\
\hline 1913159,5 & 583,13 & 1605,7 & 489,42 & \begin{tabular}{l|l}
$-0,5$ \\
\end{tabular} & 0 & 0,00 & 25 & 40,23 & & 0 & 0 \\
\hline 1913182,5 & 583,14 & 1605,6 & 489,39 & 0,5 & 0 & 0,00 & 25 & 40,23 & & 0 & 0 \\
\hline 1916200,8 & 584,06 & 1620,7 & 493,99 & 0,5 & 1,52 & 1148,96 & 25 & 40,23 & & 0 & 0 \\
\hline 1919589,9 & \begin{tabular}{l|l|}
585,09 &
\end{tabular} & 1637,6 & 499,14 & $-0,5$ & \begin{tabular}{l|}
1,52 \\
\end{tabular} & 1148,96 & 25 & 40,23 & & 0 & 0 \\
\hline
\end{tabular}




\begin{tabular}{|c|c|c|c|c|c|c|c|c|c|c|c|}
\hline \multicolumn{2}{|c|}{ Posição } & \multicolumn{2}{|c|}{ Elevação } & \multirow{2}{*}{$\begin{array}{c}\text { rampa } \\
(\%)\end{array}$} & \multicolumn{2}{|c|}{ curva } & \multicolumn{2}{|c|}{$\begin{array}{c}\text { Limite de } \\
\text { velocidade }\end{array}$} & \multirow[t]{2}{*}{ nome do local } & \multirow[t]{2}{*}{ C 1} & C 2 \\
\hline (feet) & $(\mathrm{km})$ & (feet) & $(\mathrm{m})$ & & ${ }^{\circ}$ & $(\mathrm{m})$ & MPH & $\mathrm{km} / \mathrm{h}$ & & & \\
\hline 1920646,4 & $\begin{array}{l}585,41 \\
\end{array}$ & 1632,4 & \begin{tabular}{ll|}
497,56 \\
\end{tabular} & \begin{tabular}{|c|}
$-0,5$ \\
\end{tabular} & 0 & 0,00 & 25 & 40,23 & & 0 & 0 \\
\hline 1921368,3 & 585,63 & 1628,7 & 496,43 & 0,5 & 0 & 0,00 & 25 & 40,23 & & 0 & 0 \\
\hline 1922680,5 & 586,03 & 1635,3 & 498,44 & $-0,5$ & 0 & 0,00 & 25 & 40,23 & & 0 & 0 \\
\hline 1925079,1 & 586,76 & 1623,3 & 494,78 & $-0,5$ & 0 & 0,00 & 16 & 25,75 & & 0 & 0 \\
\hline 1925419,8 & 586,87 & \begin{tabular}{ll|}
1621,6 \\
\end{tabular} & 494,26 & $-0,5$ & 0 & 0,00 & 16 & 25,75 & & 0 & 0 \\
\hline 1926978,4 & 587,34 & 1613,8 & 4991,89 & $-0,5$ & $\begin{array}{l}-1,52 \\
\end{array}$ & 1148,96 & 25 & 40,23 & & 0 & 0 \\
\hline 1929176,6 & 588,01 & 1602,8 & 488,53 & $-0,5$ & \begin{tabular}{|c|}
$-1,52$ \\
\end{tabular} & 1148,96 & 25 & 40,23 & & 0 & 0 \\
\hline 1929242,3 & 588,03 & 1602,5 & 488,44 & 0 & 0 & 0,00 & 25 & 40,23 & & 0 & 0 \\
\hline 1929898,3 & 588,23 & 1602,5 & 488,44 & $-0,5$ & 0 & 0,00 & 25 & 40,23 & & 0 & 0 \\
\hline 1931866,8 & 588,83 & 1592,7 & 485,45 & 0,5 & 0 & 0,00 & 25 & 40,23 & & 0 & 0 \\
\hline 1937116,3 & 590,43 & 1618,9 & 493,44 & $-0,5$ & 0 & 0,00 & 25 & 40,23 & & 0 & 0 \\
\hline 1938428,5 & 590,83 & 1612,3 & 491,43 & 0,5 & 0 & 0,00 & 25 & 40,23 & & 0 & 0 \\
\hline 1940987,6 & 591,61 & 1625,1 & 495,33 & 0,5 & \begin{tabular}{|c|}
$-1,52$ \\
\end{tabular} & 1148,96 & 25 & 40,23 & & 0 & 0 \\
\hline 1941939 & 591,90 & 1629,9 & 4496,79 & 0,5 & 0 & 0,00 & 25 & 40,23 & & 0 & 0 \\
\hline 1943021,8 & 592,23 & 1635,3 & 498,44 & $-0,5$ & 0 & 0,00 & 25 & 40,23 & & 0 & 0 \\
\hline 1943038,1 & 592,24 & 1635,2 & 498,41 & $-0,5$ & 1,52 & 1148,96 & 25 & 40,23 & & 0 & 0 \\
\hline 1944655,6 & 592,73 & 1627,1 & 495,94 & 0,5 & 1,52 & 1148,96 & 25 & 40,23 & & 0 & 0 \\
\hline 1945902,3 & 593,11 & 1633,4 & 497,86 & 0,5 & 0 & 0,00 & 25 & 40,23 & & 0 & 0 \\
\hline 1946706,3 & 593,36 & 1637,4 & 499,08 & 0,5 & 0 & 0,00 & 9 & 14,48 & & 0 & 0 \\
\hline 1947434,4 & 593,58 & 1641 & 500,18 & 0,5 & $\begin{array}{l}-1,52 \\
\end{array}$ & 1148,96 & 9 & 14,48 & & 0 & 0 \\
\hline 1948271 & 593,83 & 1645,2 & 501,46 & $-0,5$ & $-1,52$ & 1148,96 & 9 & 14,48 & & 0 & 0 \\
\hline 1948631,9 & 593,94 & 1643,4 & 500,91 & $-0,5$ & 0 & 0,00 & 9 & 14,48 & & 0 & 0 \\
\hline 1950452,6 & 594,50 & 1634,3 & 498,13 & $-0,5$ & 0 & 0,00 & 9 & 14,48 & & 0 & 0 \\
\hline 1952208 & 595,03 & 1625,5 & 495,45 & 0,5 & 0 & 0,00 & 25 & 40,23 & & 0 & 0 \\
\hline 1952831,4 & 595,22 & 1628,6 & 496,40 & 0,5 & \begin{tabular}{|l|}
$-1,52$ \\
\end{tabular} & 1148,96 & 25 & 40,23 & & 0 & 0 \\
\hline 1953520,4 & 595,43 & 1632,1 & $\begin{array}{l}497,46 \\
\end{array}$ & $-0,5$ & $\begin{array}{l}-1,52 \\
\end{array}$ & 1148,96 & 25 & 40,23 & & 0 & 0 \\
\hline 1955390,5 & 596,00 & 1622,7 & 494,60 & $-0,5$ & 0 & 0,00 & 25 & 40,23 & & 0 & 0 \\
\hline 1956220,5 & 596,26 & 1618,6 & 493,35 & $-0,5$ & 1,52 & 1148,96 & 25 & 40,23 & & 0 & 0 \\
\hline 1958057,8 & 596,82 & 1609,4 & 490,55 & 0 & 1,52 & 1148,96 & 25 & 40,23 & & 0 & 0 \\
\hline 1959557,1 & 597,27 & 1609,4 & 490,55 & 0 & 0 & 0,00 & 25 & 40,23 & & 0 & 0 \\
\hline 1959818,8 & 597,35 & 1609,4 & 490,55 & 0 & 0 & 0,00 & 25 & 40,23 & & 0 & 0 \\
\hline 1960032,9 & 597,42 & 1609,4 & 490,55 & 0 & 0 & 0,00 & 12 & 19,31 & PN - Perímetro urbano & 0 & 0 \\
\hline 1960085,3 & 597,43 & 1609,4 & 490,55 & 0 & 0 & 0,00 & 12 & 19,31 & ZCT - FIM & 0 & 2 \\
\hline 1960410,1 & 597,53 & 1609,4 & 490,55 & 0 & 1,52 & 1148,96 & 12 & 19,31 & PN - Perímetro urbano & 0 & 1 \\
\hline 1960670,3 & 597,61 & 1609,4 & 490,55 & 0 & 1,52 & 1148,96 & 12 & 19,31 & PN - Perímetro urbano & 0 & 1 \\
\hline 1960836,8 & 597,66 & 1609,4 & 490,55 & 0,5 & 1,52 & 1148,96 & 25 & 40,23 & & 0 & 1 \\
\hline 1961177,9 & 597,77 & 1611,1 & 491,06 & 0,5 & 1,52 & 1148,96 & 25 & 40,23 & & 0 & 1 \\
\hline 1961181,1 & 597,77 & 1611,1 & 491,06 & 0,5 & 1,52 & 1148,96 & 25 & 40,23 & CATIGUA & 8 & 1 \\
\hline 1961509,3 & 597,87 & 1612,8 & 491,58 & 0,5 & 0 & 0,00 & 25 & 40,23 & & 0 & 1 \\
\hline 1962263,8 & 598,10 & 1616,5 & 492,71 & 0,5 & \begin{tabular}{|c|}
$-1,52$ \\
\end{tabular} & 1148,96 & 25 & 40,23 & & 0 & 1 \\
\hline 1962303,3 & 598,11 & 1616,7 & 4992,77 & 0,5 & \begin{tabular}{|c|}
$-1,52$ \\
\end{tabular} & 1148,96 & 25 & 40,23 & ZCT - INICIO & 0 & 3 \\
\hline 1963905,8 & 598,60 & 1624,8 & 495,24 & 0,5 & \begin{tabular}{|c|}
$-1,52$ \\
\end{tabular} & 1148,96 & 19 & 30,58 & & 0 & 0 \\
\hline 1964246,3 & 598,70 & 1626,5 & 495,76 & 0,5 & \begin{tabular}{ll|}
$-1,52$ \\
\end{tabular} & 1148,96 & 19 & 30,58 & & 0 & 0 \\
\hline 1965357,8 & 599,04 & 1632 & \begin{tabular}{|l|l|}
497,43 \\
\end{tabular} & 0,5 & 0 & 0,00 & 25 & 40,23 & & 0 & 0 \\
\hline 1966315,8 & 599,33 & 1636,8 & 498,90 & 0,5 & 1,52 & 1148,96 & 25 & 40,23 & & 0 & 0 \\
\hline 1969071,6 & 600,17 & 1650,6 & 503,10 & 0,5 & 0 & 0,00 & 25 & 40,23 & & 0 & 0 \\
\hline 1970105 & 600,49 & 1655,7 & 504,66 & 0,5 & $-1,52$ & 1148,96 & 25 & 40,23 & & 0 & 0 \\
\hline 1972614,9 & 601,25 & 1668,3 & 508,50 & $-0,5$ & $\begin{array}{l}-1,52 \\
\end{array}$ & 1148,96 & 25 & 40,23 & & 0 & 0 \\
\hline 1973205,4 & 601,43 & 1665,3 & 507,58 & $-0,5$ & 0 & 0,00 & 25 & 40,23 & & 0 & 0 \\
\hline 1974271,8 & 601,76 & 1660 & \begin{tabular}{|l|}
505,97 \\
\end{tabular} & $-0,5$ & 1,52 & 1148,96 & 25 & 40,23 & & 0 & 0 \\
\hline 1976092,6 & 602,31 & \begin{tabular}{ll|}
1650,9 \\
\end{tabular} & \begin{tabular}{|l|}
503,19 \\
\end{tabular} & 0,5 & 1,52 & $\begin{array}{l}1148,96 \\
\end{array}$ & 25 & 40,23 & & 0 & 0 \\
\hline 1976355 & 602,39 & 1652,2 & 503,59 & 0,5 & 0 & 0,00 & 25 & 40,23 & & 0 & 0 \\
\hline 1980029,6 & 603,51 & \begin{tabular}{ll|}
1670,6 \\
\end{tabular} & 509,20 & $-0,5$ & 0 & 0,00 & 25 & 40,23 & & 0 & 0 \\
\hline 1981109 & 603,84 & 1665,2 & 507,55 & $-0,5$ & 1,52 & $\begin{array}{l}1148,96 \\
\end{array}$ & 25 & 40,23 & & 0 & 0 \\
\hline 1981899,8 & 604,08 & 1661,2 & 506,33 & $-0,5$ & 0 & 0,00 & 25 & 40,23 & & 0 & 0 \\
\hline 1982621,4 & 604,30 & 1657,6 & 505,24 & 0,5 & 0 & 0,00 & 25 & 40,23 & & 0 & 0 \\
\hline 1982910,1 & 604,39 & 1659,1 & 505,69 & 0,5 & $\begin{array}{l}-1,52 \\
\end{array}$ & 1148,96 & 25 & 40,23 & & 0 & 0 \\
\hline 1984822,9 & 604,97 & 1668,6 & 508,59 & 0,5 & 0 & 0,00 & 25 & 40,23 & & 0 & 0 \\
\hline $\begin{array}{l}1985738,3 \\
\end{array}$ & 605,25 & 1673,2 & \begin{tabular}{|l|}
509,99 \\
\end{tabular} & 0,5 & 1,52 & 1148,96 & 25 & 40,23 & & 0 & 0 \\
\hline 1985935,1 & 605,31 & 1674,2 & 510,30 & $-0,5$ & 1,52 & 1148,96 & 25 & 40,23 & & 0 & 0 \\
\hline 1987903,6 & 605,91 & 1664,4 & 507,31 & 0 & 1,52 & 1148,96 & 25 & 40,23 & & 0 & 0 \\
\hline 1988290,8 & 606,03 & 1664,4 & 507,31 & 0 & 0 & 0,00 & 25 & 40,23 & & 0 & 0 \\
\hline 1989340,6 & 606,35 & 1664,4 & 507,31 & 0 & $\begin{array}{l}-1,52 \\
\end{array}$ & 1148,96 & 25 & 40,23 & & 0 & 0 \\
\hline 1991496,1 & 607,01 & 1664,4 & 507,31 & 0 & 0 & 0,00 & 25 & 40,23 & & 0 & 0 \\
\hline 1993609 & 607,65 & 1664,4 & 507,31 & 0 & 1,52 & 1148,96 & 25 & 40,23 & & 0 & 0 \\
\hline 1994793,4 & 608,01 & 1664,4 & 507,31 & 0 & 0 & 0,00 & 25 & 40,23 & & 0 & 0 \\
\hline 1995449,5 & 608,21 & 1664,4 & 507,31 & $-0,5$ & 0 & 0,00 & 25 & 40,23 & & 0 & 0 \\
\hline 1997943 & 608,97 & 1651,9 & 503,50 & $-0,5$ & 1,52 & 1148,96 & 25 & 40,23 & & 0 & 0 \\
\hline 1999960,8 & 609,59 & 1641,8 & \begin{tabular}{|l|}
500,42 \\
\end{tabular} & 0 & 1,52 & 1148,96 & 25 & 40,23 & & 0 & 0 \\
\hline 2000164,1 & 609,65 & 1641,8 & 500,42 & 0 & 0 & 0,00 & 25 & 40,23 & & 0 & 0 \\
\hline 2000830,1 & 609,85 & 1641,8 & 500,42 & 0 & \begin{tabular}{|l|}
$-7,74$ \\
\end{tabular} & 225,80 & 25 & 40,23 & & 0 & 0 \\
\hline
\end{tabular}




\begin{tabular}{|c|c|c|c|c|c|c|c|c|c|c|c|}
\hline \multicolumn{2}{|c|}{ Posição } & \multicolumn{2}{|c|}{ Elevação } & \multirow{2}{*}{$\begin{array}{c}\text { rampa } \\
(\%) \\
\end{array}$} & \multicolumn{2}{|c|}{ curva } & \multicolumn{2}{|c|}{$\begin{array}{c}\text { Limite de } \\
\text { velocidade }\end{array}$} & \multirow[t]{2}{*}{ nome do local } & \multirow[t]{2}{*}{ C 1} & C 2 \\
\hline (feet) & $(\mathrm{km})$ & (feet) & $(\mathrm{m})$ & & o & $(\mathrm{m})$ & $\mathrm{MPH}$ & $\mathrm{km} / \mathrm{h}$ & & & \\
\hline 2001237,5 & 609,98 & 1641,8 & 500,42 & 0 & $-7,74$ & 225,80 & 25 & 40,23 & & 0 & 0 \\
\hline 2002149 & 610,25 & 1641,8 & 500,42 & 0 & 0 & 0,00 & 19 & 30,58 & PN - Perímetro urbano & 0 & 0 \\
\hline 2002929,8 & 610,49 & 1641,8 & 500,42 & 0 & 7,74 & 225,80 & 19 & 30,58 & PN - Perímetro urbano & 0 & 0 \\
\hline 2003107 & 610,55 & 1641,8 & \begin{tabular}{l|l|}
500,42 \\
\end{tabular} & 0 & 7,74 & 225,80 & 19 & 30,58 & PN - Perímetro urbano & 0 & 0 \\
\hline 2003159,5 & 610,56 & 1641,8 & 500,42 & 0 & 7,74 & 225,80 & 16 & 25,75 & ZCV - FIM & 0 & 2 \\
\hline 2003280,9 & 610,60 & 1641,8 & 500,42 & 0 & 0 & 0,00 & 19 & 30,581 & PN - Perímetro urbano & 0 & 1 \\
\hline 2004186,4 & 610,88 & 1641,8 & 500,42 & 0 & 10,15 & 172,28 & 19 & 30,58 & PN - Perímetro urbano & 0 & 1 \\
\hline 2005170,6 & 611,18 & 1641,8 & 500,42 & 0 & 0 & 0,00 & 19 & 30,58 & PN - Perímetro urbano & 0 & 1 \\
\hline 2005416,8 & 611,25 & 1641,8 & 500,42 & 0 & $-10,15$ & 172,28 & 19 & 30,58 & PN - Perímetro urbano & 0 & 1 \\
\hline 2005420 & 611,25 & 1641,8 & \begin{tabular}{l|l|}
500,42 \\
\end{tabular} & 0 & \begin{tabular}{l|l}
0 \\
\end{tabular} & \begin{tabular}{l|l}
0,00 \\
\end{tabular} & 19 & 30,58 & CATANDUVA & 8 & 1 \\
\hline 2005636,5 & 611,32 & 1641,8 & 500,42 & 0 & $-4,32$ & 404,35 & 19 & 30,581 & PN - Perímetro urbano & 0 & 1 \\
\hline 2006282,9 & 611,52 & 1641,8 & 500,42 & 0 & $-4,32$ & 404,35 & 19 & 30,58 & PN - Perímetro urbano & 0 & 1 \\
\hline 2006335,3 & 611,53 & 1641,8 & 500,42 & 0 & $-4,32$ & 404,35 & 16 & 25,75 & ZCV - INICIO & 0 & 3 \\
\hline 2006998,1 & 611,73 & 1641,8 & 500,42 & 0,5 & $-4,32$ & 404,35 & 19 & 30,58 & PN - Perímetro urbano & 0 & 0 \\
\hline 2007785,5 & 611,97 & 1645,7 & \begin{tabular}{|l|}
501,61 \\
\end{tabular} & 0,5 & 0 & 0,00 & 19 & 30,58 & PN - Perímetro urbano & 0 & 0 \\
\hline 2009673 & 612,55 & 1655,2 & \begin{tabular}{l|l}
504,50 \\
\end{tabular} & 0,5 & 0 & 0,00 & 19 & 30,58 & PN - Perímetro urbano & 0 & 0 \\
\hline 2010032,9 & 612,66 & 1657 & 505,05 & 0,5 & 1,52 & 1148,96 & 25 & 40,23 & & 0 & 0 \\
\hline 2012897 & 613,53 & 1671,3 & 509,41 & 0,3 & 1,52 & 1148,96 & 25 & 40,23 & & 0 & 0 \\
\hline 2012952,8 & 613,55 & 1671,5 & 509,47 & 0,3 & 0 & 0,00 & 25 & 40,23 & & 0 & 0 \\
\hline 2017168,8 & 614,83 & 1684,1 & 513,31 & 0,3 & $-1,52$ & 1148,96 & 25 & 40,23 & & 0 & 0 \\
\hline 2019498,1 & 615,54 & 1691,1 & 515,45 & 0,3 & 0 & 0,00 & 25 & 40,23 & & 0 & 0 \\
\hline 2025036,1 & 617,23 & 1707,7 & 520,51 & -1 & \begin{tabular}{l|l}
0 \\
\end{tabular} & 0,00 & 25 & 40,23 & & 0 & 0 \\
\hline 2027404,9 & 617,95 & 1684 & 513,28 & -1 & 1,52 & 1148,96 & 25 & 40,23 & & 0 & 0 \\
\hline 2030292 & 618,83 & 1655,2 & \begin{tabular}{l|}
504,50 \\
\end{tabular} & $-0,34$ & 1,52 & 1148,96 & 25 & 40,23 & & 0 & 0 \\
\hline 2030315 & 618,84 & 1655,1 & 504,47 & $-0,34$ & 0 & 0,00 & 25 & 40,23 & & 0 & 0 \\
\hline 2030997,4 & 619,05 & 1652,8 & 503,77 & $-0,34$ & $-1,52$ & 1148,96 & 25 & 40,23 & & 0 & 0 \\
\hline 2033444,9 & 619,79 & 1644,4 & \begin{tabular}{|l|}
501,21 \\
\end{tabular} & $-0,34$ & 0 & 0,00 & 25 & 40,23 & & 0 & 0 \\
\hline 2034288,1 & 620,05 & 1641,6 & 500,36 & $-0,34$ & 3,35 & 521,38 & 25 & 40,23 & & 0 & 0 \\
\hline 2037099,8 & 620,91 & 1632 & 497,43 & $-0,34$ & 0 & 0,00 & 25 & 40,23 & & 0 & 0 \\
\hline 2037427,9 & 621,01 & 1630,9 & 497,10 & 0 & 0 & 0,00 & 19 & 30,58 & PN - Perímetro urbano & 0 & 0 \\
\hline 2037677,3 & 621,08 & 1630,9 & 497,10 & 0 & 0 & 0,00 & 19 & 30,58 & PN - Perímetro urbano & 0 & 0 \\
\hline 2037729,8 & 621,10 & 1630,9 & \begin{tabular}{l|l}
497,10 \\
\end{tabular} & 0 & 0 & 0,00 & 12 & 19,31 & $\mathrm{ZPN}$ - FIM & 0 & 2 \\
\hline 2038956,8 & 621,47 & 1630,9 & 497,10 & 0 & $-4,32$ & 404,35 & 19 & 30,58 & PN - Perímetro urbano & 0 & 1 \\
\hline 2039412,8 & 621,61 & 1630,9 & \begin{tabular}{l|l|}
497,10 \\
\end{tabular} & 0,6 & $-4,32$ & 404,35 & 19 & 30,58 & PN - Perímetro urbano & 0 & 1 \\
\hline 2039967,3 & 621,78 & 1634,2 & 498,10 & 0,6 & $-4,32$ & 404,35 & 19 & 30,58 & PN - Perímetro urbano & 0 & 1 \\
\hline 2039970,5 & 621,78 & 1634,2 & 498,10 & 0,6 & $-4,32$ & 404,35 & 19 & 30,58 & PINDORAMA & 8 & 1 \\
\hline 2040899 & 622,07 & 1639,8 & 499,81 & 0,6 & $-4,32$ & 404,35 & 19 & 30,58 & PN - Perímetro urbano & 0 & 1 \\
\hline 2040951,5 & 622,08 & 1640,1 & \begin{tabular}{l|l}
499,90 \\
\end{tabular} & 0,6 & $-4,32$ & 404,35 & 12 & 19,312 & ZPN - INICIO & 0 & 3 \\
\hline 2041223,3 & 622,16 & 1641,8 & \begin{tabular}{l|l|}
500,42 \\
\end{tabular} & 0,6 & \begin{tabular}{ll|}
$-4,32$ \\
\end{tabular} & 404,35 & 16 & 25,75 & & 0 & 0 \\
\hline 2041223,3 & 622,16 & 1641,8 & 500,42 & 0,6 & $-4,32$ & 404,35 & 16 & 25,75 & PN - Perímetro urbano & 0 & 0 \\
\hline 2041578,1 & 622,27 & 1643,9 & \begin{tabular}{|l|}
501,06 \\
\end{tabular} & 1 & $-4,32$ & 404,35 & 16 & 25,75 & & 0 & 0 \\
\hline 2041742,3 & 622,32 & 1645,5 & 501,55 & 1 & 0 & 0,00 & 16 & 25,75 & & 0 & 0 \\
\hline 2043216 & 622,77 & 1660,3 & 506,06 & 1 & 0 & 0,00 & 16 & 25,75 & & 0 & 0 \\
\hline 2046174,6 & 623,67 & 1689,9 & \begin{tabular}{l|}
515,08 \\
\end{tabular} & 1 & \begin{tabular}{l|l}
1,52 \\
\end{tabular} & 1148,96 & 25 & 40,23 & & 0 & 0 \\
\hline 2047542,8 & 624,09 & 1703,5 & $\begin{array}{l}519,23 \\
\end{array}$ & 1 & \begin{tabular}{l|l}
0 \\
\end{tabular} & $\begin{array}{r}0,00 \\
\end{array}$ & 25 & 40,23 & & 0 & 0 \\
\hline 2049124,1 & 624,57 & 1719,3 & 524,04 & 1 & 1,52 & 1148,96 & 25 & 40,23 & & 0 & 0 \\
\hline 2051584,8 & 625,32 & 1744 & 531,57 & 1 & 0 & 0,00 & 25 & 40,23 & & 0 & 0 \\
\hline 2053536,8 & 625,92 & 1763,5 & 537,51 & 1 & $-1,52$ & 1148,96 & 25 & 40,23 & & 0 & 0 \\
\hline 2056148,3 & 626,71 & 1789,6 & 545,47 & 1 & 0 & 0,00 & 25 & 40,23 & & 0 & 0 \\
\hline 2056998,1 & 626,97 & 1798,1 & 548,06 & 1 & $-1,52$ & 1148,96 & 25 & 40,23 & & 0 & 0 \\
\hline 2058572,9 & 627,45 & 1813,8 & 552,85 & 0 & \begin{tabular}{l|l|}
$-1,52$ \\
\end{tabular} & 1148,96 & 25 & 40,23 & & 0 & 0 \\
\hline 2059360,3 & 627,69 & 1813,8 & $\begin{array}{l}552,85 \\
\end{array}$ & 0 & \begin{tabular}{l|l}
0 \\
\end{tabular} & 0,00 & 25 & 40,23 & & 0 & 0 \\
\hline 2060020,8 & 627,89 & 1813,8 & 552,85 & 0 & 0 & 0,00 & 16 & 25,75 & & 0 & 0 \\
\hline 2060872,8 & 628,15 & 1813,8 & 552,85 & 0,5 & 0 & 0,00 & 16 & 25,75 & & 0 & 0 \\
\hline 2061017 & 628,20 & 1814,6 & 553,09 & 0,5 & 0 & 0,00 & 16 & 25,75 & & 0 & 0 \\
\hline 2061164,8 & 628,24 & 1815,3 & \begin{tabular}{l|}
553,30 \\
\end{tabular} & 0,5 & \begin{tabular}{l|l|}
$-1,52$ \\
\end{tabular} & 1148,96 & 25 & 40,23 & & 0 & 0 \\
\hline 2063166,1 & 628,85 & 1825,3 & 556,35 & 1 & $-1,52$ & 1148,96 & 25 & 40,23 & & 0 & 0 \\
\hline 2064839,3 & 629,36 & 1842 & 561,44 & 1 & 0 & 0,00 & 25 & 40,23 & & 0 & 0 \\
\hline 2065987,6 & 629,71 & 1853,5 & 564,95 & 1 & 1,52 & 1148,96 & 25 & 40,23 & & 0 & 0 \\
\hline 2068481 & 630,47 & 1878,4 & 572,54 & 1 & 0 & 0,00 & 25 & 40,23 & & 0 & 0 \\
\hline 2069268,4 & 630,71 & 1886,3 & 574,94 & 1 & $-1,52$ & 1148,96 & 25 & 40,23 & & 0 & 0 \\
\hline 2071417,4 & 631,37 & 1907,8 & \begin{tabular}{l|}
581,50 \\
\end{tabular} & 1 & 0 & 0,00 & 25 & 40,23 & & 0 & 0 \\
\hline 2074714,6 & 632,37 & 1940,8 & 591,56 & 1 & \begin{tabular}{l|l|}
$-1,52$ \\
\end{tabular} & 1148,96 & 25 & 40,23 & & 0 & 0 \\
\hline 2075446,3 & 632,60 & 1948,1 & 593,78 & 1 & 0 & 0,00 & 25 & 40,23 & & 0 & 0 \\
\hline 2078070,9 & 633,40 & 1974,3 & 601,77 & 1 & 1,52 & 1148,96 & 25 & 40,23 & & 0 & 0 \\
\hline 2078586 & 633,55 & 1979,5 & 603,35 & 0 & 1,52 & 1148,96 & 25 & 40,23 & & 0 & 0 \\
\hline 2079258,6 & 633,76 & 1979,5 & 603,35 & 0 & 0 & 0,00 & 25 & 40,23 & & 0 & 0 \\
\hline 2081063 & 634,31 & 1979,5 & 603,35 & 0 & \begin{tabular}{l|l}
0 \\
\end{tabular} & 0,00 & 25 & 40,23 & & 0 & 0 \\
\hline 2081115,5 & 634,32 & 1979,5 & 603,35 & 0 & \begin{tabular}{l|l}
0 \\
\end{tabular} & 0,00 & 12 & 19,31 & ZSD - FIM & 0 & 2 \\
\hline 2081866,8 & 634,55 & 1979,5 & 603,35 & $-0,92$ & 0 & 0,00 & 25 & 40,23 & & 0 & 1 \\
\hline 2082375,4 & 634,71 & 1974,8 & 601,92 & $-0,92$ & 0 & 0,00 & 25 & 40,23 & & 0 & 1 \\
\hline
\end{tabular}




\begin{tabular}{|c|c|c|c|c|c|c|c|c|c|c|c|}
\hline \multicolumn{2}{|c|}{ Posição } & \multicolumn{2}{|c|}{ Elevação } & \multirow{2}{*}{$\begin{array}{c}\text { rampa } \\
(\%) \\
\end{array}$} & \multicolumn{2}{|c|}{ curva } & \multicolumn{2}{|c|}{$\begin{array}{c}\text { Limite de } \\
\text { velocidade }\end{array}$} & \multirow[t]{2}{*}{ nome do local } & \multirow[t]{2}{*}{ C 1} & C 2 \\
\hline (feet) & $(\mathrm{km})$ & (feet) & $(\mathrm{m})$ & & ${ }^{\circ}$ & $(\mathrm{m})$ & $\mathrm{MPH}$ & $\mathrm{km} / \mathrm{h}$ & & & \\
\hline 2082378,8 & $\begin{array}{l}634,71 \\
\end{array}$ & 1974,8 & 601,92 & \begin{tabular}{l|l|}
$-0,92$ \\
\end{tabular} & 0 & 0,00 & 25 & (40,23 & SANTA ADELIA & 8 & 1 \\
\hline 2082523 & 634,75 & 1973,5 & 601,52 & $-0,92$ & 1,52 & 1148,96 & 25 & 40,23 & & 0 & 1 \\
\hline 2082594 & 634,77 & 1972,8 & 601,31 & $-0,92$ & 1,52 & 1148,96 & 16 & 25,75 & & 0 & 1 \\
\hline 2083583,8 & 635,08 & 1963,7 & 598,54 & $-0,92$ & 1,52 & 1148,96 & 16 & 25,75 & & 0 & 1 \\
\hline 2083589,3 & 635,08 & 1963,7 & 598,54 & $-0,92$ & 0 & 0,00 & 25 & 40,23 & & 0 & 1 \\
\hline 2084494,8 & 635,35 & 1955,3 & 595,98 & $-0,92$ & 0 & 0,00 & 25 & 40,23 & & 0 & 1 \\
\hline 2084547,3 & 635,37 & 1954,8 & 595,82 & $-0,92$ & 0 & 0,00 & 12 & 19,31 & ZSD - INICIO & 0 & 3 \\
\hline 2084770,4 & 635,44 & 1952,8 & 595,21 & 0 & 0 & 0,00 & 25 & 40,23 & & 0 & 0 \\
\hline 2088133,3 & 636,46 & 1952,8 & 595,21 & 0 & 1,52 & 1148,96 & 25 & 40,23 & & 0 & 0 \\
\hline 2089117,5 & 636,76 & 1952,8 & 595,21 & 0 & 0 & 0,00 & 25 & 40,23 & & 0 & 0 \\
\hline 2091384,6 & 637,45 & 1952,8 & 595,21 & 0 & 1,52 & 1148,96 & 25 & 40,23 & & 0 & 0 \\
\hline 2092654,3 & 637,84 & 1952,8 & 595,21 & 0 & 0 & 0,00 & 25 & 40,23 & & 0 & 0 \\
\hline 2093687,8 & 638,16 & 1952,8 & 595,21 & 0 & \begin{tabular}{|l|}
$-1,52$ \\
\end{tabular} & 1148,96 & 25 & 40,23 & & 0 & 0 \\
\hline 2098208,8 & 639,53 & 1952,8 & 595,21 & 0 & 0 & 0,00 & 25 & 40,23 & & 0 & 0 \\
\hline 2100505,3 & 640,23 & 1952,8 & 595,21 & 0 & 2,24 & 779,68 & 25 & 40,23 & & 0 & 0 \\
\hline 2103192,3 & 641,05 & 1952,8 & 595,21 & 0 & 0 & 0,00 & 25 & 40,23 & & 0 & 0 \\
\hline 2106161,5 & 641,96 & 1952,8 & 595,21 & 0 & 1,52 & 1148,96 & 25 & 40,23 & & 0 & 0 \\
\hline 2108376 & 642,63 & 1952,8 & 595,21 & 1 & 1,52 & 1148,96 & 25 & 40,23 & & 0 & 0 \\
\hline 2108438,5 & 642,65 & 1953,4 & 595,40 & 1 & 0 & 0,00 & 25 & 40,23 & & 0 & 0 \\
\hline 2110475,8 & 643,27 & 1973,8 & 601,61 & 0 & 0 & 0,00 & 25 & 40,23 & & 0 & 0 \\
\hline 2111689,8 & 643,64 & 1973,8 & 601,61 & 0 & 1,52 & 1148,96 & 25 & 40,23 & & 0 & 0 \\
\hline 2112434,5 & 643,87 & 1973,8 & 601,61 & 0 & 0 & 0,00 & 25 & 40,23 & & 0 & 0 \\
\hline 2113100,5 & 644,07 & 1973,8 & 601,61 & -1 & 0 & 0,00 & 25 & 40,23 & & 0 & 0 \\
\hline 2113363 & 644,15 & 1971,2 & 600,82 & -1 & \begin{tabular}{|l|}
$-1,52$ \\
\end{tabular} & 1148,96 & 25 & 40,23 & & 0 & 0 \\
\hline 2115620 & 644,84 & 1948,6 & 593,93 & -1 & 0 & 0,00 & 25 & 40,23 & & 0 & 0 \\
\hline 2116473 & 645,10 & 1940,1 & 591,34 & -1 & 2,24 & 779,68 & 25 & 40,23 & & 0 & 0 \\
\hline 2117424,5 & 645,39 & 1930,5 & 588,42 & -1 & 0 & 0,00 & 25 & 40,23 & & 0 & 0 \\
\hline 2118540 & 645,73 & 1919,4 & 585,03 & -1 & $-1,52$ & 1148,96 & 25 & 40,23 & & 0 & 0 \\
\hline 2119662 & 646,07 & 1908,2 & 581,62 & 0 & $-1,52$ & 1148,96 & 25 & 40,23 & & 0 & 0 \\
\hline 2121302,5 & 646,57 & 1908,2 & 581,62 & 1 & \begin{tabular}{r|}
$-1,52$ \\
\end{tabular} & 1148,96 & 25 & 40,23 & & 0 & 0 \\
\hline 2122040,8 & 646,80 & 1915,5 & 583,84 & 1 & 0 & 0,00 & 25 & 40,23 & & 0 & 0 \\
\hline 2124255,3 & 647,47 & 1937,7 & 590,61 & 0 & 0 & 0,00 & 25 & 40,23 & & 0 & 0 \\
\hline 2125239,5 & 647,77 & 1937,7 & 590,61 & 0 & \begin{tabular}{r|}
$-1,52$ \\
\end{tabular} & 1148,96 & 25 & 40,23 & & 0 & 0 \\
\hline 2127126 & 648,35 & 1937,7 & 590,61 & 0 & 0 & 0,00 & 25 & 40,23 & & 0 & 0 \\
\hline 2131030,3 & 649,54 & 1937,7 & 590,61 & 0 & 1,52 & 1148,96 & 25 & 40,23 & & 0 & 0 \\
\hline 2131949 & 649,82 & 1937,7 & 590,61 & 0 & 0 & 0,00 & 25 & 40,23 & & 0 & 0 \\
\hline 2134097,8 & 650,47 & 1937,7 & 590,61 & -1 & 0 & 0,00 & 25 & 40,23 & & 0 & 0 \\
\hline 2134458,8 & 650,58 & 1934,1 & 589,51 & -1 & 1,52 & 1148,96 & 25 & 40,23 & & 0 & 0 \\
\hline 2134741 & 650,67 & 1931,3 & 588,66 & -1 & 1,52 & 1148,96 & 25 & 40,23 & & 0 & 0 \\
\hline 2134744 & 650,67 & 1931,2 & 588,63 & -1 & 1,52 & 1148,96 & 25 & 40,23 & F. PRESTES (demolida) & 8 & 0 \\
\hline 2135216,5 & 650,81 & 1926,5 & 587,20 & -1 & 0 & 0,00 & 25 & 40,23 & & 0 & 0 \\
\hline 2137706,8 & 651,57 & 1901,6 & 579,61 & 0 & 0 & 0,00 & 25 & 40,23 & & 0 & 0 \\
\hline 2138625,5 & 651,85 & 1901,6 & 579,61 & 0 & 1,52 & 1148,96 & 25 & 40,23 & & 0 & 0 \\
\hline 2138691 & 651,87 & 1901,6 & 579,61 & 1 & 1,52 & 1148,96 & 25 & 40,23 & & 0 & 0 \\
\hline 2142070,3 & 652,90 & 1935,4 & 589,91 & 1 & 0 & 0,00 & 25 & 40,23 & & 0 & 0 \\
\hline 2142631,3 & 653,07 & 1941 & 591,62 & 0 & 0 & 0,00 & 25 & 40,23 & & 0 & 0 \\
\hline 2143284,3 & 653,27 & 1941 & 591,62 & 0 & $-2,24$ & 779,68 & 25 & 40,23 & & 0 & 0 \\
\hline 2143615,5 & 653,37 & 1941 & 591,62 & $-0,7$ & \begin{tabular}{r|}
$-2,24$ \\
\end{tabular} & 779,68 & 25 & 40,23 & & 0 & 0 \\
\hline 2147450,8 & 654,54 & 1914,2 & 583,45 & $-0,7$ & 0 & 0,00 & 25 & 40,23 & & 0 & 0 \\
\hline 2148304 & 654,80 & \begin{tabular}{l|}
1908,2 \\
\end{tabular} & 581,62 & $-0,7$ & 2,24 & 779,68 & 25 & 40,23 & & 0 & 0 \\
\hline 2149708 & 655,23 & 1898,4 & 578,63 & $-0,7$ & 0 & 0,00 & 25 & 40,23 & & 0 & 0 \\
\hline 2150174 & 655,37 & 1895,1 & 577,63 & 0 & 0 & 0,00 & 25 & 40,23 & & 0 & 0 \\
\hline 2150551,3 & $\begin{array}{r}655,49 \\
\end{array}$ & \begin{tabular}{l|}
1895,1 \\
\end{tabular} & 577,63 & 0 & $-2,24$ & 779,68 & 25 & 40,23 & & 0 & 0 \\
\hline 2150830 & 655,57 & 1895,1 & 577,63 & 1 & $-2,24$ & 779,68 & 25 & 40,23 & & 0 & 0 \\
\hline 2152473,8 & 656,07 & 1911,5 & 582,63 & 1 & 0 & 0,00 & 25 & 40,23 & & 0 & 0 \\
\hline 2153261,3 & 656,31 & 1919,4 & 585,03 & 1 & 2,24 & 779,68 & 25 & 40,23 & & 0 & 0 \\
\hline 2154412,5 & 656,66 & 1930,9 & 588,54 & 1 & 2,24 & 779,68 & 16 & 25,75 & & 0 & 0 \\
\hline 2154537,5 & 656,70 & 1932,2 & 588,93 & 1 & 0 & 0,00 & 16 & 25,75 & & 0 & 0 \\
\hline 2155095,3 & 656,87 & 1937,7 & 590,61 & 0 & 0 & 0,00 & 16 & 25,75 & & 0 & 0 \\
\hline 2155396 & 656,96 & 1937,7 & 590,61 & 0 & 0 & 0,00 & 16 & 25,75 & & 0 & 0 \\
\hline 2156342 & 657,25 & 1937,7 & 590,61 & 0 & 2,24 & 779,68 & 25 & 40,23 & & 0 & 0 \\
\hline 2156998 & 657,45 & 1937,7 & 590,61 & 0 & 0 & 0,00 & 25 & 40,23 & & 0 & 0 \\
\hline 2157391,8 & 657,57 & 1937,7 & 590,61 & -1 & 0 & 0,00 & 25 & 40,23 & & 0 & 0 \\
\hline 2158216 & 657,82 & 1929,5 & 588,11 & -1 & 0 & 0,00 & 25 & 40,23 & & 0 & 0 \\
\hline 2158678 & 657,97 & 1924,9 & 586,71 & -1 & $-2,24$ & 779,68 & 19 & 30,58 & PN - Perímetro urbano & 0 & 0 \\
\hline 2159360,3 & 658,17 & 1918,1 & 584,64 & 0 & $-2,24$ & 779,68 & 19 & 30,58 & PN - Perímetro urbano & 0 & 0 \\
\hline 2159754 & 658,29 & 1918,1 & 584,64 & 0 & 0 & 0,00 & 19 & 30,58 & PN - Perímetro urbano & 0 & 0 \\
\hline 2159836 & 658,32 & 1918,1 & 584,64 & 0 & 0 & 0,00 & 19 & 30,58 & PN - Perímetro urbano & 0 & 0 \\
\hline 2159888,5 & 658,33 & 1918,1 & 584,64 & 0 & 0 & 0,00 & 19 & 30,58 & ZCZ - FIM & 0 & 2 \\
\hline 2161328,8 & 658,77 & 1918,1 & 584,64 & -1 & 0 & 0,00 & 19 & 30,58 & PN - Perímetro urbano & 0 & 1 \\
\hline 2161735,5 & 658,90 & 1914 & 583,39 & -1 & 0 & 0,00 & 19 & 30,58 & PN - Perímetro urbano & 0 & 1 \\
\hline
\end{tabular}




\begin{tabular}{|c|c|c|c|c|c|c|c|c|c|c|c|}
\hline \multicolumn{2}{|c|}{ Posição } & \multicolumn{2}{|c|}{ Elevação } & \multirow{2}{*}{$\begin{array}{c}\text { rampa } \\
(\%) \\
\end{array}$} & \multicolumn{2}{|c|}{ curva } & \multicolumn{2}{|c|}{$\begin{array}{c}\text { Limite de } \\
\text { velocidade }\end{array}$} & \multirow[t]{2}{*}{ nome do local } & \multirow[t]{2}{*}{ C 1} & C 2 \\
\hline (feet) & $(\mathrm{km})$ & (feet) & $(\mathrm{m})$ & & ${ }^{\circ}$ & $(\mathrm{m})$ & $\mathrm{MPH}$ & $\mathrm{km} / \mathrm{h}$ & & & \\
\hline 2161739 & 658,90 & 1914 & 583,39 & -1 & 0 & 0,00 & 19 & 30,58 & CANDIDO RODRIGUES & 8 & 1 \\
\hline 2161853,8 & 658,93 & 1912,8 & 583,02 & -1 & 2,24 & 779,68 & 19 & 30,58 & PN - Perímetro urbano & 0 & 1 \\
\hline 2162806,3 & 659,22 & 1903,3 & 580,13 & -1 & 2,24 & 779,68 & 19 & 30,58 & PN - Perímetro urbano & 0 & 1 \\
\hline 2162870,8 & 659,24 & 1902,6 & 579,91 & -1 & 2,24 & 779,68 & 25 & 40,23 & & 0 & 1 \\
\hline 2162923,3 & 659,26 & 1902,1 & 579,76 & -1 & 2,24 & 779,68 & 25 & 40,23 & ZCZ - INICIO & 0 & 3 \\
\hline 2163363 & 659,39 & 1897,7 & 578,42 & -1 & 0 & 0,00 & 25 & 40,23 & & 0 & 0 \\
\hline 2166250 & 6 & 1868,9 & 569,64 & 0 & 0 & 0,00 & 25 & 40,23 & & 0 & 0 \\
\hline 2167841,3 & 660,76 & 1868,9 & 569,64 & 0 & 2,24 & 779,68 & 25 & 40,23 & & 0 & 0 \\
\hline 2168422 & 660,94 & 1868,9 & 569,64 & 0 & 0 & 0,00 & 25 & 40,23 & & 0 & 0 \\
\hline 2168874,8 & 661,07 & 1868,9 & 569,64 & -1 & 0 & 0,00 & 25 & 40,23 & & 0 & 0 \\
\hline 2169202,8 & 661,17 & 1865,6 & 568,63 & -1 & $-2,24$ & 779,68 & 25 & 40,23 & & 0 & 0 \\
\hline 2170689 & 661,63 & 1850,7 & 564,09 & -1 & 0 & 0,00 & 25 & 40,23 & & 0 & 0 \\
\hline 2171755,3 & 661,95 & 1840 & 560,83 & -1 & 2,24 & 779,68 & 25 & 40,23 & & 0 & 0 \\
\hline 2174452 & 662,77 & 1813,1 & 552,63 & 0 & 2,24 & 779,68 & 25 & 40,23 & & 0 & 0 \\
\hline 2175108,3 & 662,97 & 1813,1 & 552,63 & 1 & 2,24 & 779,68 & 25 & 40,23 & & 0 & 0 \\
\hline 2175370,8 & 663,05 & 1815,7 & 553,43 & 1 & 0 & 0,00 & 25 & 40,23 & & \begin{tabular}{l|l}
0 & \\
\end{tabular} & 0 \\
\hline 2176348,5 & 663,35 & 1825,5 & 556,41 & 1 & $-2,24$ & 779,68 & 25 & 40,23 & & 0 & 0 \\
\hline 2177405 & 663,67 & 1836 & 559,61 & 0 & $-2,24$ & 779,68 & 25 & 40,23 & & 0 & 0 \\
\hline 2178061 & 663,87 & 1836 & 559,61 & $-0,5$ & $-2,24$ & 779,68 & 25 & 40,23 & & 0 & 0 \\
\hline 2180029,5 & 664,47 & 1826,2 & 556,63 & $-0,24$ & $-2,24$ & 779,68 & 25 & 40,23 & & 0 & 0 \\
\hline 2181276,3 & 664,85 & 1823,2 & 555,71 & $-0,24$ & 0 & 0,00 & 25 & 40,23 & & 0 & 0 \\
\hline 2182057 & 665,09 & 1821,3 & 555,13 & $-0,24$ & 2,24 & 779,68 & 25 & 40,23 & & 0 & 0 \\
\hline 2184163,5 & 665,73 & 1816,3 & 553,61 & 0 & 2,24 & 779,68 & 25 & 40,23 & & 0 & 0 \\
\hline 2185213,3 & 666,05 & 1816,3 & 553,61 & 0 & 0 & 0,00 & 25 & 40,23 & & 0 & 0 \\
\hline 2186007,3 & 666,30 & 1816,3 & 553,61 & 0 & 0 & 0,00 & 25 & 40,23 & & 0 & 0 \\
\hline 2186010,5 & 666,30 & 1816,3 & 553,61 & 0 & 0 & 0,00 & 25 & 40,23 & JURUPEMA (demolida) & 8 & 0 \\
\hline 2186197,5 & 666,35 & 1816,3 & 553,61 & 0,45 & 0 & 0,00 & 25 & 40,23 & & 0 & 0 \\
\hline 2191053,3 & 667,83 & 1838,1 & 560,25 & 0,45 & $-2,24$ & 779,68 & 25 & 40,23 & & 0 & 0 \\
\hline 2191978,5 & 668,12 & 1842,3 & 561,53 & 0 & $-2,24$ & 779,68 & 25 & 40,23 & & 0 & 0 \\
\hline 2192634,5 & 668,31 & 1842,3 & 561,53 & -1 & $-2,24$ & 779,68 & 25 & 40,23 & & 0 & 0 \\
\hline 2193235 & 668,50 & 1836,3 & 559,70 & -1 & 0 & 0,00 & 25 & 40,23 & & 0 & 0 \\
\hline 2194170 & 668,78 & 1826,9 & 556,84 & -1 & 2,24 & 779,68 & 25 & 40,23 & & 0 & 0 \\
\hline 2194268,5 & \begin{tabular}{ll|}
668,81 \\
\end{tabular} & 1826 & 556,56 & 0 & 2,24 & 779,68 & 25 & 40,23 & & 0 & 0 \\
\hline 2195256 & 669,11 & 1826 & 556,56 & 1 & 2,24 & 779,68 & 25 & 40,23 & & 0 & 0 \\
\hline 2197418 & 669,77 & 1847,6 & 563,15 & 1 & 0 & 0,00 & 25 & 40,23 & & 0 & 0 \\
\hline 2198235 & $\begin{array}{l}670,02 \\
\end{array}$ & 1855,7 & 565,62 & 1 & \begin{tabular}{r|}
$-1,52$ \\
\end{tabular} & 1148,96 & 25 & 40,23 & & 0 & 0 \\
\hline 2200498,8 & 670,71 & 1878,4 & 572,54 & 0 & \begin{tabular}{r|}
$-1,52$ \\
\end{tabular} & 1148,96 & 25 & 40,23 & & 0 & 0 \\
\hline 2201155 & 670,91 & 1878,4 & 572,54 & -1 & $-1,52$ & 1148,96 & 25 & 40,23 & & 0 & 0 \\
\hline 2201876,8 & 671,13 & 1871,2 & 570,34 & -1 & 0 & 0,00 & 25 & 40,23 & & 0 & 0 \\
\hline 2202880,5 & 671,44 & 1861,1 & 567,26 & -1 & $-2,24$ & 779,68 & 25 & 40,23 & & 0 & 0 \\
\hline 2204439 & 671,91 & 1845,5 & 562,51 & -1 & 0 & 0,00 & 25 & 40,23 & & 0 & 0 \\
\hline 2205636,5 & 672,28 & 1833,6 & 558,88 & -1 & $-2,24$ & 779,68 & 25 & 40,23 & & 0 & 0 \\
\hline 2206821 & 672,64 & 1821,7 & 555,25 & -1 & 0 & 0,00 & 25 & 40,23 & & 0 & 0 \\
\hline 2209032,3 & 673,31 & 1799,6 & 548,52 & 0 & 0 & 0,00 & 25 & 40,23 & & 0 & 0 \\
\hline 2209688,5 & 673,51 & 1799,6 & 548,52 & 1 & 0 & 0,00 & 25 & 40,23 & & 0 & 0 \\
\hline 2209823 & 673,55 & 1801 & 548,94 & 1 & 2,24 & 779,68 & 25 & 40,23 & & 0 & 0 \\
\hline 2211447 & 674,05 & 1817,2 & 553,88 & 1 & 0 & 0,00 & 25 & 40,23 & & 0 & 0 \\
\hline 2211702,8 & 674,13 & 1819,8 & 554,68 & 0 & 0 & 0,00 & 25 & 40,23 & & 0 & 0 \\
\hline 2212446,3 & 674,35 & 1819,8 & 554,68 & 0 & 0 & 0,00 & 25 & 40,23 & & 0 & 0 \\
\hline 2212660,8 & 674,42 & 1819,8 & 554,68 & 0 & 0 & 0,00 & 19 & 30,58 & Perímetro urbano & 0 & 0 \\
\hline 2212713,3 & 674,43 & 1819,8 & 554,68 & 0 & 0 & 0,00 & 12 & 19,31 & ZTQ - FIM & 0 & 2 \\
\hline 2213756,5 & 674,75 & 1819,8 & 554,68 & $-0,87$ & 0 & 0,00 & 19 & 30,58 & Perímetro urbano & 0 & 1 \\
\hline 2213783 & 674,76 & 1819,5 & 554,58 & $-0,87$ & 0 & 0,00 & 19 & 30,58 & Perímetro urbano & 0 & 1 \\
\hline 2213786 & 674,76 & 1819,5 & 554,58 & $-0,87$ & 0 & 0,00 & 19 & 30,58 & TAQUARITINGA & 8 & 1 \\
\hline 2214078 & 674,85 & 1817 & 553,82 & $-0,87$ & $-2,24$ & 779,68 & 19 & 30,58 & Perímetro urbano & 0 & 1 \\
\hline 2214937,8 & 675,11 & 1809,5 & 551,54 & $-0,87$ & $-2,24$ & 779,68 & 19 & 30,58 & Perímetro urbano & 0 & 1 \\
\hline 2214990,3 & 675,13 & 1809 & 551,38 & $-0,87$ & $-2,24$ & 779,68 & 12 & 19,31 & ZTQ - INICIO & 0 & 3 \\
\hline 2216735,5 & 675,66 & 1793,8 & 546,75 & $-0,87$ & $-2,24$ & 779,68 & 19 & 30,58 & Perímetro urbano & 0 & 0 \\
\hline 2217398,3 & 675,86 & 1788,1 & 545,01 & 0 & $-2,24$ & 779,68 & 25 & 40,23 & & 0 & 0 \\
\hline 2217628 & 675,93 & 1788,1 & 545,01 & 0 & 0 & 0,00 & 25 & 40,23 & & 0 & 0 \\
\hline 2218218,5 & 676,11 & 1788,1 & 545,01 & 0 & 1,52 & 1148,96 & 25 & 40,23 & & 0 & 0 \\
\hline 2218382,5 & 676,16 & 1788,1 & 545,01 & 1 & 1,52 & 1148,96 & 25 & 40,23 & & 0 & 0 \\
\hline 2220580,8 & $\begin{array}{l}676,83 \\
\end{array}$ & 1810,1 & 551,72 & 1 & 0 & 0,00 & 25 & 40,23 & & 0 & 0 \\
\hline 2222008 & 677,27 & 1824,3 & 556,05 & 1 & 1,52 & 1148,96 & 25 & 40,23 & & 0 & 0 \\
\hline 2224321 & 677,97 & 1847,5 & 563,12 & 1 & 0 & 0,00 & 25 & 40,23 & & 0 & 0 \\
\hline 2226420,5 & $\begin{array}{ll}678,61 \\
\end{array}$ & 1868,5 & 569,52 & 0 & 0 & 0,00 & 25 & 40,23 & & 0 & 0 \\
\hline 2227076,8 & 678,81 & 1868,5 & 569,52 & -1 & 0 & 0,00 & 25 & 40,23 & & 0 & 0 \\
\hline 2227228,5 & 678,86 & 1866,9 & 569,03 & -1 & 0 & 0,00 & 16 & 25,75 & & 0 & 0 \\
\hline 2228979,8 & 679,39 & 1849,4 & 563,70 & -1 & 1,52 & 1148,96 & 16 & 25,75 & & 0 & 0 \\
\hline 2229197,5 & 679,46 & 1847,2 & 563,03 & -1 & 1,52 & 1148,96 & 16 & 25,75 & & 0 & 0 \\
\hline 2231112,3 & 680,04 & 1828,1 & 557,20 & -1 & 0 & 0,00 & 25 & 40,23 & & \begin{tabular}{l|l}
0 \\
\end{tabular} & 0 \\
\hline
\end{tabular}




\begin{tabular}{|c|c|c|c|c|c|c|c|c|c|c|c|}
\hline \multicolumn{2}{|c|}{ Posição } & \multicolumn{2}{|c|}{ Elevação } & \multirow{2}{*}{$\frac{\text { rampa }}{(\%)}$} & \multicolumn{2}{|c|}{ curva } & \multicolumn{2}{|c|}{$\begin{array}{c}\text { Limite de } \\
\text { velocidade }\end{array}$} & \multirow[t]{2}{*}{ nome do local } & \multirow[t]{2}{*}{ C 1} & C 2 \\
\hline (feet) & $(\mathrm{km})$ & (feet) & $(\mathrm{m})$ & & ${ }^{\circ}$ & $(\mathrm{m})$ & $\mathrm{MPH}$ & $\mathrm{km} / \mathrm{h}$ & & & \\
\hline 2235279 & 681,31 & 1786,4 & $\begin{array}{l}544,49 \\
\end{array}$ & \begin{tabular}{c|}
-1 \\
\end{tabular} & \begin{tabular}{c|}
$-2,24 \mid$ \\
\end{tabular} & \begin{tabular}{l|l}
779,68 \\
\end{tabular} & 25 & 40,23 & & 0 & 0 \\
\hline 2238166 & 682,19 & 1757,6 & \begin{tabular}{l|}
535,72 \\
\end{tabular} & \begin{tabular}{|l|}
-1 \\
\end{tabular} & 0 & 0,00 & 25 & 40,23 & & 0 & 0 \\
\hline 2239216 & 682,51 & \begin{tabular}{l|l}
1747,1 \\
\end{tabular} & 532,52 & -1 & 1,52 & 1148,96 & 25 & 40,23 & & 0 & 0 \\
\hline 2240987,5 & 683,05 & 1729,3 & \begin{tabular}{l|l}
527,09 \\
\end{tabular} & -1 & 0 & \begin{tabular}{l|l}
0,00 \\
\end{tabular} & 25 & 40,23 & & 0 & 0 \\
\hline 2242234,3 & 683,43 & 1716,9 & \begin{tabular}{l|}
523,31 \\
\end{tabular} & -1 & $-1,52$ & 1148,96 & 25 & 40,23 & & 0 & 0 \\
\hline 2242365,5 & 683,47 & 1715,6 & 522,91 & 0 & \begin{tabular}{l|}
$-1,52$ \\
\end{tabular} & 1148,96 & 25 & 40,23 & & 0 & 0 \\
\hline 2242972,5 & 683,66 & 1715,6 & 522,91 & 0 & 0 & 0,00 & 25 & 40,23 & & 0 & 0 \\
\hline 2244990,3 & 684,27 & 1715,6 & 522,91 & 1 & 0 & 0,00 & 25 & 40,23 & & 0 & 0 \\
\hline 2246958,8 & 684,87 & 1735,2 & \begin{tabular}{l|}
528,89 \\
\end{tabular} & 0 & 0 & 0,00 & 25 & 40,23 & & 0 & 0 \\
\hline 2247450,8 & 685,02 & 1735,2 & \begin{tabular}{l|}
528,89 \\
\end{tabular} & 0 & \begin{tabular}{l|}
$-1,52$ \\
\end{tabular} & 1148,96 & 25 & 40,23 & & 0 & 0 \\
\hline 2247615 & 685,07 & 1735,2 & \begin{tabular}{l|}
528,89 \\
\end{tabular} & -1 & \begin{tabular}{r|}
$-1,52$ \\
\end{tabular} & 1148,96 & 25 & 40,23 & & 0 & 0 \\
\hline 2248205,5 & 685,25 & 1729,3 & \begin{tabular}{l|}
527,09 \\
\end{tabular} & -1 & 0 & \begin{tabular}{l|l|}
0,00 \\
\end{tabular} & 25 & 40,23 & & 0 & 0 \\
\hline 2249022,5 & 685,50 & 1721,2 & \begin{tabular}{l|}
524,62 \\
\end{tabular} & -1 & 1,52 & 1148,96 & 25 & 40,23 & & 0 & 0 \\
\hline 2250239,5 & 685,87 & 1709 & \begin{tabular}{l|}
520,90 \\
\end{tabular} & 0 & 1,52 & 1148,96 & 25 & 40,23 & & 0 & 0 \\
\hline 2250735 & 686,02 & 1709 & \begin{tabular}{l|}
520,90 \\
\end{tabular} & 0 & 0 & 0,00 & 25 & 40,23 & & 0 & 0 \\
\hline 2250895,8 & 686,07 & 1709 & 520,90 & 1 & 0 & 0,00 & 25 & 40,23 & & 0 & 0 \\
\hline 2251552 & 686,27 & 1715,6 & 522,91 & 1 & \begin{tabular}{r|}
$-1,52$ \\
\end{tabular} & 1148,96 & 25 & 40,23 & & 0 & 0 \\
\hline 2253422 & 686,84 & \begin{tabular}{|l|}
1734,3 \\
\end{tabular} & \begin{tabular}{l|}
528,61 \\
\end{tabular} & 1 & 0 & 0,00 & 25 & 40,23 & & 0 & 0 \\
\hline 2257457,5 & 688,07 & 1774,6 & \begin{tabular}{l|l}
540,90 \\
\end{tabular} & 0,5 & 0 & 0,00 & 25 & 40,23 & & 0 & 0 \\
\hline 2259836 & 688,80 & 1786,5 & \begin{tabular}{l|}
544,53 \\
\end{tabular} & 0,5 & 1,52 & 1148,96 & 25 & 40,23 & & 0 & 0 \\
\hline 2262706,8 & 689,67 & 1800,9 & \begin{tabular}{|l|}
548,91 \\
\end{tabular} & 0 & 1,52 & 1148,96 & 25 & 40,23 & & 0 & 0 \\
\hline 2263329,5 & 689,86 & 1800,9 & \begin{tabular}{|l|}
548,91 \\
\end{tabular} & 0 & 1,52 & 1148,96 & 25 & 40,23 & & 0 & 0 \\
\hline 2263461,3 & 689,90 & 1800,9 & \begin{tabular}{l|l|}
548,91 \\
\end{tabular} & 0 & 0 & \begin{tabular}{l|}
0,00 \\
\end{tabular} & 19 & 30,58 & \begin{tabular}{|l|} 
Perímetro urbano \\
\end{tabular} & 0 & 0 \\
\hline 2264777 & 690,30 & 1800,9 & 548,91 & 0 & 0 & 0,00 & 19 & 30,58 & \begin{tabular}{|l|} 
Perímetro urbano \\
\end{tabular} & 0 & 0 \\
\hline 2264829,5 & 690,32 & 1800,9 & \begin{tabular}{l|}
548,91 \\
\end{tabular} & 0 & 0 & 0,00 & \begin{tabular}{l|l}
19 \\
\end{tabular} & 30,58 & ZSH - FIM & 0 & 2 \\
\hline 2265397 & 690,49 & 1800,9 & \begin{tabular}{l|}
548,91 \\
\end{tabular} & 0 & $-2,24$ & 779,68 & 19 & 30,58 & PN - Perímetro urbano & 0 & 1 \\
\hline 2265462,5 & 690,51 & 1800,9 & 548,91 & 1 & $-2,24$ & 779,68 & 19 & 30,58 & PN - Perímetro urbano & 0 & 1 \\
\hline 2265656,3 & 690,57 & 1802,8 & \begin{tabular}{l|l}
549,49 \\
\end{tabular} & 0 & $-2,24$ & 779,68 & 19 & 30,58 & PN - Perímetro urbano & 0 & 1 \\
\hline 2265659,5 & 690,57 & 1802,8 & \begin{tabular}{|l|}
549,49 \\
\end{tabular} & 1 & $-2,24$ & 779,68 & 19 & 30,58 & SANTA ERNESTINA & 8 & 1 \\
\hline 2266328,8 & 690,78 & 1809,5 & 551,54 & 1 & $-2,24$ & 779,68 & 19 & 30,58 & PN - Perímetro urbano & 0 & 1 \\
\hline 2266381,3 & 690,79 & 1810 & \begin{tabular}{l|l}
551,69 \\
\end{tabular} & 1 & $-2,24$ & 779,68 & 19 & 30,58 & ZSH - INICIO & 0 & 3 \\
\hline 2266574,3 & 690,85 & 1811,9 & 552,27 & 1 & $-2,24$ & 779,68 & 19 & 30,58 & PN - Perímetro urbano & 5 & 0 \\
\hline 2266975 & 690,97 & 1816 & 553,52 & 1 & 0 & 0,00 & 25 & 40,23 & & 0 & 0 \\
\hline 2267733 & 691,20 & 1823,5 & \begin{tabular}{|l|l}
555,80 \\
\end{tabular} & 1 & 2,24 & 779,68 & 25 & 40,23 & & 0 & 0 \\
\hline 2270571 & 692,07 & 1851,9 & 564,46 & 1 & 0 & \begin{tabular}{l|l|}
0,00 \\
\end{tabular} & 25 & 40,23 & & 0 & 0 \\
\hline 2271243,5 & 692,27 & 1858,6 & \begin{tabular}{l|l}
566,50 \\
\end{tabular} & 1 & $-2,24$ & 779,68 & 25 & 40,23 & & 0 & 0 \\
\hline 2272621,5 & 692,70 & 1872,4 & \begin{tabular}{l|}
570,71 \\
\end{tabular} & 1 & 0 & 0,00 & 25 & 40,23 & & 0 & 0 \\
\hline 2277277 & 694,11 & 1919 & \begin{tabular}{|l|}
584,91 \\
\end{tabular} & 1 & 1,52 & 1148,96 & 25 & 40,23 & & 0 & 0 \\
\hline 2277844,5 & 694,29 & \begin{tabular}{|l|}
1924,7 \\
\end{tabular} & $\begin{array}{l}586,65 \\
\end{array}$ & 1 & 0 & 0,00 & 25 & 40,23 & & 0 & 0 \\
\hline 2279083,8 & 694,66 & 1937 & \begin{tabular}{l|}
590,40 \\
\end{tabular} & 1 & 0 & 0,00 & 12 & 19,31 & & 0 & 0 \\
\hline 2280561 & 695,11 & 1951,8 & \begin{tabular}{|l|}
594,91 \\
\end{tabular} & 0 & 0 & 0,00 & 12 & 19,31 & & 0 & 0 \\
\hline 2283362 & 695,97 & 1951,8 & \begin{tabular}{|l|}
594,91 \\
\end{tabular} & 0 & 0 & 0,00 & 12 & 19,31 & & 0 & 0 \\
\hline 2283901 & 696,13 & 1951,8 & \begin{tabular}{|l|}
594,91 \\
\end{tabular} & 0 & $\begin{array}{l}-1,52 \\
\end{array}$ & 1148,96 & 25 & 40,23 & & 0 & 0 \\
\hline 2284409,5 & 696,29 & 1951,8 & 594,91 & 0 & $-1,52$ & 1148,96 & 25 & 40,23 & & 0 & 0 \\
\hline 2284412,8 & 696,29 & 1951,8 & 594,91 & 0 & \begin{tabular}{l|}
$-1,52$ \\
\end{tabular} & 1148,96 & 25 & 40,23 & DOBRADA (demolida) & 8 & 0 \\
\hline 2287142,5 & 697,12 & 1951,8 & \begin{tabular}{l|}
594,91 \\
\end{tabular} & 0 & 0 & \begin{tabular}{l|l}
0,00 \\
\end{tabular} & 25 & 40,23 & & 0 & 0 \\
\hline 2288061 & 697,40 & 1951,8 & \begin{tabular}{|l|}
594,91 \\
\end{tabular} & 0 & 1,52 & 1148,96 & 25 & 40,23 & & 0 & 0 \\
\hline 2292136 & 698,64 & 1951,8 & 594,91 & 0 & 0 & 0,00 & 25 & 40,23 & & 0 & 0 \\
\hline 2295373,3 & 699,63 & 1951,8 & 594,91 & 0 & 0 & 0,00 & 16 & 25,75 & & 0 & 0 \\
\hline 2295702,5 & 699,73 & 1951,8 & 594,91 & 0 & 0 & 0,00 & 16 & 25,75 & & 0 & 0 \\
\hline 2297483,5 & 700,27 & 1951,8 & 594,91 & -1 & 0 & 0,00 & 25 & 40,23 & & 0 & 0 \\
\hline 2298499,5 & 700,58 & 1941,7 & 591,83 & -1 & 0 & \begin{tabular}{l|l}
0,00 \\
\end{tabular} & 16 & 25,75 & & 0 & 0 \\
\hline 2301748,8 & 701,57 & 1909,2 & \begin{tabular}{l|}
581,92 \\
\end{tabular} & -1 & \begin{tabular}{l|}
$-1,52$ \\
\end{tabular} & 1148,96 & 16 & 25,75 & & 0 & 0 \\
\hline 2302942,3 & 701,94 & 1897,2 & 578,27 & -1 & \begin{tabular}{l|}
$-1,52$ \\
\end{tabular} & 1148,96 & 16 & 25,75 & & 0 & 0 \\
\hline 2304173,3 & 702,31 & \begin{tabular}{|l|}
1884,9 \\
\end{tabular} & \begin{tabular}{l|}
574,52 \\
\end{tabular} & -1 & 0 & \begin{tabular}{l|}
0,00 \\
\end{tabular} & 25 & 40,23 & & 0 & 0 \\
\hline 2306112,3 & 702,90 & 1865,5 & \begin{tabular}{l|}
568,60 \\
\end{tabular} & -1 & 1,93 & \begin{tabular}{l|}
904,90 \\
\end{tabular} & 25 & 40,23 & & 0 & 0 \\
\hline 2308868,3 & 703,74 & 1838 & 560,22 & -1 & 0 & 0,00 & 25 & 40,23 & & 0 & 0 \\
\hline 2312782,3 & 704,94 & 1798,8 & \begin{tabular}{l|}
548,27 \\
\end{tabular} & -1 & $-2,24$ & \begin{tabular}{l|}
779,68 \\
\end{tabular} & 25 & 40,23 & & 0 & 0 \\
\hline 2313678 & 705,21 & \begin{tabular}{l|l|}
1789,9 \\
\end{tabular} & 545,56 & 0 & $-2,24$ & $\begin{array}{l}779,68 \\
\end{array}$ & 25 & 40,23 & & 0 & 0 \\
\hline 2314624,5 & 705,50 & 1789,9 & 545,56 & 0 & $-2,24$ & $\begin{array}{l}779,68 \\
\end{array}$ & 25 & 40,23 & & 0 & 0 \\
\hline 2316184,5 & 705,97 & 1789,9 & 545,56 & 0 & $-2,24$ & 779,68 & 19 & 30,58 & PN - Perímetro urbano & 0 & 0 \\
\hline 2316237 & 705,99 & 1789,9 & 545,56 & 0 & $-2,24$ & 779,68 & 12 & 19,31 & ZMA - FIM & 0 & 2 \\
\hline 2316991,5 & 706,22 & 1789,9 & 545,56 & 0 & 0 & 0,00 & 19 & 30,58 & PN - Perímetro urbano & 5 & 1 \\
\hline 2318558,3 & 706,70 & 1789,9 & 545,56 & 0 & 0 & 0,00 & 19 & 30,58 & PN - Perímetro urbano & 0 & 1 \\
\hline 2319032,3 & 706,84 & \begin{tabular}{ll|}
1789,9 \\
\end{tabular} & 545,56 & 0 & 0 & 0,00 & 19 & 30,58 & Perímetro urbano & 0 & 1 \\
\hline 2319035,5 & 706,84 & 1789,9 & 545,56 & 0 & 0 & $\begin{array}{ll}0,00 \\
\end{array}$ & 19 & 30,58 & MATAO & 8 & 1 \\
\hline 2319137,3 & 706,87 & 1789,9 & 545,56 & 0 & $-1,88$ & 928,96 & 19 & 30,58 & \begin{tabular}{|l|} 
Perímetro urbano \\
\end{tabular} & 0 & 1 \\
\hline 2319983,5 & 707,13 & 1789,9 & 545,56 & 1 & $-1,88$ & 928,96 & 19 & 30,58 & Perímetro urbano & 0 & 1 \\
\hline 2320515 & 707,29 & 1795,2 & \begin{tabular}{l|}
547,18 \\
\end{tabular} & 1 & 0 & 0,00 & 19 & 30,58 & Perímetro urbano & 0 & 1 \\
\hline 2321935,8 & 707,73 & 1809,4 & \begin{tabular}{l|}
551,51 \\
\end{tabular} & 1 & 0 & 0,00 & 19 & 30,58 & Perímetro urbano & 0 & 1 \\
\hline 2321988,3 & 707,74 & \begin{tabular}{l|l|}
1809,9 \\
\end{tabular} & 551,66 & 1 & 0 & 0,00 & 12 & 19,31 & ZMA - INICIO & 0 & 3 \\
\hline
\end{tabular}




\begin{tabular}{|c|c|c|c|c|c|c|c|c|c|c|c|}
\hline \multicolumn{2}{|c|}{ Posição } & \multicolumn{2}{|c|}{ Elevação } & \multirow{2}{*}{$\begin{array}{c}\text { rampa } \\
(\%) \\
\end{array}$} & \multicolumn{2}{|c|}{ curva } & \multicolumn{2}{|c|}{$\begin{array}{c}\text { Limite de } \\
\text { velocidade }\end{array}$} & \multirow[t]{2}{*}{ nome do local } & \multirow[t]{2}{*}{ C 1} & C 2 \\
\hline (feet) & $(\mathrm{km})$ & (feet) & $(\mathrm{m})$ & & ${ }^{\circ}$ & $(\mathrm{m})$ & $\mathrm{MPH}$ & $\mathrm{km} / \mathrm{h}$ & & & \\
\hline 2323463 & 708,19 & 1824,7 & 556,17 & 1 & 0 & 0,00 & 19 & 30,58 & Perímetro urbano & 0 & $\overline{0}$ \\
\hline 2323723,8 & 708,27 & 1827,3 & 556,96 & 1 & 1,52 & 1148,96 & 25 & 40,23 & & \begin{tabular}{l|l}
0 \\
\end{tabular} & 0 \\
\hline 2325495,5 & \begin{tabular}{l|l}
708,81 \\
\end{tabular} & 1845 & 562,36 & 1 & 0 & 0,00 & 25 & 40,23 & & 0 & 0 \\
\hline 2326479,8 & 709,11 & 1854,8 & 565,34 & 1 & \begin{tabular}{l|}
$-1,52$ \\
\end{tabular} & 1148,96 & 25 & 40,23 & & 0 & 0 \\
\hline 2329055,3 & 709,90 & 1880,6 & 573,21 & 1 & 0 & 0,00 & 25 & 40,23 & & 0 & 0 \\
\hline 2329977 & 710,18 & 1889,8 & 576,01 & 1 & 2,24 & 779,68 & 25 & 40,23 & & 0 & 0 \\
\hline 2331223,8 & 710,56 & 1902,3 & 579,82 & 1 & 0 & 0,00 & 25 & 40,23 & & 0 & 0 \\
\hline 2331945,5 & 710,78 & 1909,5 & 582,02 & 1 & $-1,52$ & 1148,96 & 25 & 40,23 & & 0 & 0 \\
\hline 2333487,5 & 711,25 & 1924,9 & 586,71 & 1 & 0 & 0,00 & 25 & 40,23 & & 0 & 0 \\
\hline 2337195 & 712,38 & 1962 & 598,02 & 1 & 2,24 & 779,68 & 25 & 40,23 & & 0 & 0 \\
\hline 2343658,3 & \begin{tabular}{l|}
714,35 \\
\end{tabular} & 2026,6 & 617,71 & 1 & 0 & 0,00 & 25 & 40,23 & & 0 & 0 \\
\hline 2345712 & 714,97 & 2047,2 & 623,99 & 1 & \begin{tabular}{|l|}
$-1,52$ \\
\end{tabular} & 1148,96 & 25 & 40,23 & & 0 & 0 \\
\hline 2349107,8 & 716,01 & 2081,1 & 634,32 & 1 & 0 & 0,00 & 25 & 40,23 & & 0 & 0 \\
\hline 2350554,5 & 716,45 & 2095,6 & 638,74 & 1 & 2,24 & 779,68 & 25 & 40,23 & & 0 & 0 \\
\hline 2351342 & $\begin{array}{l}716,69 \\
\end{array}$ & 2103,5 & 641,15 & 1 & 0 & 0,00 & 25 & 40,23 & & 0 & 0 \\
\hline 2352191,5 & 716,95 & 2112 & 643,74 & 1 & $-2,24$ & 779,68 & 25 & 40,23 & & 0 & 0 \\
\hline 2355800,5 & 718,05 & 2148 & 654,71 & 1 & 0 & 0,00 & 25 & 40,23 & & 0 & 0 \\
\hline 2355882,5 & \begin{tabular}{l|}
718,07 \\
\end{tabular} & 2148,9 & 654,98 & 0 & 0 & 0,00 & 25 & 40,23 & & 0 & 0 \\
\hline 2356850,5 & 718,37 & 2148,9 & 654,98 & 0 & 0 & 0,00 & 25 & 40,23 & & 0 & 0 \\
\hline 2356903 & 718,38 & 2148,9 & 654,98 & 0 & 0 & 0,00 & 25 & 40,23 & ZZL - FIM & 0 & 2 \\
\hline 2357503,3 & 718,57 & 2148,9 & 654,98 & 0 & 0 & 0,00 & 25 & 40,23 & & 0 & 1 \\
\hline 2357506,5 & \begin{tabular}{ll|}
718,57 \\
\end{tabular} & 2148,9 & 654,98 & 0 & 0 & 0,00 & 25 & 40,23 & SILVANIA & 8 & 1 \\
\hline 2357567,3 & 718,59 & 2148,9 & 654,98 & 0 & 0 & 0,00 & 25 & 40,23 & & 0 & 1 \\
\hline 2357654,3 & 718,61 & 2148,9 & 654,98 & 1 & 0 & 0,00 & 19 & 30,58 & Perímetro urbano & 0 & 1 \\
\hline 2358223 & 718,79 & 2154,6 & 656,72 & 1 & 0 & 0,00 & 19 & 30,58 & Perímetro urbano & 0 & 1 \\
\hline 2359317,5 & 719,12 & 2165,5 & 660,04 & 1 & 0 & 0,00 & 25 & 40,23 & & 0 & 1 \\
\hline 2359370 & 719,14 & 2166 & 660,20 & 1 & 0 & 0,00 & 25 & 40,23 & ZZL - INICIO & 0 & 3 \\
\hline 2361804,5 & 719,88 & 2190,4 & 667,63 & 1 & 1,52 & 1148,96 & 25 & 40,23 & & 0 & 0 \\
\hline 2362349 & 720,04 & 2195,8 & 669,28 & 0,5 & 1,52 & 1148,96 & 25 & 40,23 & & 0 & 0 \\
\hline 2363133,3 & 720,28 & 2199,7 & 670,47 & 0,5 & 0 & 0,00 & 25 & 40,23 & & 0 & 0 \\
\hline 2364757,3 & \begin{tabular}{l|}
720,78 \\
\end{tabular} & 2207,9 & 672,97 & 0 & 0 & 0,00 & 25 & 40,23 & & \begin{tabular}{l|l}
0 \\
\end{tabular} & 0 \\
\hline 2375682,5 & 724,11 & 2207,9 & 672,97 & 0 & 1,52 & 1148,96 & 25 & 40,23 & & 0 & 0 \\
\hline 2376460 & 724,34 & 2207,9 & 672,97 & 0 & 0 & 0,00 & 25 & 40,23 & & 0 & 0 \\
\hline 2376847,3 & 724,46 & 2207,9 & 672,97 & 0 & 0 & 0,00 & 25 & 40,23 & & 0 & 0 \\
\hline 2376899,8 & 724,48 & 2207,9 & 672,97 & 0 & 0 & 0,00 & 25 & 40,23 & ZDZ - FIM & 0 & 2 \\
\hline 2377568,5 & 724,68 & 2207,9 & 672,97 & 0 & 0 & 0,00 & 25 & 40,23 & & 0 & 1 \\
\hline 2378399 & 724,94 & 2207,9 & 672,97 & 0 & 0 & 0,00 & 19 & 30,58 & Perímetro urbano & 0 & 1 \\
\hline 2378402,3 & 724,94 & 2207,9 & 672,97 & 0 & 0 & 0,00 & 19 & 30,58 & BUENO DE ANDRADE & 8 & 1 \\
\hline 2378992,8 & 725,12 & 2207,9 & 672,97 & 0 & 1,52 & 1148,96 & 19 & 30,58 & Perímetro urbano & 0 & 1 \\
\hline 2379208 & 725,18 & 2207,9 & 672,97 & 0 & 1,52 & 1148,96 & 19 & 30,58 & Perímetro urbano & 0 & 1 \\
\hline 2379262 & 725,20 & 2207,9 & 672,97 & 0,32 & 1,52 & 1148,96 & 25 & 40,23 & & 0 & 1 \\
\hline 2380705,5 & 725,64 & 2212,5 & 674,37 & 0,32 & 0 & 0,00 & 25 & 40,23 & & 0 & 1 \\
\hline 2380797,3 & 725,67 & 2212,8 & 674,46 & 0 & 0 & 0,00 & 25 & 40,23 & & \begin{tabular}{l|l}
0 \\
\end{tabular} & 1 \\
\hline 2382670,5 & 726,24 & 2212,8 & 674,46 & 0 & 0 & 0,00 & 25 & 40,23 & & 0 & 1 \\
\hline 2382723 & 726,25 & 2212,8 & 674,46 & 0 & 0 & 0,00 & 25 & 40,23 & ZDZ - INICIO & 0 & 3 \\
\hline 2383422 & 726,47 & 2212,8 & 674,46 & 1 & 0 & 0,00 & 25 & 40,23 & & 0 & 0 \\
\hline 2383651,5 & 726,54 & 2215,1 & 675,16 & 1 & $\begin{array}{l}-1,52 \\
\end{array}$ & 1148,96 & 25 & 40,23 & & 0 & 0 \\
\hline 2386076,3 & 727,28 & 2239,3 & 682,54 & 1 & 0 & 0,00 & 25 & 40,23 & & 0 & 0 \\
\hline 2392280,3 & 729,17 & 2301,4 & 701,47 & -1 & 0 & 0,00 & 25 & 40,23 & & 0 & 0 \\
\hline 2395397 & 730,12 & 2270,2 & 691,96 & 0 & 0 & 0,00 & 25 & 40,23 & & 0 & 0 \\
\hline 2396873,5 & 730,57 & 2270,2 & 691,96 & 0 & $-1,52$ & 1148,96 & 25 & 40,23 & & 0 & 0 \\
\hline 2397733 & 730,83 & 2270,2 & 691,96 & 0 & 0 & 0,00 & 25 & 40,23 & & 0 & 0 \\
\hline 2402277 & 732,21 & 2270,2 & 691,96 & $-0,6$ & 0 & 0,00 & 25 & 40,23 & & 0 & 0 \\
\hline 2404967,3 & 733,03 & 2254 & 687,02 & $-0,6$ & \begin{tabular}{r|}
$-1,52$ \\
\end{tabular} & 1148,96 & 25 & 40,23 & & 0 & 0 \\
\hline 2405033 & 733,05 & 2253,6 & 686,90 & 0 & $-1,52$ & 1148,96 & 25 & 40,23 & & 0 & 0 \\
\hline 2405971,3 & $\begin{array}{l}733,34 \\
\end{array}$ & 2253,6 & 686,90 & 0,5 & $-1,52$ & 1148,96 & 25 & 40,23 & & 0 & 0 \\
\hline 2409055,3 & 734,28 & 2269,1 & 691,62 & 0,5 & 0 & 0,00 & 25 & 40,23 & & 0 & 0 \\
\hline 2411204 & 734,93 & 2279,8 & 694,88 & 0,5 & 1,52 & 1148,96 & 25 & 40,23 & & 0 & 0 \\
\hline 2413992,8 & 735,78 & 2293,8 & 699,15 & 0 & 1,52 & 1148,96 & 25 & 40,23 & & 0 & 0 \\
\hline 2415010 & 736,10 & 2293,8 & 699,15 & 0 & 0 & 0,00 & 25 & 40,23 & & 0 & 0 \\
\hline 2417503,3 & 736,85 & 2293,8 & 699,15 & 0 & 2,49 & 701,41 & 25 & 40,23 & & 0 & 0 \\
\hline 2417861 & 736,96 & 2293,8 & 699,15 & 1,2 & 2,49 & 701,41 & 25 & 40,23 & & 0 & 0 \\
\hline 2419862,3 & $\begin{array}{l}737,57 \\
\end{array}$ & 2317,8 & 706,47 & 1,2 & 0 & 0,00 & 25 & 40,23 & & 0 & 0 \\
\hline 2420715,3 & 737,83 & 2328 & 709,57 & 1,2 & $-2,18$ & 801,14 & 25 & 40,23 & & 0 & 0 \\
\hline 2421762 & 738,15 & 2340,6 & 713,41 & 0 & $-2,18$ & 801,14 & 25 & 40,23 & & 0 & 0 \\
\hline 2422424,5 & 738,35 & 2340,6 & 713,41 & 0 & 0 & 0,00 & 25 & 40,23 & & 0 & 0 \\
\hline 2423389,3 & 738,65 & 2340,6 & 713,41 & $-1,2$ & 0 & 0,00 & 25 & 40,23 & & 0 & 0 \\
\hline 2425849,8 & $\begin{array}{l}739,40 \\
\end{array}$ & 2311 & 704,39 & 0 & 0 & 0,00 & 25 & 40,23 & & 0 & 0 \\
\hline 2428179,3 & 740,11 & 2311 & 704,39 & 0 & 2,49 & 701,41 & 25 & 40,23 & & 0 & 0 \\
\hline 2428891 & 740,33 & 2311 & 704,39 & 1,2 & 2,49 & 701,41 & 25 & 40,23 & & 0 & 0 \\
\hline 2431319 & \begin{tabular}{l|}
741,07 \\
\end{tabular} & 2340,2 & 713,29 & 1,2 & 0 & 0,00 & 25 & 40,23 & & 0 & 0 \\
\hline
\end{tabular}




\begin{tabular}{|c|c|c|c|c|c|c|c|c|c|c|c|}
\hline \multicolumn{2}{|c|}{ Posição } & \multicolumn{2}{|c|}{ Elevação } & \multirow{2}{*}{\begin{tabular}{c|} 
rampa \\
$(\%)$
\end{tabular}} & \multicolumn{2}{|c|}{ curva } & \multicolumn{2}{|c|}{$\begin{array}{c}\text { Limite de } \\
\text { velocidade }\end{array}$} & \multirow[t]{2}{*}{ nome do local } & \multirow[t]{2}{*}{ C 1} & \multirow[t]{2}{*}{ C 2} \\
\hline (feet) & $(\mathrm{km})$ & (feet) & $(\mathrm{m})$ & & ${ }^{\circ}$ & (m) & $\mathrm{MPH}$ & $\mathrm{km} / \mathrm{h}$ & & & \\
\hline 2431410,8 & 741,09 & 2341,3 & 713,63 & \begin{tabular}{c|}
1,2 \\
\end{tabular} & 0 & 0,00 & 25 & "40,23 & & 0 & $\overline{0}$ \\
\hline 2431463,3 & 741,11 & 2341,9 & 713,81 & \begin{tabular}{l|l}
1,2 \\
\end{tabular} & 0 & 0,00 & 12 & 19,31 & ZTO - FIM & 0 & 2 \\
\hline 2431830,8 & 741,22 & 2346,3 & 715,15 & 0 & 0 & 0,00 & 25 & 40,23 & & 0 & 1 \\
\hline 2432044 & 741,29 & 2346,3 & 715,15 & 0 & $-2,18$ & 801,14 & 25 & 40,23 & & 0 & 1 \\
\hline 2433651,5 & 741,78 & 2346,3 & 715,15 & 0 & 0 & 0,00 & 25 & 40,23 & & 0 & 1 \\
\hline 2436502,8 & 742,65 & 2346,3 & 715,15 & 0 & 0 & 0,00 & 25 & 40,23 & & 0 & 1 \\
\hline 2436506 & 742,65 & 2346,3 & 715,15 & 0 & 0 & 0,00 & 25 & 40,23 & TUTOIA & 8 & 1 \\
\hline 2436834 & 742,75 & 2346,3 & 715,15 & 0 & 2,24 & 779,68 & 25 & 40,23 & & 0 & 1 \\
\hline 2437195 & 742,86 & 2346,3 & 715,15 & 0 & 2,24 & 779,68 & 25 & 40,23 & & 0 & 1 \\
\hline 2437247,5 & 742,87 & 2346,3 & 715,15 & 0 & 2,24 & 779,68 & 12 & 19,31 & ZTO - INICIO & 0 & 3 \\
\hline 2437450,8 & 742,93 & 2346,3 & 715,15 & \begin{tabular}{l|l|}
$-1,2$ \\
\end{tabular} & 2,24 & 779,68 & 25 & 40,23 & & 0 & 0 \\
\hline 2439780,3 & 743,65 & 2318,4 & 706,65 & \begin{tabular}{l|}
$-1,2$ \\
\end{tabular} & 0 & 0,00 & 25 & 40,23 & & 0 & 0 \\
\hline 2442733 & 744,54 & 2282,9 & 695,83 & $-1,2$ & 2,24 & 779,68 & 25 & 40,23 & & 0 & 0 \\
\hline 2444599,8 & 745,11 & 2260,5 & 689,00 & $-1,2$ & 0 & 0,00 & 25 & 40,23 & & 0 & 0 \\
\hline 2445420 & 745,36 & 2250,7 & 686,01 & $-1,2$ & $-1,73$ & 1009,50 & 25 & 40,23 & & 0 & 0 \\
\hline 2446010,5 & 745,54 & 2243,6 & 683,85 & 0 & $-1,73$ & 1009,50 & 25 & 40,23 & & 0 & 0 \\
\hline 2448372,8 & 746,26 & 2243,6 & 683,85 & \begin{tabular}{l|l|}
$-1,4$ \\
\end{tabular} & $-1,73$ & 1009,50 & 25 & 40,23 & & 0 & 0 \\
\hline 2450078,8 & 746,78 & 2219,7 & 676,56 & $-1,4$ & 0 & 0,00 & 25 & 40,23 & & 0 & 0 \\
\hline 2455554,5 & 748,45 & 2143,1 & 653,22 & $-1,4$ & $-2,24$ & 779,68 & 25 & 40,23 & & 0 & 0 \\
\hline 2457037,5 & 748,91 & 2122,3 & 646,88 & $-1,4$ & 0 & 0,00 & 25 & 40,23 & & 0 & 0 \\
\hline 2458176 & 749,25 & 2106,4 & 642,03 & 0 & 0 & 0,00 & 25 & 40,23 & & 0 & 0 \\
\hline 2459554 & 749,67 & 2106,4 & 642,03 & 0 & 0 & 0,00 & 25 & 40,23 & & 0 & 0 \\
\hline 2459606,3 & 749,69 & 2106,4 & 642,03 & 0 & 0 & 0,00 & 12 & 19,31 & ZAR - FIM & 0 & 2 \\
\hline 2459918 & 749,78 & 2106,4 & 642,03 & 0 & \begin{tabular}{l|}
$-5,79$ \\
\end{tabular} & 301,75 & 25 & 40,23 & & 0 & 1 \\
\hline 2460137,8 & 749,85 & 2106,4 & 642,03 & 0 & 0 & 0,00 & 25 & 40,23 & & 0 & 1 \\
\hline 2460308,5 & 749,90 & 2106,4 & 642,03 & 0 & 0 & 0,00 & 25 & 40,23 & & 0 & 1 \\
\hline 2460311,8 & 749,90 & 2106,4 & 642,03 & 0 & 0 & 0,00 & 25 & 40,23 & ARARAQUARA & 8 & 1 \\
\hline 2460991 & 750,11 & 2106,4 & 642,03 & 0 & \begin{tabular}{l|}
$-5,79$ \\
\end{tabular} & 301,75 & 25 & 40,23 & & 0 & 1 \\
\hline 2461515,8 & 750,27 & 2106,4 & 642,03 & $-1,5$ & $-5,79$ & 301,75 & 25 & 40,23 & & 0 & 1 \\
\hline 2461670 & 750,32 & 2104 & 641,30 & $-1,5$ & \begin{tabular}{l|}
$-5,79$ \\
\end{tabular} & 301,75 & 25 & 40,23 & & 0 & 1 \\
\hline 2461722,5 & 750,33 & 2103,3 & 641,09 & $-1,5$ & $-5,79$ & 301,75 & 12 & 19,31 & ZAR - INICIO & 0 & 3 \\
\hline
\end{tabular}

